EVANDRO CÉSAR FREIBERGER

\title{
MODELO CONCEITUAL PARA INSTANCIAÇÃO DE APLICAÇÕES DE REALIDADE VIRTUAL EM UMA PLATAFORMA BASEADA EM SERVIÇOS
}




\section{EVANDRO CÉSAR FREIBERGER}

\section{MODELO CONCEITUAL PARA INSTANCIAÇÃO DE APLICACCÕES DE REALIDADE VIRTUAL EM UMA PLATAFORMA BASEADA EM SERVIÇOS}

Tese apresentada à Escola Politécnica da Universidade de São Paulo para obtenção do Título de Doutor em Ciências. 


\section{EVANDRO CÉSAR FREIBERGER}

\section{MODELO CONCEITUAL PARA INSTANCIAÇÃO DE APLICACCÕES DE REALIDADE VIRTUAL EM UMA PLATAFORMA BASEADA EM SERVIÇOS}

Tese apresentada à Escola Politécnica da Universidade de São Paulo para obtenção do Título de Doutor em Ciências.

Área de Concentração: Engenharia de Computação e Sistemas Digitais

Orientador: Prof. Dr. Romero Tori 
Este exemplar foi revisado e corrigido em relação à versão original, sob responsabilidade única do autor e com a anuência de seu orientador.

São Paulo, 8 de setembro de 2014.

Assinatura do autor

Assinatura do orientador

\section{Catalogação-na-publicação}

\section{Freiberger, Evandro César}

Modelo Conceitual para Instanciação de Aplicações de Realidade Virtual em uma Plataforma Baseada em Serviços / E. C. Freiberger. - versão corr. - São Paulo, 2014.

$176 \mathrm{p}$.

Tese (Doutorado) - Escola Politécnica da Universidade de São Paulo. Departamento de Engenharia de Computação e Sistemas Digitais (PCS).

1.Realidade virtual 2.Reuso de software 3.Computação aplicada (Serviços) 4.Arquitetura orientada a serviços 5.Modelo conceitual de representação. I. Universidade de São Paulo. Escola Politécnica. Departamento de Engenharia de Computação e Sistemas Digitais (PCS) II. t. 
Dedico esse trabalho ao meu filho Rodrigo, a minha esposa Wannessa, a minha mãe Rosi, ao meu pai Waldemar e a minha sogra Elza. 


\section{AGRADECIMENTOS}

No decorrer desta pesquisa, contei com a presença e a colaboração de muitas pessoas, que me ajudaram de várias maneiras, contribuindo, incentivando e se alegrando com cada conquista.

Agradeço primeiramente a Deus, por sempre me olhar e me acompanhar em todos os momentos. Agradeço a minha família, pela torcida e carinho, em especial ao meu filho Rodrigo, pelo carinho, paciência e compreensão durante todos esses anos. A minha amada esposa que foi companheira e cúmplice desse trabalho, me ajudando e incentivando em todos os momentos, dividindo o tempo do seu doutorado com o meu, foi ótimo fazer o doutorado junto com você. Agradeço ao meu pai e a minha mãe pela construção da pessoa que sou. A minha querida sogra, que, foi nosso suporte em vários momentos, principalmente nas nossas viagens, em que ela não mediu esforços para cuidar do nosso filho.

Agradeço às instituições USP, UFMT, IFMT, CAPES e FAPEMAT por me apoiarem nas atividades do doutorado. Aos coordenadores do DINTER, que promoveram a cooperação entre UFMT e Poli-USP, professores Dra. Patricia C. Souza, Dr. Cristiano Maciel, Dr. Carlos Cugnasca e Dr. André R. Hirakawa. Aos professores da USP, que se deslocaram até Cuiabá para ministrarem as disciplinas do curso.

Aos amigos e parentes, que se fizeram presentes sempre, mesmo quando eu estava em viagem, apoiando e proporcionado momentos de alegria e conforto ao meu filho: Maurício Catharino, Rejane Catharino, Janã Pinheiro, Weber Souza, Cristiane Carlotto, Viviane Bronzatti, Charles Fonseca e Lucas Fonseca, muito obrigado!

Às pessoas especiais que conheci durante o curso, a Mariza U. Leone, pela ajuda e carinho sempre que precisei; aos colegas do Laboratório Interlab, Cléber Corrêa, Daniel Makoto e Ana Claudia pelo carinho e troca de informação, muito obrigado!

Agradeço ao meu orientador, professor Dr. Romero Tori, por me acolher no Interlab e orientar, pelo estímulo e entusiasmo. Agradecimento especial ao professor Dr. Ricardo Nakamura por ter acompanhado a orientação juntamente com o Prof. Romero, sempre contribuindo com sua excepcional visão de pesquisa. Obrigado pela amizade de vocês.

Àqueles cujo nome não mencionei peço desculpas, e aqui o meu sincero agradecimento! 


\section{RESUMO}

A Realidade Virtual é usada na produção de simulações complexas de ambientes virtuais 3D, envolvendo dispositivos de entrada e saída não triviais, para proporcionar aos usuários sensações de imersão em mundos simulados de tempo real. O projeto e o desenvolvimento de aplicações de realidade virtual caracterizam-se como tarefas complexas, devido à necessidade de integração de técnicas de diferentes áreas da computação e dispositivos não convencionais. Com o objetivo de aumentar o potencial de reutilização e compartilhamento de elementos de aplicações de realidade virtual, este trabalho propõe o RM-VRServices, um modelo conceitual de representação de aplicações de realidade virtual, e o VRServices, um modelo arquitetural para uma plataforma de software que apoia a produção, execução e compartilhamento de elementos de aplicações de realidade virtual em ambiente on-line. O RM-VRServices foi desenvolvido por meio da representação hierárquica de conceitos de mundos virtuais e aplicações de realidade virtual. A plataforma VRServices foi projetada com base no paradigma de computação orientada a serviços, com o objetivo de promover o compartilhamento de conteúdo, a interoperabilidade e a flexibilidade de acesso às funcionalidades da plataforma. $O$ desenvolvimento de protótipos do modelo RM-VRServices e da plataforma VRServices, possibilitou a produção de aplicações de realidade virtual, em um ambiente on-line, acessível por meio de serviços, com interoperabilidade de linguagem de programação e plataforma computacional.

Palavras-chave: Realidade virtual. Reuso de software. Computação orientada a serviço. Modelo de representação. 


\section{ABSTRACT}

Virtual reality is used in the production of complex simulations of $3 D$ virtual environments, involving nontrivial input and output devices, to provide users with sensations of immersion in the simulated world in real time. The design and development of virtual reality applications are characterized with complex tasks, due to the need to integrate techniques from different areas of computing and non-conventional devices. In order to increase the potential for reuse and sharing of elements of virtual reality applications, this work proposes the RM-VRServices, a conceptual model for representing virtual reality applications, and the VRServices, an architectural model for a software platform to support the production, implementation and element sharing of virtual reality applications in an online environment. The RM-VRServices was developed by using the hierarchical representation of virtual world concepts and virtual reality applications. The VRServices platform was designed based on the paradigm of service-oriented computing, with the goal of promoting content sharing, interoperability and flexibility of access to the features of the platform. The development of prototypes of the RM-VRServices model and the VRServices platform, enabled the production of virtual reality applications in an online environment, accessible through services, with interoperability of programming language and computing platform.

Keywords - Virtual Reality. Software Reuse. Service-Oriented Computing. Representation Model. 


\section{LISTA DE ILUSTRAÇÕES}

1 Delimitação do escopo da pesquisa . . . . . . . . . . . . . . . . . . . . . . . . . . . . 19

2 Visão geral das etapas realizadas na pesquisa $\ldots \ldots \ldots$. . . . . . . . . . . . . . 21

3 Etapa de revisões bibliográficas . . . . . . . . . . . . . . . . . . . . . . . . 22

4 Etapa de definição de modelos conceituais e lógicos . . . . . . . . . . . . . . . . 22

5 Etapa de verificação de representação e produção de aplicações RV . . . . . . . . 23

6 Etapa de verificação da capacidade de execução . . . . . . . . . . . . . . . . . 24

7 llustração do Sensorama . . . . . . . . . . . . . . . . . . . . . . . . . 26

8 Fluxo de Informações em Sistemas de RV . . . . . . . . . . . . . . . . . . . . . . . . . . . 29

9 Exemplo de um grafo de cena . . . . . . . . . . . . . . . . . . . . 34

10 Exemplo de uma estrutura e um grafo de cena . . . . . . . . . . . . . . . . . 35

11 Componente abstrato . . . . . . . . . . . . . . . . . . . . . . . 45

12 Classificação de serviços . . . . . . . . . . . . . . . . . . . . . . . . . . . . 47

13 Arquitetura de Web Service baseado em SOAP . . . . . . . . . . . . . . . . . . . 49

14 Estrutura do envelope SOAP . . . . . . . . . . . . . . . . . . . . . . . . . 50

15 Estrutura do documento WSDL . . . . . . . . . . . . . . . . . . . . . . 51

16 Triângulo Web Services . . . . . . . . . . . . . . . . . . . . . . . . . . . 51

17 Enterprise Service Bus . . . . . . . . . . . . . . . . . . . . . . . . . . . . . 52

18 Arquitetura da plataforma de desenvolvimento VR-Juggler . . . . . . . . . . . . 57

19 Hierarquia de abstração de dispositivos de entrada . . . . . . . . . . . . . . . . . 58

20 Classe que representa uma aplicação VR-Juggler . . . . . . . . . . . . . . . . . 58

21 Exemplo de implantação de serviços . . . . . . . . . . . . . . . . . . . 60

22 Arquitetura do arcabouço . . . . . . . . . . . . . . . . . . 61

23 Projeto arquitetural do ViMeT . . . . . . . . . . . . . . . . . . . . . . 62

24 Ambiente virtual da plataforma Hydra . . . . . . . . . . . . . . . . . . . . . . 63

25 Arquitetura da plataforma Hydra . . . . . . . . . . . . . . . . . . . . . . . 64

26 Arquitetura da plataforma VRJugglua . . . . . . . . . . . . . . . 65

27 Fases de desenvolvimento de aplicações RV . . . . . . . . . . . . . . . . . 66

28 Arquitetura do arcabouço MASCARET . . . . . . . . . . . . . . . . . 68

29 Fluxograma de decomposição de elementos de ferrovia . . . . . . . . . . . . . . 70

30 Representação do eixo principal do RM-VRServices . . . . . . . . . . . . . . . . . 81

31 Visão lógica da produção e execução de aplicações com o RM-VRServices . . . . . . 83

32 Representação parcial do RM-VRServices . . . . . . . . . . . . . . . . . . . . 84

33 Conceito Virtuallnput do RM-VRServices . . . . . . . . . . . . . . . . . . . . . 88 
34 Conceito VirtualOutput do RM-VRServices . . . . . . . . . . . . . . . . . . . . 90

35 Relações do conceito Event no RM-VRServices . . . . . . . . . . . . . . . . . . 91

36 Conceito Event do RM-VRServices . . . . . . . . . . . . . . . . . . . . . . . . 92

37 Conceito Behavior do RM-VRServices . . . . . . . . . . . . . . . . . . . . . 94

38 Conceito Resource do RM-VRServices . . . . . . . . . . . . . . . . . . . . . . 95

39 Conceito Appearance do RM-VRServices . . . . . . . . . . . . . . . . . . . . . 96

40 Conceito Light do RM-VRServices . . . . . . . . . . . . . . . . . . . . . . . . 96

41 llustração de reuso de elementos do RM-VRServices $\ldots \ldots$. . . . . . . . . . . . 97

42 Processo de produção de aplicações com RM-VRServices . . . . . . . . . . . . . . 99

43 Visão lógica dos clientes da plataforma . . . . . . . . . . . . . . . . . . . . . . 102

44 Diagrama de contexto da plataforma VRServices . . . . . . . . . . . . . . . 103

45 Diagrama de contexto da plataforma VRServices . . . . . . . . . . . . . . . 104

46 Arquitetura lógica da plataforma VRServices . . . . . . . . . . . . . . . . . 106

47 Arquitetura lógica dos subsistemas . . . . . . . . . . . . . . . . . . 107

48 Subsistema de produção . . . . . . . . . . . . . . . . . . . . . . . . . . . 109

49 Classe SceneVO representa o conceito Scene do RM-VRServices . . . . . . . . . 110

50 Classe SceneDAO da camada de persistência . . . . . . . . . . . . . . . . . . 111

51 Classe Scene da camada de domínio . . . . . . . . . . . . . . . . . . . . . . . 111

52 Classe ProductionManager da camada de interface . . . . . . . . . . . . . . . . 112

53 Classe ProductionManagerService da camada de serviços . . . . . . . . . . . . . 113

54 Sequência de mensagens para inclusão de uma instância de SceneVO . . . . . . . . 115

55 Subsistema de Execução . . . . . . . . . . . . . . . . . . . . . . . . . . . 117

56 Sequência de mensagens para iniciação do contexto de aplicação . . . . . . . . . . 119

57 Operações de entrada de dados . . . . . . . . . . . . . . . . . . . . 120

58 Sequência de mensagens para o processamento de entrada de dados . . . . . . . . 122

59 Arquitetura de distribuição dos subsistemas . . . . . . . . . . . . . . . . . . . . 123

60 Etapas de realização das provas de conceito . . . . . . . . . . . . . . . . . . . 126

61 Interface do software VIDA . . . . . . . . . . . . . . . . . . . . . . . 128

62 Representação de elementos de conteúdo do RM-VRServices . . . . . . . . . . . 130

63 Representação do comportamento de mudança de cena . . . . . . . . . . . . . . . 133

64 Representação do comportamento de manipulação dos objetos virtuais . . . . . . . . 134

65 Camada de persistência do subsistema de produção . . . . . . . . . . . . . . . . 135

66 Web Service do subsistema de recursos . . . . . . . . . . . . . . . . . . . 136

67 Interface do protótipo do cliente de gerenciamento de recursos - inclusão de recursos 137

68 Web Service do subsistema de produção . . . . . . . . . . . . . . . . . . . . 137

69 Interface do protótipo do cliente de produção - inclusão de objeto virtual . . . . . . . 138 
70 Interface do protótipo do cliente de produção - inclusão de cena ～. . . . . . . . . 138

71 Interface do protótipo do cliente de produção - edição de transformações da cena . . 139

72 Interface do protótipo do cliente de produção - configuração da transformação . . . . 139

73 Interface do protótipo do cliente de produção - edição de mundos virtuais . . . . . . 140

74 Interface do protótipo do cliente de produção - edição de aplicações ～. . . . . . . . 140

75 Web Service do subsistema de execução . . . . . . . . . . . . . . . . . . . . . . 141

76 Interface do protótipo do cliente de execução . . . . . . . . . . . . . . . . . . 142

77 Reuso de elementos do RM-VRServices . . . . . . . . . . . . . . . . . . . . . 143

78 Interface do cliente de produção - novo mundo virtual . . . . . . . . . . . . . . . 144

79 Interface do cliente de produção - reuso da cena2 na Aplicação apVida2 . . . . . . 145

80 Interface do cliente de execução - aplicação apVida2 . . . . . . . . . . . . . . . 145

81 Artigos por Abordagem de Desenvolvimento . . . . . . . . . . . . . . . . . . 164 


\section{LISTA DE TABELAS}

1 Sumarização dos trabalhos relacionados - arcabouços e plataformas . . . . . . . . 72

2 Sumarização dos trabalhos relacionados - abstrações e representações . . . . . . . 76

3 Características dos trabalhos relacionados f . . . . . . . . . . . . . . . . 78

4 Classificação de dispositivos de entrada de dados . . . . . . . . . . . . . . . . . 88

5 Mapeamento de conceitos e funções de entrada de dados . . . . . . . . . . . . . 89

6 Mapeamento das funções em subsistemas . . . . . . . . . . . . . . . . . . . . 105

7 Artigos por abordagem de Desenvolvimento . . . . . . . . . . . . . . . . . 163 


\section{LISTA DE ABREVIATURAS E SIGLAS}

3D

API

AV

AVD

CEO

COM

CORBA

COTS

$\cos$

CPU

CRUD

CTDL

DCOM

EJB

ESB

GKS

GPS

JDK

JNI

LOD

MIME

MOR

MPEG-4

PHIGS
Tridimensional ou três dimensões

Application Program Interface

Ambiente Virtual

Ambiente Virtual Distribuído

Chief Executive Officer

Component Object Model

Common Object Request Broker Architecture

Commercial off-the-shelf

Computação Orientada a Serviços

Central Processing Unit

Create, Read, Update e Delete

Collaborative Task Description Language

Distributed Component Object Model

Enterprise JavaBeans

Enterprise Service Bus

Graphical Kernel System

Global Positioning System

Java Development Kit

Java Native Interface

Level Of Detail

Multipurpose Internet Mail Extensions

Mapeamento Objeto-Relacional

Moving Picture Experts Group

Programmer's Hierarchical Interactive Graphics System

RM-VRServices Representation Model of Virtual Reality Services 


$\begin{array}{ll}\text { RMI } & \text { Remote Method Invocation } \\ \text { RA } & \text { Realidade Aumentada } \\ \text { REST } & \text { Representational State Transfer } \\ \text { RV } & \text { Realidade Virtual } \\ \text { SOA } & \text { Service-Oriented Architecture } \\ \text { SOAP } & \text { Simple Object Access Protocol } \\ \text { SRV } & \text { Sistema de Realidade Virtual } \\ \text { UML } & \text { Unified Medical Language } \\ \text { URI } & \text { Uniform Resource Identifier } \\ \text { UDDI } & \text { Universal Description, Discovery and Integration } \\ \text { VRML } & \text { Virtual Reality Modeling Language } \\ \text { VRServices } & \text { Virtual Reality Services } \\ \text { WADL } & \text { Web Application Description Language } \\ \text { WSDL } & \text { Web Services Description Language } \\ \text { XML } & \text { Extensible Markup Language }\end{array}$




\section{SUMÁRIO}

1 Introdução 14

1.1 Problema . . . . . . . . . . . . . . . . . . . . . 16

1.2 Motivação . . . . . . . . . . . . . . . . . . . . . . 18

1.3 Objetivos . . . . . . . . . . . . . . . . . . . . . . . . . . . . . . . . . . 19

1.4 Escopo da Pesquisa . . . . . . . . . . . . . . . . . . . . . . . . . . . 19

1.5 Materiais e Métodos . . . . . . . . . . . . . . . . . . 20

1.6 Organização do Texto . . . . . . . . . . . . . . . . . . . . 24

2 Realidade Virtual 26

2.1 Sistemas de Realidade Virtual . . . . . . . . . . . . . . . . . . . . . . 28

2.1 .1 Componentes Físicos . . . . . . . . . . . . . . . . . . . . . 31

2.1.2 Componentes Lógicos . . . . . . . . . . . . . . . . . . . 32

2.2 Representação Hierárquica de Aplicações RV . . . . . . . . . . . . . . . . 34

2.3 Considerações Finais do Capítulo . . . . . . . . . . . . . . . . . . . . . 35

3 Aspectos de Engenharia de Software e Tecnologias 37

3.1 Reuso de Software . . . . . . . . . . . . . . . . . . . . . . . . . . . 37

3.2 Arquitetura de Software . . . . . . . . . . . . . . . . . . . . . . . 41

3.2.1 Processo de Desenvolvimento de Arquitetura . . . . . . . . . . . 42

3.2.2 Reuso Arquitetural . . . . . . . . . . . . . . . . . . . . . . . 43

3.3 Desenvolvimento Orientado a Componentes . . . . . . . . . . . . . . . 43

3.3.1 Infraestruturas de Componentes . . . . . . . . . . . . . . . . 44

3.4 Computação Orientada a Serviços . . . . . . . . . . . . . . . . . . . . . 45

3.4.1 Classificação de Serviços . . . . . . . . . . . . . . . . . . . . . 46

3.4.2 Questões Tecnológicas de Serviços . . . . . . . . . . . . . . . . 47

3.4.2.1 Web Services . . . . . . . . . . . . . . . . . . . . 48

3.4.2.2 Enterprise Service Bus . . . . . . . . . . . . . . 52

3.4.3 Reuso de Serviços . . . . . . . . . . . . . . . . . . . . . . . . . 54

3.5 Considerações Finais do Capítulo . . . . . . . . . . . . . . . . . . . . 54

4 Trabalhos Relacionados 56

4.1 Plataformas e Arcabouços para Aplicações de RV . . . . . . . . . . . . 56

4.1 .1 VR Juggler . . . . . . . . . . . . . . . . . . 56 
4.1.2 Streaming Web Services . . . . . . . . . . . . . . . . 59

4.1 .3 ViMeT . . . . . . . . . . . . . . . . . . . . . 61

4.1 .4 Hydra . . . . . . . . . . . . . . . . . 62

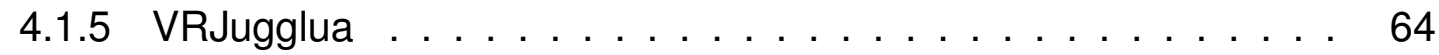

4.2 Estratégias de Abstração de Elementos de Aplicações de RV . . . . . . 65

4.2.1 VR-WISE . . . . . . . . . . . . . . . . 66

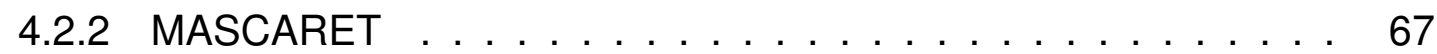

4.2.3 High-Speed Railway . . . . . . . . . . . . . . . . . . . . . . . 69

4.3 Sumarização dos Trabalhos Relacionados . . . . . . . . . . . . . . 70

4.4 Considerações Finais do Capítulo $\ldots \ldots \ldots \ldots$. . . . . . 78

5 Modelo Conceitual de Representação de Aplicações de Realidade Virtual 81

5.1 Descrição do Modelo RM-VRServices . . . . . . . . . . . . . . 83

5.1 .1 Conceito Virtuallnput . . . . . . . . . . . . . . 86

5.1 .2 Conceito VirtualOutput . . . . . . . . . . . . . . . . 90

5.1 .3 Conceito Event . . . . . . . . . . . . . . . . . . . . . . . . . . 91

5.1 .4 Conceito Behavior . . . . . . . . . . . . . . . . . . . 93

5.1 .5 Conceito Resource . . . . . . . . . . . . . . . . . . . . . 95

5.1.6 Conceitos Appearance e Light . . . . . . . . . . . . . . . . 96

5.2 Reuso de Elementos do RM-VRServices . . . . . . . . . . . . . . 97

5.3 Processo de Produção de Aplicações . . . . . . . . . . . . . . . . . . 98

5.4 Considerações Finais do Capítulo . . . . . . . . . . . . . . . . 100

6 Modelo Arquitetural da Plataforma 101

6.1 Descrição Funcional da Plataforma VRServices . . . . . . . . . . . 103

6.2 Arquitetura Lógica da Plataforma . . . . . . . . . . . . . . . . . . 105

6.2.1 Arquitetura Lógica dos Subsistemas . . . . . . . . . . . . . 107

6.3 Descrição dos Subsistemas de Plataforma VRServices . . . . . . . . 108

6.3.1 Subsistema de Produção . . . . . . . . . . . . . . . . . 108

6.3.2 Subsistema de Execução . . . . . . . . . . . . . . . . . . 116

6.4 Distribuição de Componentes e Serviços . . . . . . . . . . . . . . 123

6.5 Considerações Finais do Capítulo . . . . . . . . . . . . . . . . 125

7 Resultados $\quad 126$

7.1 Escopo Funcional das Provas de Conceito . . . . . . . . . . . . . . 127

7.2 Capacidade de Representação do RM-VRServices . . . . . . . . . . . 129

7.3 Capacidade de Produção em Ambiente On-line . . . . . . . . . . . . 136 
7.4 Capacidade de Execução em Ambiente On-line . . . . . . . . . . . . . 141

7.5 Capacidade de Reuso de Elementos de Aplicações . . . . . . . . . . 142

7.6 Discussão dos Resultados . . . . . . . . . . . . . . . . . . . . . 146

8 Conclusão 148

8.1 Contribuições . . . . . . . . . . . . . . . . . . . . . . . . . 149

8.2 Trabalhos Futuros . . . . . . . . . . . . . . . . . . 150

8.3 Considerações Finais . . . . . . . . . . . . . . . . . . . 151

$\begin{array}{ll}\text { Referências } & 154\end{array}$

Apêndice A - Revisão Sistemática $\quad 160$

A.1 Protocolo de Revisão . . . . . . . . . . . . . . . . . . . . . . . . . . . . 160

A.1.1 Processo de Seleção dos Trabalhos . . . . . . . . . . . . . 162

A.1.2 Sumarização dos resultados . . . . . . . . . . . . . . . . . 162

Apêndice B - Listagem de Classes por Subsistema 165

B.1 Subsistema de Recursos . . . . . . . . . . . . . . . . . . . . . 165

B.1.1 Lado Servidor . . . . . . . . . . . . . . . . . . . . 165

B.1.2 Lado Cliente . . . . . . . . . . . . . . . . . . . . . . . 166

B.2 Subsistema de Controle de Acesso . . . . . . . . . . . . . . . . 166

B.2.1 Lado Servidor . . . . . . . . . . . . . . . . . . . . . 166

B.2.2 Lado Cliente . . . . . . . . . . . . . . . . . . . . . . . 167

B.3 Subsistema de Produção . . . . . . . . . . . . . . . . . . . . 168

B.3.1 Lado Servidor . . . . . . . . . . . . . . . . . . . . . 168

B.3.2 Lado Cliente . . . . . . . . . . . . . . . . . . . . . . . 173

B.4 Subsistema de Execução . . . . . . . . . . . . . . . . . . . . . . 174

B.4.1 Lado Servidor . . . . . . . . . . . . . . . . . . . . 174

B.4.2 Lado Cliente . . . . . . . . . . . . . . . . . . . . . . . 175 


\section{INTRODUÇÃO}

A Realidade Virtual (RV) representa uma categoria de aplicações de software que reúne um conjunto de características que permite ao usuário a experiência de interação e imersão em um ambiente virtual sintético (SHERMAN; CRAIG, 2003).

O desenvolvimento de sistemas de software para a produção de aplicações de $\mathrm{RV}$ normalmente envolve diversas áreas de conhecimento em decorrência da grande aplicabilidade desse tipo de sistema, tais como: educação, visualização científica, socialização, simulação, treinamento, reabilitação, medicina e entretenimento. Essa característica produz um conjunto complexo de requisitos de software, que dificulta ou impede a construção de um único sistema capaz de atender a todos esses requisitos. Nesse cenário a necessidade de reuso de software é acentuada, em função da complexidade inerente a esses sistemas, bem como da necessidade de adaptação para o atendimento a novos domínios de problema (OLIVEIRA; CROWCROFT; SLATER, 2003).

O desenvolvimento de novas técnicas e tecnologias de RV e o avanço dos recursos computacionais tornaram as representações interativas e imersivas mais acessíveis. As interfaces rompem os limites das telas dos computadores, teclado e mouse, permitindo que os usuários controlem o espaço tridimensional com gestos, sons e sensores.

A RV possibilita a ampliação dos sentidos e das capacidades dos seres humanos, podendo ver, ouvir, sentir, acionar e viajar além das capacidades naturais, criando alternativas para a produção de aplicações voltadas para o entretenimento, simulação e treinamento, dentre outros (TORI; KIRNER, 2006). Esses ambientes simulados otimizam os gastos com recursos necessários à realização de viagens, experimentos e testes. Também contribuem para o aumento da segurança de determinados testes que são arriscados para realização em ambiente real, bem como possibilitam a simulação de ações não suportadas pelo ser humano.

Uma característica predominante de sistemas de RV é sua dependência de recursos e dispositivos não convencionais, tais como: dispositivos de entrada de dados especiais, equipamentos de visualização especiais, além da alta capacidade de 
processamento computacional, em especial, o processamento gráfico. Equipamentos e dispositivos volumosos e desconfortáveis usados na interação com aplicações de RV, podem causar desconforto aos usuários. O uso de equipamentos leves e portáteis pode facilitar a interação com essas aplicações. Equipamentos móveis como notebooks, tablets e smartphones, além de serem leves, normalmente trazem uma série de recursos de interação, como teclado, câmera, bússola e sensores (TAYLOR; PASQUALE, 2010).

Um fato contemporâneo e importante é o advento da computação em nuvem, caracterizada principalmente pela possibilidade dos conteúdos serem produzidos de forma colaborativa, fortalecendo e viabilizando o conceito de inteligência coletiva. A popularização das comunidades virtuais permite que pessoas do mundo todo possam trocar informações e experiências. A computação em nuvem mudou o modelo tradicional de publicação de informação na Web para um modelo de produção colaborativa de informação. Atualmente as pessoas usam extensivamente as aplicações como: Wikipedia (WIKIPEDIA, 2014), YouTube (YOUTUBE, 2014), Linkedln (LINKEDIN, 2014), Twitter (TWITTER, 2014), Facebook (FACEBOOK, 2014) e Google Applications (Google, 2014) para criar e compartilhar informações (BEIN; BEIN; MADIRAJU, 2009).

Aplicações de mundos virtuais on-line compartilhados, como o Second Life (LAB, 2014) e o Facebook (FACEBOOK, 2014), ganharam popularidade nos últimos anos. As aplicações de mundos virtuais de multiusuários em massa são típicas de ambientes virtuais distribuídos (AVD). As aplicações AVD fornecem mundos virtuais simulados no computador onde os usuários se reúnem em um espaço compartilhado e interagem uns com os outros. O aumento do número de usuários nesses ambientes traz grandes desafios para os desenvolvedores. Terceirização de implementação por meio de interfaces de programação de aplicativos (API) abertas e integração de componentes de terceiros nas aplicações provaram ser alternativas viáveis em aplicações Web populares (ZHANG; GRACANIN, 2008a).

A integração de aplicativos tridimensionais (3D) distribuídos resulta em novos desafios, um deles é a interoperabilidade de dados. Diferentes aplicações 3D usam vários formatos de dados para representação de modelos e usam diferentes implementações de cenários gráficos para o propósito de renderização. O desafio é a exigência de desempenho em tempo real para aplicações 3D, que no ambiente distribuído torna-se fator crítico, dependendo da natureza da aplicação (ZHANG; GRACANIN, 2008b).

Com o objetivo de viabilizar a instanciação de aplicações $\mathrm{RV}$, por meio da 
composição de elementos reutilizáveis, este trabalho propõe um modelo conceitual de representação e uma plataforma baseada em serviços para proporcionar um ambiente on-line de produção e execução de instâncias de aplicações RV, acessível por meio de interfaces de serviços. O modelo define os elementos, relações, restrições e comportamentos das aplicações RV, que podem ser recombinados para produzirem diferentes aplicações. O público alvo da plataforma são desenvolvedores de software que devem inserir chamadas de serviços de produção e execução nos códigos-fonte de suas aplicações.

\subsection{Problema}

Trabalhos de pesquisa estão sendo desenvolvidos para promoverem ganhos na produção de aplicações de RV. Várias abordagens com diferentes níveis de granularidade de elementos de software foram propostas para viabilizar o aumento de produtividade e qualidade no desenvolvimento de aplicações de RV. Podem ser citados exemplos como as API, que generalizam questões específicas, os arcabouços que generalizam uma família de aplicações que podem ser personalizadas para um domínio de problema e as plataformas de componentes que podem ser reusados para compor diferentes aplicações.

Podem ser citados, trabalhos de pesquisa como (OLIVEIRA; CROWCROFT; SLATER, 2003), (OLIVEIRA et al., 2006), (ZHANG; GRACANIN, 2008a), (SHAO; MCGRAW, 2009), (LI; WANG; HE, 2010), (FILHO, 2011), que promoveram a flexibilidade e o aumento da possibilidade de reuso de elementos de software, por meio de combinações de abordagens como: componentes, arcabouços e API. Nessas propostas, o reuso se dá principalmente por meio de incorporação ou extensão de código de terceiro ao código da aplicação em desenvolvimento.

Folmer (2007) discute os pontos favoráveis e desfavoráveis das abordagens de desenvolvimento baseadas em componentes e arcabouços. O desenvolvimento baseado em componentes é mais flexível em termos de composição de soluções, possui maior facilidade de distribuição e implantação, e não é vinculado a um domínio específico de aplicação. Contudo, exige maior esforço para a integração dos componentes. A abordagem baseada em arcabouços ameniza os esforços de integração, pois estabelece uma aplicação genérica extensível que antecipa boa parte da integração dos componentes, mas torna-se, por consequência, específica para domínios de aplicação e exige maiores esforços de distribuição e implantação. Essas características explicam as ocorrências de projetos que unem as duas abordagens, 
tirando proveito das vantagens e amenizando as deficiências de cada uma.

Outras propostas, como (TOBLER, 2011), (CHEVAILLIER et al., 2012) e (JINHONG et al., 2013) buscam o reuso em nível de abstração mais alto que no nível do desenvolvedor de software. Nessas propostas, o objetivo é produzir aplicações virtuais por meio da representação de elementos lógicos ou pelo reuso de modelos 3D. Nessas propostas os desenvolvedores não manipulam diretamente os componentes ou API que compõem a aplicação ou a estrutura de suporte, mas as representações lógicas, semânticas e de conteúdo 3D.

Segundo Zhang e Gracanin (2008a), o aumento de usuários em ambientes virtuais traz desafios para os desenvolvedores, principalmente com a necessidade de expandir os conteúdos dos mundos virtuais. A terceirização de implementação por meio de interfaces de programação de aplicativos (APIs) abertas e a integração de componentes de terceiros demostraram ser uma abordagem válida para aplicações Web populares, como o Facebook (FACEBOOK, 2014) e Second Life (LAB, 2014). No entanto, tal abordagem carece de padronização, que limita a capacidade de reutilização dos componentes desenvolvidos.

Após a análise de diversos trabalhos, o que se observa é a intersecção de algumas funcionalidades e a distinção de outras, na maioria dos casos destinadas a questões particulares de cada projeto. Assim, observa-se que não existe uma solução para todos os casos e que uma alternativa é investir em interoperabilidade para viabilizar a troca de conteúdo entre diversas abordagens. Observa-se também uma tendência em direcionar as pesquisas para a produção de aplicações RV com níveis de abstração acima do código fonte, não exigindo conhecimentos técnicos de desenvolvimento de software aos produtores de aplicações RV.

O desenvolvimento de aplicações de RV carece de pesquisas que fomentem a produção de aplicações com níveis de abstração mais alto do que código fonte, API, extensão de arcabouços ou incorporação de componentes (TROYER et al., 2007). Também é preciso facilitar a produção, o compartilhamento e o reuso de elementos de aplicações RV em diferentes níveis de representação, permitindo a recombinação de elementos existentes para a produção de novos elementos compostos.

Outro fator importante no desenvolvimento de aplicações RV, principalmente em ambientes on-line, é a busca pela interoperabilidade, quer seja na representação de conteúdo ou na capacidade de acesso às funcionalidades existentes. Outra possibilidade de interoperabilidade está relacionada com a capacidade de clientes remotos interagirem com um ambiente compartilhado por meio de diferentes dispositivos de interação. 
Assim, os problemas identificados nessa pesquisa estão voltados ao baixo potencial de reuso e compartilhamento de elementos de aplicações de $R V$, dependências tecnológicas para a execução e interação com tais sistemas, e as dificuldades em produzir sistemas extensíveis, interoperáveis e com baixo acoplamento entre os elementos que compõem os sistemas de RV.

A hipótese é que uma representação conceitual de elementos de aplicações de realidade virtual, com diferentes níveis de granularidade de composição, juntamente com a possibilidade de produção e execução em um ambiente on-line, permita a interoperabilidade de conteúdo e forma de acesso ao ambiente remoto, reuso e compartilhamento de conteúdos de mundos virtuais.

\subsection{Motivação}

Muitas tarefas antes executadas em ambiente computacional standalone estão migrando para ambientes on-line. Ambientes on-line facilitam a produção, acesso e compartilhamento de conteúdo, otimizando rotinas de trabalho e viabilizando a produção de conteúdo de forma colaborativa (KURKOVSKY et al., 2008).

No caso da atividade de desenvolvimento de software, existem poucas iniciativas de migração da tarefa de produção de aplicações para o ambiente on-line. A forma mais comum é a produção de componentes de software em ambiente standalone e a disponibilização ou implantação do software em ambiente on-line.

A possibilidade de produção de aplicações de software em ambiente on-line é um fator motivador, pois permite que elementos de software possam ser reusados e compartilhados por uma comunidade de desenvolvedores. Outro aspecto importante de ambientes on-line é a capacidade de fornecer recursos computacionais que alguns clientes não possuem, como por exemplo, capacidade de processamento gráfico e armazenamento.

Considerando a possibilidade de produção e execução de aplicações de RV em ambiente on-line, são fatores motivadores:

- possibilidade de reuso e compartilhamento de artefatos para o desenvolvimento de aplicações;

- redução de exigências de recursos computacionais, como o alto potencial de processamento, a aceleração gráfica e o armazenamento de dados;

- facilidade na produção de aplicações multiusuários em ambiente on-line;

- os serviços prestados pelo ambiente on-line podem ser consumidos por diferentes plataformas de clientes. 


\subsection{Objetivos}

O objetivo deste trabalho é conceber e demonstrar a viabilidade de um modelo de representação para a instanciação de aplicações de realidade virtual voltado ao reuso e compartilhamento de conteúdos de mundos virtuais em ambiente on-line.

Para atingir esse objetivo são necessários os seguintes objetivos específicos:

- definir e analisar a viabilidade de um modelo de representação de aplicações de realidade virtual;

- definir e analisar a viabilidade de um modelo arquitetural para uma plataforma baseada em serviços, objetivando a produção, reuso e execução de mundos virtuais em ambiente on-line.

\subsection{Escopo da Pesquisa}

Este trabalho está inserido no contexto de produção de mundos virtuais em ambiente on-line, especificamente aqueles que podem ser classificados como aplicações de realidade virtual. Considerando as várias abordagens de abstração e representação de aplicações de RV, este trabalho concentra-se nos modelos hierárquicos de representação de mundos virtuais.

A Figura 1 ilustra os elementos que compõem o escopo de pesquisa deste trabalho, são eles:

Figura 1: Delimitação do escopo da pesquisa

\section{Modelo Conceitual para Instanciação de \\ Aplicações de Realidade Virtual em uma \\ Plataforma Baseada em Serviços}

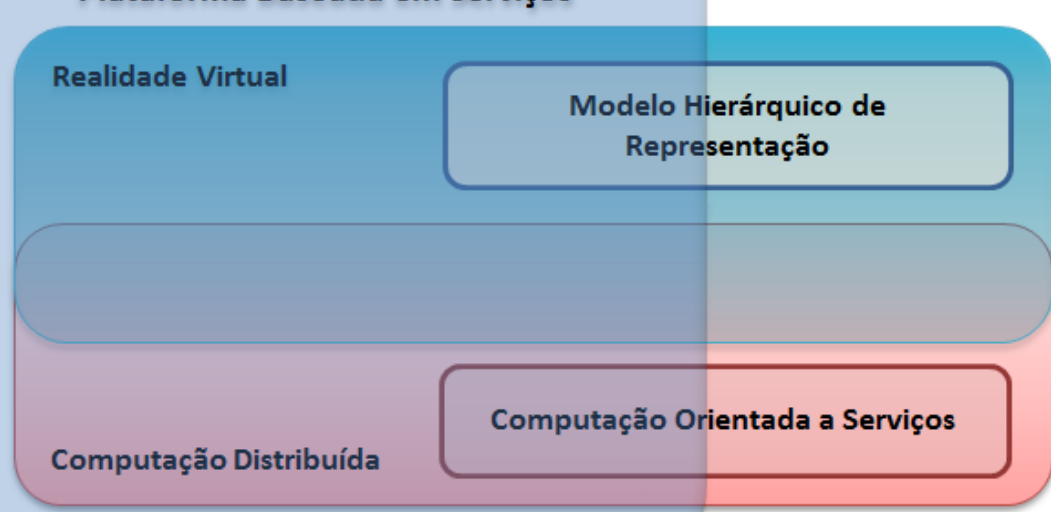

Fonte: Autor (2014) 
Realidade Virtual - além dos conceitos, características e restrições que delimitam as aplicações de RV, o trabalho explora o uso de um modelo conceitual de representação de mundos virtuais, caracterizado pela representação hierárquica de elementos. O modelo hierárquico é usado como base para o desenvolvimento do modelo proposto de representação de aplicações RV.

Computação Distribuída - como a capacidade de produção e execução de aplicações RV em ambiente on-line faz parte do objetivo da pesquisa, é necessário uma arquitetura que promova a distribuição de componentes na rede.

Computação Orientada a Serviços - além da distribuição de componentes que constituem a plataforma proposta, é usado o paradigma de computação orientada a serviços. O objetivo é expor as funcionalidades da plataforma como serviços Web, permitindo que tanto os componentes distribuídos da plataforma, quanto os clientes consumidores possam consumir as funcionalidades por meio de serviços.

Dessa forma, a produção e a execução de aplicações RV, por meio da representação conceitual proposta, são realizadas com o apoio de uma plataforma baseada em serviços disponibilizados na Internet.

\subsection{Materiais e Métodos}

A presente pesquisa é caracterizada como uma pesquisa exploratória qualitativa. Para atingir o objetivo estabelecido e conduzir os resultados para as conclusões relacionadas à hipótese considerada, foram executadas as etapas ilustradas na Figura 2. Nesta figura são ilustradas as etapas que descrevem como foram realizadas as revisões bibliográficas, a definição de modelos conceituais e lógicos e a verificação dos resultados obtidos. O detalhamento dessas etapas é ilustrado por meio das Figuras 3, 4, 5 e 6.

A etapa de revisões bibliográficas, ilustrada na Figura 3, teve como objetivo investigar arcabouços, plataformas, bibliotecas ou API propostas para o desenvolvimento de aplicações de RV. Foi realizada uma investigação exploratória inicial com o objetivo de localizar trabalhos para subsidiar o planejamento de uma revisão sistemática conforme (KITCHENHAM, 2004), (MIAN; NATALI; TRAVASSOS, 2005).

A partir das primeiras investigações foi produzido um protocolo de revisão sistemática com o objetivo de obter trabalhos de pesquisa que discutem abordagens de reuso e o uso de componentes ou serviços no desenvolvimento de aplicações de RV em ambiente distribuído (FREIBERGER; NAKAMURA; NUNES, 2012). Também 
Figura 2: Visão geral das etapas realizadas na pesquisa

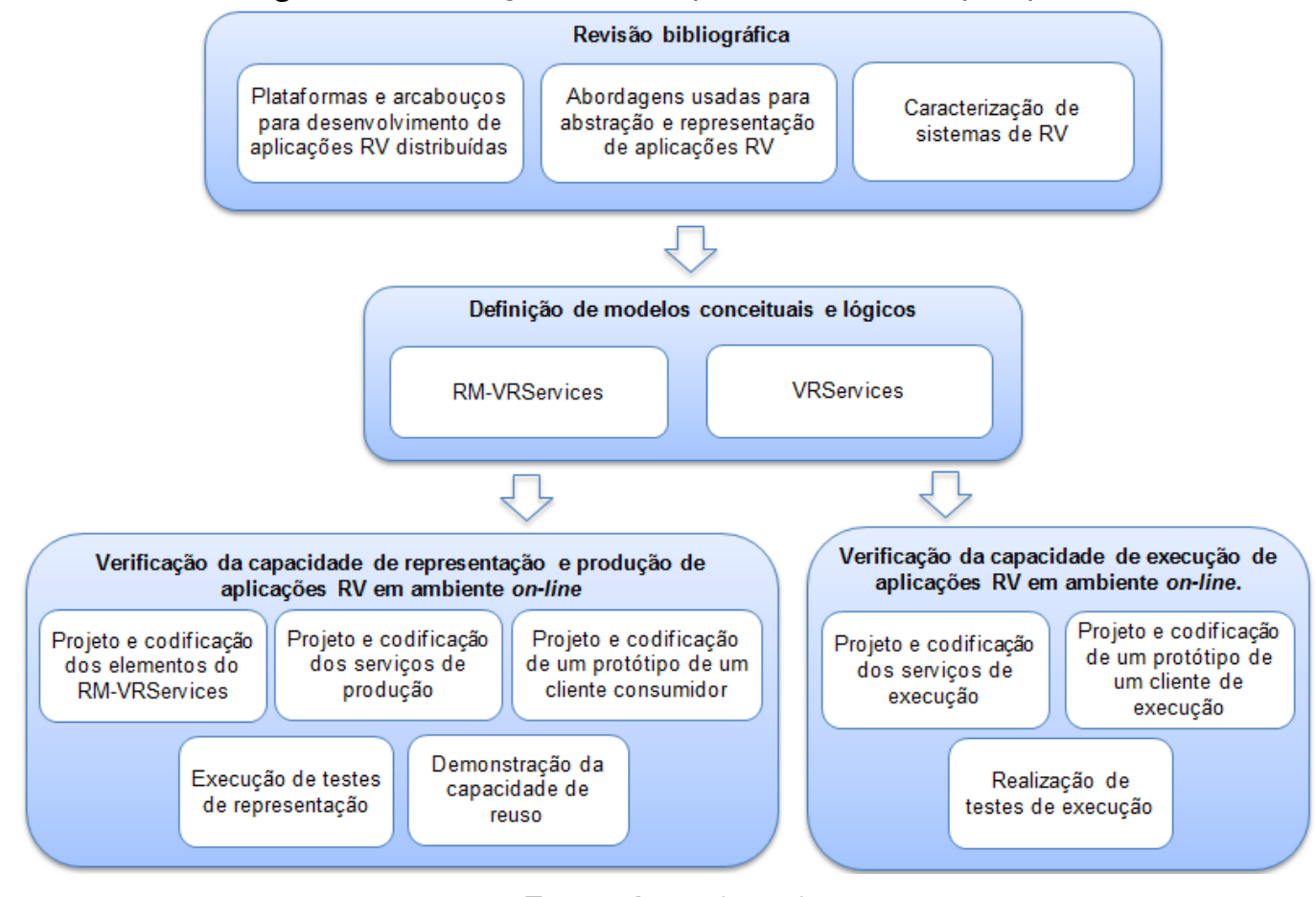

Fonte: Autor (2014)

foram investigadas formas de abstração de elementos de aplicações RV com o objetivo de verificar quais representações lógicas são usadas para abstrair os elementos que constituem as aplicações RV. Por último, foram pesquisadas e analisadas as referências que proporcionam as fundamentações de conceitos e características de sistemas de RV, com o objetivo de reunir os requisitos envolvidos nesse tipo de sistema.

A próxima etapa, ilustrada na Figura 4, está relacionada diretamente com um dos objetivos específicos da pesquisa, que é a produção de um modelo de representação de aplicações $\mathrm{RV}$ que satisfaça duas premissas estabelecidas: 1) permita a produção, edição e execução de aplicações RV em ambiente on-line, e 2) permita a representação de subelementos de aplicações RV em diferentes níveis de granularidade, permitindo que sejam reusados na produção de novas aplicações RV.

O modelo conceitual de representação produzido recebeu o acrônimo RM-VRServices, constituído pelas definições de elementos, atributos de elementos, relações e as restrições que estabelecem regras de validação do modelo.

Para que as instâncias do RM-VRServices possam ser criadas, editadas e executadas em ambiente on-line, que corresponde ao segundo objetivo específico da pesquisa, foi proposto um modelo arquitetural para uma plataforma de software baseada em serviços, denominado VRServices. Os serviços da plataforma foram 
Figura 3: Etapa de revisões bibliográficas

\begin{tabular}{|l|l|}
\hline $\begin{array}{l}\text { Levantamento e análise de plataformas e arcabouços } \\
\text { para desenvolvimento de aplicações RV distribuídas. } \\
\text { Eevisões } \\
\text { Eibliográficas em abordagens com reuso de elementos de } \\
\text { aplicaçes RV. }\end{array}$ \\
$\begin{array}{l}\text { Levantamento e análise de abordagens usadas para } \\
\text { abstração e representação de aplicações RV. }\end{array}$ \\
Caracterização de sistemas de RV.
\end{tabular}

Fonte: Autor (2014)

Figura 4: Etapa de definição de modelos conceituais e lógicos

\begin{tabular}{|l|l|}
\hline $\begin{array}{c}\text { Definição de } \\
\text { modelos } \\
\text { conceituais e } \\
\text { lógicos }\end{array}$ & $\begin{array}{l}\text { Definição do Modelo Conceitual para a Instanciação do modelo arquitetural para a plataforma } \\
\text { de Aplicações de Realidade Virtual (RM-VRServices). } \\
\text { de produção e execução de aplicaçães RV em } \\
\text { ambiente on-line. }\end{array}$ \\
\hline $\begin{array}{l}\text { Revisão bibliográfica especializada nos assuntos } \\
\text { abordados nessa etapa. }\end{array}$ \\
\hline
\end{tabular}

Fonte: Autor (2014)

divididos em dois grupos, o primeiro relacionado às funcionalidades de produção de aplicações RV e o segundo relacionado às funcionalidades de execução das aplicações.

Com a definição do RM-VRServices e do modelo de arquitetura da plataforma, iniciou-se a etapa de verificação da capacidade de representação e produção de aplicações RV em ambiente on-line.

O objetivo é verificar se o RM-VRServices reúne as características necessárias para a representação de aplicações RV, conforme estabelecido no escopo da pesquisa. Também é necessária a verificação da viabilidade de produção de aplicações RV por meio do modelo arquitetural proposto para a plataforma. A Figura 5 ilustra as atividades desta etapa. A etapa foi iniciada com o projeto e codificação 
dos elementos que constituem uma instância do RM-VRServices, dividido em duas atividades: 1) estrutura que define os elementos, atributos e relações, e 2) estrutura de validação e consistência do modelo. Também foi definida a estratégia de persistência e recuperação de instâncias do RM-VRServices.

Figura 5: Etapa de verificação de representação e produção de aplicações RV

\begin{tabular}{|c|c|}
\hline \multirow{6}{*}{$\begin{array}{l}\text { Verificação da } \\
\text { capacidade de } \\
\text { representação } \\
\text { e produção de } \\
\text { aplicações RV } \\
\text { em ambiente } \\
\text { on-line }\end{array}$} & $\begin{array}{l}\text { Projeto e codificação dos elementos concretos de } \\
\text { representação e verificação do RM-VRServices. }\end{array}$ \\
\hline & $\begin{array}{l}\text { Projeto e codificação dos serviços de produção de } \\
\text { aplicações RV por meio do RM-VRServices em } \\
\text { ambiente on-line. }\end{array}$ \\
\hline & $\begin{array}{l}\text { Revisão bibliográfica específica de assuntos } \\
\text { abordados nessa etapa. }\end{array}$ \\
\hline & $\begin{array}{l}\text { Projeto e codificação de um protótipo de aplicação } \\
\text { cliente consumidor dos serviços de produção. }\end{array}$ \\
\hline & $\begin{array}{l}\text { Execução de testes de representação de aplicações } \\
\text { RV por meio do RM-VRServices. }\end{array}$ \\
\hline & $\begin{array}{l}\text { Demonstração da capacidade de reuso de elementos } \\
\text { do RM-VRServices. }\end{array}$ \\
\hline
\end{tabular}

Fonte: Autor (2014)

Após a definição das questões relacionadas a edição e persistência de instâncias do RM-VRServices, foram projetados e codificados os serviços de produção da plataforma. Os serviços possibilitam a edição de instâncias do RM-VRServices no ambiente on-line por meio do paradigma de serviços.

Para testar os serviços de produção da plataforma foram produzidos dois protótipos de aplicação cliente: 1) aplicação de gerenciamento de recursos usados na produção de aplicações, tais como imagens, sons, vídeos, modelos 3D, texturas, e 2) uma aplicação cliente consumidora dos serviços de produção, que permite criar, editar, excluir e reusar elementos do RM-VRServices para a produção de aplicações RV.

O protótipo de produção permite a verificação da capacidade de representação do RM-VRServices e da capacidade de produção em ambiente on-line por meio de serviços. 
A última etapa, ilustrada na Figura 6, teve o objetivo de verificar a capacidade de execução de aplicações produzidas por meio de instâncias do RM-VRServices no ambiente on-line da plataforma. A etapa foi iniciada com o projeto e codificação dos serviços de execução da plataforma. Os serviços de execução permitem a localização de aplicações RV armazenadas no repositório da plataforma, a preparação do contexto de execução e a execução da aplicação com as interações e comportamentos previstos na aplicação.

Figura 6: Etapa de verificação da capacidade de execução

\begin{tabular}{|l|l|}
\hline $\begin{array}{l}\text { Perificação da } \\
\text { capacidade de } \\
\text { execução de } \\
\text { aplicações RV }\end{array}$ & $\begin{array}{l}\text { Projeto e confificação dos serviços de execução de } \\
\text { de execução, consuano de um protótipo de um cliente } \\
\text { da plataforma. }\end{array}$ \\
$\begin{array}{c}\text { em ambiente } \\
\text { on-line. }\end{array}$ & $\begin{array}{l}\text { Realização de testes de execução em ambiente on- } \\
\text { line de aplicações produzidas por meio de execução } \\
\text { VRServices. }\end{array}$ \\
\end{tabular}

Fonte: Autor (2014)

Para realizar a verificação dos serviços de execução foi produzido um protótipo de uma aplicação cliente consumidora dos serviços de execução. A partir desse protótipo foi possível verificar a capacidade de execução e interação com o contexto de execução da plataforma por meio de serviços. Também foram realizados testes de latência na execução das aplicações. Estes testes permitiram o estabelecimento de tipos de aplicações suportadas pela plataforma, bem como o estabelecimento de trabalhos futuros para ampliar suas capacidades.

\subsection{Organização do Texto}

O trabalho está organizado em sete capítulos e dois apêndices, além dessa introdução. No Capítulo 2 são apresentados os conceitos relacionados a realidade virtual.

No Capítulo 3 são apresentados conceitos e tecnologias relacionados a reuso de software, arquitetura de software, desenvolvimento orientado a componentes e computação orientada a serviços. 
No Capítulo 4 são apresentados os principais trabalhos de pesquisa encontrados na literatura e relacionados ao tema desta pesquisa. Também é apresentada uma sumarização com o posicionamento desta pesquisa em relação aos trabalhos relacionados.

No Capítulo 5 é apresentado o modelo de representação de aplicações de realidade virtual proposto.

No Capítulo 6 é apresentado o modelo arquitetural proposto para a plataforma orientada a serviços de produção e execução de aplicações de realidade virtual.

No Capítulo 7 são apresentados os resultados de provas de conceitos realizadas para a análise da capacidade de representação do modelo proposto e capacidade de produção e execução on-line de aplicações de realidade virtual da plataforma proposta.

O Capítulo 8 apresenta as considerações finais deste trabalho de pesquisa, apresentando ainda as contribuições e os trabalhos futuros.

Por último, são apresentadas as referências utilizadas nesta pesquisa e os dois apêndices. O Apêndice $A$ apresenta o protocolo da revisão sistemática realizada e o Apêndice B apresenta uma listagem das classes que foram implementadas nas provas de conceito realizadas. 


\section{REALIDADE VIRTUAL}

Neste Capítulo são apresentados os conceitos, as caracterizações e as tecnologias relacionados com sistemas e aplicações de realidade virtual. Também são discutidos os principais elementos que compõem um sistema RV e a representação hierárquica de mundos virtuais.

O conceito de realidade virtual tem origem antes mesmo do estabelecimento do termo. Historicamente, na década de 1950, o cineasta Morton Heilig propôs e criou um sistema imersivo, denominado de Sensorama, ilustrado na Figura 7, que submetia o usuário a sensações, movimentos, sons, odores, ventos e visão estereoscópica com o objetivo de aumentar a sensação de imersão do usuário. Na década de 1960, o engenheiro Ivan Sutherland desenvolveu o Sketchpad, sistema que iniciou as bases da computação gráfica e o primeiro capacete de realidade virtual (JORDAN; PACKER, 2002) e (SHERMAN; CRAIG, 2003).

Figura 7: Ilustração do Sensorama

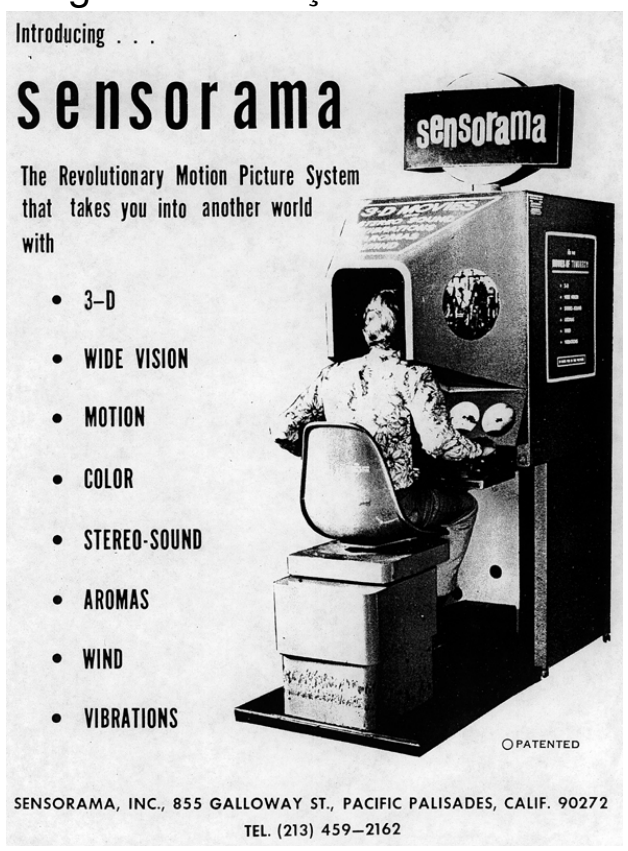

Fonte: http://www.telepresence.org/sensorama/

O termo realidade virtual foi estabelecido no final da década de 1980 por 
Jaron Lanier, artista e cientista da computação que convergiu dois conceitos, até então antagônicos, fundindo o termo real com o virtual (BIOCCA; LEVY, 1995).

Existem muitas definições do termo Realidade Virtual na literatura. Uma definição adotada por Tori e Kirner (2006) é apresentada a seguir:

Realidade Virtual é uma interface avançada para aplicações computacionais, que permite ao usuário a movimentação (navegação) e interação em tempo real, em um ambiente tridimensional, podendo fazer uso de dispositivos multissensoriais, para atuação ou feedback (TORI; KIRNER, 2006).

Realidade virtual são aplicações de software que reúne um conjunto de características que permite ao usuário ter experiências de interação e imersão em um ambiente virtual. Os autores Sherman e Craig (2003) estabelecem que essa experiência é obtida considerando quatro elementos chaves:

- Mundo Virtual - é uma descrição de uma coleção de objetos em um espaço e, as regras e relações que regem esses objetos;

- Imersão - sensação de estar em um ambiente, considerando um estado puramente mental ou por meios físicos. A imersão física é uma característica definidora da realidade virtual que pode ser obtida com a imersão corporal em um meio ou por estímulos sintéticos dos sentidos por meio de dispositivos tecnológicos, não sendo necessário o estímulo de todos os sentidos ou a imersão de todo o corpo. A imersão mental é o estado de estar profundamente envolvido, de tal forma, que o usuário perde a noção do que é real ou virtual;

- Resposta Sensorial - o sistema VR oferece resposta sensorial direta aos participantes com base em sua posição física;

- Interatividade - para a realidade virtual parecer autêntica, ela deve responder às ações do usuário, ou seja, ser interativa.

Além da visualização podem ser usados outros sentidos, como o tato $\mathrm{e}$ a audição, para aumentar a sensação de imersão. Aplicações de RV devem proporcionar um ambiente tridimensional sintético, visualização de qualquer ponto desse ambiente, movimentação no espaço 3D e a interação com os elementos do espaço 3D. Os objetos 3D podem possuir comportamento próprio ou reagir a estímulos, como eventos, tempo e colisões (TORI; KIRNER, 2006).

Algumas aplicações de realidade virtual são projetadas para combinar as representações virtuais com a percepção do mundo físico. A representação virtual dá ao usuário a possibilidade de obter informações adicionais sobre o mundo físico que 
não são percebidos naturalmente pelos sentidos humanos. Esse tipo específico de aplicações de realidade virtual recebe o nome de realidade aumentada (RA). Segundo Sherman e Craig (2003) realidade aumentada é:

Um tipo de realidade virtual em que os estímulos sintéticos são registrados e sobrepostos a objetos do mundo real, muitas vezes usado para tornar perceptíveis as informações, sendo que de outra forma não são percebíveis aos sentidos humanos (SHERMAN; CRAIG, 2003).

\subsection{Sistemas de Realidade Virtual}

Um sistema computacional é classificado como um sistema de realidade virtual (SRV) se apresenta três aspectos: interação, imersão e envolvimento (TORI; KIRNER, 2006). A interação estabelece a forma como o sistema deve responder a uma ação do usuário, a imersão está relacionada à sensação de presença do usuário no AV e o envolvimento se preocupa com a motivação do usuário em relação ao uso da aplicação (CORRÊA; NUNES, 2009).

Para um SRV é importante que o usuário tenha a sensação de estar presente no ambiente virtual, apontando, pegando, manipulando ou executando ações sobre os objetos virtuais em tempo real. Isso é proporcionado por dispositivos de entrada e saída de dados permitindo que o usuário forneça estímulos ao ambiente virtual e receba o feedback provocado por esses estímulos (TORI; KIRNER, 2006).

A Figura 8 ilustra o fluxo de informações para uma configuração típica de um SRV. Elementos do mundo virtual são mapeados em representações adequadas para exibição visual, auditiva e tátil. A renderização do mundo virtual leva em conta os movimentos do usuário para criar o ponto de vista imersivo. Informações de rastreamento de corpo são integradas com as informações do mundo virtual para exibir um ponto de vista do participante.

As informações de rastreamento de corpo, que incluem cliques de botões, mouse, gestos, dentre outros, alimentam diretamente o sistema que processa os resultados para os vários dispositivos de saída sensoriais. Informações de rastreamento também alimentam o mundo virtual para auxiliar na determinação de colisões, seleções e outros aspectos do mundo, sendo relacionados com a postura do participante. Para os sistemas de realidade aumentada, a renderização do mundo virtual é misturada com uma visão do mundo real. 
Figura 8: Fluxo de Informações em Sistemas de RV

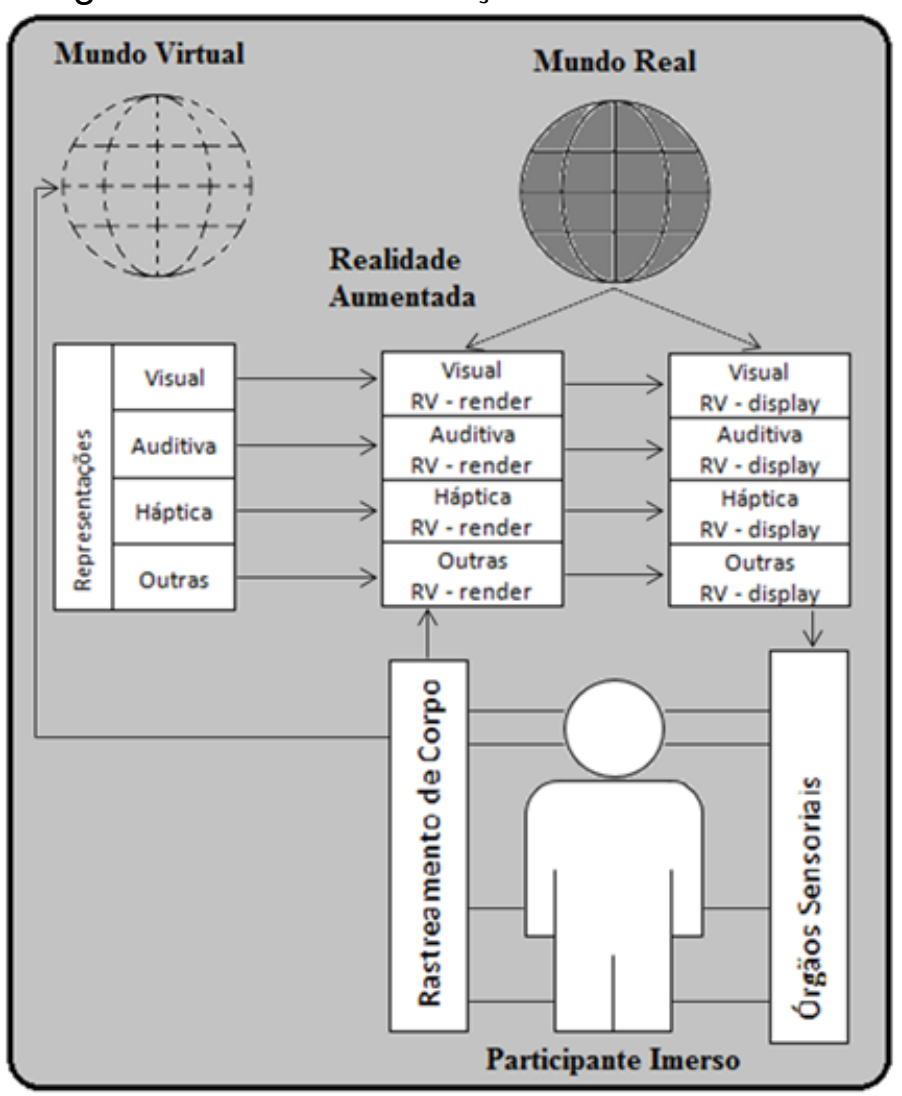

Fonte: adaptado de (SHERMAN; CRAIG, 2003)

Segundo Tori e Kirner (2006) as características dos SRV são divididas em três categorias, a primeira refere-se as características de conteúdo dos ambientes virtuais, a segunda remete aos comportamentos ou capacidades dos ambientes virtuais e a terceira apresenta as restrições de desempenho que garantem as características de tempo real e da imersão do usuário no ambiente virtual.

- As características relacionadas com o conteúdo de sistemas de realidade virtual são:

- ambiente virtual é formado por objetos virtuais;

- atributos de objetos virtuais contêm informações sobre: geometria, cores, texturas, iluminação, características dinâmicas, restrições físicas e atributos acústicos;

- deve possuir canais de entrada de dados ligados a dispositivos como: mouse, mouse 3D, teclado, reconhecedor de movimentos do corpo, reconhecedor de voz, luvas, sensores, joystick, sistema de posicionamento global (GPS), câmera de vídeo, etc;

- deve possuir canais de saída de dados ligados a dispositivos como: 
display visual, display de áudio, display háptico;

- acesso a banco de dados para o gerenciamento de dados envolvidos na execução de aplicações no ambiente virtual.

- As características relacionadas com o comportamento de sistemas de realidade virtual são:

- controle dos canais de entrada e saída;

- interação do usuário com o ambiente, como: navegação, seleção, manipulação e controle do sistema;

- renderização sensorial visual, auditiva e háptica;

- gerenciamento de banco de dados;

- tratamento de nível de detalhes de objetos (em inglês, Level Of Detail - LOD);

- detecção e tratamento de colisões;

- capacidade de rastreamento para posicionamento de objetos ou controle do ambiente;

- gerenciamento de recursos de rede;

- processamento gráfico;

- capacidade de combinar objetos virtuais com o ambiente real;

- capacidade de alinhamento de objetos reais com objetos virtuais.

- As características relacionadas com requisitos de tempo para sistemas de realidade virtual são:

- tempo de latência com atraso máximo de 100 milissegundos na execução de comandos;

- taxa de renderização visual de no mínimo 10 quadros (frames) por segundo.

Sistemas de RV são constituídos por componentes que podem ser classificados em físicos e lógicos. Os componentes físicos abrangem equipamentos convencionais, tais como processadores, meio de armazenamento, dispositivos de interconexão de equipamentos e dispositivos de interface com o usuário, como também equipamentos não convencionais, específicos da área de realidade virtual (LUZ; KIRNER, 2006). 


\subsubsection{Componentes Físicos}

A realidade virtual permite diferentes possibilidades do usuário interagir com o ambiente virtual. Assim, o SRV pode necessitar de dispositivos de hardware que monitoram o usuário a fim de obter informações necessárias para produzir uma exposição fisicamente imersiva do usuário. Entradas do usuário também possibilitam a interação com o mundo virtual (SHERMAN; CRAIG, 2003).

Considerando a direção do fluxo de dados entre usuário e SRV, os equipamentos podem ser classificados em equipamentos de entrada, saída e mistos. Os equipamentos de entrada são representados por equipamentos, tais como mouse, teclado, joystick, câmeras, luvas, roupas, braços mecânicos que possuem sensores de movimento, força e pressão. Os equipamentos de saída são representados por monitores, telas de projeção, capacetes de realidade virtual, caixas de som dentre outros. Os equipamentos mistos combinam as duas formas de fluxo de informação anteriormente citadas e são representados por luvas de captura com retorno de força, braços mecânicos, dispositivos hápticos, além de capacetes integrados com sensores de localização e movimento (LUZ; KIRNER, 2006).

O monitoramento do usuário é o acompanhamento em tempo real das ações do participante em uma experiência RV. Sem a capacidade de obter a entrada do usuário, uma exposição gerada por computador não é interativa, e não caracteriza um sistema de realidade virtual. O monitoramento do usuário inclui o acompanhamento contínuo dos movimentos do usuário e das ações iniciadas pelo usuário, como pressionar um botão, mover um dispositivo de posicionamento, movimentar membros do corpo ou a emissão de um comando de voz para o sistema. Isso permite que o sistema possa mostrar o mundo virtual a partir de uma perspectiva centrada no usuário, proporcionando o efeito de imersão (SHERMAN; CRAIG, 2003).

Além do monitoramento dos usuários, pode existir o monitoramento do mundo virtual. Nessa categoria são fornecidas entradas do mundo real e informações sobre mudanças no mundo virtual, provocadas em decorrência do tempo ou de manipulações do usuário. Essas informações podem ser obtidas e incorporadas à experiência RV a partir de fontes que não estão diretamente relacionadas com os usuários (SHERMAN; CRAIG, 2003).

Um elemento importante de uma experiência de RV é a forma como o usuário percebe o ambiente. Sua percepção física do mundo virtual é inteiramente baseada no que os computadores disponibilizam por meio de saídas do sistema. O termo display é largamente usado para referenciar um método de apresentação de informação, 
considerando quaisquer dos sentidos humanos. O sistema de percepção humana tem, pelo menos, cinco sentidos que fornecem informação para o cérebro. Três desses sentidos, visual, auditivo e tátil, são os mais explorados como estímulos sintéticos em uma experiência RV (SHERMAN; CRAIG, 2003).

Existem três classificações básicas para os displays sensoriais: 1) saídas em dispositivos estacionários que dependem da postura do usuário, como monitores, telas de projeção, alto-falantes de áudio; 2) saídas incorporadas à cabeça do usuário (Head-based display - HBD) são ligadas de alguma forma à cabeça do usuário e se movem em conjunto com ela. Assim, não importa o caminho que o usuário toma ou o movimento da cabeça, as saídas irão mover-se em conjunto com a cabeça, permanecendo em uma posição fixa em relação às entradas sensoriais da cabeça, neste caso, os olhos e ouvidos; e 3) saídas baseadas na mão, como computadores de mão e luvas, movem-se em conjunto com a mão do usuário (SHERMAN; CRAIG, 2003).

\subsubsection{Componentes Lógicos}

Os componentes lógicos de SRV são essenciais para a integração dos componentes físicos e tratamento dos dados do sistema. A criação de SRV envolve diversas disciplinas, pode exigir a utilização de uma vasta gama de tecnologias, softwares e linguagens de programação, cujo objetivo é produzir um mundo virtual. Para que um mundo virtual seja criado é necessário produzir o conteúdo e sua lógica de execução (LUZ; KIRNER, 2006).

O conteúdo lógico de um SRV é o mundo virtual (SHERMAN; CRAIG, 2003), o conteúdo do mundo virtual são os objetos tridimensionais formados por características de aparência e comportamento (LUZ; KIRNER, 2006).

A produção de objetos do mundo virtual envolve normalmente a utilização de ferramentas de modelagem 3D, edição de imagem, som, vídeo e comportamento. A modelagem 3D permite a representação computacional de objetos a serem usados no mundo virtual, normalmente representados por uma matriz de coordenadas espaciais. Esta atividade é realizada por diversos tipos de profissionais, tais como artistas, designers, modeladores, sonoplastas e programadores (LUZ; KIRNER, 2006).

As principais ferramentas para a criação de conteúdo de um SRV são as de modelagem 3D e de edição de texturas. A transformação das representações dos conteúdos para a forma perceptível aos sentidos humanos, utiliza técnicas conhecidas pelo termo geral de renderização, podendo existir a renderização visual, 
auditiva ou tátil. Os comportamentos atribuídos aos objetos e ao mundo virtual são implementados por meio de linguagens de programação, fazendo com que o mundo virtual torne-se interativo e mais próximo da realidade (LUZ; KIRNER, 2006). São exemplos de linguagens de programação utilizadas para a programação de aplicações de RV: C, C++, Java, X3D, VRML e C\#.

A ligação entre a parte lógica e a física dos SRV normalmente é realizada por meio de bibliotecas e arcabouços que abstraem e isolam a complexidade de dispositivos de hardware e aumentam a produtividade do desenvolvimento de aplicações de RV.

No nível mais baixo da hierarquia de isolamento de hardware estão as bibliotecas gráficas, que são responsáveis por intermediar a aplicação de RV e as unidades de processamento gráfico (Graphics Processing Unit - GPU). Segundo Silva, Raposo e Gattass (2004), as bibliotecas gráficas mais utilizadas são a DirectX e a OpenGL. No nível de interfaceamento com hardware também estão os drivers e bibliotecas de manipulação de dispositivos de entrada e saída de SRV.

Um nível acima das bibliotecas gráficas existem as bibliotecas e arcabouços de apoio ao desenvolvimento de aplicações de RV, que fornecem funcionalidades como interfaceamento com equipamentos de RV, organização lógica dos objetos do mundo virtual, interface com usuário, manipulação de objetos 3D (operações geométricas), interação com objetos e detecção de colisões (LUZ; KIRNER, 2006). São exemplos de bibliotecas RV: Avango ${ }^{1}$, FreeVR², VRJuggle ${ }^{3}$, OpenSceneGraph ${ }^{4}$.

No nível mais alto de abstração estão os pacotes, ambientes e plataformas de desenvolvimento de aplicações RV. Nesse nível o objetivo é fornecer produtividade de desenvolvimento por meio de plataformas e ambientes que integram vários pacotes, bibliotecas e oferecem um alto nível de abstração. Podem ser citados, como exemplos, Alice $3 D^{5}$, EON Studio ${ }^{6}$, Open $\mathrm{Sim}^{7}$, Unity ${ }^{8}$. Normalmente nesse nível as plataformas e ambientes de desenvolvimento de aplicações RV são especializados para um domínio de problema.

\footnotetext{
${ }^{1} \mathrm{http}: / /$ www.avango.org

${ }^{2} \mathrm{http}: / /$ www.freevr.org/

${ }^{3} \mathrm{https}: / /$ code.google.com/p/vrjuggler/

${ }^{4} \mathrm{http}: / /$ www.openscenegraph.org/

${ }^{5} \mathrm{http}: / /$ www.alice.org/

${ }^{6} \mathrm{http}: / /$ www.eonreality.com/

${ }^{7} \mathrm{http}: / /$ opensimulator.org

${ }^{8} \mathrm{http}: / /$ unity3d.com/
} 


\subsection{Representação Hierárquica de Aplicações RV}

Muitas bibliotecas e pacotes de desenvolvimento de RV usam uma abstração conceitual para representação e manipulação de mundo virtual conhecida como grafo de cena. O grafo de cena é uma ferramenta que fornece uma representação gráfica completa e flexível de um mundo virtual. Pode especificar a localização relativa e orientação entre os objetos no mundo virtual, incluindo objetos geométricos e, em algumas situações, rastreadores de posição (SHERMAN; CRAIG, 2003).

O grafo de cena provê uma abstração que organiza os elementos do mundo virtual de maneira espacial por meio de um grafo acíclico direcionado (SILVA; RAPOSO; GATTASS, 2004). Os grafos de cena encapsulam a estrutura hierárquica de uma cena 3D completa e combinam os aspectos semânticos e de renderização (TOBLER, 2011). Também é usado para organizar atributos visuais, volumes delimitadores de ações e animações como uma hierarquia de objetos, fornecendo uma maneira conveniente de representar grupos lógicos de objetos formados por suas posições espaciais e atributos (MUKUNDAN, 2012).

Figura 9: Exemplo de um grafo de cena

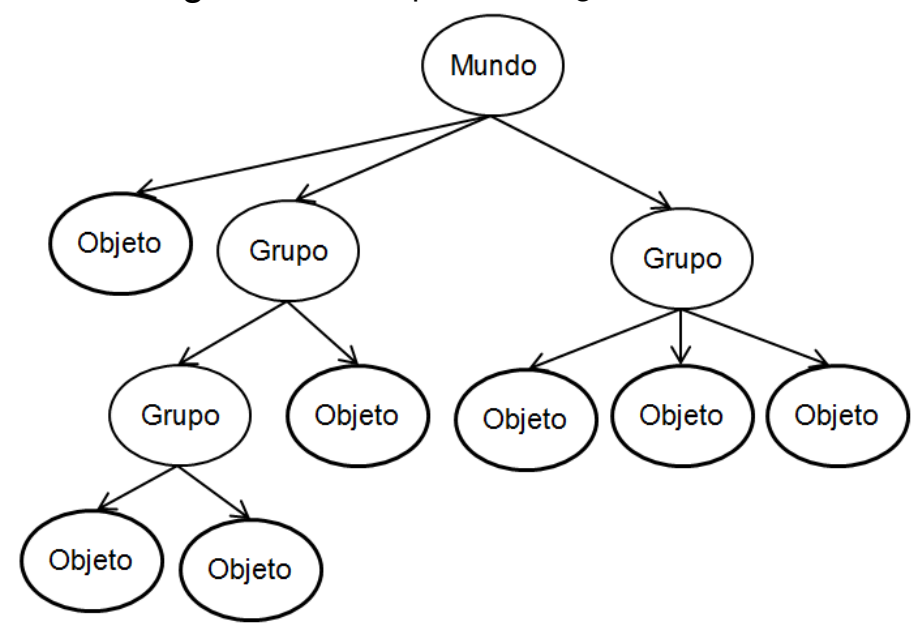

Fonte: adaptado de (MUKUNDAN, 2012)

A Figura 9 ilustra uma estrutura de grafo de cena composto por três tipos de nós: 1) nó raiz da árvore que representa todo o conjunto de objetos em uma cena tridimensional, normalmente chamado de Mundo ou Universo Virtual. O nó raiz é um tipo especial de nó grupo; 2) nó grupo é um nó interno da árvore. Ele pode conter qualquer número de nós filhos e representa um agrupamento lógico de objetos. O nó grupo não armazena os dados geométricos, mas pode conter informações semânticas; 3) nó folha, que representa um objeto ou uma parte de um objeto. Mantém dados de geometria e aparência, além de informações semânticas. Câmera e fonte 
de luz também podem ser representadas por nós folha (MUKUNDAN, 2012).

A Figura 10 ilustra um exemplo de uma estrutura geométrica e um grafo de cena com os três tipos de nós descritos acima. A Figura 10-a ilustra a estrutura geométrica composta de uma base e três partes, a parte-2 e parte-3 formam um grupo. A Figura 10-b, ilustra o grafo de cena que representa a estrutura geométrica.

O grafo de cena possui uma característica importante chamada de herança de estado. Os nós intermediários no grafo armazenam o estado do mundo virtual, por meio dos atributos que definem a posição, orientação e aparência dos objetos. A herança de estado estabelece que um nó deve herdar as características de todos os nós ascendentes em sua hierarquia. O nó que herda as características de seus ancestrais na hierarquia pode sobrepor atributos e assim definir novas características para os seus nós descendentes (SILVA; RAPOSO; GATTASS, 2004), (MUKUNDAN, 2012).

Figura 10: Exemplo de uma estrutura e um grafo de cena

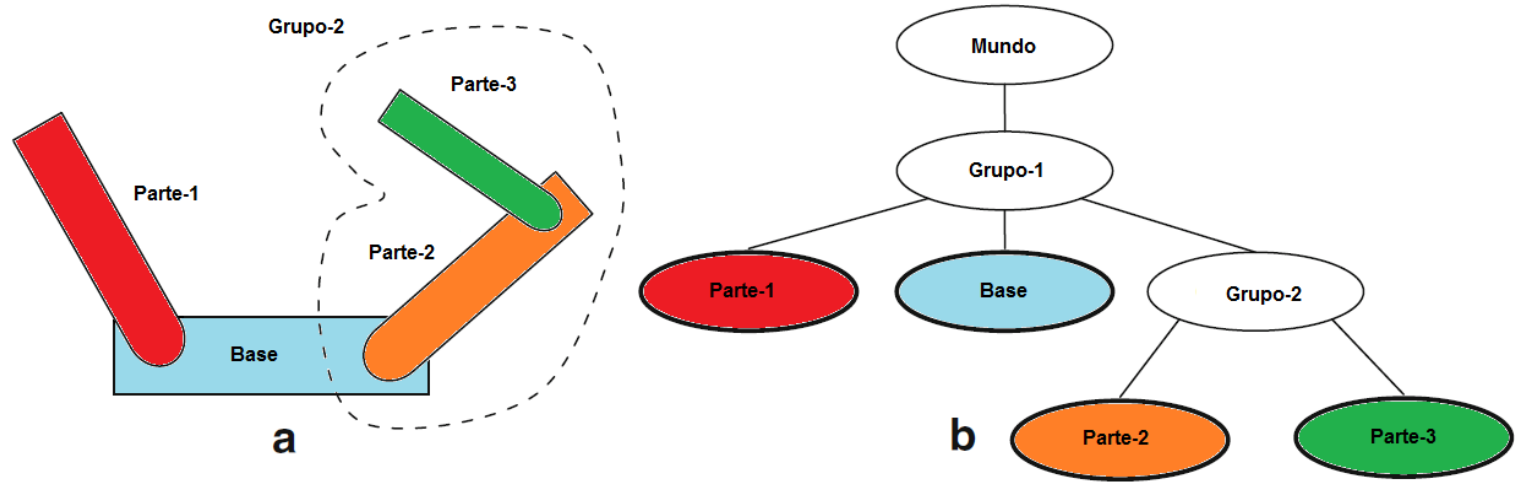

Fonte: adaptado de (MUKUNDAN, 2012)

Em linhas gerais um grafo de cena é formado por dados que estabelecem: 1) a geometria dos objetos do mundo virtual; 2) câmeras virtuais que definem as visões que serão obtidas do mundo virtual; 3) transformações que posicionam e movimentam os objetos; 4) características de aparência que definem os aspectos visuais, tais como material, textura, transparência, sombras e reflexões dos objetos; e 5) comportamentos que determinam os aspectos dinâmicos do mundo virtual, que podem mudar posicionamento, forma, aparência, iluminação de objetos do mundo virtual.

\subsection{Considerações Finais do Capítulo}

O desenvolvimento de ambientes virtuais representa um problema desafiador, pois pode envolver diversas áreas de conhecimento. A alta complexidade desses 
ambientes torna o desenvolvimento oneroso, tanto em tempo quanto em custo. Sua aplicabilidade em diferentes domínios de problemas, tais como em visualização científica, socialização, formação, reabilitação, medicina e entretenimento, produz um conjunto de requisitos que torna a construção de um SRV genérico muito difícil ou inviável.

A necessidade de proporcionar a interação e imersão dos usuários de aplicações $\mathrm{RV}$ produzem requisitos que contribuem para o aumento da complexidade do desenvolvimento, além de exigir capacidades de desempenho que geram a necessidade do uso de recursos computacionais não triviais.

Este capítulo apresentou os principais conceitos e características de sistemas computacionais para aplicações de RV. Também foram apresentadas as características da representação hierárquica de mundos virtuais. O objetivo do capítulo não é esgotar os assuntos, e sim apresentar aspectos importantes e necessários à discussão do tema proposto. 


\section{ASPECTOS DE ENGENHARIA DE SOFTWARE E TECNOLOGIAS}

Neste capítulo são apresentados os conceitos e tecnologias que dão suporte a esta pesquisa, relacionados com questões de engenharia de software e tecnologias. São tratados os conceitos, vantagens e desvantagens do reuso de software, os conceitos e recomendações para o projeto de arquitetura de software, os conceitos e características do desenvolvimento baseado em componentes e do desenvolvimento orientado a serviços. Os assuntos abordados, neste capítulo, também tem o objetivo de subsidiar o entendimento e as discussões de assuntos envolvidos nos trabalhos relacionados, apresentados no Capítulo 4.

\subsection{Reuso de Software}

Apesar do reuso de software ser reconhecido como um importante instrumento no desenvolvimento de software, somente nas duas últimas décadas observam-se mudanças, na forma de desenvolvimento, que viabilizaram o desenvolvimento baseado em reuso. Tais mudanças são decorrentes principalmente das necessidades de diminuição do custo de produção e manutenção de software, entregas mais rápidas de sistemas e o aumento das exigências de qualidade do software (SOMMERVILLE, 2007).

Segundo Gamma et al. (2007), existe um consenso entre os melhores projetistas de software que afirmam que não se deve resolver cada problema a partir de princípios elementares, mas ao invés disso, deve-se reutilizar soluções que já funcionaram em situações anteriores.

É reconhecido o aumento da complexidade na produção de software, em função da crescente abrangência de novos domínios de problema e da crescente exigência e complexidade dos sistemas computacionais. A reutilização de software é um instrumento importante em processos de desenvolvimento de software (SAMETINGER, 2001).

Segundo Sommerville (2007), o reuso de artefatos de software promove 
benefícios que justificam os investimentos em tal prática, são eles:

- software reusado tende a ser mais confiável, pois um artefato reusado já foi experimentado e testado em outros sistemas, assim seus defeitos de projetos e implementação já foram minimizados;

- riscos de estimativas são menores em desenvolvimento com reuso de artefatos do que no desenvolvimento de novos artefatos. O custo de software existente já é conhecido, enquanto as estimativas para um novo artefato são de difícil precisão;

- reuso dos conhecimentos de especialistas incorporados nos artefatos, ao invés de executar o mesmo trabalho repetidas vezes;

- redução do tempo total de entrega, pois tanto o tempo de desenvolvimento, quanto o tempo de validação tendem a serem menores.

Por outro lado, Mili et al. (2002) afirmam que o reuso de software possui limitações e necessidades específicas, tais como:

- artefatos de software possuem um potencial limitado de reuso, pois sistemas computacionais são ricos em diversidade de informação. Isso limita a probabilidade de uma correspondência entre uma necessidade específica e a disponibilidade de um artefato que a satisfaça;

- os custos relacionados a produção de artefatos de software reutilizáveis não podem ser negligenciados, visto que produzir software reutilizável é caro e o retorno desse custo depende de planejamento e políticas de gestão;

- a implantação de reuso requer mudanças nos procedimentos operacionais de uma organização. Essas mudanças geralmente encontram resistência, além disso, a reutilização necessita de investimentos específicos e não traz retorno imediato, portanto, requer suporte gerencial e financeiro de longo prazo.

Segundo Prieto-Diaz (1993), existem várias facetas de reuso de software que estabelecem as características e a maneira como os itens serão reutilizados, são elas: essência, escopo, técnica, intenção e produto.

A essência do reuso define a natureza dos itens a serem reutilizados, tais como: ideias, conceitos, artefatos, componentes, procedimentos e habilidades. A reutilização de um componente automaticamente resultará na reutilização das ideias e conceitos que foram usados na sua construção. 
O escopo do reuso define duas características: a forma, que pode ser vertical ou horizontal; e a extensão, que define se o reuso é de domínio especificado, propósito geral, pequena escala e grande escala. A quantidade possível de reuso de software depende do grau de elementos comuns generalizados das aplicações de software. Se a maioria das aplicações está em um domínio específico, existirá provavelmente um maior grau de reutilização entre as aplicações. Domínio específico de reuso normalmente leva ao reuso vertical e, por outro lado, o reuso de propósito geral leva ao reuso horizontal.

Técnica de reuso define a abordagem que é usada para implementar o reuso, composicional ou generativo. O reuso composicional apoia desenvolvimento bottom-up de sistemas a partir de um repositório de componentes disponíveis de nível inferior. O reuso por composição é baseado na ideia de componentes reutilizáveis que, de maneira ideal, não exigem alterações na sua reutilização. Componentes de nível superior ou mais complexos são construídos por meio da combinação de componentes de menor nível ou componentes mais simples de granularidade mais baixa. Os componentes que podem ser reutilizados são coletados em repositórios. Desenvolvimento generativo é aplicável em situações em que os artefatos reutilizáveis são representados em termos de padrões instanciáveis, em vez de produtos acabados. Consiste em instanciar o modelo que incorpora o artefato reutilizável e fornecer parâmetros em nível de especificação. Um gerador de código, por exemplo, usa esses parâmetros para gerar instâncias específicas de uso do padrão (MILl et al., 2002).

Intenção de reuso define como os elementos serão usados, por exemplo, como caixa-preta, caixa-branca, estado atual ou por adaptação. O reuso de componente como caixa-preta significa usá-lo sem ver, saber ou modificar qualquer parte interna. O componente fornece uma interface que contém todas as informações necessárias para sua utilização. O reuso como caixa-branca é o caso típico da reutilização ad-hoc não planejada. Componentes de software caixa-branca geralmente não são reutilizados diretamente, mas sim pela adaptação. Eles criam mais oportunidades para os clientes, devido à facilidade de fazer mudanças arbitrárias. Por outro lado, o reuso caixa-branca exige testes adicionais e manutenção mais cara.

Produto de reuso define o que é reutilizado no processo de desenvolvimento de software, tais como: código fonte, documentação, projeto, especificação, objeto, texto, padrões de projeto, padrões de dados e arquiteturas. O código fonte é o artefato mais comum de reutilização. No entanto, quanto maior o nível de abstração de reuso, maior o potencial de reuso. Uma evidência disso é que o código fonte pode ser gerado 
automaticamente a partir de níveis mais elevados de abstração (PRIETO-DIAZ, 1993).

Segundo Sametinger (2001) e Sommerville (2007), existem várias abordagens de desenvolvimento que permitem apoiar o reuso de artefatos de software. As principais são:

- Padrões de Projeto - descrições de objetos e classes comunicantes que precisam ser personalizadas para resolver um problema geral de projeto orientado a objetos, num contexto particular (GAMMA et al., 2007);

- Desenvolvimento baseado em componentes - sistema desenvolvido por meio da integração de componentes que estão em conformidade com uma especificação de componentes;

- Frameworks de aplicações - é uma aplicação reutilizável, quase completa que pode ser especializada para produzir aplicações personalizadas (FAYAD; SCHMIDT; JOHNSON, 1999);

- Empacotamento de sistemas legados - sistemas que podem ser empacotados pela definição de um conjunto de interfaces que proveem acesso a esses sistemas legados;

- Sistemas orientados a serviços - representam uma nova geração de computação distribuída, na qual o elemento fundamental é o serviço, que pode ser provido pelo contexto interno ou externo das organizações (ERL, 2009);

- Linhas de produtos de aplicação - um tipo de aplicação generalizada com base em uma arquitetura comum, para um domínio de problema, de tal maneira que pode ser adaptada para clientes diferentes;

- Integração de Commercial off-the-shelf (COTS) - sistema produzido pela integração de outros sistemas existentes;

- Aplicações verticais configuráveis - sistema genérico projetado de tal maneira que pode ser configurado para as necessidades de diferentes clientes;

- Bibliotecas de programa - conjunto de classes e funções que implementam abstrações comumente usadas e disponibilizadas para reuso;

- Geradores de programas - sistema gerador de código que incorpora conhecimento de um determinado tipo de aplicação e pode gerar sistemas ou fragmentos de sistemas;

- Desenvolvimento orientado a aspectos - componentes reusados em uma aplicação em diferentes lugares quando o programa é compilado. 


\subsection{Arquitetura de Software}

A arquitetura de um sistema computacional é uma visão abstrata, que não inclui detalhes de implementação, algoritmos e representação de dados, mas apresenta uma visão de caixa-preta dos comportamentos e interações dos elementos que a compõe. A definição de uma arquitetura de software é o primeiro passo na construção de um sistema que possui um conjunto de propriedades desejadas. Segundo Bass, Clements e Kazman (2003), arquitetura de software pode ser definida como:

A arquitetura de software de um programa ou sistema de computação é a estrutura ou estruturas do sistema, que compreendem elementos de software, as propriedades externas visíveis desses elementos, e as relações entre eles (BASS; CLEMENTS; KAZMAN, 2003).

A especificação de arquitetura de software define os elementos do software e as informações sobre como esses elementos se relacionam. Algumas informações de elementos podem ser omitidas, pois não são envolvidas em interações com outros elementos. Assim, uma arquitetura é acima de tudo, uma abstração de um sistema que suprime detalhes de elementos que não afetam a maneira como eles são usados, como se relacionam, ou interagem com outros elementos. Em quase todos os sistemas modernos, elementos interagem entre si por meio de interfaces contendo partes públicas e privadas. A arquitetura de software se preocupa com o lado público desta divisão, os detalhes particulares estão relacionados somente com a implementação interna dos elementos e não fazem parte das questões de arquitetura (BASS; CLEMENTS; KAZMAN, 2003).

Quando um sistema de computação é projetado, muitas pessoas e organizações podem ter interesses sobre ele. As necessidades dos stakeholders ${ }^{1}$ são traduzidas tecnicamente em propriedades, tais como: desempenho, confiabilidade, disponibilidade, compatibilidade com plataformas, utilização de memória, uso de rede, segurança, modificabilidade, usabilidade e interoperabilidade com outros sistemas (BASS; CLEMENTS; KAZMAN, 2003; SOMMERVILLE, 2007).

Segundo Bass, Clements e Kazman (2003), existem três razões que tornam a arquitetura de software importante para um sistema:

1. Comunicação entre as partes interessadas. A arquitetura de software representa uma abstração comum de um sistema que a maioria, se não todos,

\footnotetext{
${ }^{1}$ Stakeholders - denominação dada para os interessados em um sistema e compreendem, por exemplo, os clientes, os usuários finais, desenvolvedores, o gerente do projeto e os mantenedores (BASS; CLEMENTS; KAZMAN, 2003).
} 
os envolvidos no sistema podem usar como base para a compreensão mútua, negociação, consenso e comunicação;

2. Primeiras decisões de projeto. A arquitetura de software se manifesta como o conjunto das primeiras decisões de projeto de um sistema, e essas decisões têm um peso muito grande no desenvolvimento, implantação e manutenção;

3. Abstração transferível de um sistema. A arquitetura de software constitui um modelo relativamente pequeno de como um sistema é estruturado e como os seus elementos trabalham em conjunto, e este modelo pode ser reusado em outros sistemas, que exibem atributos de qualidade e requisitos funcionais similares, permitindo grande escala de reutilização.

\subsubsection{Processo de Desenvolvimento de Arquitetura}

Para Sommerville (2007), o projeto de arquitetura é um processo criativo altamente influenciável pelo tipo de sistema que será desenvolvido, a origem e a experiência do arquiteto e os requisitos específicos do sistema. Assim, sugere que é mais conveniente pensar o processo de arquitetura em termos de decisões e não de tarefas. $O$ arquiteto então, durante o processo de desenvolvimento de arquitetura, deve responder uma série de perguntas fundamentais para o sistema, são elas:

1. Existe uma arquitetura genérica de aplicação que possa funcionar como um modelo para o sistema que está sendo projetado?

2. Como o sistema será distribuído ao longo de vários processadores?

3. Quais estilos de arquitetura são apropriados para o sistema?

4. Qual será a abordagem fundamental usada para estruturar o sistema?

5. Como as unidades estruturais de um sistema serão decompostas em módulos?

6. Qual estratégia será usada para controlar as operações das unidades no sistema?

7. Como o projeto de arquitetura será avaliado?

8. Como a arquitetura do sistema deve ser documentada?

Bass, Clements e Kazman (2003), também estabelecem um conjunto de decisões que o arquiteto deve tomar para projetos arquitetônicos:

1. Como o sistema deve ser estruturado em um conjunto de unidades de código (módulos)?

2. Como o sistema deve ser estruturado em um conjunto de elementos que têm comportamento de tempo de execução (componentes) e interações (conectores)? 
3. Como o sistema deve se relacionar com estruturas que não sejam software em seu ambiente (por exemplo, CPU, sistemas de arquivos, redes, dispositivos, dentre outros)?

\subsubsection{Reuso Arquitetural}

Um aspecto importante da arquitetura é a possibilidade de usá-la como modelo reutilizável que pode ser transferido a outros projetos e equipes. Quanto mais cedo, no ciclo de vida de desenvolvimento, a reutilização é aplicada, maior será a possibilidade de benefícios. A reutilização de código fonte é benéfica, contudo a reutilização a nível arquitetônico oferece grande ajuda para sistemas com requisitos semelhantes. Não apenas o código pode ser reutilizado, mas os requisitos que levaram à arquitetura, bem como a experiência da construção da arquitetura.

Uma arquitetura incorpora decisões de projeto sobre a interação dos elementos que, embora reflitam na implementação de vários elementos, pode ser localizada e escrita apenas uma vez. Modelos podem ser usados para capturar em um só lugar os mecanismos de interação entre elementos. A inclusão de uma descrição de como os elementos interagem para realizar o comportamento necessário, pode servir como introdução ao sistema para os membros de um novo projeto. Isso reforça o aspecto de que um dos fatores de uso mais importantes da arquitetura de software é apoiar e incentivar a comunicação entre as várias partes do sistema.

\subsection{Desenvolvimento Orientado a Componentes}

O desenvolvimento orientado a componentes surgiu no final da década de 1990 como uma abordagem para promover reuso de software. Segundo Wang e Qian (2005), componente de software pode ser definido:

Um componente de software é um pedaço de código de computador autocontido e autoimplantável, com funcionalidade bem definida que pode ser montado com outros componentes por meio da sua interface (WANG; QIAN, 2005, Pag. 6).

O desenvolvimento orientado a componentes teve como principal elemento motivador a baixa eficiência do desenvolvimento orientado a objetos, pois as classes são elementos de software muito específicos e dependentes de ligações que ocorrem na maioria das vezes em tempo de compilação. Essa característica do desenvolvimento orientado a objetos restringe as possibilidades de distribuição e reuso. Assim, um componente é um programa ou um conjunto de programas que 
podem ser compilados e executados. É autossuficiente, pois, fornece funcionalidades coerentes. É autoimplantável, uma vez que ele pode ser instalado e executado em um ambiente de produção do usuário. Pode ser combinado com outros componentes, permitindo o reuso em vários contextos. A integração é obtida por meio da interface do componente, isso significa que a implementação de um componente permanece oculta de seu usuário (WANG; QIAN, 2005).

Componentes devem ser independentes, os detalhes de implementação devem permanecer ocultos, permitindo que sua implementação mude, sem afetar o restante do sistema. Segundo Sommerville (2007), uma maneira de entender o conceito de componente de forma concreta é considerá-lo como um provedor de serviços independentes. Quando um sistema necessita de um serviço, chama o componente para fornecer tal serviço, sem considerar como foi implementado. O autor considera duas características primordiais para componentes de software:

- componentes são entidades executáveis independentes, cujo código fonte não precisa estar disponível para seu uso;

- serviços de um componente são oferecidos por meio de uma interface que deve ser suficiente para sustentar suas interações possíveis. A interface de um componente deve ser expressa por meio de operações parametrizadas e o estado interno do componente nunca deve ser exposto.

Uma característica importante do desenvolvimento baseado em componentes, é a capacidade de produzir um sistema por meio da colaboração e composição de componentes (SOMMERVILLE, 2007). Dessa forma, o sistema será produzido a partir dos componentes escritos em conformidade com um padrão, e uma infraestrutura que fornece recursos que apoiam a comunicação, gerenciamento de transações, concorrência e proteção dos componentes.

A Figura 11 ilustra a visão abstrata de componentes. As interfaces providas estabelecem as funcionalidades que o componente presta aos outros componentes do sistema. As interfaces requeridas estabelecem as funcionalidades que o componente necessita de outros componentes presentes no sistema, para seu funcionamento.

\subsubsection{Infraestruturas de Componentes}

Componentes de software devem estar associados com uma infraestrutura de componente. Tecnologias diferentes de componentes possuem diferentes infraestruturas, portanto, possuem diferentes definições de componentes. 
Figura 11: Componente abstrato

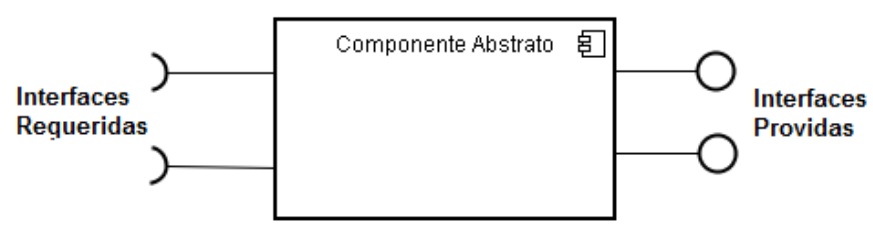

Fonte: adaptado de Sommerville (2007)

Uma infraestrutura de componentes é a estrutura básica, que permite a implementação, implantação e o gerenciamento de componentes. É formada por três modelos: um modelo de componentes, um modelo de conexão e um modelo de implantação. O modelo de componentes define como é um componente válido e como criar um novo componente para a infraestrutura. O modelo de conexão define um conjunto de conectores e elementos de apoio à montagem de componentes. $O$ modelo de implantação descreve como implantar componentes em um ambiente de produção (WANG; QIAN, 2005, Pag. 18).

\subsection{Computação Orientada a Serviços}

Computação orientada a serviços (COS) é o paradigma de computação que tem o serviço como elemento básico do desenvolvimento. O desenvolvimento é realizado por meio da cooperação entre serviços, onde os componentes de aplicação são montados em uma rede de serviços que podem abranger diferentes organizações e plataformas de computação (PAPAZOGLOU et al., 2008).

Segundo Erl (2009), COS pode ser entendida como a junção de vários elementos, são eles:

Orientação a Serviços - é um paradigma de projeto composto por um conjunto específico de princípios. A aplicação desses princípios define a Lógica Orientada a Serviços.

Serviço - é a unidade fundamental da lógica orientada a serviços considerando-o como elemento lógico. Cada serviço possui um conjunto de capacidades associadas. Essas capacidades são expostas ao meio externo como contratos de serviços, que estabelecem políticas de uso, formatos de chamadas e resultados.

Arquitetura Orientada a Serviços (SOA) - modelo arquitetural conceitual de computação orientada a serviços que estabelece conceitos e requisitos necessários à implementação de uma arquitetura orientada a serviços. SOA também define uma 
arquitetura tecnológica que estabelece a combinação de tecnologias, produtos, API e infraestruturas de suporte à implantação de uma instância de arquitetura orientada a serviços.

Composição de Serviços - é a possibilidade de combinar serviços existentes de maneira coordenada para produzir novos serviços.

Inventário de Serviços - é a coleção padronizada e governada de serviços. Uma organização corporativa pode conter diversos inventários de serviços, cada um deles com sua própria padronização e governança.

Dessa forma, uma arquitetura orientada a serviços representa uma instância tecnológica, projetada para dar suporte à lógica orientada a serviços, que contém serviços e composições de serviços catalogados e governados por um inventário de serviços, em conformidade com o paradigma da orientação a serviços (ERL, 2009).

Serviços podem ser descritos, publicados, descoberto, e dinamicamente montado para desenvolver sistemas altamente distribuídos, interoperáveis e evoluíveis. Podem desempenhar funções que vão de responder a simples pedidos até executar sofisticados processos de negócios (PAPAZOGLOU; HEUVEL, 2007). Qualquer trecho de código ou componente de aplicativo implantado em um sistema pode ser reutilizado e transformado em serviços disponíveis na rede. Serviços refletem um paradigma para a programação, baseada na ideia de compor aplicações por meio da descoberta e invocação de serviços disponíveis na rede, ao invés de construir novas aplicações. O prestador de serviços e os consumidores devem ser fracamente acoplados (PAPAZOGLOU et al., 2008).

COS envolve conceitos originários de uma variedade de disciplinas, como sistemas de computação distribuída, arquiteturas de computadores e middleware, computação em grade, engenharia de software, linguagens de programação, sistemas de banco de dados, segurança e representação de conhecimento (PAPAZOGLOU; HEUVEL, 2007).

\subsubsection{Classificação de Serviços}

Segundo Erl (2009), é possível estabelecer uma classificação de serviços em três níveis: serviço de entidade, serviço tarefa e serviço utilitário. A Figura 12 apresenta uma ilustração dessa classificação.

Serviço de Entidade - representa os serviços relacionados às entidades do domínio do problema da organização. Esses serviços têm existência própria, independente de quais processos de negócio sejam mapeados. São equivalentes a 
Figura 12: Classificação de serviços

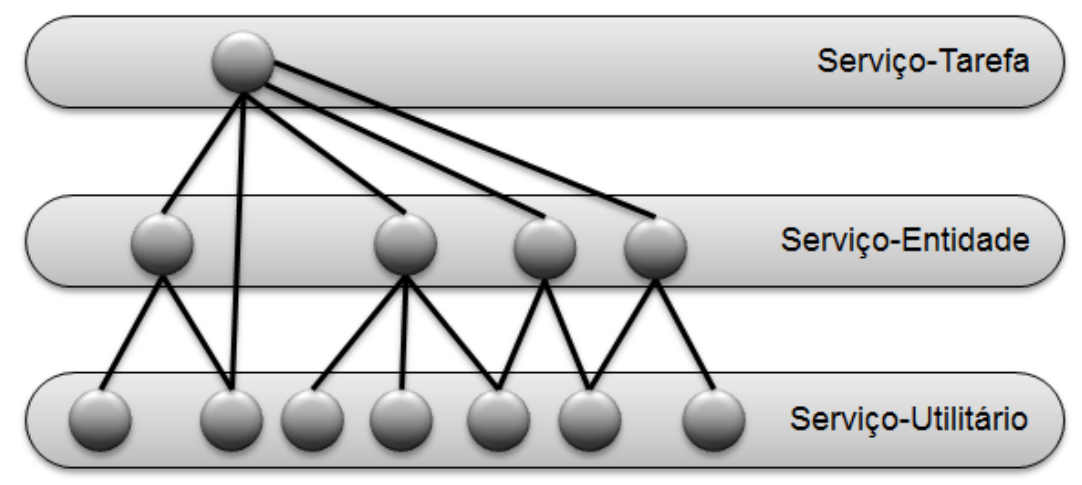

Fonte: adaptado de (ERL, 2009)

entidades conceituais de um modelo orientado a objetos. Normalmente possuem uma alta capacidade de reuso, já que podem ser usados em vários processos de negócio. Suas capacidades mais comuns equivalem as operações CRUD (create, read, update e delete).

Serviço Tarefa - representa um serviço relacionado a um processo de negócio. Um serviço tarefa normalmente é formado pela composição das capacidades de serviços de entidade. A principal diferença entre serviços tarefa e serviços de entidades é que estes tem seu escopo delimitado pelo conceito que ele representa (a entidade), já os serviços tarefa extrapolam vários escopos de entidades.

Serviço Utilitário - São serviços que não representam contextos funcionais de negócio e sim serviços voltados a questões técnicas de implementação ou gerenciamento. São serviços projetados para proporcionarem reuso de serviços tais como: registro de eventos, tratamento de exceções, autenticação e autorização de usuários, etc.

A classificação é importante, pois estabelece níveis de abstrações dos serviços, promove maior clareza na decomposição do problema e aumenta as chances de reuso dos serviços.

\subsubsection{Questões Tecnológicas de Serviços}

A abordagem orientada a serviços é independente de linguagens de programação ou plataforma de execução. Ela permite que as organizações possam expor suas principais competências de programação por meio da Internet ou uma variedade de redes, usando padrões baseados em Extensible Markup Language (XML) que descrevem linguagens, protocolos e implementação de interfaces autodescritivas. 
Dentre as várias tecnologias envolvidas na implementação de uma arquitetura orientada a serviços serão discutidas duas: Web Services e Enterprise Service Bus (ESB). Foram escolhidas em função da importância que elas representam para implementações de arquiteturas orientadas a serviços e também por estarem relacionadas aos objetivos desta pesquisa.

\subsubsection{Web Services}

Web Service é um conjunto de padrões, especificações e tecnologias usados para entregar serviços de aplicações na plataforma Web. Possibilita uma forma de Web programável, não apenas uma Web interativa implementada com páginas HTML estáticas ou páginas dinâmicas implementadas por meio de PERL, ASP, JSP, JSF, entre outras. Web Services são componentes reutilizáveis de computação distribuída, implementados como blocos de construção caixa-preta (WANG; QIAN, 2005).

A forte adoção de Web Services na implementação de computação orientada a serviços está relacionada às suas características, dentre elas pode-se destacar: independência de plataforma e linguagens de programação, possibilidade de expor quaisquer funcionalidades de aplicações como serviço pela Internet e uso de padrões abertos (PAPAZOGLOU; HEUVEL, 2007).

Embora existam muitos outros arcabouços de componentes distribuídos disponíveis na indústria, tais como Common Object Request Broker Architecture (CORBA), Distributed Component Object Model (DCOM) e Enterprise JavaBeans (EJB), apenas Web Service fornece características completas de interoperabilidade, tais como: multiplataforma, multilinguagem, linguagens cruzadas, tecnologias cruzadas e soluções amigáveis para firewall de Internet (WANG; QIAN, 2005).

Segundo Wang e Qian (2005), implementar computação distribuída por meio da tecnologia Web Services, reúne as seguintes vantagens:

- aumenta a portabilidade e interoperabilidade da computação distribuída;

- aumenta a reusabilidade e escalabilidade de componentes distribuídos;

- reduz a complexidade da composição e implantação de componentes;

- simplifica a administração do sistema distribuído;

- facilita a publicação de código legado por meio de interfaces distribuídas de serviços.

Outro fator importante para a adoção de Web Service, é a existência de especificações controladas por consórcios que o torna menos vulnerável às questões particulares de uma ou outra implementação. É baseado em padrões abertos, tais 
como: descrição de serviços por meio da Web Services Description Language ${ }^{2}$ (WSDL); protocolo de transporte por meio do Simple Object Access Protoco $\beta$ (SOAP); e registro e descoberta de serviços por meio do Universal Description, Discovery and Integration ${ }^{4}$ (UDDI), definidos como extensões de elementos XML.

\section{Protocolo SOAP}

Web Services podem ser divididos em dois grupos de tecnologia de implementação: Web Services baseados em SOAP e Web Services de estilo Representational State Transfer (REST). Nas implementações de Web Services baseados em SOAP, a comunicação entre o cliente e provedor do serviço ocorre por meio de mensagens SOAP. O cliente envia uma mensagem de solicitação de serviço, por meio de um envelope SOAP, e o Web Service responde com uma mensagem de retorno, também por meio de um envelope SOAP.

Figura 13: Arquitetura de Web Service baseado em SOAP

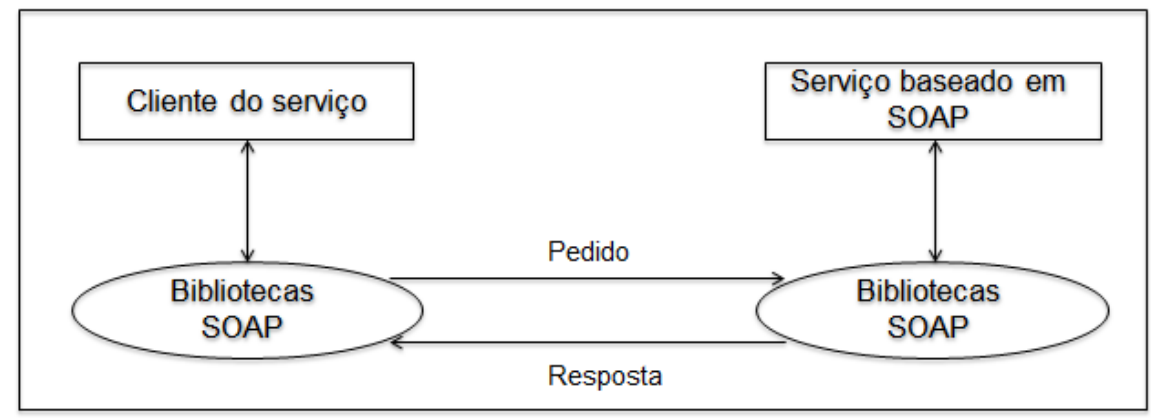

Fonte: Kalin (2010, p. 2)

A Figura 13 ilustra essa troca de envelopes SOAP. A tecnologia REST é caracterizada como um estilo arquitetural de desenvolvimento de Web Services. Nesse estilo, não existe o protocolo SOAP para transporte de dados, ao invés disso, o transporte é feito diretamente com o protocolo HTTP (KALIN, 2010).

SOAP é um protocolo de troca de mensagens baseadas em XML, especificado pelo consórcio W3C. É usado para especificar o formato de requisições e respostas na comunicação de Web Services mais comumente usado sobre protocolo HTTP, com o método HTTP POST. Cada mensagem SOAP tem um envelope que identifica um documento XML como uma mensagem SOAP. O envelope SOAP pode conter um subelemento cabeçalho (Header), deve conter o elemento corpo (Body) e opcionalmente o elemento Mime para anexos (WANG; QIAN, 2005). A Figura 14 ilustra a estrutura do envelope SOAP.

\footnotetext{
${ }^{2}$ http://www.w3.org/standards/webofservices/description

${ }^{3} \mathrm{http}: / /$ www.w3.org/standards/techs/soap

${ }^{4}$ https://www.oasis-open.org/committees/uddi-spec/doc/tcspecs.htm
} 
Figura 14: Estrutura do envelope SOAP

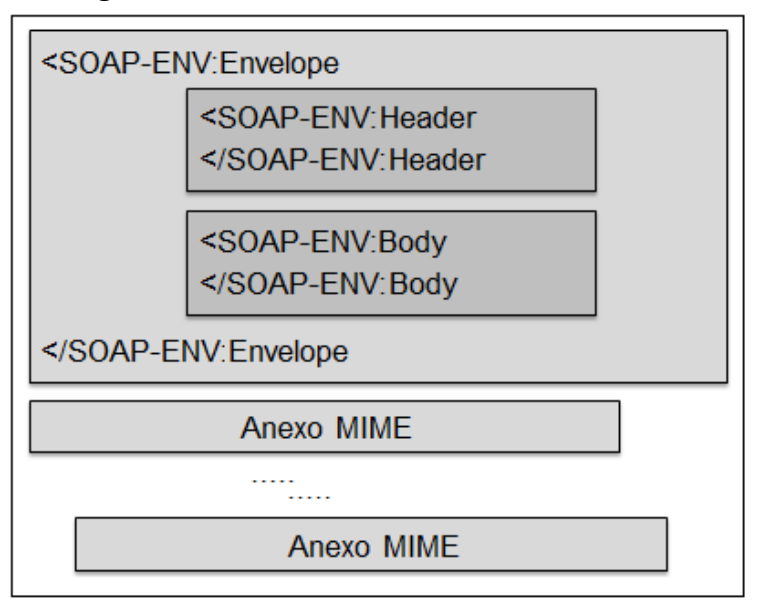

Fonte: Kumar, Narayan e $\mathrm{Ng}(2012$, p. 58)

As mensagens SOAP podem conter informações textuais e binárias. As informações textuais são inseridas no elemento Body do envelope e as informações binárias são inseridas como anexos MIME. O elemento Header é opcional e pode conter informações complementares aos dados contidos no elemento Body, como dados de transação, autenticação, autorização, dentre outras (KUMAR; NARAYAN; NG, 2012).

\section{Descritor WSDL}

A especificação da Web Services Description Language (WSDL) fornece a estrutura e o formato de elementos XML para descrever Web Services. A especificação WSDL especifica uma linguagem para descrever as funcionalidades abstratas, bem como uma estrutura para descrever os detalhes concretos do serviço. A especificação também define os critérios de conformidade de documentos escritos a partir da especificação WSDL (W3C, 2007).

Um arquivo WSDL contém a descrição de um ou mais serviços por meio de um conjunto pré-definido de elementos XML, que representam a definição e a descrição completa das informações de um Web Service. Como o documento WSDL é uma extensão da XML, os aplicativos clientes podem processar esse arquivo com o objetivo de obter as informações necessárias para entender e usar o Web Service.

A Figura 15 ilustra o conteúdo do arquivo WSDL, formado pelo elemento definitions, que abriga cinco subelementos: uma ou mais ocorrência dos elementos type, message e portType, uma ocorrência dos elementos binding e service. Os elementos type, message e portType formam a parte abstrata do WSDL e os elementos binding e service formam a parte concreta do WSDL, vinculando ao 
Figura 15: Estrutura do documento WSDL

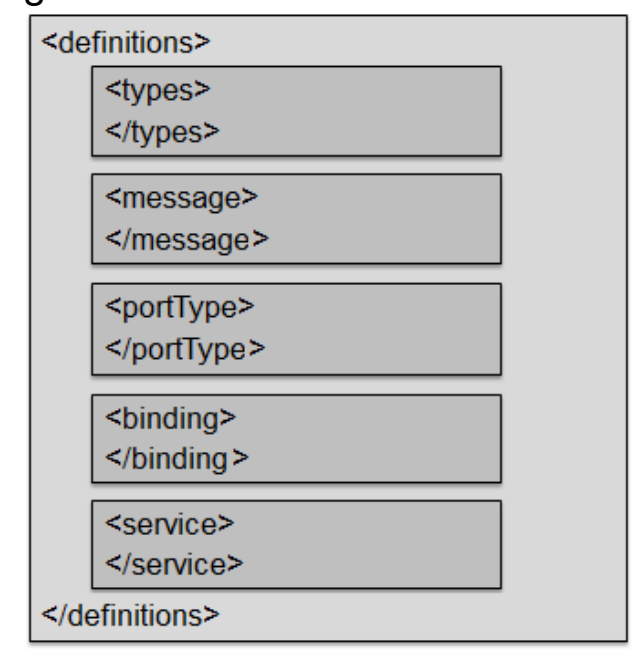

Fonte: Kumar, Narayan e Ng (2012, p. 92)

protocolo de transporte e endereço real do serviço (KUMAR; NARAYAN; NG, 2012).

Figura 16: Triângulo Web Services

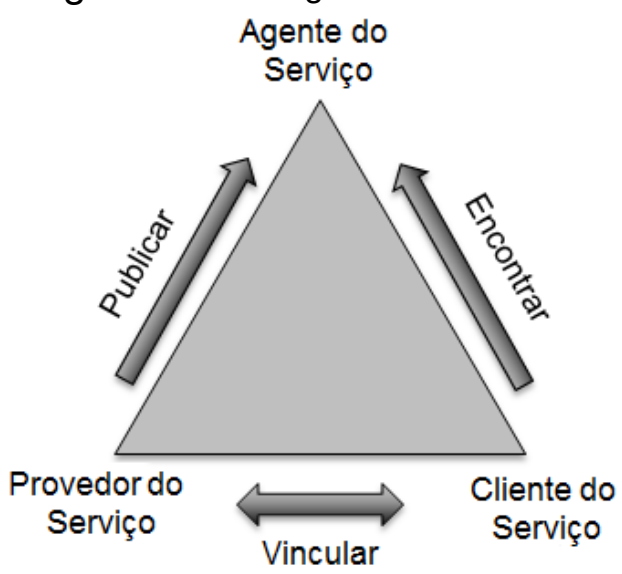

Fonte: adaptado de Kumar, Narayan e Ng (2012, p. 79)

O WSDL é um componente chave da implementação de computação orientada a serviços usando Web Service com SOAP. A Figura 16 ilustra os três elementos de uma SOA. O Provedor é responsável por fornecer o serviço e publicar o descritor WSDL de seus serviços. O Agente é responsável por armazenar informações sobre os WSDL e viabilizar mecanismos de buscas aos potenciais clientes consumidores. Por último, o Cliente busca os serviços no Agente e, por meio dos WSDL dos serviços localizados, vincula-se ao Provedor para invocar e consumir os serviços desejados.

Para Web Services com implementação REST, não existe um equivalente WSDL padronizado e largamente difundido. Existe uma iniciativa de um grupo de pesquisa ligado à tecnologia Java, cujo objetivo é a definição de um descritor 
de serviços com estilo REST. Essa proposta de especificação é denominada Web Application Description Language ${ }^{5}$ (WADL) (KALIN, 2010).

\subsubsection{Enterprise Service Bus}

O cenário típico em uma SOA é caracterizado por operações de negócio representadas por uma série de invocações aos componentes de software distribuídos. Para construir uma instância de SOA é necessária uma comunicação altamente distribuível e um backbone de integração. Esta funcionalidade é fornecida por um elemento denominado de Enterprise Service Bus (ESB) (PAPAZOGLOU et al., 2007), (PAPAZOGLOU et al., 2008). A infraestrutura do ESB possui dois objetivos:

1. estabelecer um baixo acoplamento entre sistemas que participam da integração;

2. eliminar integrações particulares, padronizando e fornecendo mecanismos de gerenciamento para as integrações.

Um ESB fornece uma plataforma de software para integração de aplicações por meio de mensagens, Web services, transformações de dados e roteamento de mensagens. Fornece também a capacidade de gerenciamento centralizado dos componentes distribuídos (KUMAR; NARAYAN; NG, 2012). A Figura 17 ilustra a estrutura de um ESB.

Figura 17: Enterprise Service Bus

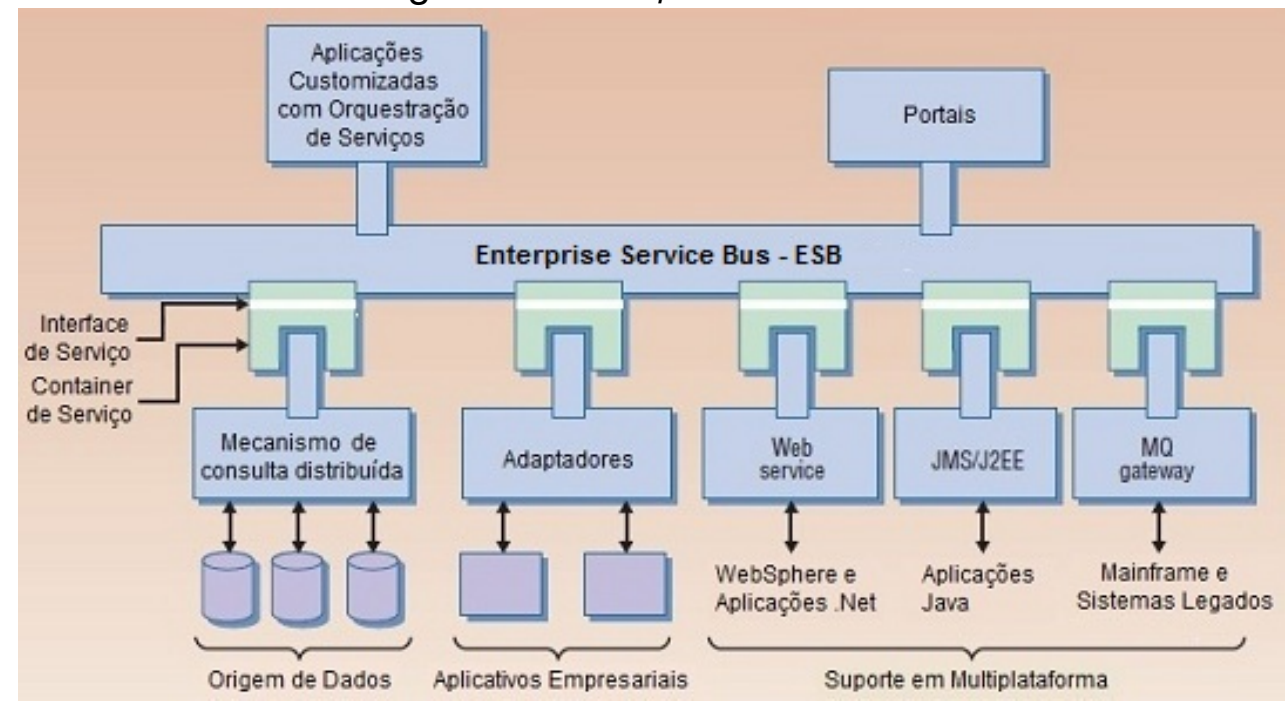

Fonte: adaptado de (PAPAZOGLOU et al., 2007)

Segundo Kumar, Narayan e Ng (2012), o ESB possui intersecção de características com outras tecnologias. Contudo, existe um grupo de características específicas que um ESB deve atender:

\footnotetext{
${ }^{5}$ https://wadl.java.net/
} 
- Roteamento inteligente - mecanismo de roteamento de mensagens eficiente e flexível que fornece serviços de roteamento baseado em conteúdo ou no roteamento de itinerário definido previamente;

- Transformação - o ESB deve desacoplar ao máximo os clientes dos provedores dos serviços. Deve possuir a capacidade de transformar requisições e resultados para compatibilizar possíveis diferenças entre solicitante e provedor;

- Transporte com múltiplos protocolos - deve permitir que diferentes protocolos de comunicação sejam usados para vinculação das aplicações que fornecem os serviços, criando um canal comum de comunicação para os clientes da arquitetura SOA;

- Mensagem confiável - estabelece controles de níveis de garantia de entrega de mensagens, que podem ser ajustados conforme a criticidade dos conteúdos;

- Segurança - deve garantir os requisitos fundamentais de segurança, permitindo a definição de critério de autenticação, autorização, controle de acesso para todos os componentes integrados na plataforma.

Dessa forma, o ESB é um conjunto de recursos de infraestrutura implementado com a tecnologia de middleware e mensagens que permite uma instância SOA reduzir os problemas de incompatibilidade entre aplicações que estejam em plataformas heterogêneas e formatos diferentes de dados (PAPAZOGLOU et al., 2008). Ele estabelece o controle adequado de mensagens, questões de segurança, políticas, confiabilidade e compatibilidade (PAPAZOGLOU et al., 2008). 


\subsubsection{Reuso de Serviços}

O reuso de serviços, em uma SOA, pode ser abordado de várias maneiras. Uma das premissas da COS estabelece que serviços tenham um alto potencial de reuso. A própria natureza do uso de serviço é um fator que promove o reuso, pois quanto mais aplicações clientes consumirem um serviço, maior será o reuso do serviço como componente de software distribuído. A interoperabilidade dos serviços, principalmente aqueles implementados com a tecnologia de Web Service, é uma característica que apoia o reuso do serviço como componente distribuído, visto que facilita seu consumo por aplicações desenvolvidas em diferentes tecnologias.

Segundo Erl (2009), a natureza dos serviços é propícia ao reuso, contudo é necessário aplicar princípios de projeto adequados para garantir essa capacidade. Um exemplo é a abstração de serviços seguindo a classificação de serviços utilitários, serviços entidade e serviço tarefa. Serviços utilitários são reusados por serviços entidade e serviços tarefa, e serviços entidade são reusados por serviços tarefa.

O princípio da capacidade de composição de serviços também promove o reuso, pois serviços podem ser produzidos por meio da composição de outros serviços existentes. Cada composição criada reusa serviços existentes para dar origem a um novo serviço.

\subsection{Considerações Finais do Capítulo}

Neste capítulo foram abordados assuntos relacionados aos objetivos da pesquisa e também assuntos que dão suporte às decisões relacionadas à arquitetura da plataforma proposta.

O primeiro assunto trata de aspectos conceituais de reuso de software, pontos favoráveis e desfavoráveis a respeito de técnicas de reuso no desenvolvimento de software. Constata-se que existem vários fatores que justificam o uso de técnicas para promoverem o reuso, contudo, tais abordagens exigem um processo de desenvolvimento de software mais complexo, que envolve o planejamento e investimentos a longo prazo. Também é possível constatar que, quanto maior o nível de abstração dos elementos reutilizados, maior a probabilidade de ganhos com 0 reuso, e mais abrangente ele será.

Foi apresentada uma visão dos conceitos e elementos que compõem uma especificação de arquitetura de software e as questões que devem ser resolvidas durante a definição de arquitetura de sistemas computacionais. O objetivo desse 
conteúdo é apoiar as atividades de definição da arquitetura da plataforma proposta nesta pesquisa.

Foram abordados dois modelos de decomposição de software, o modelo baseado em componentes e o modelo orientado a serviços. O modelo baseado em componentes está relacionado com a estratégia de decomposição e encapsulamento dos elementos de software que compõem a plataforma VRServices, principalmente pelas características de encapsulamento e implantação em uma infraestrutura de componentes. O modelo baseado em componentes é usado tanto para decomposição das funcionalidades, quanto para a implementação e implantação das funcionalidades desenvolvidas como prova de conceito.

O modelo orientado a serviços é usado para especificação e implementação dos serviços da plataforma proposta. As características de interoperabilidade de plataforma, linguagem e formato de dados, apoiam o objetivo da pesquisa, que é fornecer um barramento de serviços de produção e execução de aplicações RV em ambiente on-line. A meta é disponibilizar os serviços de produção e execução para aplicações consumidoras sem restrição de plataforma de execução ou linguagem de programação, além de permitir o reuso desses serviços em diversas aplicações. Foram abordadas algumas tecnologias relacionadas com a computação orientada a serviços, como Web Service, WSDL, SOAP e ESB. O objetivo é apresentar aspectos que justificam a escolha da computação orientada a serviço como meio de publicação das funcionalidades da plataforma proposta. 


\section{TRABALHOS RELACIONADOS}

Para subsidiar os objetivos desta pesquisa, foi realizado um levantamento bibliográfico com o objetivo de identificar plataformas e arcabouços de software que dão suporte ao desenvolvimento de aplicações de RV, com ênfase na reutilização de componentes de software, em especial, aqueles que utilizam a abordagem de computação orientada a serviços. Também foram pesquisados trabalhos que propõem algum tipo de abstração de representação de aplicações RV. O capítulo está organizado em quatro seções. A seção 4.1 apresenta os trabalhos que propõem plataformas e arcabouços para o desenvolvimento de aplicações de RV, a seção 4.2 apresenta os trabalhos que propõem estratégias de abstração de elementos de aplicações de RV, a seção 4.3 apresenta a sumarização dos trabalhos, por meio de duas tabelas que reúnem as características mais relevantes dos trabalhos apresentados. Por último, a seção 4.4 apresenta um comparativo dos trabalhos apresentados, destacando as diferenças e semelhanças com a proposta desta pesquisa.

\subsection{Plataformas e Arcabouços para Aplicações de RV}

Nesta seção são descritos trabalhos de pesquisa que propõem plataformas e arcabouços para o desenvolvimento de aplicações RV. Foram selecionados trabalhos cujo objetivo é a otimização do desenvolvimento e reuso de artefatos de softwares relacionados a ambientes virtuais e aplicações $\mathrm{RV}$.

\subsubsection{VR Juggler}

O primeiro trabalho descrito é uma plataforma virtual extensível para o desenvolvimento de aplicações de RV denominada VR Juggler. A plataforma virtual fornece um ambiente de desenvolvimento e execução, que é independente da arquitetura de hardware, sistema operacional e configurações de hardware disponíveis para RV. A plataforma VR Juggler fornece um ambiente operacional 
unificado no qual os desenvolvedores podem escrever e testar aplicações utilizando os recursos disponíveis, permitindo a portabilidade da aplicação para outros recursos computacionais (BIERBAUM et al., 2001). A figura 18 ilustra os componentes que formam a plataforma VR Juggler.

Figura 18: Arquitetura da plataforma de desenvolvimento VR-Juggler

\begin{tabular}{|c|c|c|}
\hline \multicolumn{2}{|c|}{ VR Juggler } \\
\hline Tweek & JCCL & Gadgeteer \\
\hline CORBA & Ambiente de Execução Portável VR Juggler (VPR) & OpenAL \\
\hline
\end{tabular}

Fonte: adaptado de http://vrjuggler.org/images/vrj-arch.png

O componente Ambiente de Execução Portável VR Juggler (VPR) é uma biblioteca portável em múltiplas plataformas que permite o acesso às funcionalidades do sistema operacional como o threading, rede e dispositivos de entrada e saída, utilizados principalmente pelos outros componentes do VR Juggler, estabelecendo uma camada virtual a esses recursos. O componente JCCL é responsável por centralizar todas as configurações da plataforma, oferecendo acesso centralizado e padronizado aos arquivos de configuração escritos em XML. O componente Gadgeteer fornece abstração aos dispositivos de entrada e suporte de carga dinâmica de controladores de hardware previamente registrados na plataforma. Sonix é um componente opcional, fornece uma camada de abstração sobre recursos de áudio. Por último, a biblioteca VR Juggler fornece gerenciamento de exibição e transferências de controle durante períodos específicos do ciclo de execução dos objetos que representam uma aplicação.

Para permitir a independência de sistema operacional, VR Juggler isola as dependências específicas por meio de uma interface simples que representa a plataforma virtual, implementada como um componente kernel. A interface do objeto kernel define a plataforma virtual de desenvolvimento RV e encapsula os detalhes específicos do sistema para que os aplicativos não tenham que depender desses detalhes.

Outra característica importante do VR Juggler é a abstração de dispositivos de entrada e saída, tendo como base suas funcionalidades. Dispositivos de RV podem ser representados em várias classes básicas de entrada e saída, como por exemplo, dados de posição, orientação, luva e gesto. Para isso, são definidas interfaces de 
classes $^{1}$ para cada categoria de dispositivos, com o objetivo de criar um tipo comum para todos os dispositivos de uma determinada categoria, com a mesma interface disponível para os desenvolvedores. A Figura 19 ilustra a hierarquia de classes que generalizam os dispositivos de entrada.

Figura 19: Hierarquia de abstração de dispositivos de entrada

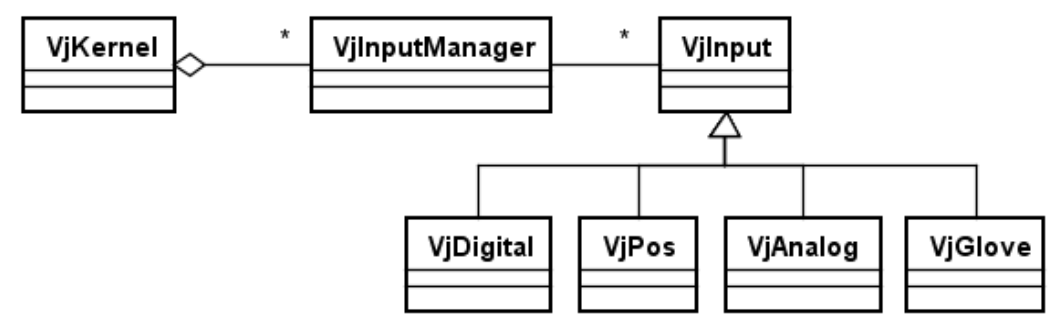

Fonte: adaptado de Bierbaum et al. (2001)

VR Juggler suporta múltiplas APIs gráficas por meio do encapsulamento dos comportamentos gráficos específico de cada API em gerenciadores gráficos. Além da interface do kernel, que representa a parte da plataforma virtual que encapsula os detalhes do sistema, existe também uma interface que é específica para cada API gráfica suportada. A interface do gerenciador gráfico pode ser considerada uma pequena plataforma virtual que apresenta uma abstração específica de uma API gráfica.

As aplicações RV são produzidas por meio da extensão e instanciamento de uma classe específica do VR Juggler, ilustrada na Figura 20. A classe VjApp é usada para criar o ambiente RV com o qual o usuário interage. Um objeto da classe VjApp implementa as interfaces necessárias da plataforma virtual do VR Juggler para criar o ambiente virtual.

Figura 20: Classe que representa uma aplicação VR-Juggler

\begin{tabular}{|l|}
\hline \multicolumn{1}{|c|}{ VjApp } \\
\hline+ init() $:$ void \\
+ apilnit() $:$ void \\
+ exit() : void \\
+ preFrame() : void \\
+ intraFrame() : void \\
+ postFrame() $:$ void \\
\hline
\end{tabular}

Fonte: adaptado de Bierbaum et al. (2001)

O kernel mantém o controle sobre o ambiente e chama os métodos definidos na interface do objeto aplicação. Quando os métodos do objeto aplicação são

\footnotetext{
${ }^{1}$ Interface de classe - visão externa de uma classe. Conjunto de assinaturas de todas as operações visíveis de uma classe. Em algumas linguagens de programação ela pode ser definida separadamente da classe (PAGE-JONES, 2001).
} 
chamados, o controle da execução é temporariamente transferido para o objeto aplicação para que o aplicativo possa executar.

O reuso na plataforma VR-Juggler é obtido pela infraestrutura oferecida ao desenvolvedor. A capacidade de abstração da plataforma desonera o desenvolvedor do conhecimento específico de recursos e tecnologias, e possibilita a portabilidade da aplicação desenvolvida para outras plataformas. A abstração dos recursos computacionais e de API gráficas, permite também, a flexibilidade de troca e adequação de componentes da plataforma, sem afetar as aplicações desenvolvidas a partir dela.

\subsubsection{Streaming Web Services}

Os autores Zhang e Gracanin possuem três trabalhos (ZHANG; GRACANIN, 2007), (ZHANG; GRACANIN, 2008a) e (ZHANG; GRACANIN, 2008b). Os trabalhos que apresentam a produção de portais 3D por meio da integração de serviços em uma SOA.

No trabalho de Zhang e Gracanin (2008a), foi proposto um arcabouço para construção de aplicações em ambiente virtuais multiusuários. É proposta uma SOA para a construção de aplicações RV por meio de serviços de ambientes virtuais distribuídos. A plataforma oferece um ambiente virtual multiusuário por meio de uma arquitetura orientada a serviços.

O arcabouço proposto foi projetado para realizar as seguintes funções: 1) integração dinâmica de conteúdo da aplicação; 2) uma apresentação 3D unificada para acessar o conteúdo do aplicativo; e 3) um espaço virtual multiusuário compartilhado. O conteúdo da aplicação 3D é fornecido pelos serviços de terceiros, denominados de Serviço Componente. O conteúdo do aplicativo é dinamicamente montado por composição dos serviços. Os usuários podem acessar o conteúdo do aplicativo com navegadores por meio do padrão X3D².

O arcabouço proposto em (ZHANG; GRACANIN, 2008b), usa SOA para criar aplicativos de portais 3D. As aplicações são produzidas por meio da integração de serviços distribuídos, denominados de Serviço Componente. Cada serviço componente expõe duas interfaces, uma de Web Service e outra de fluxo de transmissão. A interface Web Service é usada para o controle dos aplicativos remotos, alterar o estado do aplicativo e produzir as mudanças no cenário gráfico. A interface de transmissão é usada como ponto de acesso ao fluxo de dados que transmitem as

\footnotetext{
${ }^{2}$ http://www.web3d.org/x3d/specifications/, acesso em 10/03/2014
} 
mudanças do cenário gráfico.

A Figura 21 ilustra uma possível implantação em um Container Web, no caso o Tomcat ${ }^{3}$. A aplicação é implantada na forma de uma biblioteca dinâmica, acessível via Java Native Interface ${ }^{4}$ (JNI) e exposta por duas interfaces, uma de Web Service e uma de fluxo de transmissão (Stream).

Figura 21: Exemplo de implantação de serviços

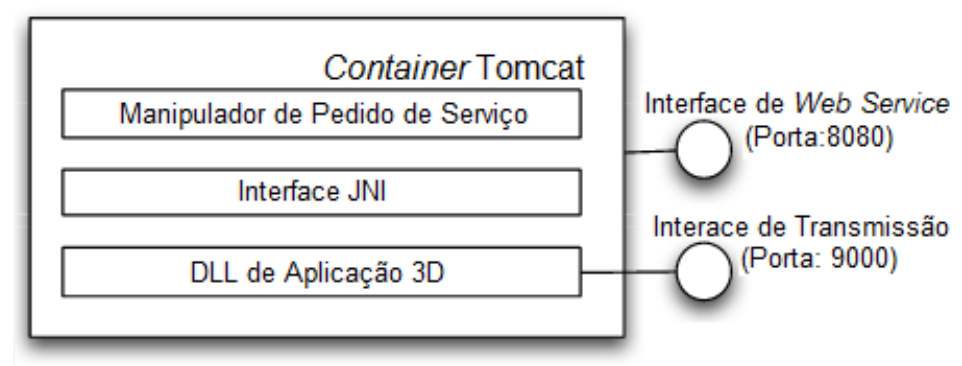

Fonte: adaptado de Zhang e Gracanin (2008b)

O arcabouço proposto possui uma estrutura de três camadas: Cliente, Container e Provedor de Serviço. Na camada Cliente é usado um navegador X3D ou reprodutor 3D MPEG-4 para acessar o aplicativo do portal 3D. Com base nas interações dos usuários, os clientes enviam os pedidos ao Container. Na camada Container, os perfis são carregados dinamicamente para definir a semântica das aplicações suportadas pelos provedores de serviços. O Container mantém o estado do aplicativo e gera um grafo de cena global para a aplicação de portal 3D. Os serviços são acessados pelo Container por meio de suas interfaces definidas com WSDL. Os serviços também usam o canal de transmissão para enviar o conteúdo do cenário ou as atualizações para o Container. As linhas tracejadas na Figura 22 indicam o fluxo de dados.

Foram considerados três princípios de projeto para a plataforma: 1) o cliente serve apenas como um navegador 3D interativo ou um reprodutor de fluxo de vídeo; 2) além da interface de serviços da Web, os fornecedores de serviços utilizam canais de transmissão para transmitir os dados de cenário e as atualizações de cena; e 3) a coordenação do serviço é orientado a eventos e definido com base na lógica da aplicação e comportamentos descritos em scripts.

Os serviços a serem acessados e manipulados pelo Container são acessíveis por meio de suas interfaces descritivas que fornecem a sintaxe dos métodos para a

\footnotetext{
${ }^{3} \mathrm{http}: / /$ tomcat.apache.org/ acesso em 15/03/2014

${ }^{4} \mathrm{JNI}$ é um padrão de programação que permite que a máquina virtual da linguagem Java acesse bibliotecas construídas com o código nativo de um sistema. Fonte: (WIKIPEDIA, 2014), acesso em $15 / 03 / 2014$
} 
Figura 22: Arquitetura do arcabouço

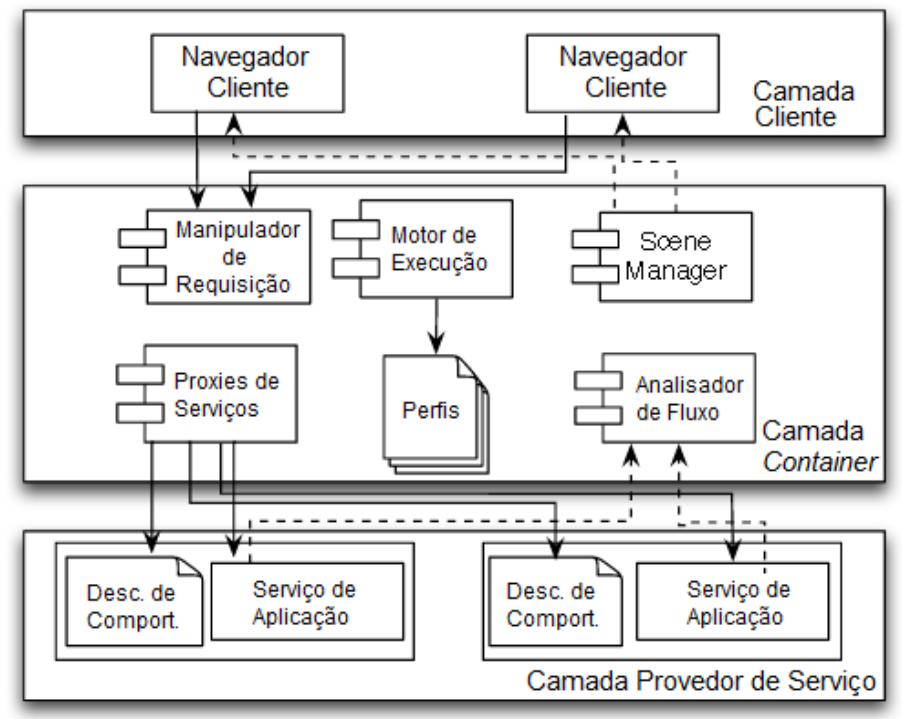

Fonte: adaptado de Zhang e Gracanin (2008b)

manipulação de serviço, especificadas nos documentos WSDL. Além do WSDL, um documento suplementar é necessário para descrever a semântica da interface e a semântica associada aos dados de cenário entregues no canal de transmissão. Os desenvolvedores de serviços podem fornecer um script denominado de Collaborative Task Description Language (CTDL) derivado de outro trabalho dos autores (ZHANG; GRACANIN, 2007).

A CTDL define os eventos e ações correspondentes aos objetos, associando a definição de interface em WSDL, com as anotações semânticas definidas. A lógica da aplicação é introduzida no documento CTDL para descrever a lógica de negócios da aplicação. Documentos de descrição de comportamento e documentos de lógica da aplicação são utilizados pelo arcabouço para a integração dos serviços em tempo de execução.

\subsubsection{ViMeT}

No trabalho de Oliveira e Nunes (2010) é descrito o Virtual Medical Training (ViMeT), um arcabouço orientado a objetos para a produção de aplicações de RV para simulação de exames de biópsia.

O diagrama ilustrado na Figura 23, apresenta os tipos de instanciação possíveis no ViMeT. Podem ser realizadas por meio do instanciamento direto das classes do ViMeT no código de uma aplicação em desenvolvimento ou por meio da ferramenta ViMeTWizard. Também apresenta as bases de dados que armazenam os objetos 3D modelados e as aplicações geradas pela ferramenta ViMeTWizard. 
Figura 23: Projeto arquitetural do ViMeT

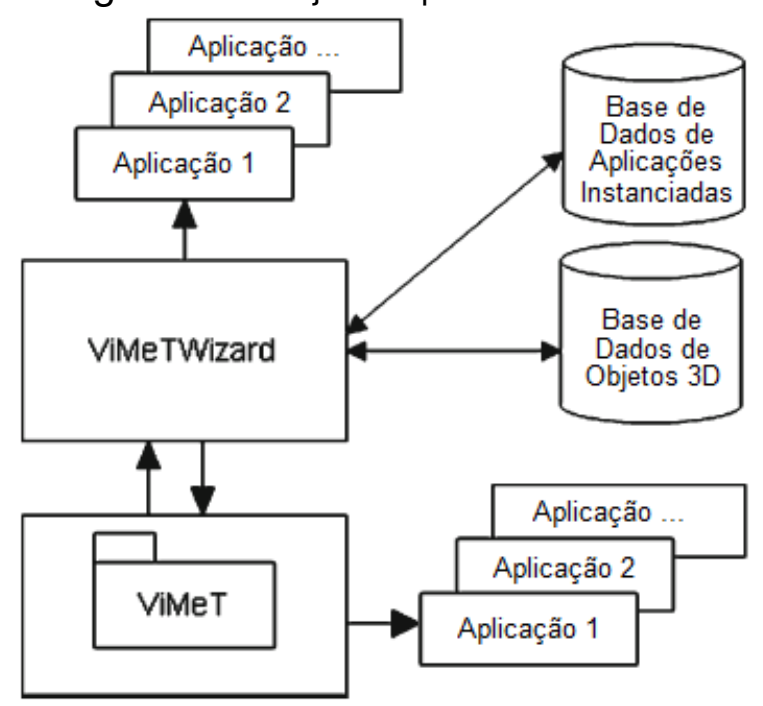

Fonte: adaptado de Oliveira e Nunes (2010)

A ferramenta ViMeTWizard permite a definição de parâmetros particulares de cada aplicação a ser produzida, a partir dos quais, a ferramenta gera o código fonte personalizado para o instanciamento do arcabouço, reduzindo a curva de aprendizagem do arcabouço e os esforços de codificação para produção das aplicações. A ferramenta fornece uma interface gráfica onde o usuário escolhe as características e os objetos que irão compor a aplicação, depois a ferramenta gera e compila o código fonte, criando uma aplicação final a partir do instanciamento e particularização do arcabouço ViMeT.

O reuso de componentes de software no arcabouço ViMeT pode ser obtido por meio de duas abordagens: 1) caixa-branca com o instanciamento das classes do ViMeT diretamente como uma extensão do arcabouço em uma aplicação concreta e 2) caixa-cinza com a produção e personalização do código fonte da aplicação produzido automaticamente pela ferramenta ViMeTWizard.

\subsubsection{Hydra}

Filho (2011) propõem uma plataforma para desenvolvimento de ambientes virtuais denominada Hydra. O Hydra é composto por um conjunto de arcabouço e ferramentas com o propósito de facilitar e acelerar o desenvolvimento de aplicações, além de proporcionar flexibilidade na alteração de sua estrutura, em função da abordagem baseada em plugins.

A plataforma Hydra possui uma estrutura modular que fornece uma API para desenvolvimento de ambientes virtuais e um conjunto de arcabouços e bibliotecas 
que podem ser utilizados em separado. Cada arcabouço que faz parte da plataforma Hydra abstrai, a partir da abordagem de plugins, o uso de outras ferramentas.

Figura 24: Ambiente virtual da plataforma Hydra

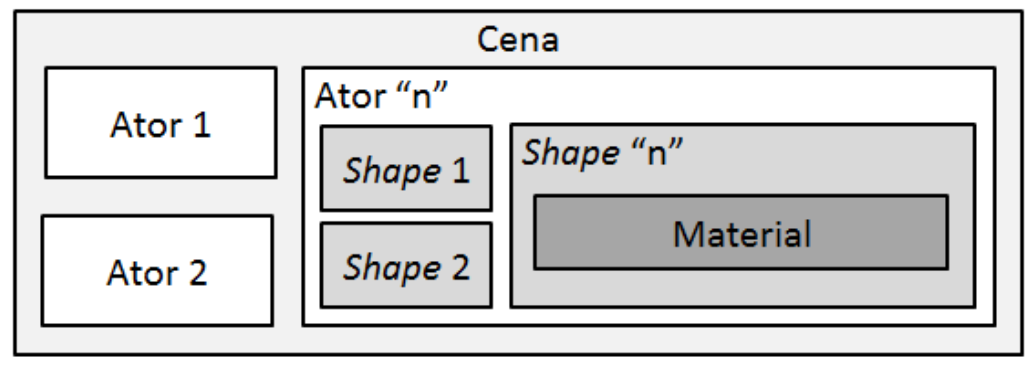

Fonte: adaptado de Filho (2011)

Os ambientes virtuais produzidos na plataforma Hydra são constituídos por quatro entidades base: Cena, que define o ambiente em si; Ator, que representa os objetos presentes no ambiente virtual; Shape, que são as entidades atômicas que dão forma as entidades Ator; e, Material, que é a entidade responsável pela definição dos comportamentos da entidade Shape, como resposta a colisões, atrito, reflexão de luz, interferência na reprodução de sons, dentre outros. A Figura 24 ilustra as entidades que constituem um ambiente virtual Hydra.

A arquitetura da plataforma Hydra, ilustrada na Figura 25, é organizada em três camadas e composta por nove módulos: 1) Básico, que define as entidades que fazem parte do ambiente virtual: Cena, Ator, Shape e Material; 2) Física, contém a definição das conexões que podem existir entre as entidades Ator, podendo ser: fixa, prismática, de distância, de polia, de revolução, esférica, universal e com seis graus de liberdade; 3) Renderizador, módulo que possui a definição de elementos relacionados com o ambiente virtual gráfico, como luzes, câmeras virtuais, dentre outros; 4) Som, módulo com a definição das entidades responsáveis pela reprodução de som; 5) Dispositivo, possui a definição das entidades responsáveis pelo mapeamento dos dispositivos utilizados para interação do usuário com o sistema ou do sistema com o usuário, por meio de renderização háptica; 6) Fábrica, módulo responsável pela instanciação de todas as entidades construídas no ambiente virtual; 7) Sinais, módulo que possui as definições dos eventos utilizados pela plataforma Hydra e seus arcabouços; 8) Descritores, possui as entidades responsáveis pela construção das representações dos elementos virtuais; 9) e por último, o módulo Núcleo é responsável por gerenciar os demais módulos na execução do ambiente virtual.

Os componentes descritos da plataforma Hydra formam um conjunto de arcabouços e bibliotecas que implementam funcionalidades como a manipulação de 
Figura 25: Arquitetura da plataforma Hydra

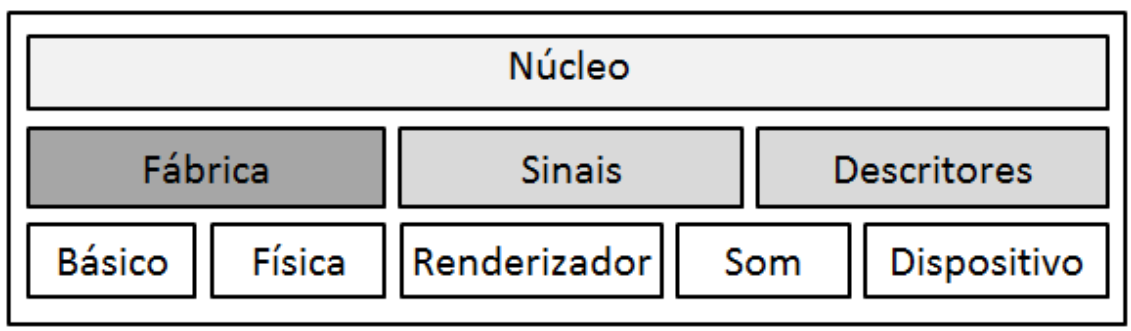

Fonte: adaptado de Filho (2011)

estruturas de dados, gerenciamento de concorrência, conexão e comunicação de rede, cálculos matemáticos relacionados a vetores, matrizes, cálculos e efeitos de física, recursos de processamento de áudio e manipulação de dispositivos táteis.

As aplicações são desenvolvidas por meio de código fonte escrito com a linguagem de programação $\mathrm{C}++$, onde são definidos quais plugins serão usados. Também devem ser definidas as entidades que compõem o ambiente virtual. Por fim, devem ser definidos os comportamentos associados aos eventos dos dispositivos representados pelas instâncias de Dispositivos (FILHO, 2011).

O reuso é obtido pela abordagem de plugins, que proporciona a reutilização dos arcabouços e bibliotecas de maneira flexível nas aplicações produzidas na plataforma.

\subsubsection{VRJugglua}

Os autores propõem um arcabouço de aplicações de RV baseado na combinação da linguagem de programação $L a^{5}$, a plataforma VR Juggler e a biblioteca gráfica OpenSceneGraph. O arcabouço resultante dessa combinação foi chamado de VRJugglua. Segundo os autores, o objetivo é ter uma base sólida de execução de aplicações RV, neste caso suportada pela plataforma VR Juggler e a biblioteca OpenSceneGraph e uma linguagem de alto nível para a construção de aplicações RV (PAVLIK; VANCE, 2012).

A Figura 26 ilustra a arquitetura da plataforma VRJugglua. Em função da linguagem de programação Lua ser interpretada, ela exige uma aplicação hospedeira que deve instanciar um interpretador Lua. Cada aplicação hospedeira cria uma única instância do interpretador Lua. As ligações do código Lua com a plataforma VR Juggler e a biblioteca OpenSceneGraph são realizadas pelos componentes Luabind, e OSgLua e OSgIntrospection respectivamente.

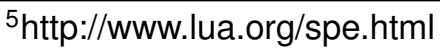


Figura 26: Arquitetura da plataforma VRJugglua

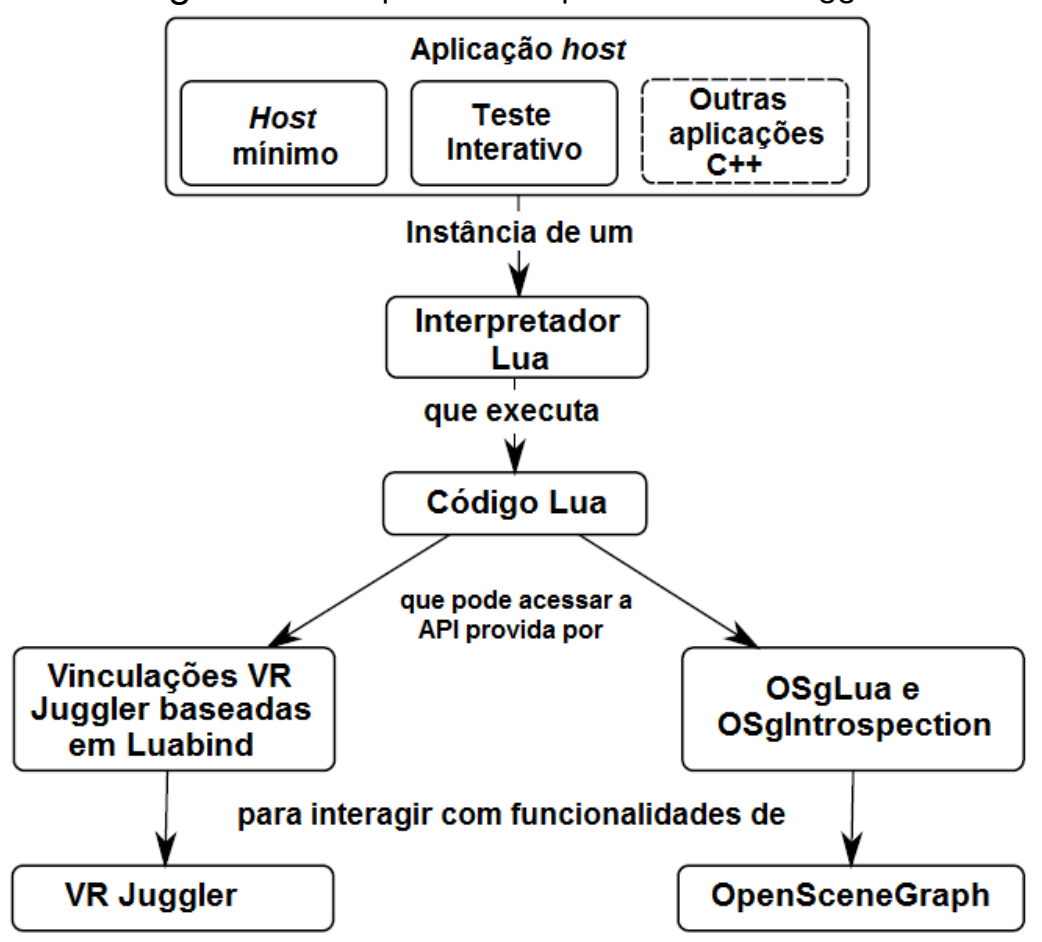

Fonte: adaptado de Pavlik e Vance (2012)

A plataforma VRJugglua possibilita que as aplicações sejam escritas em $\mathrm{C}++$ puro, sendo executadas diretamente sobre a plataforma VR Juggler, ou que contenham parte do código escrito em $\mathrm{C}++$ e parte escrito em Lua, ou ainda, aplicações escritas totalmente em código Lua. O uso de código escrito em código Lua puro é a estratégia recomendada pelos autores, em função das características de alto nível da linguagem Lua, permitindo que sejam obtidas experiências de autoria de aplicações RV sem conhecimento profundo nas plataformas e bibliotecas subjacentes, no caso VR Juggler e OpenSceneGraph.

\subsection{Estratégias de Abstração de Elementos de Aplicações de RV}

Nesta seção são descritos trabalhos que propõem estratégias de representação e abstração de elementos de aplicações $R V$, cujo objetivo é diminuir a complexidade do desenvolvimento e a necessidade de conhecimento técnico relacionado ao desenvolvimento de aplicações $\mathrm{RV}$. Os trabalhos apresentados nessa seção propõem formas alternativas de construção de aplicações RV, que ao invés da codificação em código fonte, usam simbologia de alto nível para especificar o conteúdo e comportamento dos mundos virtuais. As especificações de alto nível são orientadas 
a modelos e permitem a geração de código fonte de forma automatizada.

\subsubsection{VR-WISE}

Neste trabalho foi proposta uma linguagem de especificação conceitual e uma fase de projeto conceitual explícito no ciclo de desenvolvimento de aplicações RV. $\mathrm{Na}$ fase de projeto conceitual são produzidos os modelos conceituais que constituem uma descrição de alto nível do mundo virtual, os objetos do mundo virtual, as relações que se mantém entre os objetos e como esse objetos se comportam e interagem entre si e com o usuário. A linguagem de especificação conceitual usa a abordagem orientada a modelo, permitindo a representação gráfica de todos os elementos necessários para a produção de código fonte de forma automatizada. Essa abordagem de produção de aplicações RV foi denominada de VR-WISE (TROYER et al., 2007).

Figura 27: Fases de desenvolvimento de aplicações RV

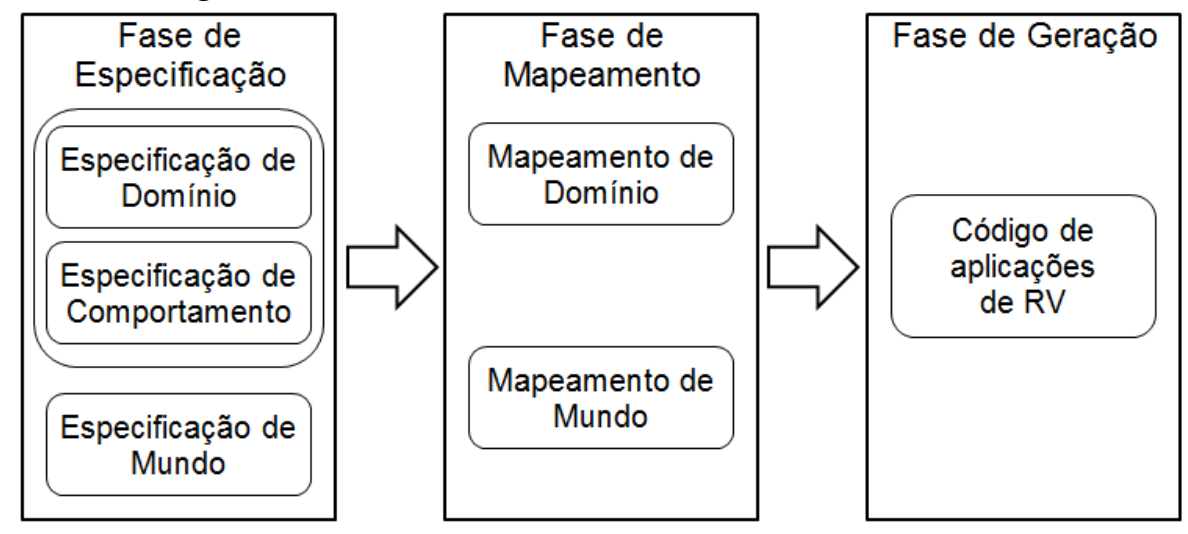

Fonte: adaptado de Troyer et al. (2007)

A Figura 27 ilustra as fases do processo de desenvolvimento proposto. Segundo os autores, devido à grande lacuna entre o nível conceitual e o nível de implementação, o processo de desenvolvimento foi dividido em três fases, a fase de especificação conceitual, a fase de mapeamento e a fase de geração.

$\mathrm{Na}$ fase de especificação conceitual, o projetista especifica o mundo virtual em alto nível, usando os conceitos de modelagem oferecidos pela abordagem VR-WISE. A especificação consiste de dois níveis: 1) especificação de domínio, que descreve os conceitos do domínio da aplicação necessários para o mundo virtual, semelhante aos tipos de objetos ou classes usados em métodos orientados a objetos. Os conceitos podem ter propriedades que estabelecem características de visualização ou aparência, dimensões, dentre outras. Nesse nível, também são descritas as relações entre esses conceitos e seus comportamentos; 2) especificação de mundo, que contém a descrição conceitual do mundo virtual a ser construído, 
definida pela instanciação dos conceitos estabelecidos na especificação de domínio. As instâncias representam os objetos que povoarão o mundo virtual. Além disso, os comportamentos associados aos objetos são vinculados à ações que podem desencadeá-los, por exemplo, por meio de uma interação de usuários, uma detecção de colisão ou um intervalo de tempo.

A fase de mapeamento tem o objetivo de preencher a lacuna entre as especificações conceituais e a implementação. Também é executada em dois níveis: 1) mapeamento de domínio, deve especificar como os conceitos da especificação de domínio serão visualizados, pode ser por meio de elementos gráficos simples ou por modelos 3D sofisticados; 2) mapeamento do mundo, permite especificar visualizações particulares que sobrepõem o mapeamento realizado para os conceitos, permitindo que existam visualizações particulares de um conceito em diferentes mundos virtuais, ou ainda, visualizações diferentes para cada instância do conceito.

$\mathrm{Na}$ fase de geração, o código fonte do mundo virtual é gerado. Para isso as especificações conceituais são convertidas em uma aplicação funcional por meio do mapeamento realizado na fase de mapeamento. A ferramenta usada como prova de conceito no VR-WISE suporta a geração de código para a linguagem $\times 3 \mathrm{D}^{6}$.

\subsubsection{MASCARET}

Neste trabalho, os autores apresentam uma metodologia e um arcabouço, chamado MultiAgent System for Collaborative, Adaptive and Realistic Environments for Training (MASCARET), destinados a concepção semântica de ambientes de realidade virtual. O ponto central da proposta é a abordagem baseada em um metamodelo, que é uma especialização e uma extensão do Unified Modeling Language (UML) e que abrange todos os aspectos da representação semântica de AV com a ontologia do domínio, a estrutura do ambiente, o comportamento das entidades, tanto nas interações e atividades do usuário, quanto dos agentes. O desenvolvimento das aplicações RV é feito por meio da especificação dos modelos a partir da extensão da UML (CHEVAILLIER et al., 2012).

O arcabouço MASCARET é uma estrutura genérica que fornece as abstrações necessárias para a modelagem semântica de aplicações RV e a implantação em diferentes plataformas de execução. Também disponibiliza uma linguagem de especificação para a modelagem de conhecimentos do domínio específico e semântica operacional, para a modelagem de características de sistema que são

\footnotetext{
${ }^{6} \mathrm{http}: / /$ www.web3d.org acesso em 10/05/2014
} 
Figura 28: Arquitetura do arcabouço MASCARET

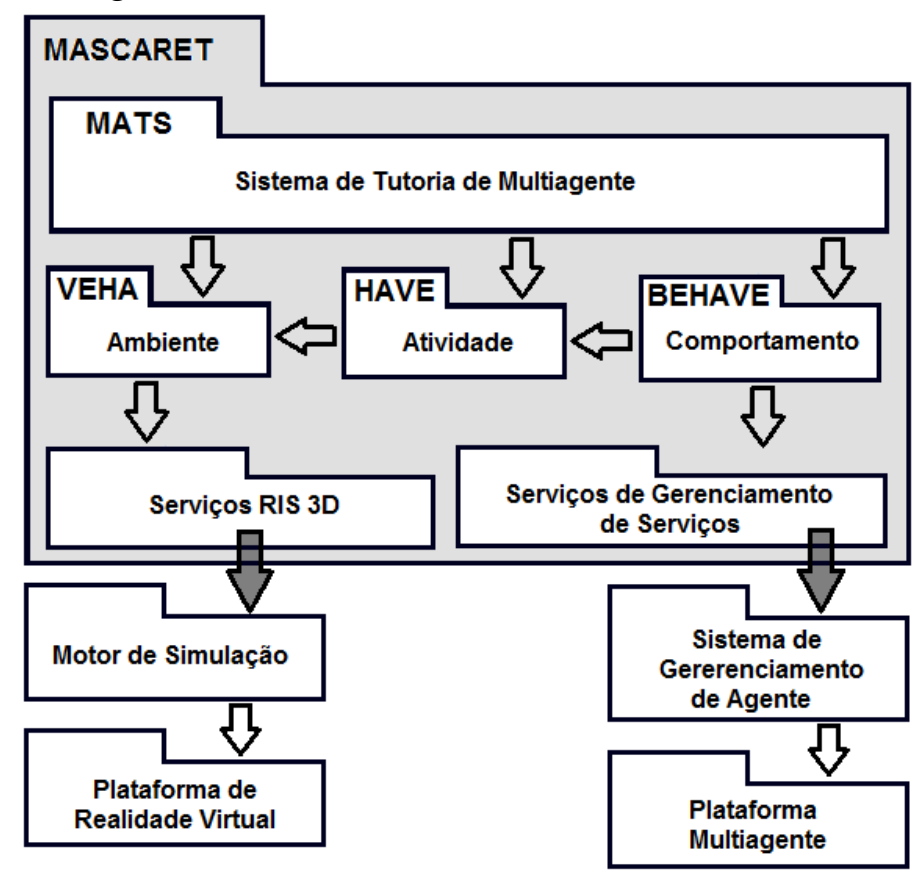

Fonte: adaptado de Chevaillier et al. (2012)

interpretadas pela plataforma de execução.

A Figura 28 ilustra os pacotes do arcabouço MASCARET. O pacote VEHA permite a modelagem das entidades que formam o $A V$, seus tipos, estruturas e seus comportamentos. O pacote HAVE permite descrever as interações e as atividades que os usuários e agentes artificiais podem realizar no AV. O pacote MATS é dedicado às funcionalidades de tutoria de sistemas multiagentes.

Os pacotes Serviços RIS 3D e Serviços de Gerenciamento de Agente funcionam como fachada para bibliotecas e API. O primeiro está relacionado às funções de renderização 3D em tempo real e a manipulação de dispositivos de interação. O segundo encapsula serviços fornecidos por sistemas de gestão de agentes como programação e instanciação, nomeação e referência, e serviços de mensagens.

As aplicações RV, no MASCARET, são desenvolvidas em duas etapas. A primeira etapa compreende a produção de um modelo, denominado de M1 e composto por diagramas UML-MASCARET. O modelo M1 é constituído por diagramas de classe, diagramas de estado e diagrama de atividades, produzido em um editor UML, compatível com a definição de metamodelos UML. O modelo M1 deve ser exportado usando o padrão $\mathrm{XMI}^{7}$. A segunda etapa é executada em uma ferramenta de modelagem 3D, capaz de suportar um plugin MASCARET para importar o modelo M1

\footnotetext{
${ }^{7}$ http://www.omg.org/spec/XMl/ acesso em 20/03/2014
} 
armazenado em um arquivo XMI. Na segunda etapa são definidas as características de aparência dos objetos modelados na primeira etapa, produzindo o modelo M0. $\mathrm{O}$ resultado da segunda etapa é exportado para uma representação XML, como VRML ou X3D.

A execução da aplicação é realizada pela plataforma de execução do MASCARET, que instancia os modelos M1 e M0 e executa as atividades especificadas como comportamento do sistema e seus agentes. Apesar de não ter sido explorado no trabalho, a abordagem de especificação permite que os modelos M1 poderiam ser reusados para especificação de outras aplicações, desde que sejam apoiados por ferramentas que permitam a busca e reuso dos modelos.

\subsubsection{High-Speed Railway}

O trabalho de Jinhong et al. (2013) propõe um método de construção de simulações para ferrovias de alta velocidade, por meio da combinação de modelos 3D básicos, que são usados para a construção de um ambiente virtual. Os modelos 3D básicos são representações generalizadas de partes do cenário de ferrovias de alta velocidade, formado por objetos 3D, suas propriedades de aparência geométrica e as relações espaciais que posicionam cada elemento na simulação.

O cenário de ferrovias de alta velocidade foi decomposto em elementos básicos reutilizáveis, seguindo um fluxo ilustrado na Figura 29. O fluxograma de modelagem do cenário virtual de ferrovia de alta velocidade foi dividido em três partes: criação de modelos de elementos básicos, modelagem do cenário da ferrovia de alta velocidade, e definição de interação do cenário.

A criação de modelos básicos é realizada por meio da classificação, abstração e simplificação dos elementos. São definidos os aspectos geométricos e as características dos modelos de elementos básicos para garantir a sua generalidade e reuso. A decomposição do cenário de ferrovias de alta velocidade produz elementos tais como: pontes, túneis, fundações de estrada, estruturas de trilhos e sistema de distribuição de energia elétrica.

A modelagem de cenário de ferrovia de alta velocidade é realizada com base na distância a ser percorrida e na localização e posição espacial dos modelos, baseados no tamanho de cada estrutura. O posicionamento de cada elemento depende de cálculos que levam em consideração a distância relativa da origem, se a estrutura está em uma reta, em curva para a direita ou em curva para a esquerda. O processamento da simulação combina os modelos e adiciona terrenos e imagens 
Figura 29: Fluxograma de decomposição de elementos de ferrovia

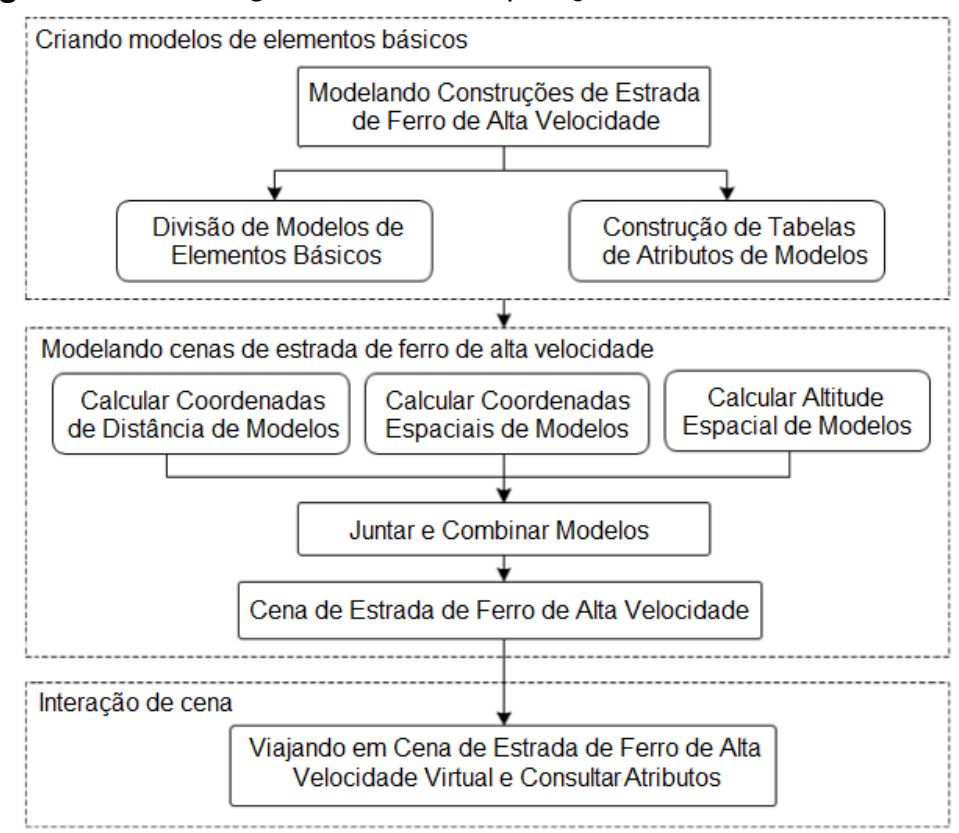

Fonte: adaptado de Jinhong et al. (2013)

para construir o cenário virtual de ferrovia de alta velocidade. A interação do cenário é realizada pela execução de operações de interação como viajar pelo cenário e consultar atributos.

O reuso é obtido por meio da recombinação dos elementos básicos modelados, representados por modelos 3D, atributos de posicionamento e os cálculos realizados durante a renderização. A partir dos elementos básicos são produzidas as cenas das simulações que são usadas para compor a simulação completa.

\subsection{Sumarização dos Trabalhos Relacionados}

Os trabalhos classificados como arcabouços e plataformas, de uma forma geral, propõem abordagens e estruturas que proporcionam ganho de desenvolvimento, principalmente pelo reuso do arcabouço e pelo encapsulamento de complexidades inerentes ao desenvolvimento de aplicações RV. O objetivo central dessas propostas é a junção de módulos que desempenham funções especializadas e independentes, produzindo arcabouços que fornecem algum nível de encapsulamento, ocultando as particularidades de cada módulo integrado. Também é comum o fornecimento de alguma forma de definição da lógica que estabelece o fluxo de execução das aplicações produzidas, normalmente por meio de scripts que são interpretados por um módulo coordenador de execução.

Para apresentar a sumarização dos trabalhos foram produzidas duas tabelas. 
A Tabela 1 apresenta a sumarização dos trabalhos de pesquisa que propõem arcabouços e plataformas para o desenvolvimento de aplicações RV. As colunas da Tabela 1 possuem os seguintes significados:

- Estilos Arquiteturais - quais estilos arquiteturais foram observados nos trabalhos selecionados, como por exemplo: arcabouços de módulos integrados, arcabouços extensíveis ou plataforma de componentes;

- Abordagem de Produção - como as aplicações são produzidas nas plataformas e arcabouços descritos, podendo ser por exemplo: por código fonte, instanciação de arcabouços ou por integração de componentes;

- Abordagem de Reuso - como pode ser promovido o reuso de elementos de software em cada trabalho descrito, são exemplos possíveis: pelo reuso do arcabouço de módulos integrados, pela extensão de arcabouços orientados a objetos ou pelo reuso de componentes;

- Pontos Favoráveis - indica quais são as características que chamam a atenção de maneira favorável ao projeto e concepção da plataforma VRServices. 
Tabela 1: Sumarização dos trabalhos relacionados - arcabouços e plataformas

\begin{tabular}{|c|c|c|c|c|}
\hline Trabalho & $\begin{array}{l}\text { Estilos } \\
\text { Arquiteturais }\end{array}$ & $\begin{array}{l}\text { Abordagem de } \\
\text { Produção }\end{array}$ & $\begin{array}{l}\text { Abordagem de } \\
\text { Reuso }\end{array}$ & Pontos Favoráveis \\
\hline $\begin{array}{l}\text { VR Juggler } \\
\text { (BIERBAUM et } \\
\text { al., 2001) }\end{array}$ & $\begin{array}{l}\text { Arcabouço } \\
\text { orientado a } \\
\text { objetos }\end{array}$ & $\begin{array}{l}\text { Codificação de } \\
\text { classes com } \\
\text { interfaces } \\
\text { pré-definidas }\end{array}$ & $\begin{array}{l}\text { Reuso do } \\
\text { arcabouço virtual }\end{array}$ & $\begin{array}{l}\text { 1) O conceito de plataforma virtual que isola } \\
\text { as particularidades de sistemas operacionais, } \\
\text { arquiteturas de hardware e configurações de } \\
\text { dispositivos de RV. } \\
\text { 2) A abstração dos dispositivos de entrada, que } \\
\text { isola as particularidades de dispositivos de entrada, } \\
\text { generalizados segundo suas funcionalidades. } \\
\text { 3) A abstração de biblioteca gráfica, que libera } \\
\text { o desenvolvedor da necessidade de conhecimento } \\
\text { específico de cada biblioteca. }\end{array}$ \\
\hline $\begin{array}{l}\text { Streaming Web } \\
\text { Services } \\
\text { (ZHANG; } \\
\text { GRACANIN, } \\
\text { 2008a), (ZHANG; } \\
\text { GRACANIN, } \\
\text { 2008b) }\end{array}$ & $\begin{array}{l}\text { Arcabouço } \\
\text { orientado a } \\
\text { serviços }\end{array}$ & $\begin{array}{l}\text { Composição de } \\
\text { serviços }\end{array}$ & $\begin{array}{l}\text { Reuso dos serviços } \\
\text { e da infraestrutura } \\
\text { de composição }\end{array}$ & $\begin{array}{l}\text { 1) Uso de serviços para compor aplicações de } \\
\text { ambientes virtuais. } \\
\text { 2) Uso de fluxo de transmissão (stream) para } \\
\text { melhorar o desempenho das mensagens SOAP dos } \\
\text { serviços. } \\
\text { 3) Uso do padrão de projeto MVC distribuído para } \\
\text { controlar as atualizações do estado da aplicação e } \\
\text { as visões dos clientes. } \\
\text { 4) Uso de scripts para associação de eventos com as } \\
\text { respectivas ações executadas pelos serviços. }\end{array}$ \\
\hline
\end{tabular}




\begin{tabular}{|c|c|c|c|c|}
\hline Trabalho & $\begin{array}{l}\text { Estilos } \\
\text { Arquiteturais }\end{array}$ & $\begin{array}{l}\text { Abordagem de } \\
\text { Produção }\end{array}$ & $\begin{array}{l}\text { Abordagem de } \\
\text { Reuso }\end{array}$ & Pontos Favoráveis \\
\hline $\begin{array}{l}\text { ViMeT } \\
\text { (OLIVEIRA; } \\
\text { NUNES, 2010) }\end{array}$ & $\begin{array}{l}\text { Arcabouço } \\
\text { orientado a } \\
\text { objetos }\end{array}$ & $\begin{array}{l}\text { Instanciação do } \\
\text { arcabouço } \\
\text { explicitamente ou } \\
\text { geração automática } \\
\text { de código de } \\
\text { instanciamento do } \\
\text { arcabouço }\end{array}$ & $\begin{array}{l}\text { Reuso do } \\
\text { arcabouço, podendo } \\
\text { ser nos estilos } \\
\text { caixa-branca ou } \\
\text { caixa-cinza }\end{array}$ & $\begin{array}{l}\text { 1) Reúne um conjunto de funcionalidades de } \\
\text { aplicações RV, em especial, as de simulação de } \\
\text { exames de biópsia. } \\
\text { 2) Usufrui dos benefícios de arcabouços extensíveis } \\
\text { com a possibilidade de geração automática de código } \\
\text { de instanciamento. } \\
\text { 3) Isola a complexidade do desenvolvimento e } \\
\text { diminui a curva de aprendizagem do arcabouço com } \\
\text { o uso de uma ferramenta de geração e execução do } \\
\text { código de instanciamento do arcabouço. }\end{array}$ \\
\hline $\begin{array}{l}\text { Hydra (FILHO; } \\
\text { TEICHRIEB; } \\
\text { KELNER, 2011) }\end{array}$ & $\begin{array}{l}\text { Arcabouço } \\
\text { orientado a } \\
\text { objetos e plugins }\end{array}$ & $\begin{array}{l}\text { Criação de objetos } \\
\text { cenas, compostos } \\
\text { pelos elementos } \\
\text { que definem o } \\
\text { ambiente virtual }\end{array}$ & $\begin{array}{l}\text { Reuso do } \\
\text { arcabouço que } \\
\text { abstrai outros } \\
\text { arcabouços e } \\
\text { bibliotecas na forma } \\
\text { de plugins }\end{array}$ & $\begin{array}{l}\text { 1) Abstração e encapsulamento de elementos } \\
\text { do arcabouço por meio do conceito de plugins, } \\
\text { permitindo a flexibilidade da plataforma. } \\
\text { 2) As configurações das aplicações desenvolvidas } \\
\text { definem quais plugins serão usados, permitindo } \\
\text { mudança de comportamento com a mudança de } \\
\text { plugins. } \\
\text { 3) As aplicações são produzidas por meio da } \\
\text { instanciação de elementos conceituais de aplicações } \\
\text { RV pré-definidos. }\end{array}$ \\
\hline
\end{tabular}

continua... 


\begin{tabular}{|c|c|c|c|c|}
\hline Trabalho & $\begin{array}{l}\text { Estilos } \\
\text { Arquiteturais }\end{array}$ & $\begin{array}{l}\text { Abordagem de } \\
\text { Produção }\end{array}$ & $\begin{array}{ll}\text { Abordagem de } \\
\text { Reuso }\end{array}$ & Pontos Favoráveis \\
\hline \multirow[t]{2}{*}{$\begin{array}{l}\text { VRJugglua } \\
\text { (PAVLIK; } \\
\text { VANCE, 2012) }\end{array}$} & \multirow[t]{2}{*}{ Arcabouço } & \multirow{2}{*}{$\begin{array}{l}\text { Código fonte } \mathrm{C}++\mathrm{e} \\
\text { código fonte Lua } \\
\text { para instanciar } \\
\text { elementos do } \\
\text { arcabouço }\end{array}$} & \multirow{2}{*}{$\begin{array}{l}\text { Reuso dos } \\
\text { elementos do } \\
\text { arcabouço integrado }\end{array}$} & $\begin{array}{l}\text { 1) Integração de duas bibliotecas, VR Juggler } \\
\text { e OpenSceneGraph, por meio de código Lua, } \\
\text { aumentando o nível de abstração de particularidades } \\
\text { das bibliotecas. }\end{array}$ \\
\hline & & & & $\begin{array}{l}\text { 2) A linguagem de programação Lua oferece maior } \\
\text { nível de abstração, exigindo menor conhecimento } \\
\text { técnico a questões relacionadas a tecnologias RV. } \\
\text { 3) A possibilidade de trabalhar com código } \\
\text { interpretado possibilita flexibilidade da lógica } \\
\text { em tempo de execução. }\end{array}$ \\
\hline
\end{tabular}

Fonte: Autor (2014)

conclusão 
Os trabalhos classificados como estratégias de abstração e representação, propõem abordagens e representações simbólicas que tem como principal objetivo a produção de aplicações de ambientes virtuais e RV por meio de descrições que estão em níveis mais abstratos que o código fonte de linguagens de programação. A Tabela 2 apresenta um resumo das principais características dos trabalhos de pesquisa classificados como estratégias de abstração e representações de aplicações RV. Suas colunas possuem o seguinte significado:

- Elementos Abstraídos - estabelece quais elementos de mundos virtuais são abstraídos, podendo ser: conceitos do mundo virtual, conceitos do problema que será resolvido com a aplicação, relações entre conceitos ou comportamentos do mundo virtual ou de elementos que compõem o mundo virtual;

- Forma de Representação - os elementos abstraídos são representados de maneira, usando diferentes simbologias, como por exemplo: conceitos orientados a objetos ou simbologia gráfica;

- Pontos Favoráveis - indica quais são as características que chamam a atenção de maneira favorável ao projeto e concepção da plataforma VRServices. 
Tabela 2: Sumarização dos trabalhos relacionados - abstrações e representações

\begin{tabular}{|c|c|c|c|}
\hline Trabalho & $\begin{array}{l}\text { Elementos } \\
\text { Abstraídos }\end{array}$ & $\begin{array}{l}\text { Forma de } \\
\text { Representação }\end{array}$ & Pontos Favoráveis \\
\hline $\begin{array}{l}\text { VR-WISE } \\
\text { (TROYER et al., } \\
\text { 2007) }\end{array}$ & $\begin{array}{l}\text { Conceitos do } \\
\text { mundo virtual, suas } \\
\text { relações e } \\
\text { comportamentos }\end{array}$ & $\begin{array}{l}\text { Representação } \\
\text { gráfica de conceitos } \\
\text { de mundos virtuais, } \\
\text { propriedades e } \\
\text { relações }\end{array}$ & $\begin{array}{l}\text { 1) Alto nível de abstração de representação de elementos que } \\
\text { compõem o mundo virtual. } \\
\text { 2) O desenvolvimento é realizado no nível do domínio e não no nível } \\
\text { da solução. } \\
\text { 3) A modelagem pode ser reusada para produção de diferentes } \\
\text { implementações. }\end{array}$ \\
\hline $\begin{array}{l}\text { MASCARET } \\
\text { (CHEVAILLIER } \\
\text { et al., 2012) }\end{array}$ & $\begin{array}{l}\text { Conceitos do } \\
\text { mundo virtual, suas } \\
\text { relações e } \\
\text { comportamentos }\end{array}$ & $\begin{array}{l}\text { Baseada em } \\
\text { modelos com } \\
\text { simbologia gráfica } \\
\text { estendidas da UML }\end{array}$ & $\begin{array}{l}\text { 1) Alto nível de abstração de representação de elementos que } \\
\text { compõem o mundo virtual. } \\
\text { 2) O desenvolvimento é realizado no nível do domínio e não no nível } \\
\text { da solução. } \\
\text { 3) A modelagem pode ser reusada para produção de diferentes } \\
\text { implementações. } \\
\text { 4) A modelagem dos elementos, relações e comportamentos são } \\
\text { produzidas por meio de representação com simbologia gráfica. } \\
\text { 5) A representação com simbologia gráfica é obtida com a extensão da } \\
\text { UML, isso facilita o aprendizado. }\end{array}$ \\
\hline
\end{tabular}

continua... 
...continuação

\begin{tabular}{|c|c|c|c|}
\hline Trabalho & $\begin{array}{l}\text { Elementos } \\
\text { Abstraídos }\end{array}$ & $\begin{array}{l}\text { Forma de } \\
\text { Representação }\end{array}$ & Pontos Favoráveis \\
\hline $\begin{array}{l}\text { High-Speed } \\
\text { Railway } \\
\text { (JINHONG et al., } \\
\text { 2013) }\end{array}$ & $\begin{array}{l}\text { Modelos 3D básicos } \\
\text { para composição de } \\
\text { cenas }\end{array}$ & $\begin{array}{l}\text { Modelos 3D, } \\
\text { expressões de } \\
\text { posicionamento e } \\
\text { relações espaciais }\end{array}$ & $\begin{array}{l}\text { 1) Generalização e classificação de elementos que compõem o cenário } \\
\text { de ferrovias de alta velocidade. } \\
\text { 2) Definição de expressões matemáticas de posicionamento e relações } \\
\text { espaciais para a construção de cenas de simulações a partir dos } \\
\text { modelos 3D generalizados. }\end{array}$ \\
\hline
\end{tabular}

Fonte: Autor (2014)

conclusão 


\subsection{Considerações Finais do Capítulo}

Para auxiliar a análise das características dos trabalhos descritos neste capítulo foi produzida a Tabela 3. O objetivo desta Tabela é permitir a comparação das características da plataforma VRServices com os demais trabalhos de pesquisa descritos, evidenciando as intersecções e as diferenças. As características da VRServices foram inseridas na última linha da Tabela 3.

Tabela 3: Características dos trabalhos relacionados

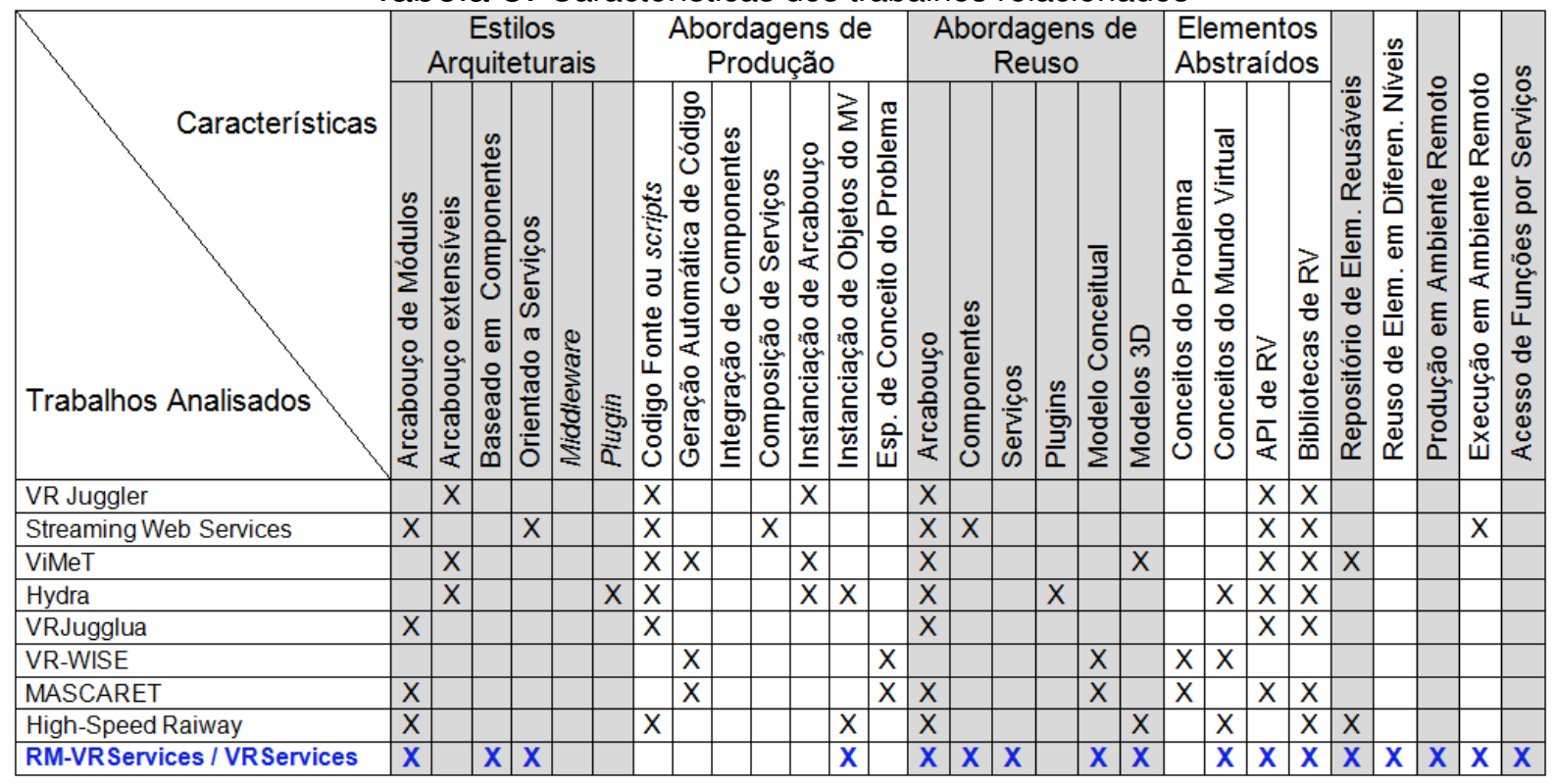

Fonte: Autor (2014)

Não foi observado, nos trabalhos analisados, abordagens que permitam: 1) reuso de elementos de aplicações em diferentes níveis de abstração; 2) a produção de elementos de aplicações RV em ambiente remoto; e 3) acesso às funcionalidades de produção e execução de aplicações RV por meio de serviços.

O reuso de elementos de aplicações em diferentes níveis de abstração é uma característica inserida na plataforma VRServices com o objetivo de permitir que a representação da aplicação RV seja constituída por elementos distribuídos em diferentes níveis, por exemplo: nível de recursos (arquivos de imagem, som, vídeos, modelos 3D), nível de objetos virtuais, nível de cenas, nível de mundos virtuais e por último o nível da aplicação. A divisão em diferentes níveis permite que os elementos possam ser recombinados para produzir outros elementos com maior granularidade, por exemplo, uma cena composta por um conjunto de objetos virtuais ou um mundo virtual composto por um conjunto de cenas.

A produção de elementos de aplicações $\mathrm{RV}$ em ambiente remoto é uma 
característica inserida na plataforma VRServices para possibilitar que aplicações de $\mathrm{RV}$ possam ser criadas e editadas em um repositório on-line a partir de clientes remotos, viabilizando o reuso e o compartilhamento de elementos que constituem as aplicações produzidas na plataforma.

O acesso às funcionalidades de produção e execução de aplicações RV, por meio de serviços, foi inserido como característica da plataforma VRServices como forma de permitir a interoperabilidade da produção e execução de aplicações RV. Com o uso do paradigma de serviços, apoiado por tecnologias como Web Services, é possível que as aplicações clientes da plataforma possam ser produzidas em diferentes plataformas, usando diferentes linguagens de programação e diferentes dispositivos de RV. A plataforma VRServices caracteriza-se como um barramento de serviços que incorpora capacidades de edição e execução de aplicações RV em ambiente on-line.

Também vale ressaltar que a característica Repositório de Elementos Reutilizáveis presente no trabalho ViMeT de Oliveira e Nunes (2010) e no trabalho High-Speed Railway de Jinhong et al. (2013) foi ampliada na plataforma VRServices. No ViMeT existem dois repositórios, um para os modelos 3D usados nas aplicações e outro constituído pelas configurações que representam cada instanciação de aplicação. No trabalho High-Speed Railway o repositório é constituído apenas por modelos 3D usados para construir as simulações de ferrovias de alta velocidade. $\mathrm{Na}$ plataforma VRServices o repositório é usado para armazenar as referências aos modelos 3D e para o armazenamento dos elementos de aplicações criados em diferentes níveis de abstração, como recursos, objetos virtuais, cenas, mundos virtuais e aplicações. Essa característica da plataforma VRServices potencializa as possibilidades de reuso de elementos que compõem as definições de aplicações RV.

A plataforma VRServices usa, como Elemento de Abstração, a representação de conceitos de mundos virtuais e aplicações $\mathrm{RV}$, extraídos da literatura e bibliotecas de desenvolvimento. A representação de conceitos é realizada por meio de classes, atributos de classes e relações do modelo orientado a objetos (PAGE-JONES, 2001). A escolha por tal representação se deve ao fato de que a plataforma VRServices contempla o lado servidor de uma plataforma de RV orientada a serviços. Uma simbologia gráfica, como é o caso, do trabalho VR-WISE (TROYER et al., 2007) e do trabalho MASCARET (CHEVAILLIER et al., 2012) são destinadas ao lado cliente, no qual o usuário final tem acesso. Nada impede que sejam produzidas aplicações clientes que ofereçam uma simbologia gráfica para a representação de elementos de mundos virtuais e consumam os serviços de produção e execução da plataforma 
VRServices. Outra justificativa para a escolha da estratégia de representação é o fato de que os elementos criados na plataforma, e armazenados nos repositórios, sejam de fácil localização e recuperação, permitindo que sejam localizados, recuperados e reusados no desenvolvimento de aplicações $\mathrm{RV}$. O modelo orientado a objetos mostrou-se favorável a essas características.

Os dois capítulos seguintes apresentam os elementos que constituem 0 modelo de representação de aplicações RV definidos para a plataforma VRServices, bem como o modelo arquitetural que apoia a criação, edição e execução dessas representações de aplicações $\mathrm{RV}$ em ambiente on-line. 


\section{MODELO CONCEITUAL DE REPRESENTAÇÃO DE APLICAÇÕES DE REALIDADE VIRTUAL}

Neste capítulo é apresentado o modelo de representação de aplicações de realidade virtual para a plataforma VRServices, denominado a partir daqui de RM-VRServices. O modelo de representação proposto deve atender a três objetivos: 1) permitir a produção de aplicações $R V$, por meio da representação de elementos em um nível de abstração acima de código fonte de linguagens de programação; 2) permitir a representação de aplicações em uma granularidade de elementos que possibilite o reuso de frações de representação na produção de novas aplicações; e 3) permitir a edição, compartilhamento e execução das especificações de aplicações $\mathrm{RV}$ em um ambiente on-line baseado em serviços.

Para atingir os três objetivos estabelecidos com o RM-VRServices foram usados, como elemento de abstração, os conceitos de mundos virtuais e aplicações RV extraídos da literatura e de bibliotecas de desenvolvimento. A representação desses conceitos é realizada por meio de classes, atributos de classes e relações do modelo orientado a objetos (PAGE-JONES, 2001). A produção de aplicações de $\mathrm{RV}$ é realizada com instâncias das classes conceituais definidas no RM-VRServices.

A Figura 30 ilustra, por meio de um diagrama de classes conceituais, a parte central do RM-VRServices. O objetivo desta ilustração é descrever os principais elementos que compõem o RM-VRServices. Os conceitos definidos para representação de aplicações $\mathrm{RV}$ são inspirados na estrutura de representação de grafos de cena (MUKUNDAN, 2012), que estabelece uma estrutura hierárquica de nós, que no caso do RM-VRServices, são representados por conceitos do modelo orientado a objetos. A Figura 30 ilustra os quatro conceitos que constituem o eixo central da representação do RM-VRServices.

Figura 30: Representação do eixo principal do RM-VRServices

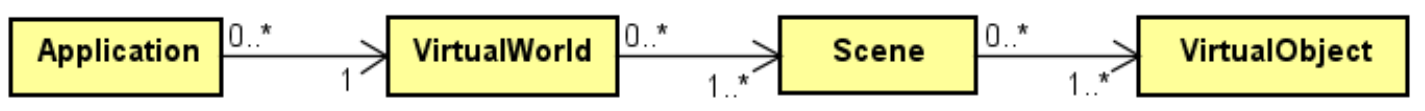

Fonte: Autor (2014) 
- VirtualObject - é uma generalização de objetos virtuais que podem ser usados para compor cenas de mundos virtuais. Cada ocorrência de VirtualObject reúne informações sobre a estrutura geométrica e de aparência do objeto virtual representado, que pode ser uma representação simples de um elemento geométrico ou o resultado de uma composição de elementos geométricos;

- Scene - representa um conjunto de objetos virtuais com informações de posicionamento, propriedades de aparência da cena, monitoramento de eventos e comportamentos. O conceito Scene foi proposto como forma de fracionar o conteúdo de um mundo virtual, aumentando a possibilidade de reuso;

- VirtualWorld - representa uma instância de um mundo virtual, reúne um conjunto de cenas, pontos de visão do mundo virtual e monitoramento de eventos e comportamentos;

- Application - representa uma instância de aplicação RV, composta por um mundo virtual, e informações de entradas e saída de dados da aplicação.

A escolha pela representação por meio de conceitos de mundos virtuais, estruturados em um grafo, se deve ao fato de que a plataforma VRServices representa o lado servidor de uma plataforma de RV orientada a serviços. Uma simbologia gráfica, como é o caso dos trabalhos de Troyer et al. (2007) e de Chevaillier et al. (2012), é destinada ao lado cliente, no qual o usuário final tem acesso. A plataforma VRServices tem como cliente as aplicações consumidoras dos serviços e não o usuário final. Por outro lado, nada impede que sejam produzidas aplicações clientes que ofereçam uma simbologia gráfica para a representação de elementos de mundos virtuais e consumam os serviços de produção e execução da plataforma VRServices.

Outra justificativa para a escolha da estratégia de representação é o fato de que os elementos criados na plataforma, e armazenados nos repositórios, devem ser de fácil localização e recuperação, permitindo que sejam localizados, recuperados e reusados no desenvolvimento de novas aplicações RV. O modelo orientado a objetos mostrou-se favorável a essas características, principalmente pelo fato que as funcionalidades da plataforma VRServices são acessíveis por meio de serviços, exigindo a troca de mensagens entre a plataforma e as aplicações clientes, cujos parâmetros são instâncias das classes conceituais do RM-VRServices. As características da plataforma serão descritas em detalhes no Capítulo 6.

A Figura 31 ilustra, de maneira abstrata, a produção e execução de aplicações RV por meio do RM-VRServices. O processo de produção de aplicações é 
constituído pela busca de recursos e elementos previamente criados e armazenados nos repositórios, formando uma representação hierárquica de instâncias de classes conceituais definidas no RM-VRServices.

Figura 31: Visão lógica da produção e execução de aplicações com o RM-VRServices

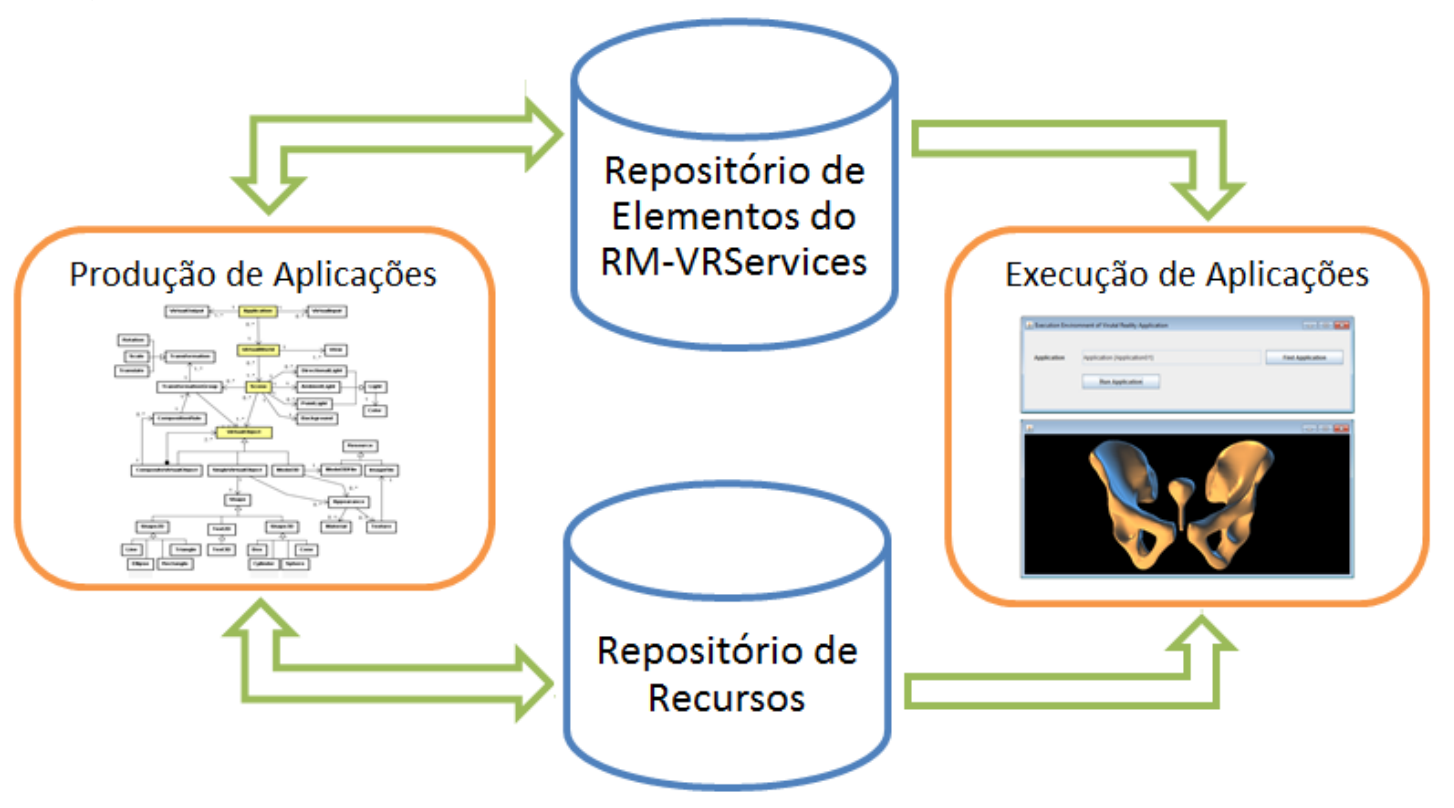

Fonte: Autor (2014)

A execução das aplicações é realizada pela busca de aplicações armazenadas no repositório, carregamento da instância desejada e execução. Esse processo é realizado por meio de serviços que a plataforma oferece aos seus clientes, nesse caso, aplicações consumidoras dos serviços. Os detalhes arquiteturais e tecnológicos que dão suporte a produção e execução de instâncias do RM-VRServices serão apresentados no capítulo 6.

\subsection{Descrição do Modelo RM-VRServices}

O modelo ilustrado na Figura 30 estabelece as seguintes premissas de representação de aplicações $\mathrm{RV}$ para a plataforma VRServices: 1) uma aplicação deve fazer referência a um e somente um mundo virtual e um mundo virtual pode ser referenciado por inúmeras aplicações; 2) um mundo virtual deve possuir pelo menos uma referência a uma cena e uma cena pode ser referenciada por inúmeros mundos virtuais; 3) uma cena deve possuir pelo menos um objeto virtual e um objeto virtual pode ser referenciado por inúmeras cenas. Essas premissas conferem ao modelo de representação a possibilidade de representar aplicações $\mathrm{RV}$ por meio da recombinação de objetos virtuais, cenas e mundos virtuais. 
Figura 32: Representação parcial do RM-VRServices

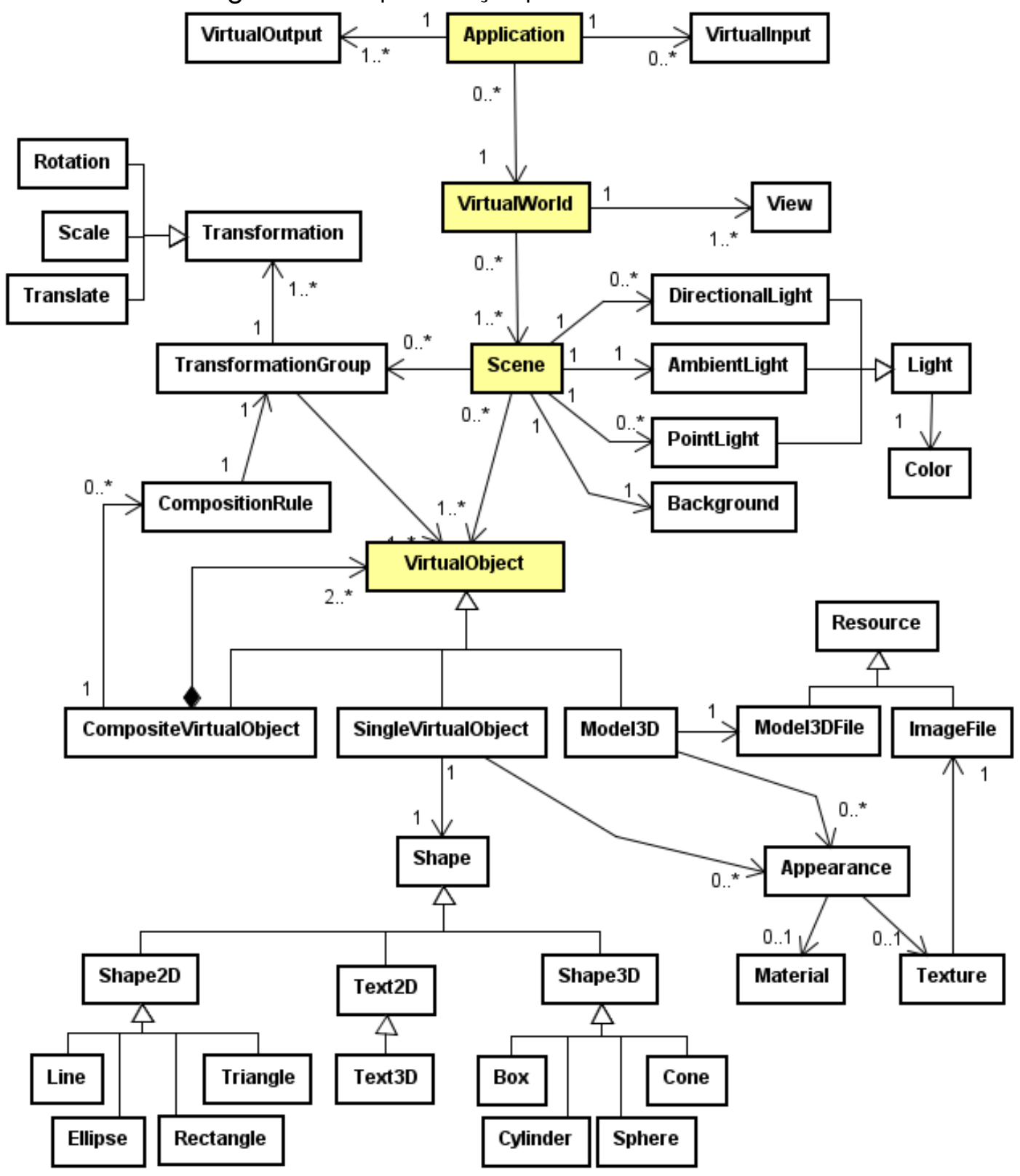

Fonte: Adaptado de (FREIBERGER; NAKAMURA; TORI, 2014b)

Com o objetivo de ampliar o entendimento dos conceitos e condições estabelecidas pelas relações e cardinalidades, a Figura 32 ilustra um diagrama de classes conceituais que contêm os conceitos já apresentados, acrescido de conceitos e relações que estabelecem novos elementos do RM-VRServices. Para cada um dos quatro conceitos centrais do RM-VRServices (VirtualObject, Scene, VirtualWorld e Application) serão apresentadas as restrições de especialização e relacionamentos com os demais conceitos apresentados na Figura 32.

- VirtualObject

- podem existir três especializações do conceito VirtualObject: Mode/3D, 
SingleVirtualObject ou CompositeVirtualObject;

- a especialização Model3D representa o conceito de objetos virtuais que são obtidos a partir de arquivos que armazenam modelos 3D, produzidos em ferramentas especializadas;

- a especialização SingleVirtualObject representa o conceito de objetos virtuais produzidos por meio de estruturas geométricas 3D, como: caixa cúbica, cilindro, cone e esfera; ou estruturas geométricas 2D, como: linha, circulo, retângulo, quadrado ou triângulo; ou ainda textos 2D e 3D;

- a especialização CompositeVirtualObject representa o conceito de objeto virtual composto por outros objetos virtuais, sendo possível compor com quaisquer das três especializações de VirtualObject;

- cada composição deve conter uma lista com pelo menos dois objetos virtuais;

- cada composição pode conter várias ocorrências de CompositionRule, que estabelecem transformações geométricas necessárias para o posicionamento dos objetos virtuais na composição.

- Scene

- cada instância de Scene deve conter pelo menos uma instância de VirtualObject;

- cada instância de Scene deve conter uma instância de Background, para estabelecer as características de fundo da cena;

- cada ocorrência de Scene deve conter uma instância de AmbientLight, para estabelecer as características de iluminação do ambiente da cena;

- cada instância de Scene pode conter várias instâncias de PointLight, para estabelecer pontos de luz da cena;

- cada instância de Scene pode conter várias instâncias de DirectionalLight, para estabelecer luzes direcionais da cena;

- cada instância de Scene pode conter instâncias de TransformationGroup, que representa um grupo de transformações geométricas que são aplicadas a um conjunto de objetos virtuais relacionados.

\section{- VirtualWorld}

- uma instância de VirtualWorld deve conter pelo menos uma instância de Scene;

- uma instância de VirtualWorld deve conter pelo menos uma referência a um ponto de visão, representado pelo conceito View. 


\section{- Application}

- Virtuallnput - classe genérica para representar conceitos de categorias de entradas de dados para as aplicações representadas;

- VirtualOutput - classe genérica para representar conceitos de categorias de saídas de dados resultantes da execução da aplicação;

- cada instância de Application deve possuir uma e apenas uma instância de VirtualWorld associada;

- cada instância de Application deve possuir referência a pelo menos uma instância de VirtualOutput, ou seja, deve possuir pelo menos uma forma de saída de dados para aplicação;

- cada instância de Application pode conter uma ou mais instâncias de Virtuallnput.

A partir da descrição dos principais elementos do RM-VRServices, serão descritos com mais detalhes, conjuntos separados de elementos, bem como a apresentação de elementos que não aparecem na ilustração da Figura 32, como é o caso dos elementos que representam os eventos e seus respectivos comportamentos associados.

\subsubsection{Conceito Virtuallnput}

Com o objetivo de compatibilizar a representação e execução de aplicações RV em ambiente remoto, o RM-VRServices deve possibilitar a representação de entrada de dados desvinculada dos dispositivos físicos de entrada. A entrada de dados para o contexto de execução das aplicações na plataforma VRServices é promovida por meio de mensagens de serviços, emitidas pelas aplicações clientes. Essa característica tornam os dispositivos de entrada de dados transparentes para a plataforma.

A primeira alternativa considerada para representar as entradas de dados foi a representação dos dispositivos físicos como dispositivos virtuais. Assim, por exemplo, para um mouse físico no cliente, deveria existir uma instância de mouse virtual na representação da aplicação e posteriormente no contexto de execução da aplicação. Foi produzido um protótipo para avaliação dessa alternativa. O protótipo disponibiliza um conjunto de operações de serviços que são usadas para alterar o estado da instância de cada dispositivo virtual. Assim, no exemplo do mouse virtual, o protótipo disponibiliza operações que são usadas para atualizar o estado do mouse virtual, tais como: botão direito pressionado na posição x e y; botão esquerdo pressionado na 
posição x e y; ou ainda, arrasto de mouse da posição x1 e y1 até a posição x2 e y2. Embora essa alternativa mostrou-se viável funcionalmente, ela foi desconsiderada, pois a representação do RM-VRServices ficaria vulnerável ao surgimento de novos dispositivos de entrada de dados. Outro agravante considerado é a quantidade de modelos de dispositivos de entrada, aumentando a complexidade de representação dos dispositivos virtuais e a quantidade de operações de serviços que deveriam existir para atender a especificidade de cada dispositivo virtualizado.

A segunda alternativa analisada e posteriormente adotada, é a proposta de classificação de dispositivos considerando sua função de entrada de dados e não suas características físicas. Os autores Foley e Wallace (1974) propõem uma classificação de dispositivos físicos em quatro categorias de dispositivos virtuais: 1) pick - representa a função de selecionar elementos da interface do usuário; 2) button - inicialmente considerada as funções pré-programadas em teclados, acionadas por botões; 3) locator - usado para indicar um local ou orientação no espaço de desenho conceitual do usuário; e 4) valuator - é usado para determinar um único valor no espaço de números.

Segundo Myers (1990), existem muitas iniciativas que propõem a separação dos dispositivos de entrada de dados das aplicações. Padrões como Graphical Kernel System (GKS) e Programmer's Hierarchical Interactive Graphics System (PHIGS) identificam cinco ou seis tipos básicos de entrada: locator, stroke, valuator, choice, pick, e string, baseados no modelo de Foley e Wallace (1974).

Os autores He e Kaufman (1993) propõem uma interface unificada para dispositivos de entrada de dados. A ideia central é generalizar e unificar dados de dispositivos físicos para um dispositivo virtual que é visível para a aplicação. A proposta tem dois objetivos, um é promover a independência de aplicações frente as especificidades de dispositivos de entrada, e segundo, é permitir que diversos dispositivos possam ser usados para a mesma função de entrada de dados. Os autores também usam a classificação de dispositivos de entrada baseada na função da entrada de dados (FOLEY; WALLACE, 1974). A Tabela 4 apresenta a classificação de alguns dispositivos de entrada pela função que cada um pode desempenhar.

A representação de entrada de dados do RM-VRServices, estabelece uma representação unificada e virtual de entrada de dados por meio do conceito Virtuallnput, conforme ilustrado na Figura 33. Baseado na classificação funcional de dispositivos de entrada de dados, proposto por Foley e Wallace (1974) e citadas por Myers (1990), foram definidas quatro especializações para representar as funções de entrada de dados: VirtualLocale, VirtualSelect, VirtualCommand e VirtualDatalnput. 
Tabela 4: Classificação de dispositivos de entrada de dados

\begin{tabular}{|l|c|c|c|c|}
\hline & Locator & Choice & Command & Valuator \\
\hline Teclado & 1 & 2 & 3 & 1 \\
\hline Mouse & 3 & 3 & 1 & \\
\hline Spaceball & 3 & 2 & 1 & \\
\hline Luva & 3 & 1 & 3 & \\
\hline Rastreador ocular & 2 & 2 & & \\
\hline Voz & & 2 & 3 & 1 \\
\hline Tablet & 3 & 2 & & \\
\hline
\end{tabular}

3: muito adequado 2: adequado 1: pode ser usado

Fonte: adaptado de He e Kaufman (1993)

Figura 33: Conceito Virtuallnput do RM-VRServices

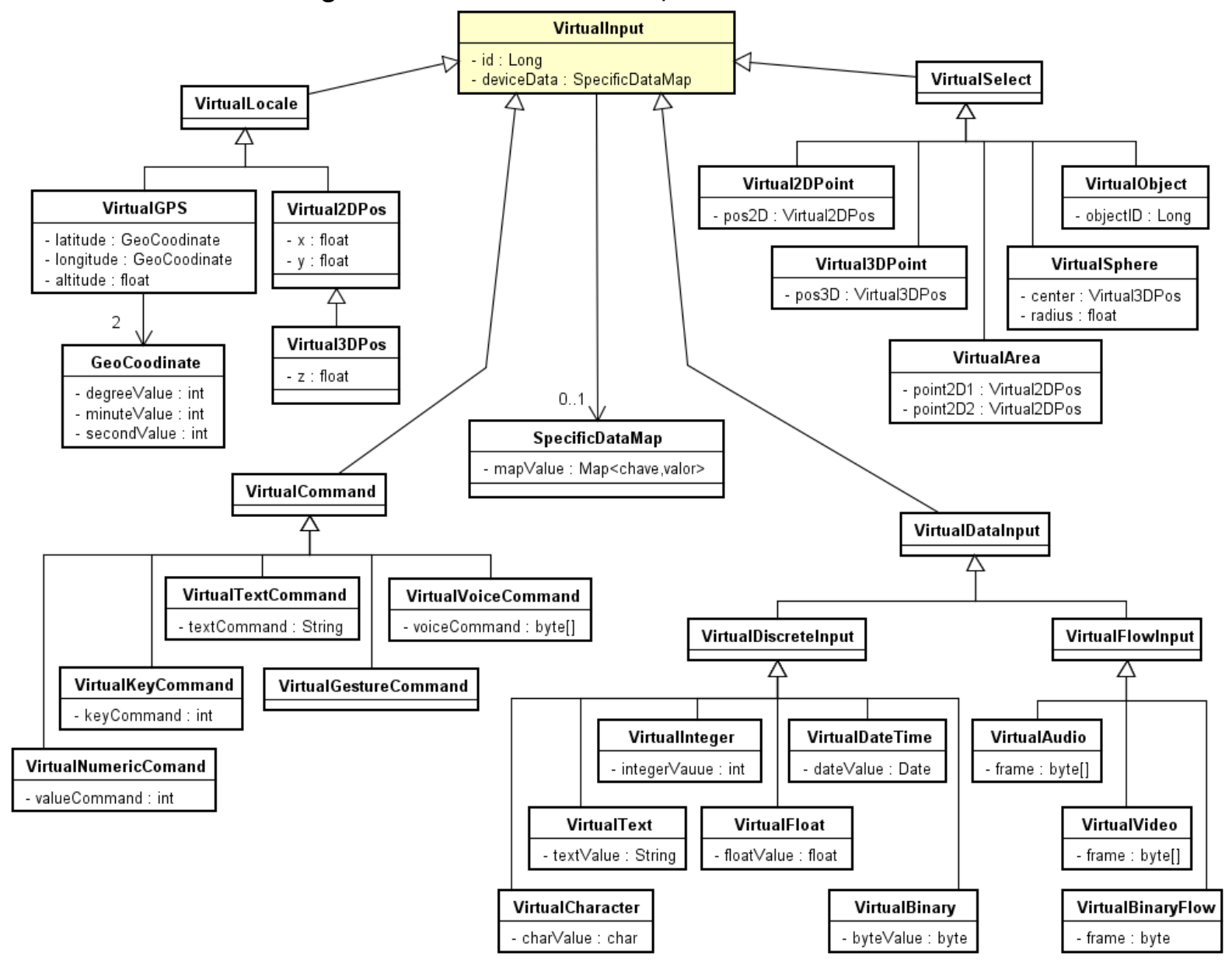

Fonte: Autor (2014)

A Tabela 5 apresenta o mapeamento dos conceitos definidos no RM-VRServices relacionados com as categorias de dispositivos de entrada de dados.

O conceito VirtualLocale representa dados referentes a posicionamento de algo no mundo virtual, podendo ser representadas posições com pontos 2D, pontos 3D ou por meio de coordenadas de um sistema de posicionamento global.

O conceito VirtualSelect representa dados que são usados para representar 
Tabela 5: Mapeamento de conceitos e funções de entrada de dados

\begin{tabular}{|l|c|c|c|c|c|c|}
\hline & Locator & Choice & Select & Command & Valuator & String \\
\hline VirtualLocale & $\mathrm{X}$ & & & & & \\
\hline VirtualSelect & & $\mathrm{X}$ & $\mathrm{X}$ & & & \\
\hline VirtualCommand & & & & $\mathrm{X}$ & & \\
\hline VirtualDatalnput & & & & & $\mathrm{X}$ & $\mathrm{X}$ \\
\hline
\end{tabular}

Fonte: Autor (2014)

seleções realizadas no mundo virtual, como a seleção em um ponto $2 \mathrm{D}$, ou em um ponto 3D, uma área retangular delimitada por dois pontos $2 \mathrm{D}$, uma região delimitada por uma esfera ou um objeto referenciado por um identificador.

O conceito VirtualCommand representa comandos que são enviados para o contexto de execução da aplicação. Foi especializado para representar comandos por meio de valores numéricos, teclas, textos, gestos ou voz.

O conceito VirtualDatalnput representa a entrada de dados para aplicação. Foi divido em dois grupos: o primeiro para representar dados discretos, como caracteres, textos, valores inteiros, valores reais, data ou valores binários; o segundo grupo representa fluxos contínuos de entrada de dados, como: fluxo de áudio, fluxo de vídeo ou fluxo de valor binário.

Além das entradas de dados representadas pelas especializações do conceito Virtuallnput, existe a possibilidade de representar entradas compostas, por meio de duas ou mais instâncias dos subconceitos de Virtuallnput. Por exemplo, para representar uma seleção de uma área retangular usando um mouse como dispositivo de entrada, é possível representá-la com duas instâncias de Virtual2DPoint, uma para a origem do arrasto do mouse e outra para marcar o final do arrasto e ainda usar uma instância de VirtualTextCommand para representar o botão do mouse que foi pressionado. Outro exemplo de composição pode ser dado pela necessidade de representar uma combinação de teclas de função do teclado, usando duas ou mais instâncias de VirtualKeyCommand.

Para os casos que seja necessária a representação de dados específicos de dispositivos de entrada de dados, foi reservado o conceito SpecificDataMap, que pode representar dados por meio de uma estrutura do tipo dicionário, que estabelece uma lista de dados representados por meio de pares de chaves e valores. 0 conceito Virtuallnput e qualquer um dos subconceitos podem conter uma instância de SpecificDataMap para representar uma informação específica de um dispositivo de entrada de dados. 


\subsubsection{Conceito VirtualOutput}

A representação de aplicações RV do RM-VRServices deve oferecer elementos que definem as formas de saídas de dados que cada aplicação produzirá aos clientes da plataforma VRServices. A Figura 34 ilustra a hierarquia de conceitos que representam as formas de saída de dados das aplicações RV produzidas com o RM-VRServices.

O conceito VirtualOutput generaliza três possíveis tipos de saída que podem ser representadas no RM-VRServices: VideoRender, AudioRender e HapticRender (SHERMAN; CRAIG, 2003). A Figura 34 ilustra os subtipos relacionados com o conceito VirtualOutput.

Figura 34: Conceito VirtualOutput do RM-VRServices

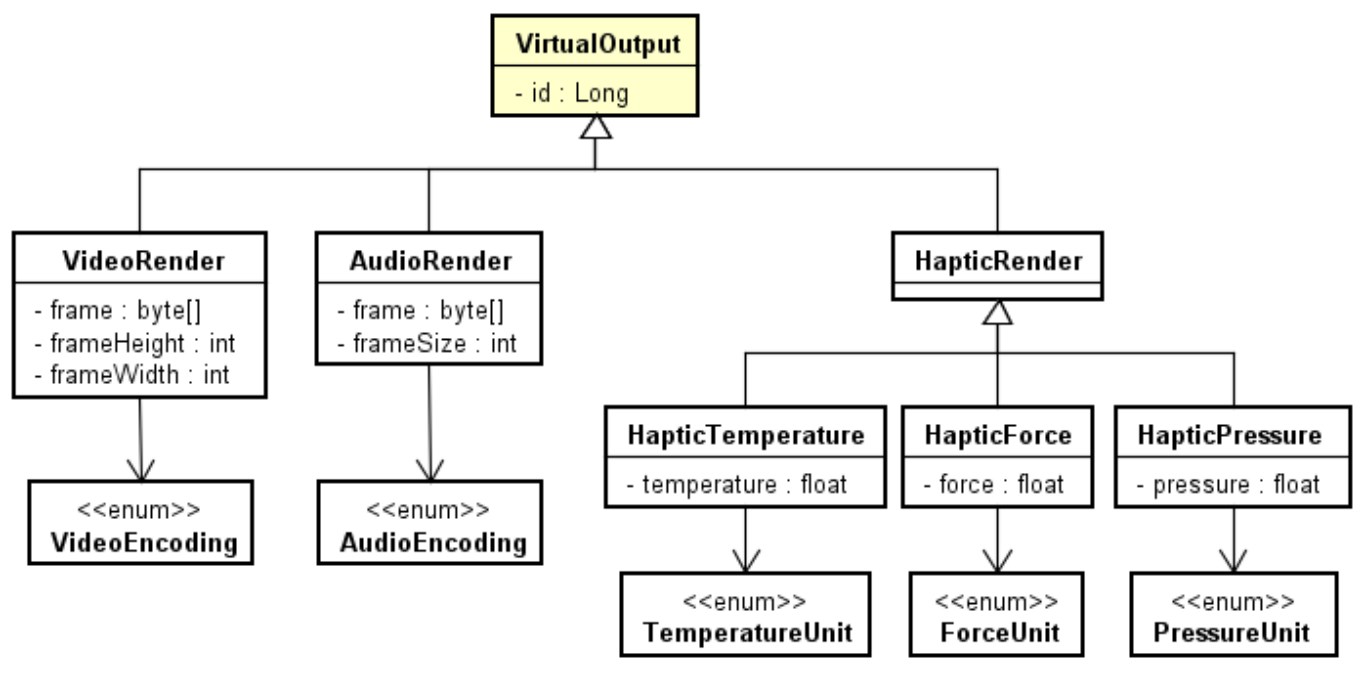

Fonte: Autor (2014)

A especialização VideoRender representa a modalidade de renderização que expõe os resultados da execução da aplicação RV por meio de um fluxo de vídeo. O subconceito AudioRender representa a renderização de áudio e o subconceito HapticRender representa a renderização háptica, podendo ser especializada em três categorias: HapticTemperature, HapticForce e HapticPressure.

Os conceitos que fazem parte da representação de saída de dados das aplicações não definem a tecnologia, e sim, estabelecem de forma declarativa, as modalidades que existirão nas aplicações representadas a partir do RM-VRServices. A plataforma VRServices define as formas de acesso a cada uma das modalidades declaradas nas aplicações, por meio de mensagens de serviços. Isso será detalhado no Capítulo 6. 


\subsubsection{Conceito Event}

Os conceitos Resource, VirtualObject, Scene, VirtualWorld e Application, em conjunto com os conceitos que complementam suas características, representam a parte estática do modelo RM-VRServices. A parte dinâmica do RM-VRServices é representada pelos conceitos Event e Behavior. Além da representação por meio do modelo orientado a objetos, o RM-VRServices incorpora características do modelo orientado a eventos (SOMMERVILLE, 2007, p. 202), para representar os comportamentos das aplicações RV criadas a partir dele.

$O$ conceito Event generaliza seis categorias de eventos que podem ser representados no RM-VRServices: TimeEvent, ApplicationEvent e VirtualWorldEvent, SceneEvent, ObjectEvent e InputEvent. A Figura 35 ilustra as relações dos subconceitos de Event com os conceitos que formam a base dos elementos que compõem as aplicações no RM-VRServices.

Figura 35: Relações do conceito Event no RM-VRServices

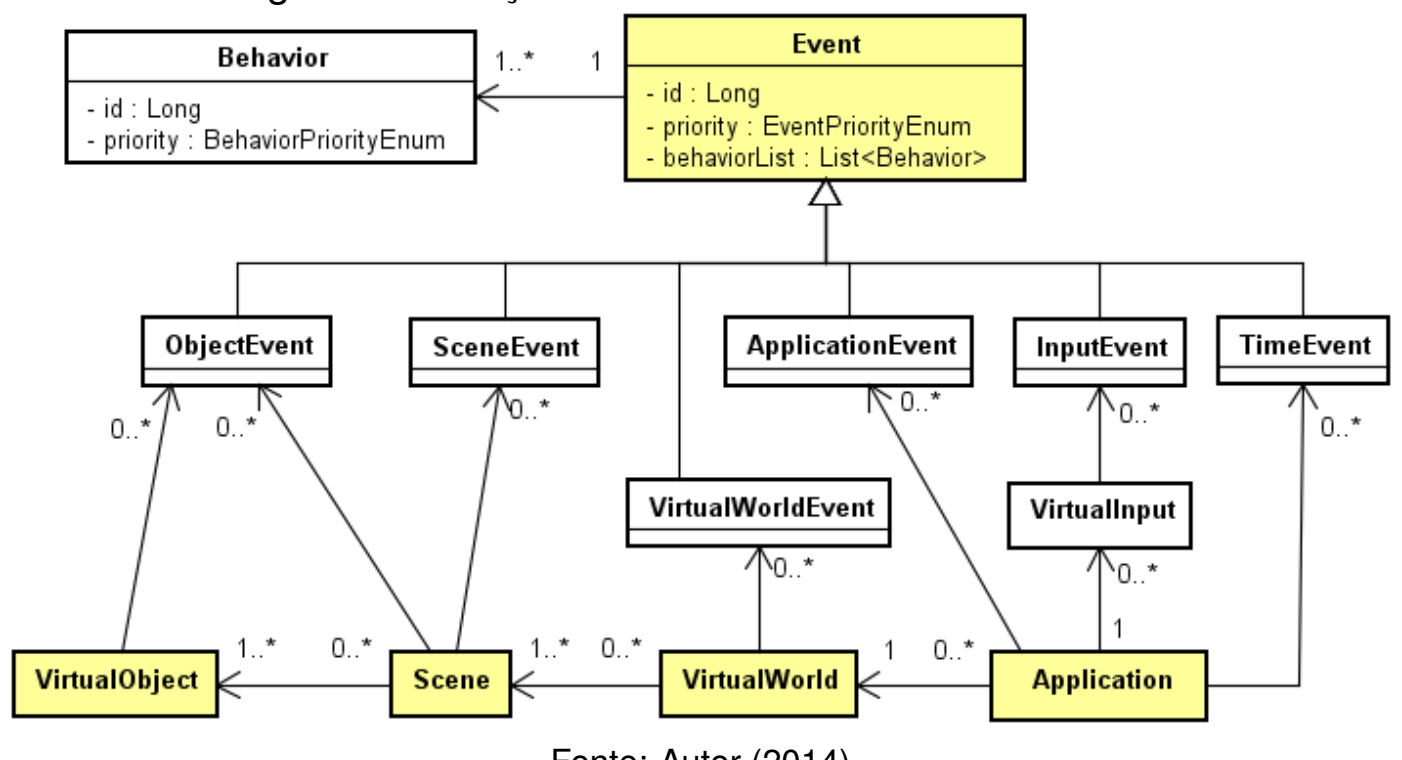

Fonte: Autor (2014)

A Figura 36 ilustra a hierarquia dos subconceitos do conceito Event, apresentando as especializações que determinam quais eventos podem ser representados no RM-VRServices.

O subconceito TimeEvent representa eventos que ocorrerem com o decorrer do tempo de execução da aplicação RV. Foi especializado nos subconceitos TimeDiscrete e TimeContinuous para representar respectivamente eventos que ocorrem uma única vez na linha do tempo de execução ou eventos que correm repetidamente em um intervalo de tempo definido.

O subconceito ApplicationEvent representa os eventos que ocorrem baseados 
Figura 36: Conceito Event do RM-VRServices

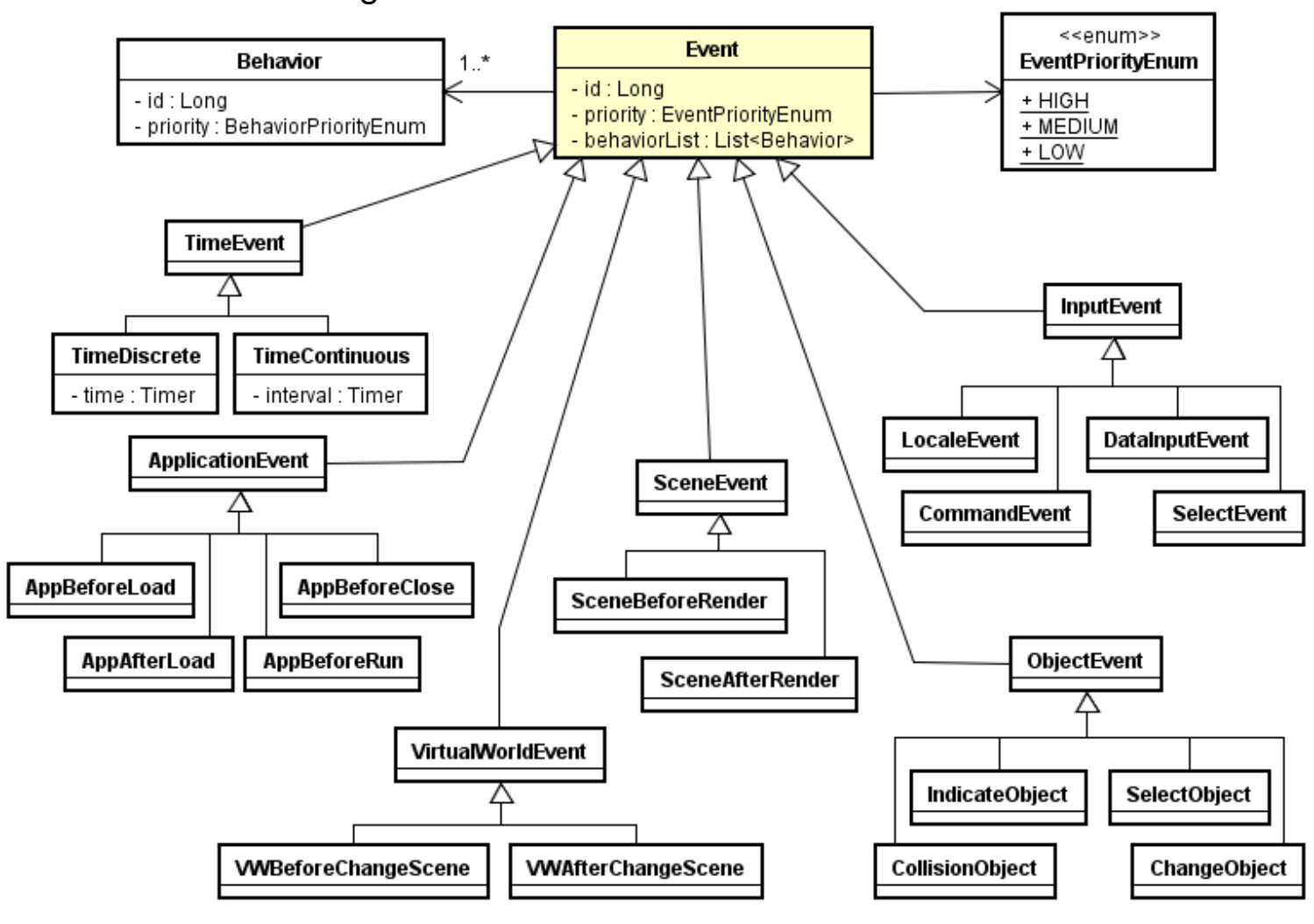

Fonte: Autor (2014)

em acontecimentos com as instâncias de aplicações durante a execução. Para definir esses acontecimentos foram produzidas quatro especializações: 1) AppBeforeLoad representa o evento que ocorre antes de iniciar o carregamento de uma aplicação armazenada no repositório da plataforma; 2) AppAfterLoad representa o evento que ocorre depois do carregamento de uma aplicação armazenada no repositório da plataforma; 3) AppBeforeRun representa o evento que ocorre antes de iniciar a execução de uma aplicação já carregada em memória; 4) AppBeforeClose representa o evento que ocorre antes da aplicação ser encerrada e descarregada da memória.

O subconceito VirtualWorldEvent representa os eventos que ocorrem baseados em acontecimentos relacionados às instâncias de mundos virtuais. Foram definidos os subconceitos VWBeforeChangeScene para representar o evento que ocorre antes de uma mudança de cena no mundo virtual e VWAfterChangeScene que representa o evento que ocorre depois de uma mudança de cena do mundo virtual.

O subconceito SceneEvent representa os eventos que ocorrem baseados em acontecimentos relacionados às instâncias de cenas de mundos virtuais. Foram definidos os subconceitos SceneBeforeRender para representar o evento que ocorre antes da renderização de uma cena e SceneAfterRender que representa o evento que ocorre depois da renderização de uma cena. 
O subconceito ObjectEvent representa os eventos que ocorrem baseados em acontecimentos relacionados às instâncias de objetos virtuais que compõem as cenas. Foram definidos quatro subconceitos para representar esses acontecimentos: 1) IndicateObject representa o evento que ocorre quando um objeto virtual é indicado ou apontado na cena; 2) CollisionObject representa o evento que ocorre com cada um dos objetos participantes de uma colisão na cena; 3) SelectObject representa o evento que ocorre quando um objeto é selecionado na cena; e 4) ChangeObject representa o evento que ocorre quando mudar o valor de alguma propriedade do objeto.

O subconceito InputEvent representa os eventos originados a partir de entradas de dados que ocorrem durante a execução da aplicação. Assim como foram especificadas as categorias de entradas de dados, os eventos de entrada também foram classificados seguindo o critério de funcionalidade da entrada de dados e não relacionados a dispositivos físicos de entrada de dados. Foram definidos quatro subconceitos de InputEvent para representar os eventos de entrada de dados para as categorias de entrada de dados, são elas: 1) LocaleEvent que representa os eventos que ocorrem em função de entradas de dados relacionados a localização; 2) CommandEvent representa eventos que ocorrem em função de entrada de dados relacionados a comandos; 3) SelectEvent representa eventos que ocorrem a partir de entradas de dados relacionadas a seleção de algum elemento do mundo virtual; e 4) DatalnputEvent representa eventos relacionados a entrada de dados literais, como valores numéricos, caracteres e textos.

As especializações do conceito Event apresentadas não contemplam todas as possibilidades de eventos da plataforma. A medida que ocorram necessidades ainda não representadas, estas deverão ser inseridas em uma das hierarquias existentes, ou deve ser criada uma nova hierarquia como subtipo do conceito Event.

\subsubsection{Conceito Behavior}

Associado ao conceito Event, deve existir pelo menos uma instância do conceito Behavior, que representa os comportamentos que são executados quando o evento ocorre. Assim, a representação de comportamento no RM-VRServices é estabelecida com a relação entre os conceitos Event e Behavior, podendo existir mais de um comportamento associado ao mesmo evento.

A Figura 37 ilustra a hierarquia de subconceitos especializados a partir do conceito Behavior. Foram definidas quatro especializações: 1) SceneBehavior representa o comportamento de mudança de cenas de um mundo virtual. As 
Figura 37: Conceito Behavior do RM-VRServices

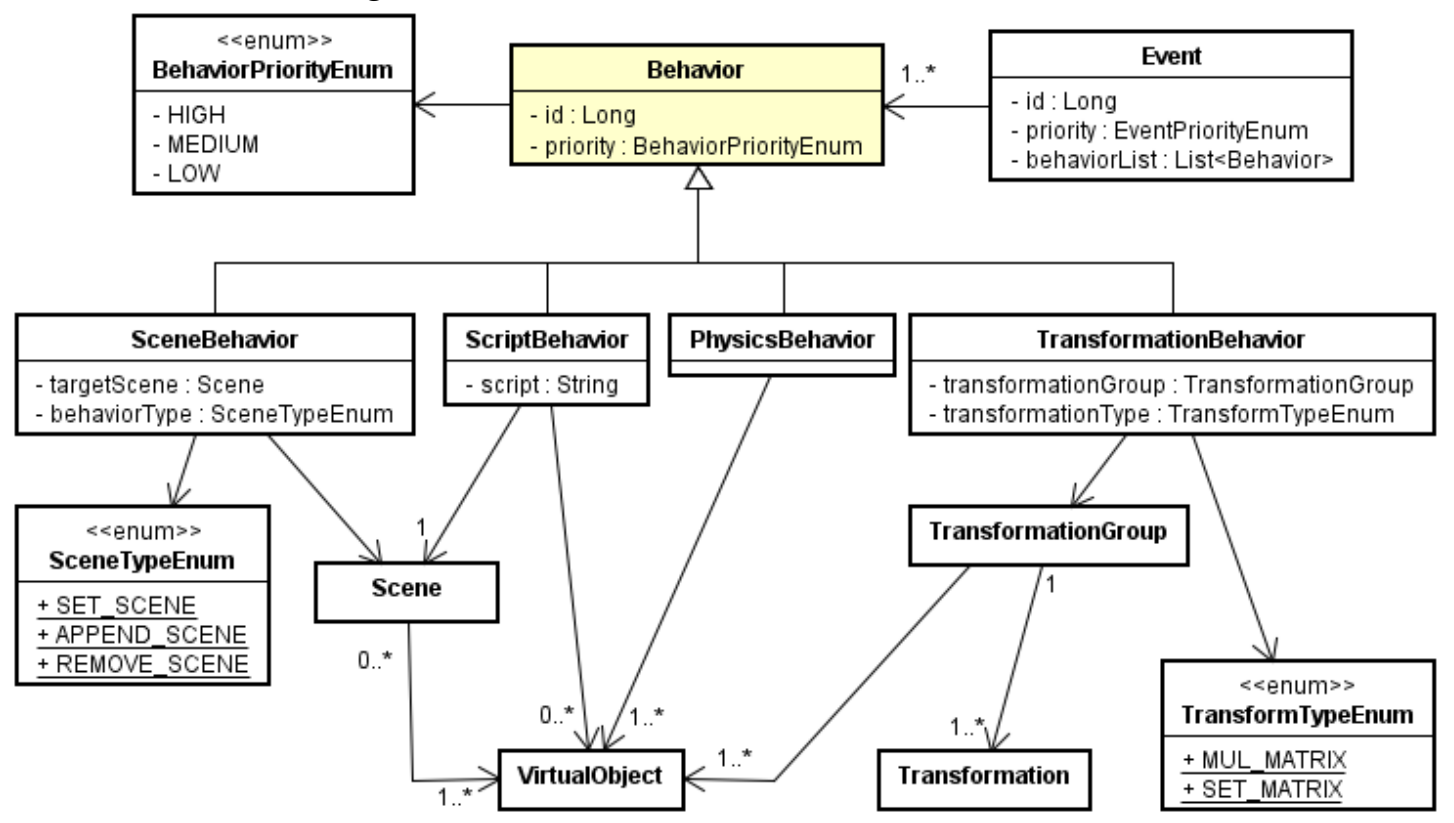

Fonte: Autor (2014)

mudanças possíveis são: definir uma cena para um mundo virtual, adicionar uma cena a um mundo virtual ou remover uma cena de um mundo virtual; 2) TransformationBehavior representa o comportamento que executa um conjunto de transformações geométricas sobre um conjunto de objetos virtuais de uma cena; 3) PhysicsBehavior representa a aplicação de comportamentos relacionados às leis da física, sobre um conjunto de objetos virtuais. Ainda não foram definidos os efeitos de física que serão incorporados à plataforma. Cada efeitos de física incorporado ao MR-VRServices e a plataforma será representado como subconceito do conceito PhysicsBehavior; e 4) ScripBehavior representa o comportamento por meio de trechos de código definidos por linguagem script. Essa alternativa de especificação de comportamento será usada para suprir situações onde os comportamentos pré-existentes não atenderão as necessidades.

Ainda não foi definida a linguagem de script e o interpretador a serem usados na especificação de comportamentos da plataforma. Uma linguagem em estudo é a Lua, considerando as recomendações dos autores (PAVLIK; VANCE, 2012). Pode ser considerada também a hipótese de existir mais de uma linguagem script, para a especificação de comportamentos, uma vez que podem existir especializações do conceito ScripBehavior e a incorporação de mais de um interpretador na plataforma VRServices. 


\subsubsection{Conceito Resource}

O conceito Resource, ilustrado na Figura 38, representa os recursos que são usados para compor as aplicações RV na plataforma VRServices. Os recursos são referências a arquivos que podem conter imagens, áudios, modelos 3D e texturas. Uma instância de Resource não armazena o conteúdo do arquivo, apenas faz referência por meio de Uniform Resource Identifier (URI) ao arquivo correspondente.

Os recursos são usados para definir características de outros elementos do RM-VRServices, como por exemplo: especificação de objetos virtuais 3D por meio de modelos 3D armazenados em arquivos, imagens de plano de fundo de cenas, imagens de texturas de objetos virtuais e áudios que devem ser reproduzidos em cenas.

Figura 38: Conceito Resource do RM-VRServices

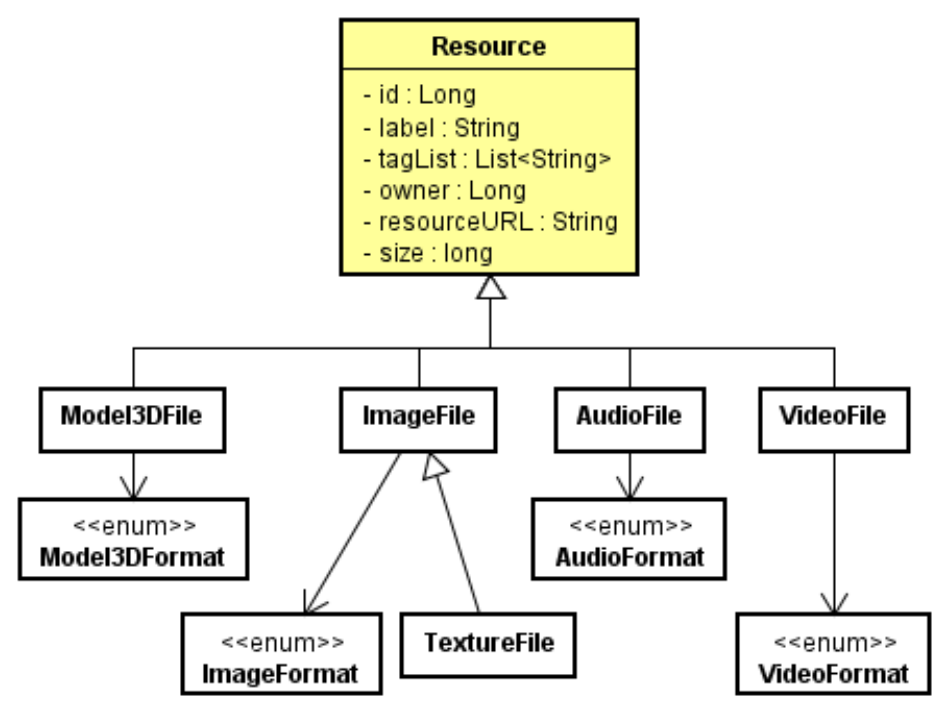

Fonte: Autor (2014)

Foram definidas cinco especializações do conceito Resouce, visando representar os conceitos específicos de cada tipo de recurso, são eles: 1) Model3DFile para representar modelos 3D de objetos virtuais; 2) ImageFile para representar referência a arquivos cujo conteúdo são imagens; 3) TextureFile para representar imagens usadas como texturas; 4) AudioFile para representar arquivos de áudio a serem reproduzidos em cenas que compõem os mundos virtuais; e 5) VideoFile para representar referências a arquivos de vídeos que podem ser reproduzidos nas cenas dos mundos virtuais. 


\subsubsection{Conceitos Appearance e Light}

O conceito Appearance, ilustrado na Figura 39, representa informações que são usadas para definir características de aparência de objetos virtuais representados pelo conceito SingleVirtualObject ou Model3D. O conceito Appearance pode ser composto pelos conceitos Material e Texture que ampliam as definições de aparência, por meio da aplicação de texturas e a definição de características do material aplicado ao objeto virtual relacionado.

Figura 39: Conceito Appearance do RM-VRServices

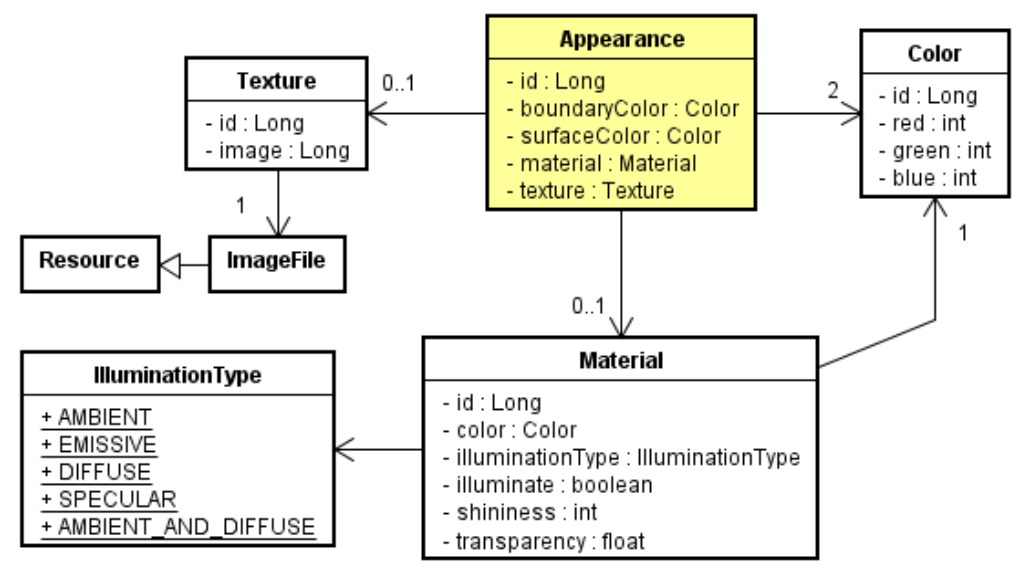

Fonte: Autor (2014)

O conceito Light, ilustrado na Figura 40 é usado para definir as características de iluminação de cenas que compõem os mundos virtuais.

Figura 40: Conceito Light do RM-VRServices

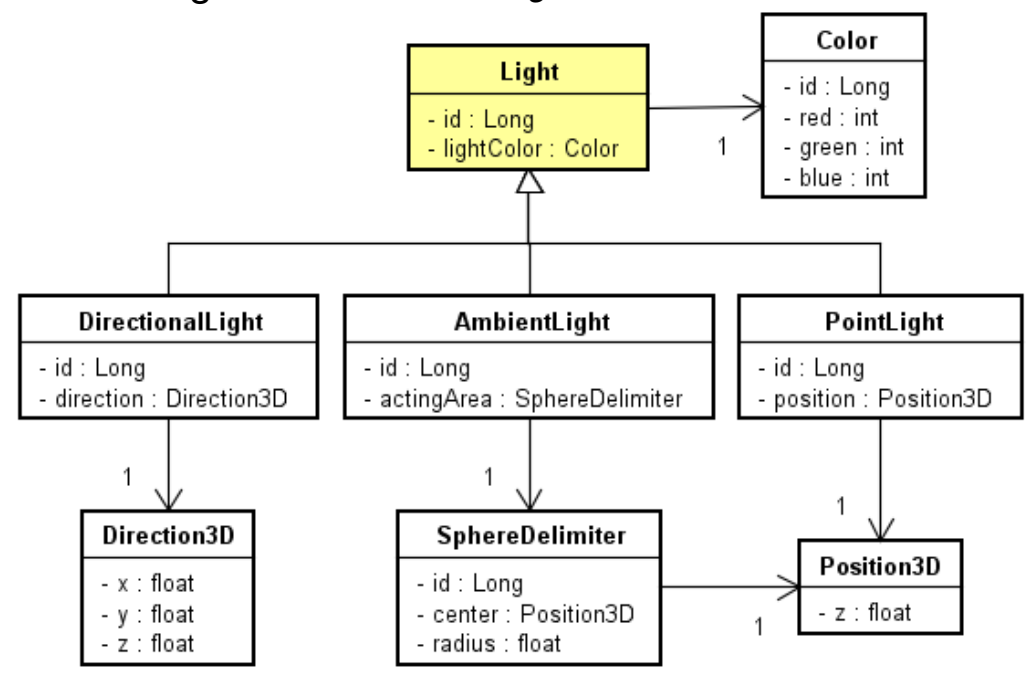

Fonte: Autor (2014)

Foram definidas três especializações para o conceito Light: DirectionalLight, AmbientLight e PointLight, que estabelecem respectivamente a representação de 
iluminação direcionada, iluminação ambiente e pontos de iluminação para as cenas dos mundos virtuais.

\subsection{Reuso de Elementos do RM-VRServices}

O modelo de representação de RM-VRServices foi concebido para suprir os objetivos da capacidade de representação de aplicações RV em ambiente on-line e a capacidade de reuso de elementos previamente armazenados em repositórios na produção de novas aplicações.

Considerando os quatro conceitos centrais do RM-VRServices, VirtualObject, Scene, VirtualWorld e Application, e mais o conceito Resource, foi produzida a Figura 41 com o objetivo de ilustrar possibilidades de reuso de instâncias de elementos armazenados em seus respectivos repositórios. Na figura é possível observar a representação simbólica de quatro aplicações $\mathrm{RV}$ produzidas pela combinação dos demais elementos presentes nos repositórios da plataforma.

Figura 41: llustração de reuso de elementos do RM-VRServices

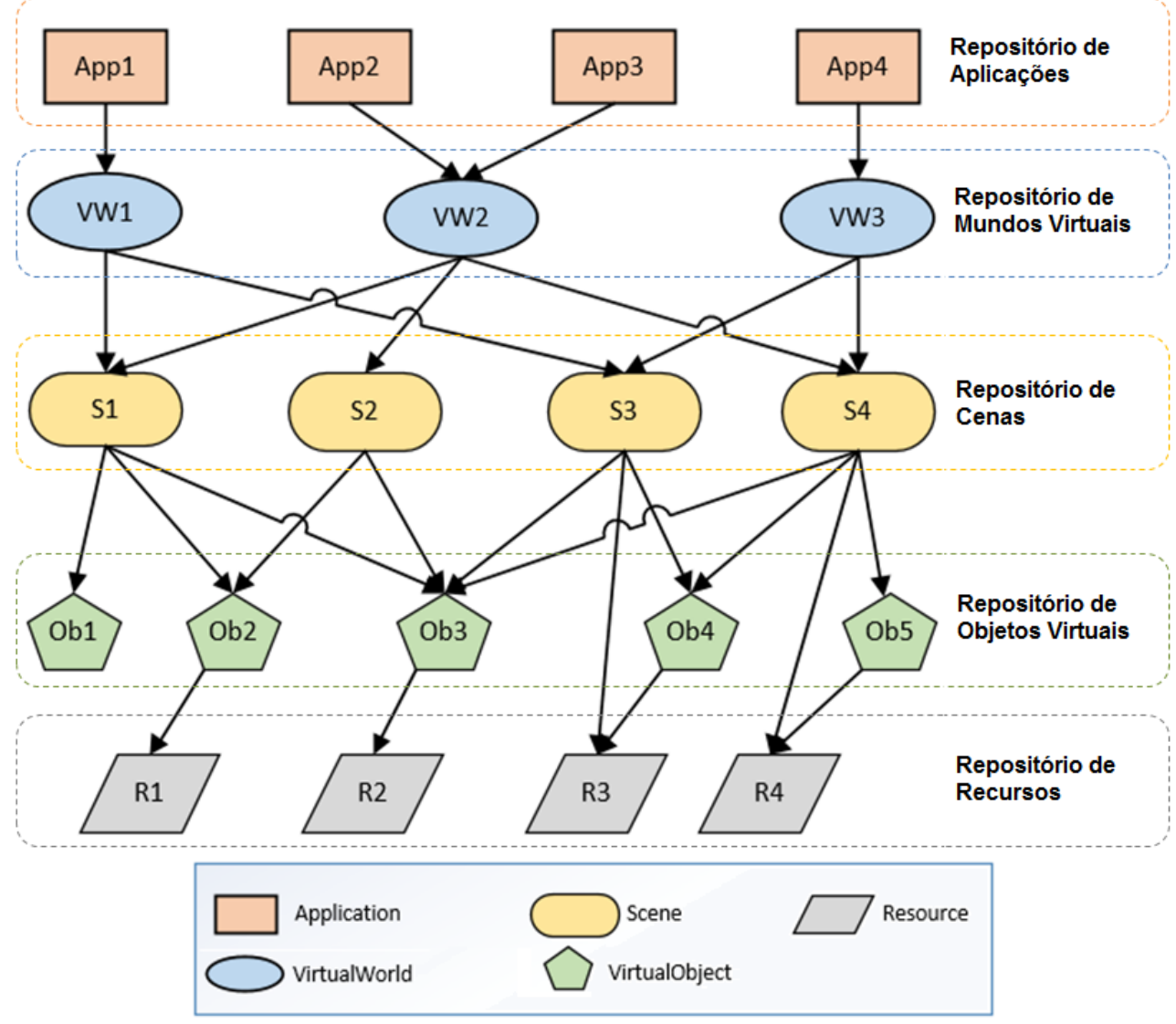

Fonte: Autor (2014)

No RM-VRServices o reuso pode ocorrer em quatro níveis: 1) um elemento 
Resource criado e armazenado pode ser reusado para definir as características de objetos virtuais ou cenas, como por exemplo, um objeto virtual definido por um modelo 3D em um arquivo, uma imagem usada como textura em um objeto virtual ou como fundo de uma cena; 2) o elemento VirtualObject pode ser referenciado por diversas cenas; 3) o elemento Scene pode ser referenciado por diferentes mundos virtuais; e 4) o elemento VirtualWorld pode ser usado para compor diferentes aplicações.

\subsection{Processo de Produção de Aplicações}

O desenvolvimento de aplicações de RV, na plataforma proposta, é realizado por meio do instanciamento de objetos que compõem o modelo de representação de aplicações. Nessa seção é apresentado um conjunto de ações possíveis para a produção de uma aplicação RV, considerando que as aplicações podem ser produzidas por novos elementos ou pelo reuso de elementos existentes.

A Figura 42 ilustra o processo de produção de aplicações por meio de um diagrama de atividades da UML. O processo de produção de aplicação inicia pelo reconhecimento dos requisitos da aplicação que devem ser satisfeitos. A partir dos requisitos, a primeira ação é buscar um mundo virtual existente no repositório da plataforma que satisfaça os requisitos totalmente ou parcialmente. Caso seja localizado um mundo virtual que satisfaça plenamente os requisitos da aplicação os próximos passos são: definir comportamentos da aplicação, definir parâmetros de execução e persistir a aplicação no repositório. Caso seja localizado um mundo virtual que satisfaça parcialmente os requisitos da aplicação, o fluxo segue um caminho que permitirá a edição das cenas e objetos virtuais que compõem o mundo virtual. Caso não seja localizado um mundo virtual que satisfaça os requisitos da aplicação, o fluxo segue um caminho que permite que seja criado um novo mundo virtual. A mesma sequência lógica é usada para os fluxos que permitem a edição ou criação de cenas e objetos virtuais.

O processo de produção estabelece uma sequência de ações para a produção de aplicações considerando o ciclo completo de elementos que compõem uma aplicação RV na plataforma proposta. Contudo, a produção de objetos virtuais, cenas e mundos virtuais pode ser realizada de maneira independente. Dessa forma é possível a especialização da tarefa de produção, como por exemplo, um produtor especializado em produzir objetos virtuais, outro especializado em produzir cenas a partir dos objetos virtuais e outro especializado em produzir mundos virtuais a partir das cenas existentes no repositório. 
Figura 42: Processo de produção de aplicações com RM-VRServices

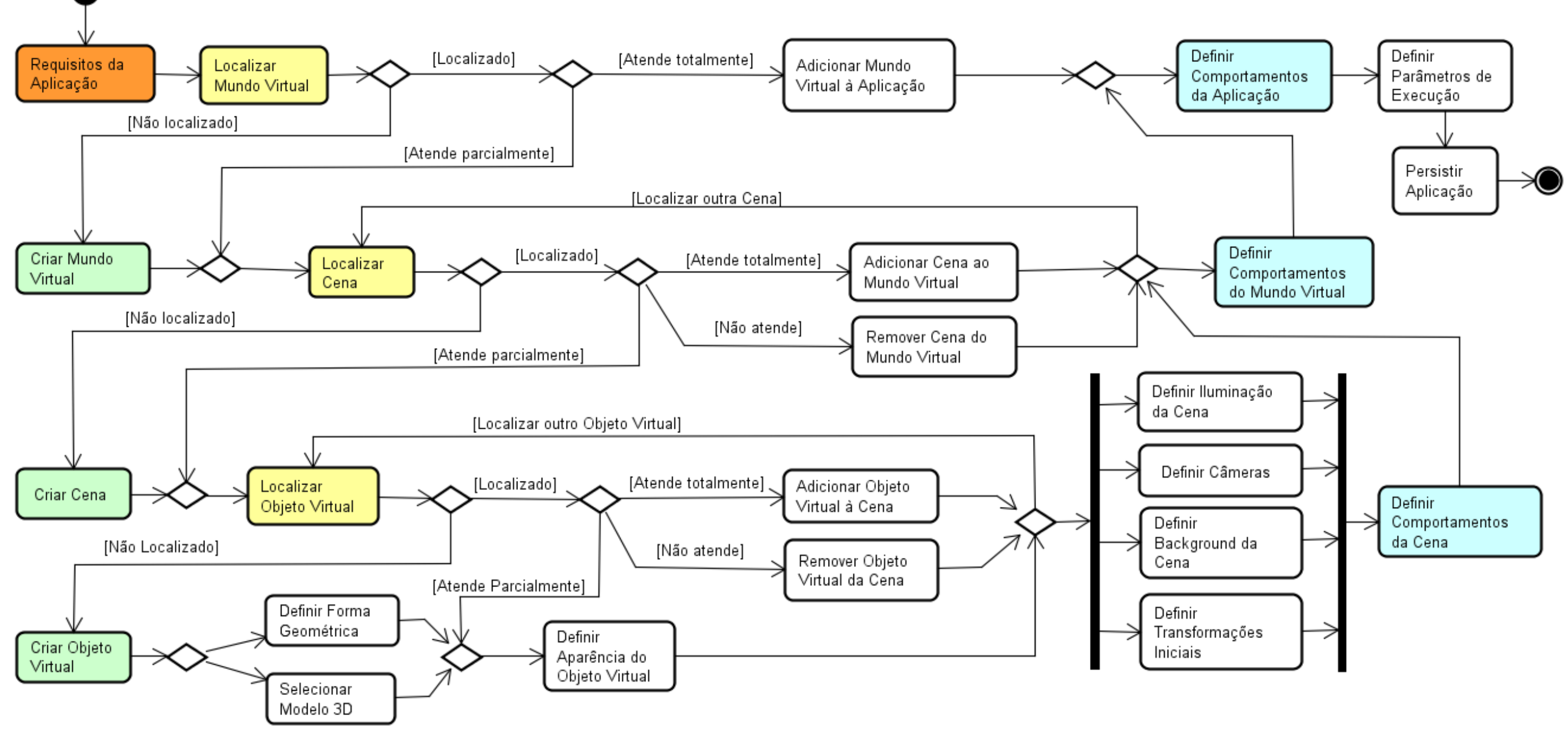

Fonte: Adaptado de (FREIBERGER; NAKAMURA; TORI, 2014b) 


\subsection{Considerações Finais do Capítulo}

O capítulo apresentou o modelo de representação de aplicações RV proposto, seus objetivos e as descrições de seus principais elementos. A proposta atual do RM-VRServices não possui o objetivo de esgotar todos os conceitos envolvidos no desenvolvimento de aplicações RV, mas sim, apresentar um conjunto de conceitos que permitam os experimentos de produção e execução de aplicações em um ambiente on-line, acessível por meio de serviços.

O próximo capítulo apresenta a arquitetura da plataforma VRServices, cujo objetivo é apoiar a produção e execução de aplicações RV por meio da representação com o RM-VRServices. Os resultados das provas de conceito, realizadas com protótipos parciais da plataforma e do modelo de representação, são apresentados no Capítulo 7. 


\section{MODELO ARQUITETURAL DA PLATAFORMA}

O modelo RM-VRServices, conforme apresentado no Capítulo 5, tem como objetivos: 1) permitir a especificação de aplicações RV por meio de instâncias de conceitos de mundos virtuais, 2) permitir o reuso de partes de representação na produção de novas aplicações e 3) viabilizar a edição, compartilhamento e execução das especificações de aplicações RV em um ambiente on-line. Para isso, é necessária uma plataforma de software que apoie essas funcionalidades, por meio de um canal de comunicação interoperável, sem restrições tecnológicas.

Os dois primeiros objetivos são alcançados por meio do uso do modelo RM-VRServices para especificar partes de aplicações RV, que combinadas, constituem as aplicações completas. O terceiro objetivo é obtido com uma plataforma de software orientada a serviços (PAPAZOGLOU et al., 2007), (PAPAZOGLOU et al., 2008) e (ERL, 2009), que permite expor as funcionalidades da plataforma por meio de serviços remotos. A associação de serviços com as instâncias de conceitos do modelo RM-VRServices, produz um barramento de serviços capaz de proporcionar a produção, compartilhamento e execução de aplicações RV em um ambiente on-line.

Os serviços da plataforma VRServices foram divididos em dois grupos, um grupo de serviços relacionados às atividades de produção de aplicações RV e outro grupo relacionado às atividades de execução das aplicações RV.

A Figura 43-a ilustra a plataforma VRServices (lado servidor) constituída pelos serviços que expõem as funcionalidades de produção de aplicações. Também ilustra os potenciais clientes dos serviços de produção da plataforma, que podem ser aplicações destinadas aos usuários produtores de aplicações. Os clientes de produção da plataforma podem oferecer diferentes interfaces aos usuários produtores de aplicação, com diferentes formas de abstração e representação dos elementos que são criados, editados e salvos nos repositórios da plataforma. As tecnologias de desenvolvimento orientado a serviços também oferecem a interoperabilidade de plataforma computacional e linguagens de implementação (PAPAZOGLOU; HEUVEL, 2007). O fluxo de dados que ocorre entre os clientes de produção e a plataforma VRServices é constituído por instâncias de elementos do modelo RM-VRServices, 
nos dois sentidos da comunicação.

Figura 43: Visão lógica dos clientes da plataforma

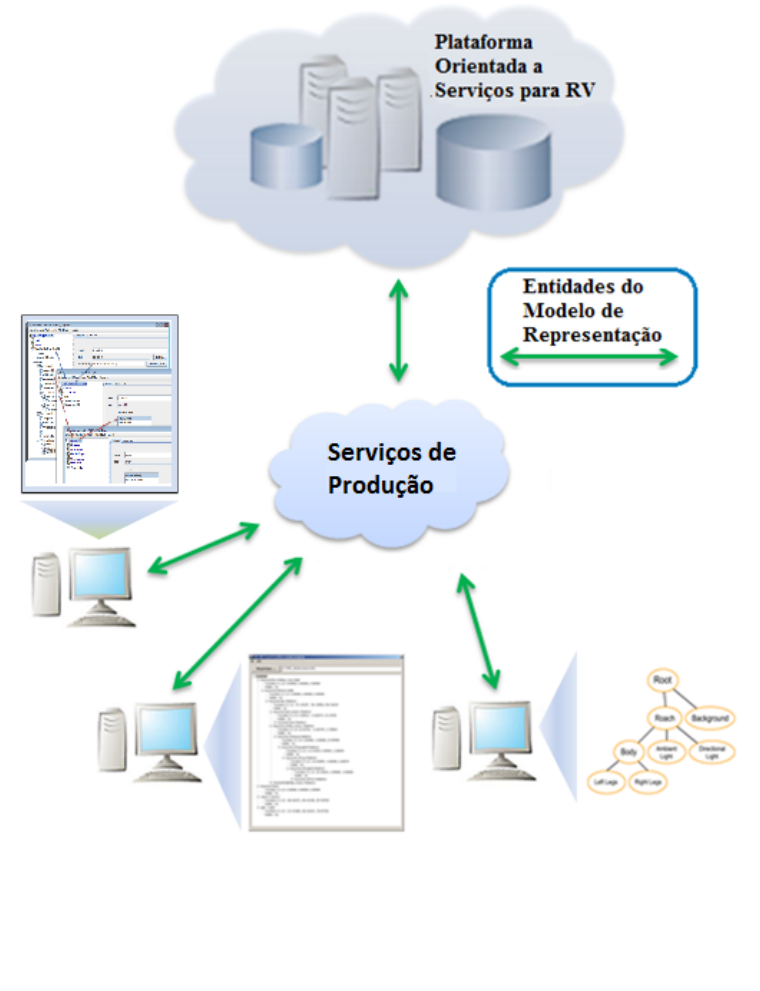

a) Visão de Produção na VRServices

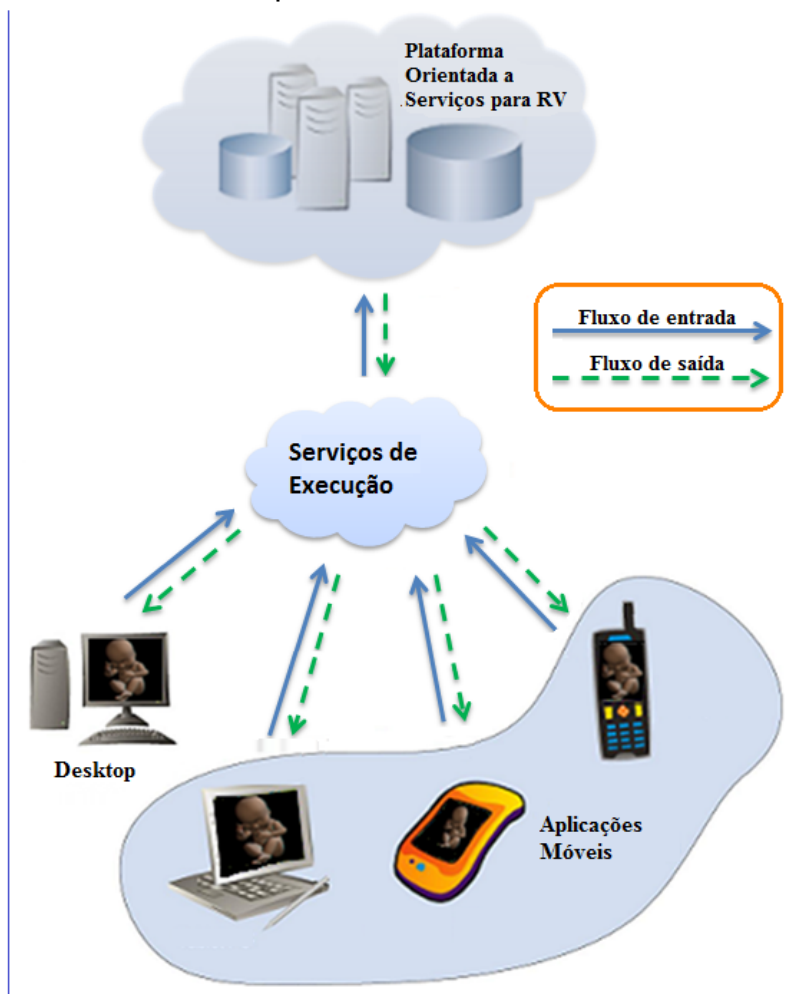

b) Visão de Execução na VRServices

Fonte: Autor (2014)

A Figura 43-b ilustra a plataforma (lado servidor) e os serviços que expõem as funcionalidades relacionadas à execução das aplicações. Apresenta também os possíveis clientes dos serviços de execução, que são as aplicações consumidoras destes serviços, destinadas aos usuários finais da plataforma. Cada cliente de execução pode ser executado em diferentes plataformas computacionais, implementado com diferentes linguagens de programação e oferecer diferentes formas de interação. O fluxo de dados que ocorre entre os clientes de execução e a plataforma VRServices pode ter duas naturezas: 1) no sentido cliente de execução para a plataforma, o fluxo será de dados que representam as entradas de dados, enviados por meio de mensagens de serviços à plataforma, e 2) no sentido plataforma para o cliente de execução, o fluxo será de dados que representam a saída de informações provenientes da execução da aplicação na plataforma, enviados por meio de streams de dados ao cliente de execução. 


\subsection{Descrição Funcional da Plataforma VRServices}

Nessa seção é apresentada a descrição funcional da plataforma VRServices. Para isso, serão usados diagramas de casos de uso que ilustram as funções da plataforma. O diagrama de caso de uso ilustrado na Figura 44 apresenta a visão de contexto da plataforma, destacando quatro funções: Produzir Aplicações RV, Executar Aplicações RV, Gerenciar Recursos e Gerenciar Usuários e Direitos de Acesso.

Figura 44: Diagrama de contexto da plataforma VRServices

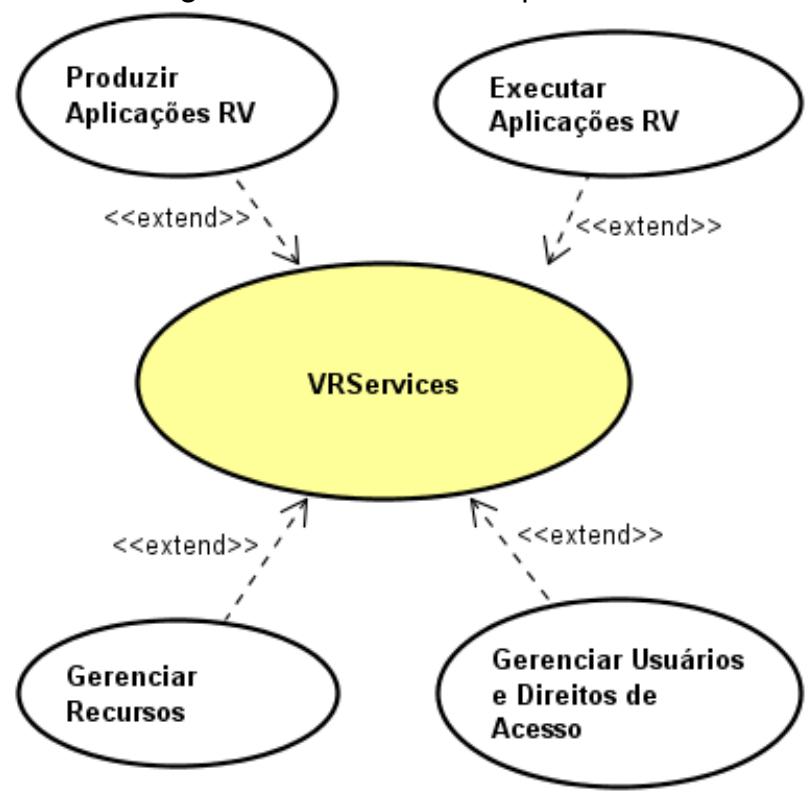

Fonte: Autor (2014)

A função Produzir Aplicações $R V$ reúne as subfuncionalidades que permitem a produção, armazenamento e recuperação de aplicações de RV, constituídas por instâncias do modelo RM-VRServices.

A função Executar Aplicações $R V$ reúne as subfuncionalidades que permitem a execução de aplicações de RV, produzidas e armazenadas nos repositórios da plataforma VRServices. Essa função deve gerenciar as entradas de dados, fluxos de saída, recursos usados na execução e os eventos que ocorrem durante a execução.

A função Gerenciar Usuários e Direitos de Acesso são as funcionalidades relacionadas com a manutenção de dados de usuários, perfis de usuários e credenciais, que estabelecem as funcionalidades que cada usuário tem autorização para realizar na plataforma.

A função Gerenciar Recursos reúne funcionalidades relacionadas com a manutenção de recursos. Os recursos são usados na produção e execução das aplicações produzidas na plataforma, tais como: imagens, sons, texturas, modelos 
de objetos 3D.

Figura 45: Diagrama de contexto da plataforma VRServices

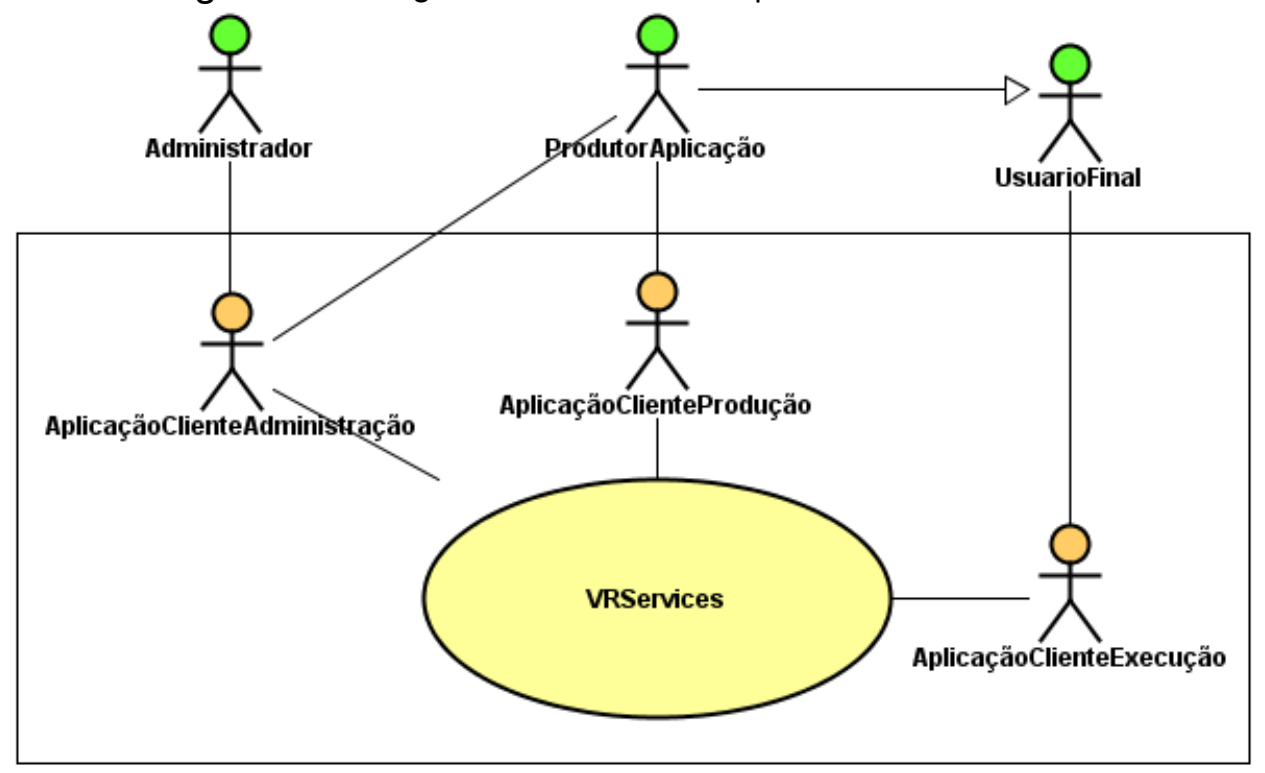

Fonte: Autor (2014)

O diagrama de caso de uso ilustrado na Figura 45, destaca os atores que interagem com a plataforma. Em função de a plataforma ser caracterizada como um barramento de serviços, seus atores diretos não são os usuários finais, que produzem ou executam aplicações RV, e sim, aplicações que consomem seus serviços. São três atores diretos da plataforma VRServices:

- AplicaçãoClienteProdução - representa as aplicações que consomem os serviços de produção da plataforma e oferecem interfaces de alto nível para usuários produtores de aplicações. Aplicações clientes de produção podem ser desenvolvidas de maneira independente do restante da plataforma, em qualquer linguagem de programação e plataforma de operação.

- AplicaçãoClienteExecucão - representa as aplicações que consomem os serviços de execução da plataforma, por meio de interfaces de alto nível para usuários finais;

- AplicaçãoClienteAdministração - representa as aplicações que consomem serviços de administração da plataforma, tais como: manutenção de perfis de usuários, manutenção de usuários, credenciais e recursos.

A partir das aplicações clientes, existe um segundo grupo de atores, que interagem com as interfaces das aplicações que consomem os serviços da plataforma. A seguir, são apresentados os atores que têm relação indireta com a plataforma. Esses atores estão fora do escopo funcional da plataforma. São eles: 
- UsuárioFinal - representa os usuários que interagem com as aplicações cliente de execução, cujo interesse é executar as aplicações disponíveis no repositório da plataforma;

- ProdutorAplicação - é uma especialização do ator UsuárioFinal e representa uma categoria de usuários finais que interagem com as aplicações clientes de produção. Seu papel é usar as aplicações clientes de produção para produção e armazenamento de elementos de aplicações RV, representados por conceitos do RM-VRServices. $O$ ator ProdutorAplicação também pode interagir com as aplicações cliente de administração da plataforma, principalmente para inserir e editar recursos da plataforma;

- Administrador - são os usuários das aplicações cliente que executam tarefas de manutenção de usuários e perfis de usuários, configurações da plataforma e manutenção de repositórios de recursos.

Considerando o contexto de atores estabelecido, o público alvo principal da plataforma são os desenvolvedores de programas de computadores que estão interessados em consumir os serviços de produção e execução da plataforma VRServices, quer seja, consumo pontual de algum serviço, ou no desenvolvimento de aplicações clientes de administração, clientes de produção ou clientes de execução.

A partir da definição do escopo funcional e das quatro funções apresentadas nessa seção, foram produzidos diagramas de casos de uso que representam a decomposição funcional, refinando os casos de uso em funções de menor granularidade.

\subsection{Arquitetura Lógica da Plataforma}

A arquitetura lógica da plataforma tem origem na decomposição funcional realizada. Cada função especificada no diagrama da Figura 44 resultou em um subsistema na arquitetura lógica. A Tabela 6 apresenta o mapeamento entre as funções e os subsistemas projetados.

Tabela 6: Mapeamento das funções em subsistemas

\begin{tabular}{|l|l|}
\hline \multicolumn{1}{|c|}{ Especificação Funcional } & \multicolumn{1}{c|}{ Arquitetura Lógica } \\
\hline Produzir Aplicações RV & Subsistema de Produção \\
\hline Gerenciar Recursos & Subsistema de Recursos \\
\hline Gerenciar Usuários e Direitos de Acesso & Subsistema de Controle de Acesso \\
\hline Executar Aplicações RV & Subsistema de Execução \\
\hline
\end{tabular}

Fonte: Autor (2014) 
A Figura 46 ilustra os quatro subsistemas projetados para a plataforma e suas relações de dependências.

Figura 46: Arquitetura lógica da plataforma VRServices

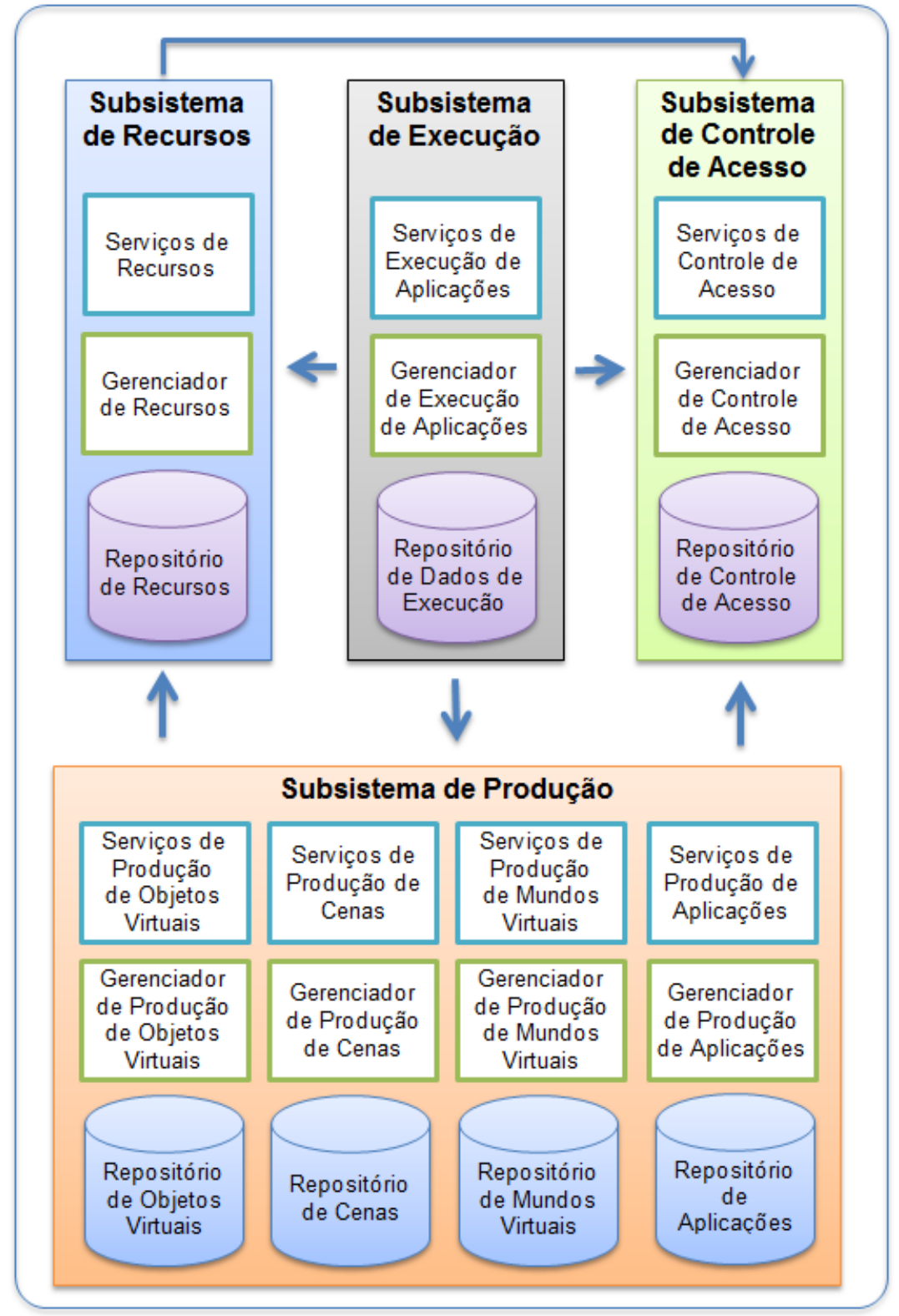

Fonte: Autor (2014)

Cada subsistema expõe suas funcionalidades por meio de serviços, que podem ser consumidos pelos próprios subsistemas da plataforma ou pelas aplicações clientes. Cada subsistema é divido em três elementos lógicos: serviços, componente de domínio e repositório. O elemento serviço expõe as funcionalidades do subsistema, o componente de domínio implementa as funcionalidades do subsistema e o repositório armazena as informações relacionadas ao subsistema.

A próxima seção apresenta a arquitetura base para o componente de domínio, 
adotada como padrão arquitetural para todos os subsistemas da plataforma.

\subsubsection{Arquitetura Lógica dos Subsistemas}

A Figura 47 ilustra a arquitetura padrão definida para o componente de domínio dos subsistemas. O componente de domínio dos subsistemas é dividido em três camadas de abstração (FOWLER, 2006), são elas:

Figura 47: Arquitetura lógica dos subsistemas

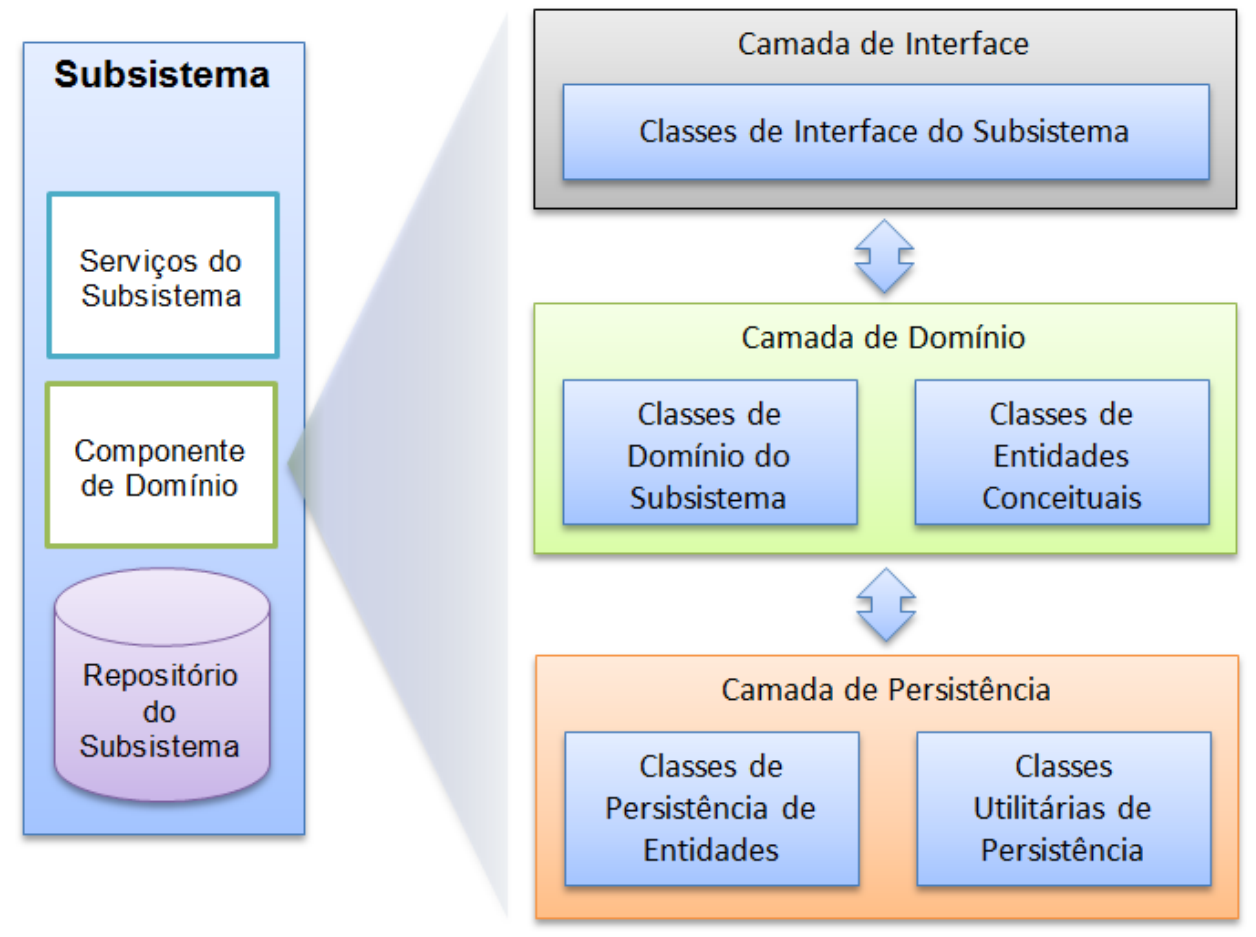

Fonte: Autor (2014), baseado em Fowler (2006)

- Camada de Persistência - é formada por classes que possuem a responsabilidade de executar a persistência e recuperação das entidades do subsistema. Também podem existir classes utilitárias que auxiliam a execução da persistência das entidades. Essa camada é responsável pela execução do Mapeamento Objeto-Relacional (MOR) das entidades definidas na camada de domínio do subsistema, isolando essa ação do restante do subsistema (WAZLAWICK, 2004). A camada de persistência usa o padrão arquitetural de fontes de dados denominado Gateway de Tabela de Dados (FOWLER, 2006).

- Camada de Domínio - é constituída por dois grupos de classes: classes de domínio do subsistema e classes de entidades conceituais. As classes de domínio reúnem as funcionalidades relacionadas ao domínio do subsitema. 
As classes de entidades conceituais representam o modelo de conceitos de domínio do subsistema, usando o paradigma da orientação a objetos. A camada de domínio usa o padrão arquitetural para lógica de domínio denominado Modelo de Domínio (FOWLER, 2006).

- Camada de Interface - representa a interface do subsistema, definida por classes que reúnem as funcionalidades públicas do subsistema. Tem o objetivo de ocultar a complexidade do subsistema e abstrair as responsabilidades das classes que o compõe. Essa camada é implementada usando o padrão arquitetural para lógica de domínio denominado Camada de Serviço (FOWLER, 2006).

A comunicação entre as três camadas projetadas para o componente de domínio é realizada por meio de objetos de transferência de dados, conhecidos como objeto de valor (em Inglês Value Object). As classes da camada de interface do subsistema expõem as assinaturas dos métodos contendo como parâmetros de entrada e saída os objetos de valor, que são transferidos para a camada de domínio e depois para a camada de persistência.

\subsection{Descrição dos Subsistemas de Plataforma VRServices}

Nesta seção são apresentadas as descrições dos principais elementos que compõem os subsistemas de produção e execução da plataforma VRServices.

\subsubsection{Subsistema de Produção}

O subsistema de Produção, ilustrado na Figura 48, reúne as funcionalidades destinadas à criação, alteração, exclusão, busca e reuso de elementos do modelo RM-VRServices. Como foi estabelecido na arquitetura lógica de subsistemas, o subsistema de Produção possui quatro camadas de abstração: persistência, domínio, interface e serviço.

A camada de persistência do subsistema de Produção possui as classes que são responsáveis pela persistência das instâncias do modelo RM-VRServices, concentradas em quatro classes: ApplicationDAO, VirtualWorldDAO, SceneDAO e VirtualObjectDAO. A camada de persistência usa o padrão arquitetural denominado Gateway de Tabela de Dados, que estabelece que uma classe de persistência manipula uma coleção de registros da base de dados (FOWLER, 2006). 
Figura 48: Subsistema de produção

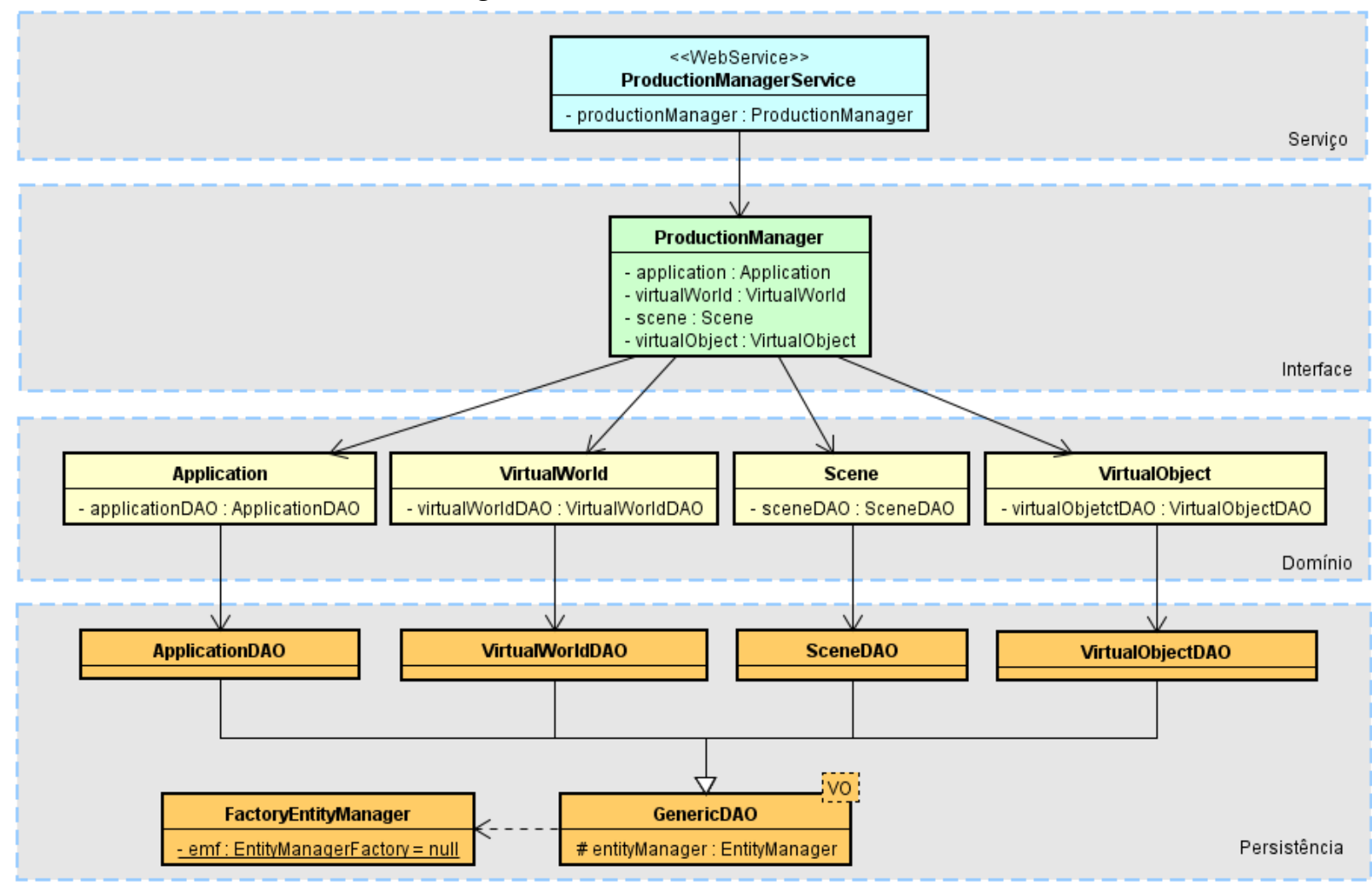

Fonte: Autor (2014)

Para exemplificar a camada de persistência, será apresentada a classe SceneDAO que tem a responsabilidade de persistir e recuperar instância do conceito Scene do modelo RM-VRServices. Com o objetivo de diferenciar a instância que representa o conceito Scene das demais classes, é usado o sufixo VO (do Inglês Value Object) para denotar que é um objeto de valor usado na comunicação entre as camadas do subsistema e entre as aplicações clientes e a plataforma VRServices.

Em função do modelo RM-VRService ser representado e implementado com o uso do modelo orientado a objetos, a camada de persistência deve realizar o mapeamento objeto-relacional (WAZLAWICK, 2004), persistindo e recuperando as instâncias de objetos da base de dados relacional. O mapeamento objeto-relacional das instâncias é realizado por meio da Java Persistence API (JPA) (BAUER; KING, 2007). A Figura 49 ilustra um trecho de código da classe SceneVO, que apresenta as definições dos atributos da classe e suas respectivas anotações da JPA que estabelecem as informações necessárias para realizar o mapeamento objeto-relacional. As anotações da API JPA iniciam com o caractere "@".

As operações de inclusão, alteração, exclusão e recuperação das instâncias de SceneVO são realizadas pela classe SceneDAO. A Figura 50 ilustra a classe 
Figura 49: Classe SceneVO representa o conceito Scene do RM-VRServices

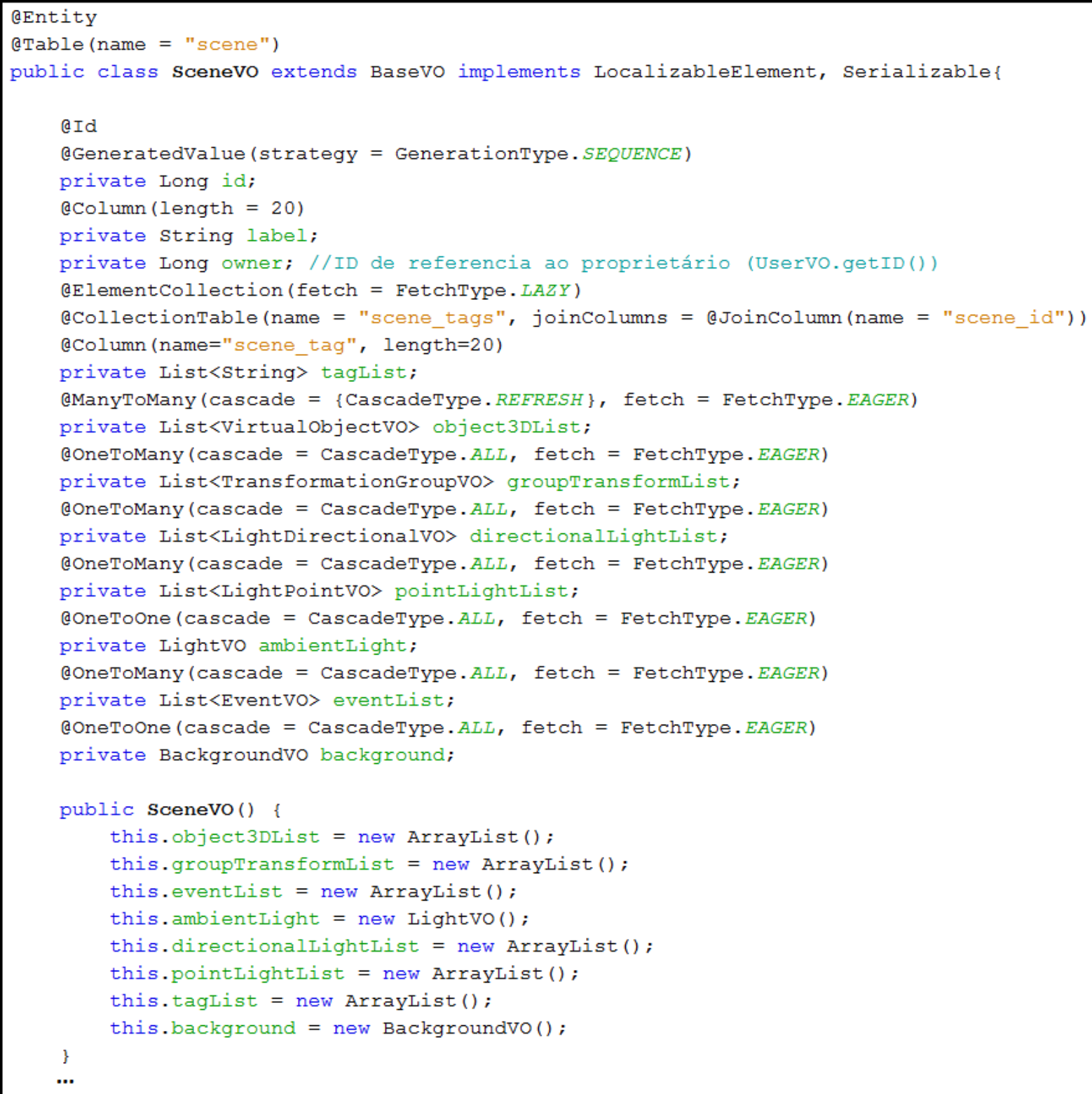

Fonte: Autor (2014)

SceneDAO, sua relação com a superclasse GenericDAO, que serve de base para todas as classes de persistência da plataforma e a classe SceneVO, que representa a implementação do conceito Scene do RM-VRServices. A classe SceneVO é constituída por atributos simples e atributos complexos, definidos a partir de outras classes conceituais do modelo RM-VRServices, tais como: lista de objetos VirtualObject3DVO, lista de TransformationGroupVO, lista de objetos DirectionalLightVO, lista de EventVO, entre outros. O mecanismo de persistência deve armazenar a instância de SceneVO e todas as instâncias agregadas a ela, nas operações de inclusão e alteração, assim como, deve recuperar uma instância de 
SceneVO e todas as instâncias associadas a ela, nas operações de seleção. As outras classes da camada de persistência seguem a mesma estrutura arquitetural.

Figura 50: Classe SceneDAO da camada de persistência

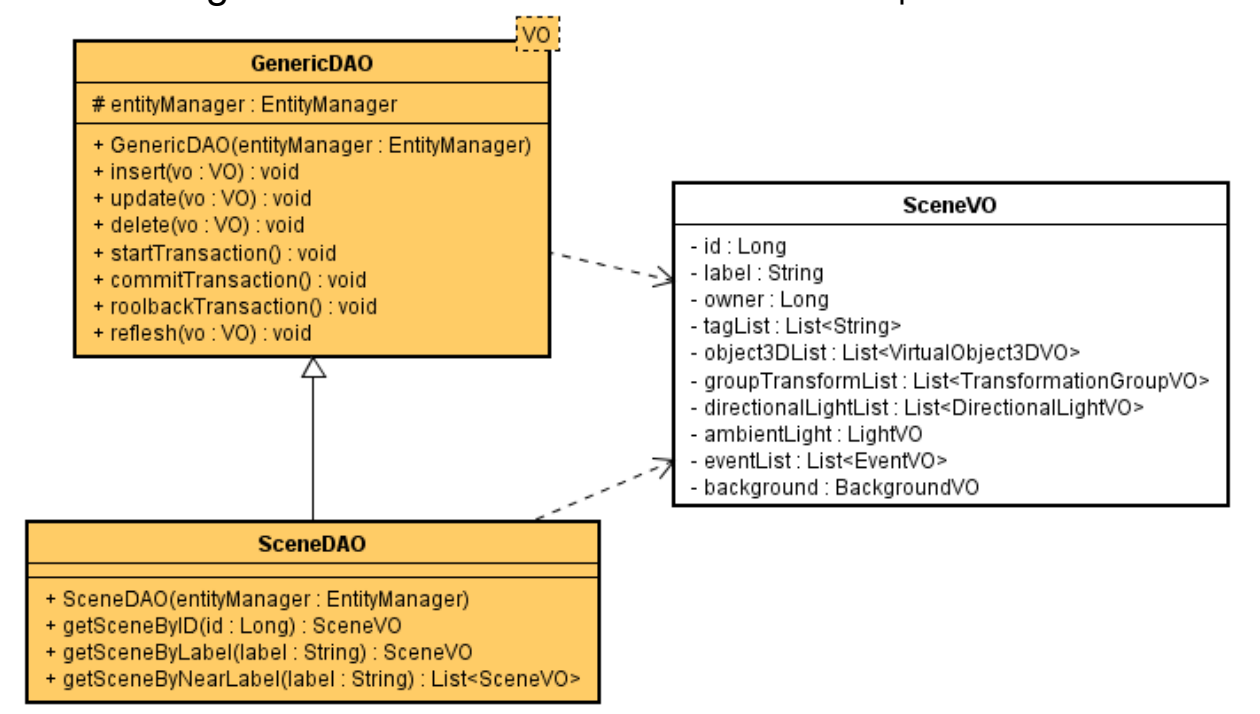

Fonte: Autor (2014)

A camada de domínio é formada pelas classes responsáveis pelas operações relacionadas à produção de aplicações $\mathrm{RV}$, distribuídas em quatro classes: Application, VirtualWorld, Scene e VirtualObject. Para exemplificar a camada de domínio será apresentada a classe Scene, responsável especificamente pelas operações de domínio do conceito Scene. A Figura 51 ilustra a classe de domínio Scene e a relação com as classes SceneVO e SceneDAO. As demais classes da camada de domínio seguem a mesma estrutura arquitetural.

Figura 51: Classe Scene da camada de domínio

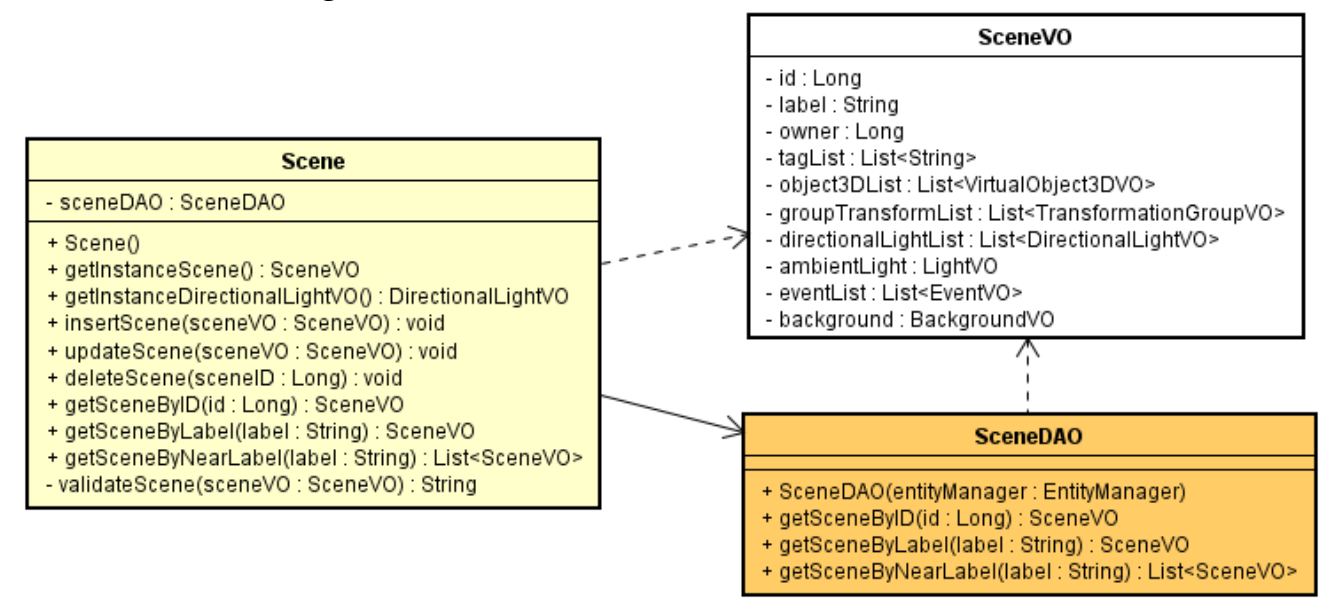

Fonte: Autor (2014)

A camada de interface do subsistema de produção tem o objetivo de encapsular a complexidade do subsistema e isolar as classes de domínio do restante 
da plataforma. A classe ProductionManager mantém instâncias das classes de domínio e delega as operações para essas instâncias. A comunicação entre a camada de serviço, camada de interface e camada de domínio é realizada por meio de parâmetros do tipo objeto de valor, que representam as instâncias dos conceitos do modelo RM-VRServices.

A classe ProductionManager, ilustrada na Figura 52, é a única classe da camada de interface do subsistema de produção, concentrando todas as operações relacionadas com a produção de aplicações. A classe ProductionManager foi projetada com base no padrão de projeto Facade (GAMMA et al., 2007), que tem o objetivo de fazer o papel de fachada ou controlador, permitindo que sejam inseridas tarefas de controle em um nível que antecede as classes de domínio. O projeto da classe ProductionManager também facilita a implementação de serviços, pois simplifica as chamadas das operações no código fonte que implementa os serviços.

Figura 52: Classe ProductionManager da camada de interface

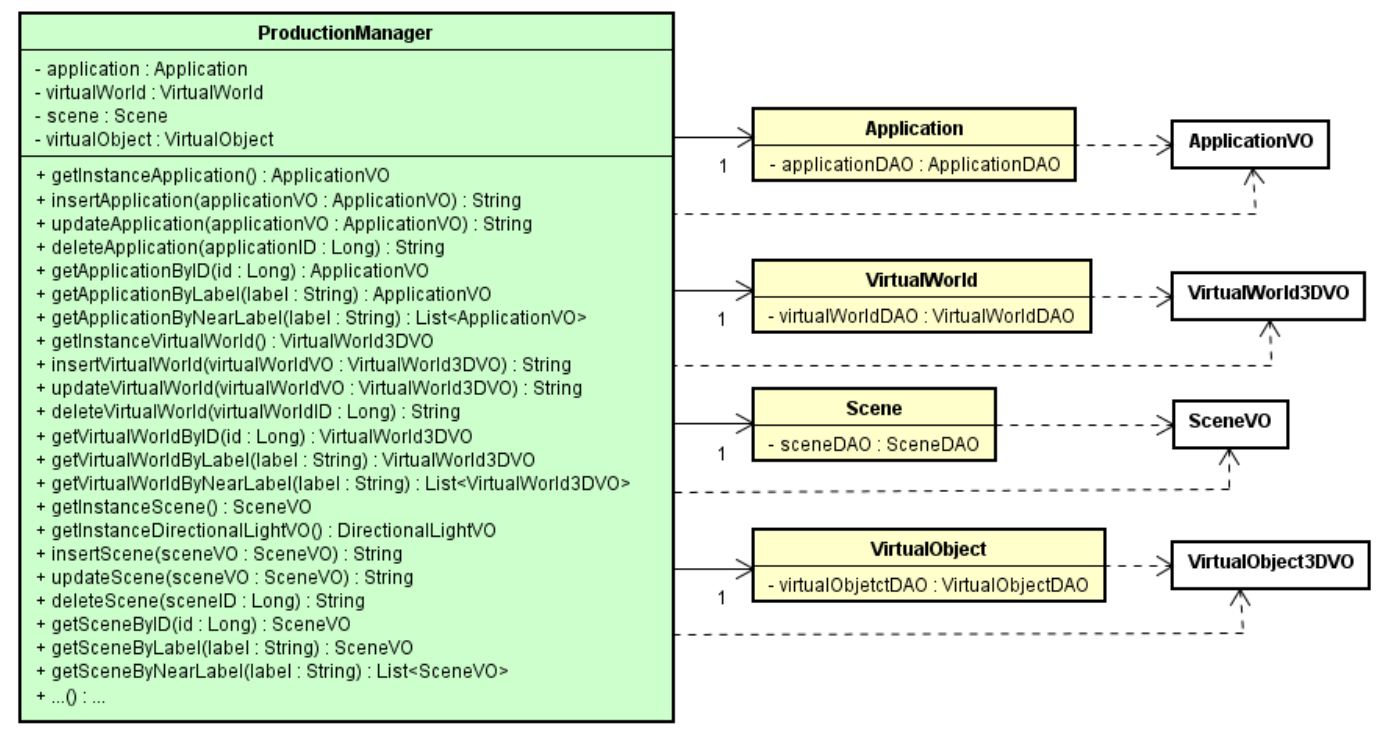

Fonte: Autor (2014)

Outro padrão de projeto incorporado à classe ProductionManager é o padrão Creator (LARMAN, 2007), para incorporar a responsabilidade de instanciamento de objetos. Exemplos disso são os métodos getInstanceApplication, getInstanceVirtualWorld, getInstanceScene e getInstanceVirtualObject. A necessidade da implementação de tais métodos se deve ao fato de que as instâncias geradas por esses métodos são complexas e exigem a inicialização de uma grande quantidade de informações que são agregadas como atributos. A implementação dos métodos para a criação de instâncias desonera os usuários dessas classes do conhecimento necessário para sua inicialização, principalmente o desenvolvedor 
remoto que irá consumir os serviços da plataforma.

A camada de serviço do subsistema de produção é constituída pela classe ProductionManagerService, ilustrada na Figura 53, é implementada com a tecnologia de Web Services. Seu principal papel é expor as funcionalidades do subsistema de produção como serviços, que podem ser consumidos por qualquer cliente remoto que seja capaz de consumir Web Services, independente de plataforma computacional e linguagem de programação (PAPAZOGLOU et al., 2007).

Figura 53: Classe ProductionManagerService da camada de serviços

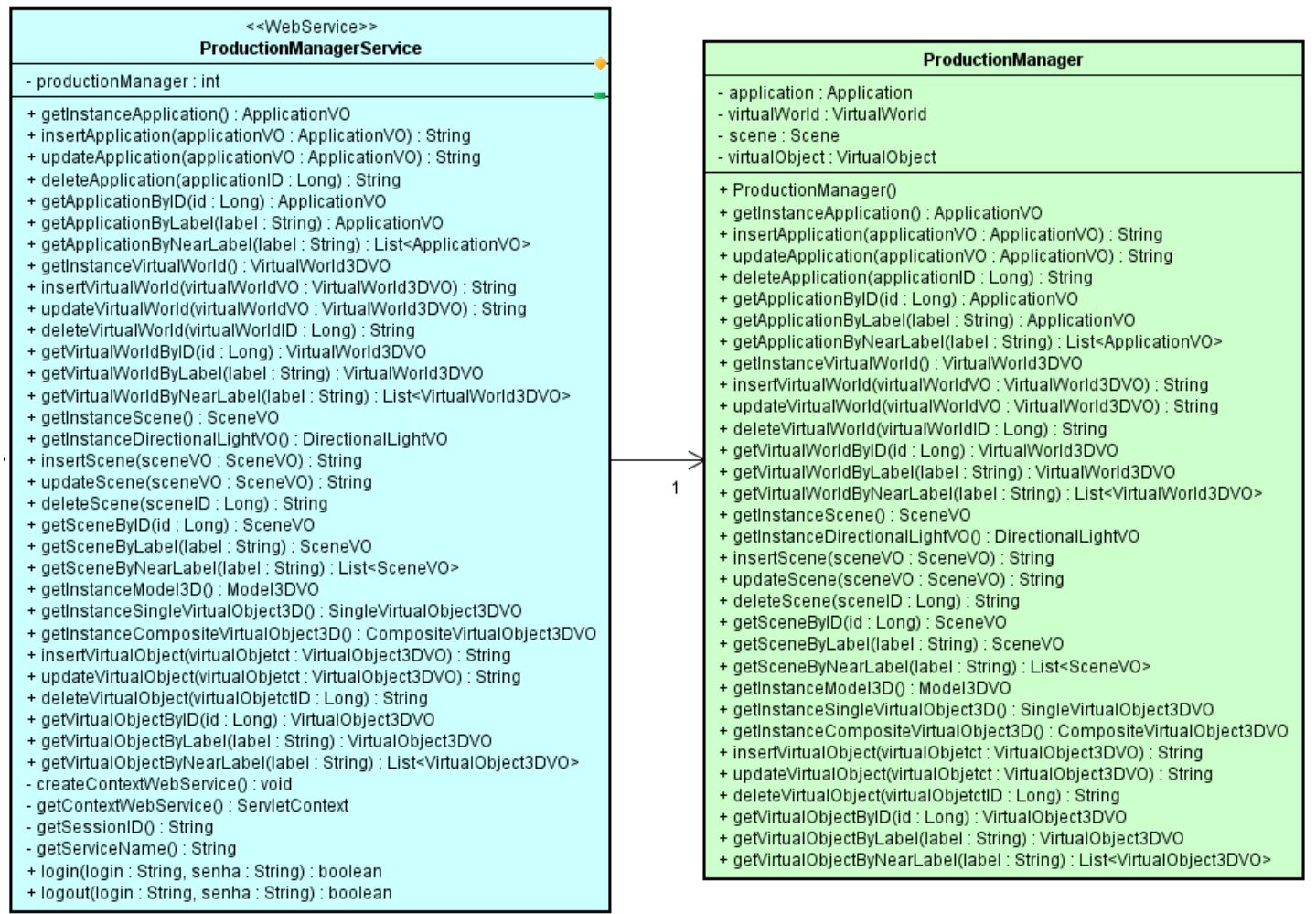

Fonte: Autor (2014)

A classe ProductionManagerService mantém uma instância da classe ProductionManager, a qual delega as operações de produção de aplicações RV. Além disso a classe ProductionManagerService contém operações específicas da camada de serviço, por exemplo: createContextWebService, getSessionID, login e logout que são operações relacionadas a identificação e autorização de usuários consumidores do serviço.

Com o objetivo de apresentar o fluxo completo de mensagens que ocorrem nas chamadas de operações do subsistema de produção, foi produzido um diagrama de sequência. O diagrama, ilustrado na Figura 54, apresenta como exemplo, a sequência de mensagens para a inclusão de um instância da classe SceneVO, que representa o conceito Scene do modelo RM-VRServices. 
A sequência inicia em uma aplicação remota que representa um cliente de produção, invocando a operação login() do Web Service ProductionManagerService, que por sua vez, chama o serviço do subsistema de controle de acesso, por meio da operação login() do Web Service AccessControlServices. A necessidade de login ocorre apenas na primeira vez que uma operação é invocada pela aplicação cliente, as demais chamadas de operações irá verificar a identificação e autorização do usuário pelos dados da seção do Web Service.

Em seguida, a aplicação remota, invoca a operação insertScene() do WebService ProductionManagerService, que verifica a autorização do usuário e caso esteja autorizado irá invocar a operação insertScene() da classe ProductionManager, que irá propagar a mensagem para a classe de domínio Scene, que verifica a integridade dos dados, e caso estejam válidos, irá persistir a nova instância de SceneVO por meio da classe SceneDAO. Esse modelo arquitetural é replicado para todas as operações do serviço ProductionManagerService do subsistema de produção. 
Figura 54: Sequência de mensagens para inclusão de uma instância de SceneVO

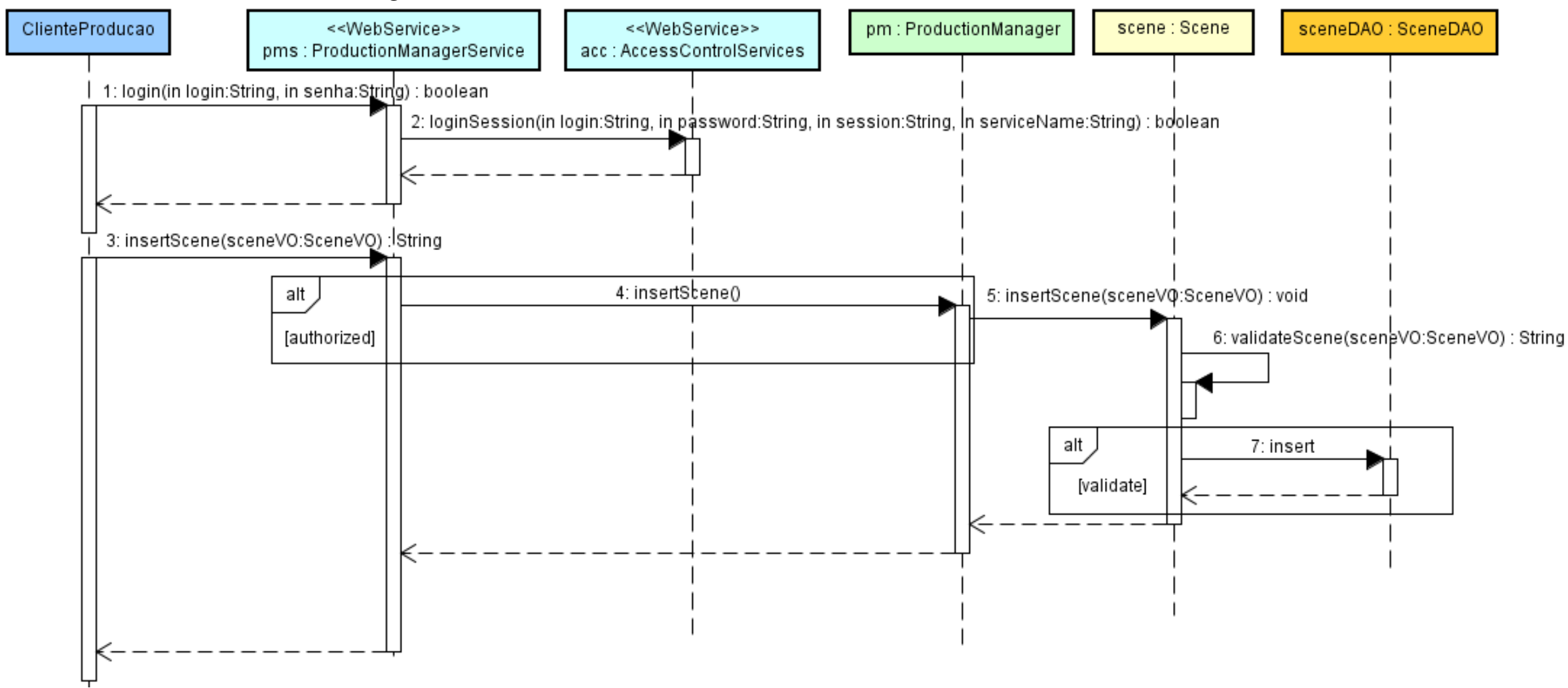

Fonte: Autor (2014) 


\subsubsection{Subsistema de Execução}

Nesta seção é descrito o subsistema de execução da plataforma VRServices. O subsistema de execução é responsável por criar um contexto de execução remoto a partir das aplicações RV produzidas com o modelo RM-VRServices no subsistema de produção.

A arquitetura do subsistema de execução tem como objetivo permitir o controle da execução, a interação e o retorno da execução das aplicações por meio de serviços. Como foi ilustrado na Figura 43-b, existe dois tipos de fluxo de dados entre os clientes de execução e a plataforma VRServices: um é o fluxo de entrada de dados, que representa os dados provenientes das interações dos usuários nas interfaces dos clientes de execução; e o outro fluxo é o de retorno da execução, que pode ser um fluxo de áudio, vídeo ou háptico.

A Figura 55 ilustra o modelo arquitetural e as principais classes do subsistema de execução. Assim como nos demais subsistemas, a arquitetura possui quatro camadas: persistência, domínio, interface e serviço.

A camada de persistência do subsistema de execução tem o objetivo de armazenar e recuperar dados resultantes da execução das aplicações. Foi projetada uma estrutura de dados genérica, capaz de armazenar campos de dados relacionados a uma sessão de execução de uma aplicação. A classe ExecutionDataVO é usada para representar cada instância de dados da execução de uma aplicação. As instâncias de dados da execução de uma aplicação são identificadas por meio de três informações: identificador da aplicação, identificador do usuário que a executou e o identificador da sessão de execução, gerado pelo servidor de aplicação.

A camada de domínio do subsistema de execução é constituída por um conjunto de classes cujo objetivo é gerenciar contextos de execução de aplicações $\mathrm{RV}$ criadas a partir do modelo RM-VRServices. A principal classe dessa camada é a ApplicationContext, que tem a responsabilidade de gerenciar cada instância de execução. Para a plataforma VRServices, uma instância de execução é o resultado da execução de uma aplicação, para um usuário, em uma sessão de execução. As outras classes que constituem a camada de domínio são:

- InputManager - responsável por gerenciar as entradas de dados, que são classificadas segundo as especializações do conceito Virtuallnput do RM-VRServices. Cada aplicação pode ter uma lista de instâncias de entradas virtuais, que são mapeadas para os respectivos eventos relacionados a entrada de dados; 
Figura 55: Subsistema de Execução

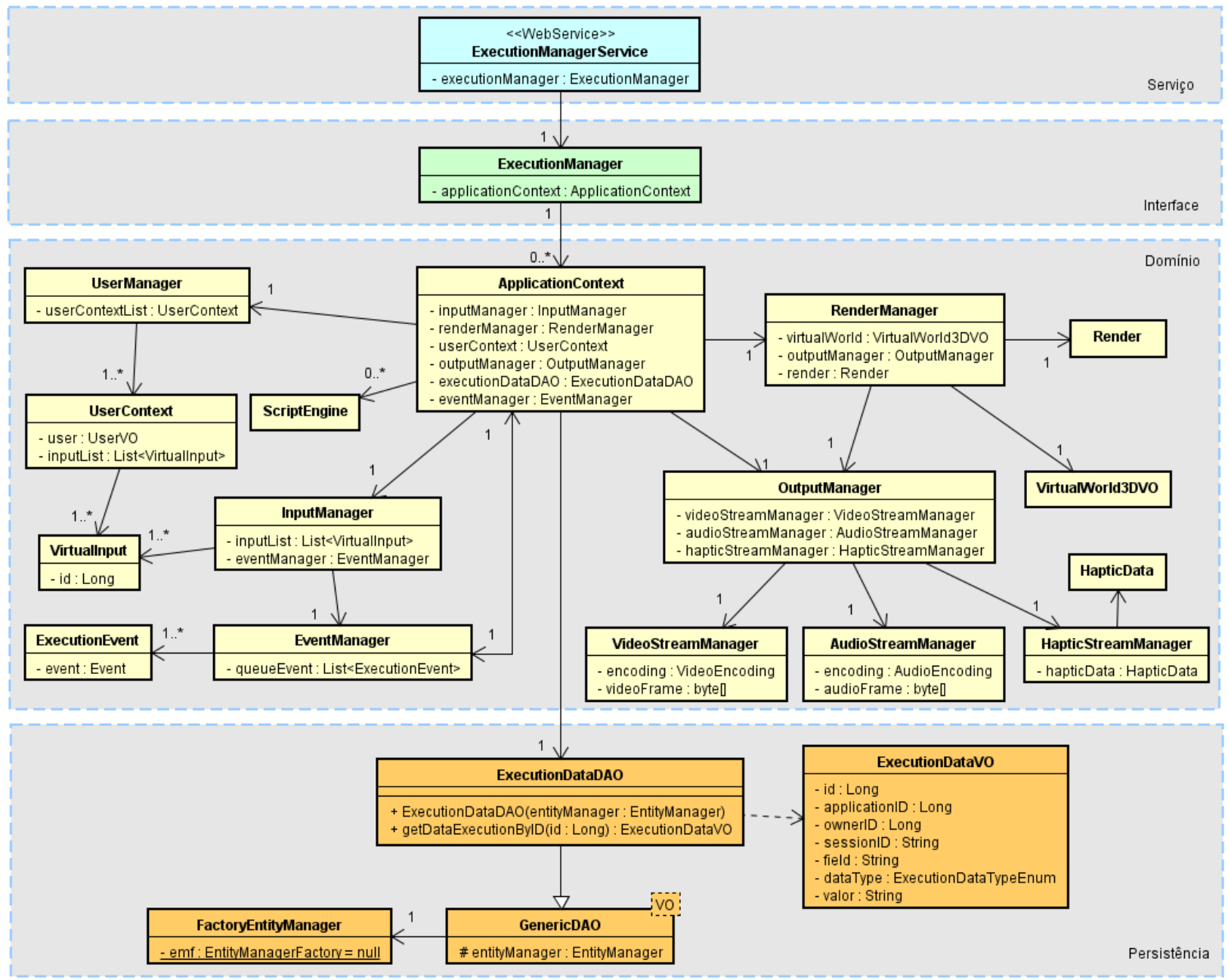

Fonte: Autor (2014)

- EventManager - mantém uma fila de instância de ExecutionEvent, que são os eventos já mapeados para a execução. O mapeamento deve ocorrer pois, em alguns casos, entradas de dados compostas podem gerar um único evento de execução, como é o caso de uma entrada de posição, combinada com um comando, pode produzir um único evento para o processamento na execução. A classe também é responsável pela ordenar e lançar os eventos segundo suas prioridades;

- RenderManager - essa classe é responsável por gerenciar a renderização do mundo virtual associado à aplicação. Para isso ela mantém uma instância do mundo virtual, do gerenciador de saída e do renderizador que irá delegar as ações de renderização;

- Render - encapsula um mecanismo de renderização, ocultando as características particulares de bibliotecas e API de renderização. objetivo é isolar as bibliotecas de renderização do restante da camada de 
domínio, para isso a classe Render implementa o padrão de projeto Facade (GAMMA et al., 2007);

- OutputManager - é responsável pelo gerenciamento das saídas de dados provenientes da execução das aplicações. Os clientes da plataforma, por meio de serviços, se conectam em canais de transmissão de dados (streams) e recebem três tipos de fluxos possíveis: fluxo de vídeo, fluxo de áudio e fluxo de dados de atualização de dispositivos hápticos. A transferência de fluxo de saída é baseada nos trabalhos (ZHANG; GRACANIN, 2008a) e (ZHANG; GRACANIN, 2008b);

- UserManager - gerencia os contextos de usuários por meio de uma lista de instâncias de UserContext;

- UserContext - mantém as informações de cada usuário conectado ao contexto de execução da aplicação. Cada contexto de usuário possui uma lista de instâncias do conceito Virtuallnput, que informa quais entradas cada usuário irá enviar ao contexto de execução. As instâncias de Virtuallnput também dá suporte às aplicações que necessitem da distinção das interações por usuário;

- ScriptEngine - representa a interface para um ou mais interpretadores de scripts que são usados para interpretar código de comportamentos associados a eventos.

A camada de interface do subsistema de execução contém a classe ExecutionManager que concentra todas as operações relacionadas a execução das aplicações, que vão desde a inicialização do contexto da aplicação, entrada de dados, negociação com os canais de saída de dados, até o encerramento da execução da aplicação. Para cada sessão de execução, a classe ExecutionManger gera uma instância da classe ApplicationContext e gerencia seu ciclo de vida.

A camada de serviço do subsistema de execução é formada pela classe ExecutionManagerService, que publica todas as operações da classe ExecutionManager, por meio de delegação das operações. A classe ExecutionManagerService mantém a mesma estrutura arquitetural da classe ProductionManagerService já apresentada.

Para apresentar as principais ações executadas na iniciação do contexto de execução das aplicações na plataforma VRServices, foi produzido o diagrama de sequência ilustrado na Figura 56. As ações são iniciadas com o pedido de carregamento de aplicação a partir de uma aplicação cliente de execução. 
Figura 56: Sequência de mensagens para iniciação do contexto de aplicação

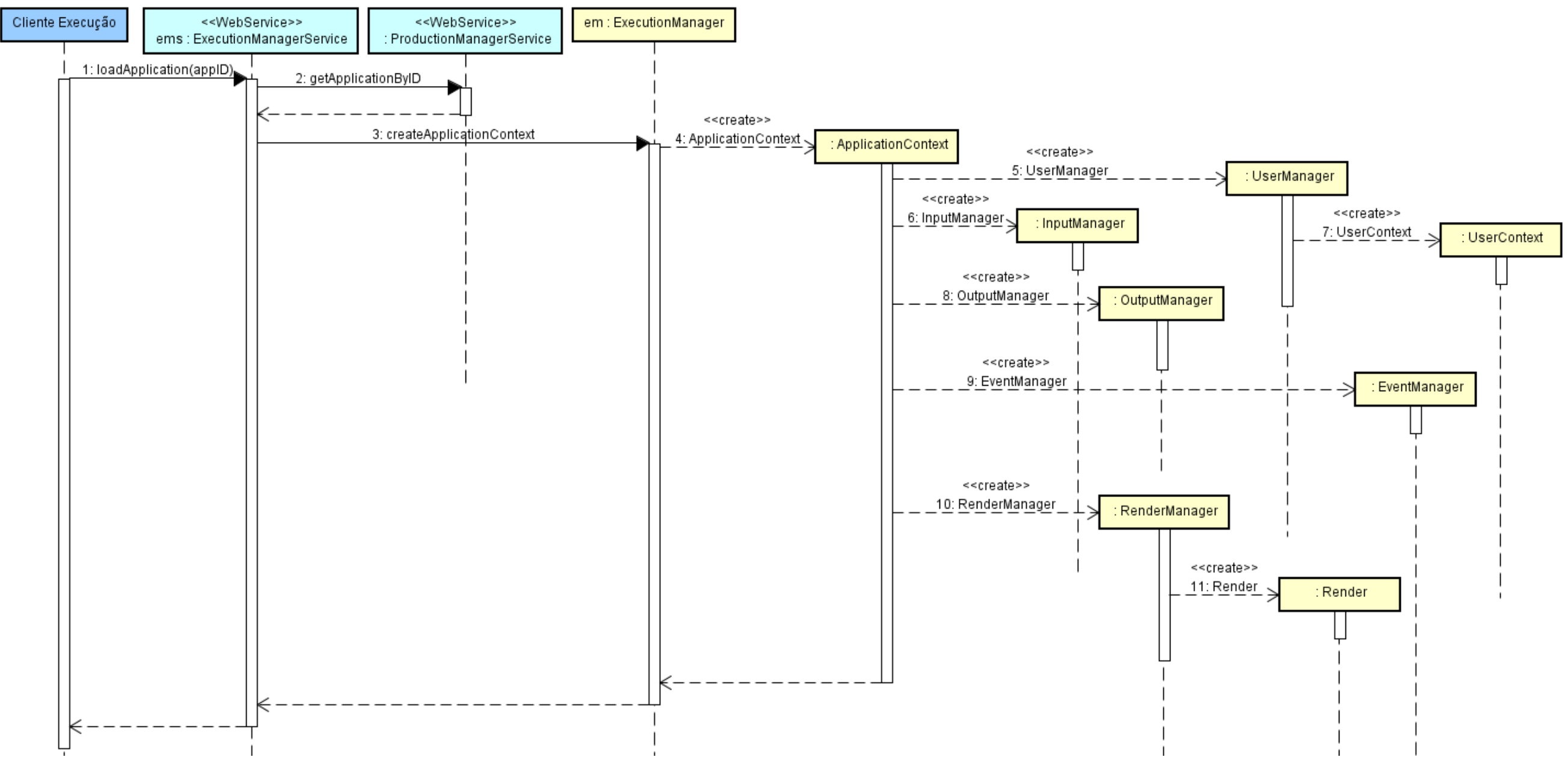

Fonte: Autor (2014) 
O subsistema de execução usa o serviço do subsistema de produção para localizar e recuperar a instância da aplicação desejada, que é enviada para a classe ExecutionManager, responsável por criar uma instância de contexto de execução específico para a aplicação desejada. A partir da instância da classe ApplicationContext, são criadas as instâncias das classes: UserManager, InputManager, OutputManager, EventManager, RenderManager e Render. A identificação do contexto de execução da aplicação é feita por meio do identificador de sessão gerado pelo servidor de aplicação. Esse identificador é usado pelo objeto ExecutionManager para diferenciar as requisições de aplicações clientes.

Como foi apresentado no capítulo 5, o modelo RM-VRServices define a representação das entradas de dados para as aplicações tendo como base as funcionalidades dos dados de entrada, e não os dispositivos físicos de entrada de dados. As quatro categorias propostas pelos autores Foley e Wallace (1974) foram estendidas por meio da especialização de conceitos para a representação de aplicações RV no modelo RM-VRServices. O objetivo é definir um mecanismo de entrada de dados voltado às características dos dados e não dos dispositivos de entrada. Para isso a camada de serviço e interface do subsistema de execução foram projetadas para que possam receber informações de entrada de dados baseadas na representação do modelo RM-VRServices. A Figura 57 ilustra parte das classes ExecutionManagerService e ExecutionManager, com algumas operações que representam entradas de dados ao contexto de execução das aplicações na plataforma VRServices.

Figura 57: Operações de entrada de dados

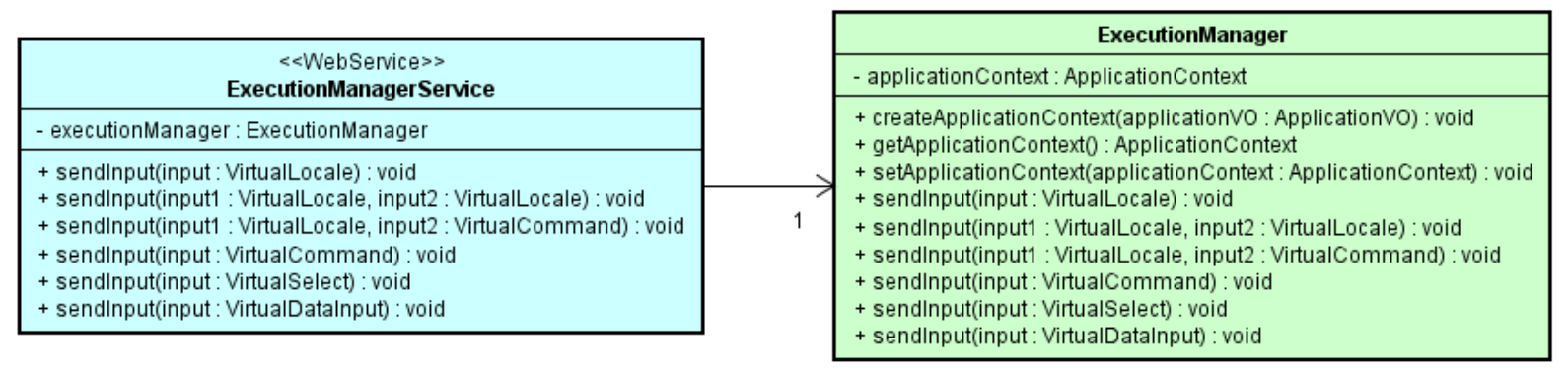

Fonte: Autor (2014)

O projeto das camadas de serviço e interface, para a realização de entrada de dados, usa o conceito de sobrecarga de operações, onde a assinatura das operações são constituídas pelos subconceitos de Virtuallnput do modelo RM-VRServices. Como exemplo, a operação sendlnput(input: VirtualLocale), recebe como parâmetro um objeto VirtualLocale. Essa assinatura permite que o contexto 
de execução do subsistema de execução receba objetos de quaisquer subconceito de VirtualLocale. Isso flexibiliza a entrada de dados da plataforma, pois permite que outros subconceitos possam ser definidos sem impacto no mecanismo de execução da plataforma. Outro exemplo é a operação sendlnput(input1: VirtualLocale, input2: VirtualCommand), que recebe uma entrada de dados composta, também baseada nas superclasses, que podem receber objetos de quaisquer uma das suas subclasses. As operações compostas são usadas para representar entradas de dados provenientes de dispositivos que fornecem mais de uma informação, por exemplo, quando um botão do mouse é pressionado em uma posição, pode produzir uma entrada composta por duas informações: VirtualLocale e VirtualCommand. A mesma ideia pode ser usada para representar o deslocamento de um dispositivo de posicionamento, por exemplo, quando o usuário arrasta o dedo em uma superfície sensível ao toque, ou arrasta o mouse, pode ser representado por uma operação sendlnput(input1 : VirtualLocale, input2 : VirtualLocale), representando a posição de início e fim do movimento.

Para ilustrar o modelo arquitetural para o tratamento da entrada de dados, baseada nos conceitos do modelo RM-VRService, foi produzido um diagrama de sequência que ilustra o fluxo de duas operações de entrada de dados. A Figura 58 apresenta o diagrama de sequência com os fluxos de mensagens de entrada de dados.

O fluxo inicia no cliente de execução, que usa os serviços de entrada de dados da plataforma. A camada de serviço envia a instância de entrada de dados para a camada de interface, por meio da classe ExecutionManager, que encaminha para o contexto da aplicação em questão. Na sequência, a entrada de dados é processada pelo gerenciador de entrada. Por fim, as informações da entrada de dados chegam ao gerenciador de eventos que irá produzir uma instância de evento de entrada para ser processado pelo contexto de execução.

O modelo arquitetural do subsistema de execução apresentado evidencia o uso de três modelos de desenvolvimento:

- modelo orientado a objetos para o projeto das classes e camadas do subsistema;

- modelo orientado a serviços para disponibilizar as funcionalidades do subsistemas na forma de operações distribuídas orientadas a serviços;

- modelo orientado a eventos usado para a representação e definição dos comportamentos das aplicações produzidas por meio do modelo RM-VRServices e apoiada pela arquitetura de produção e execução VRServices. 
Figura 58: Sequência de mensagens para o processamento de entrada de dados

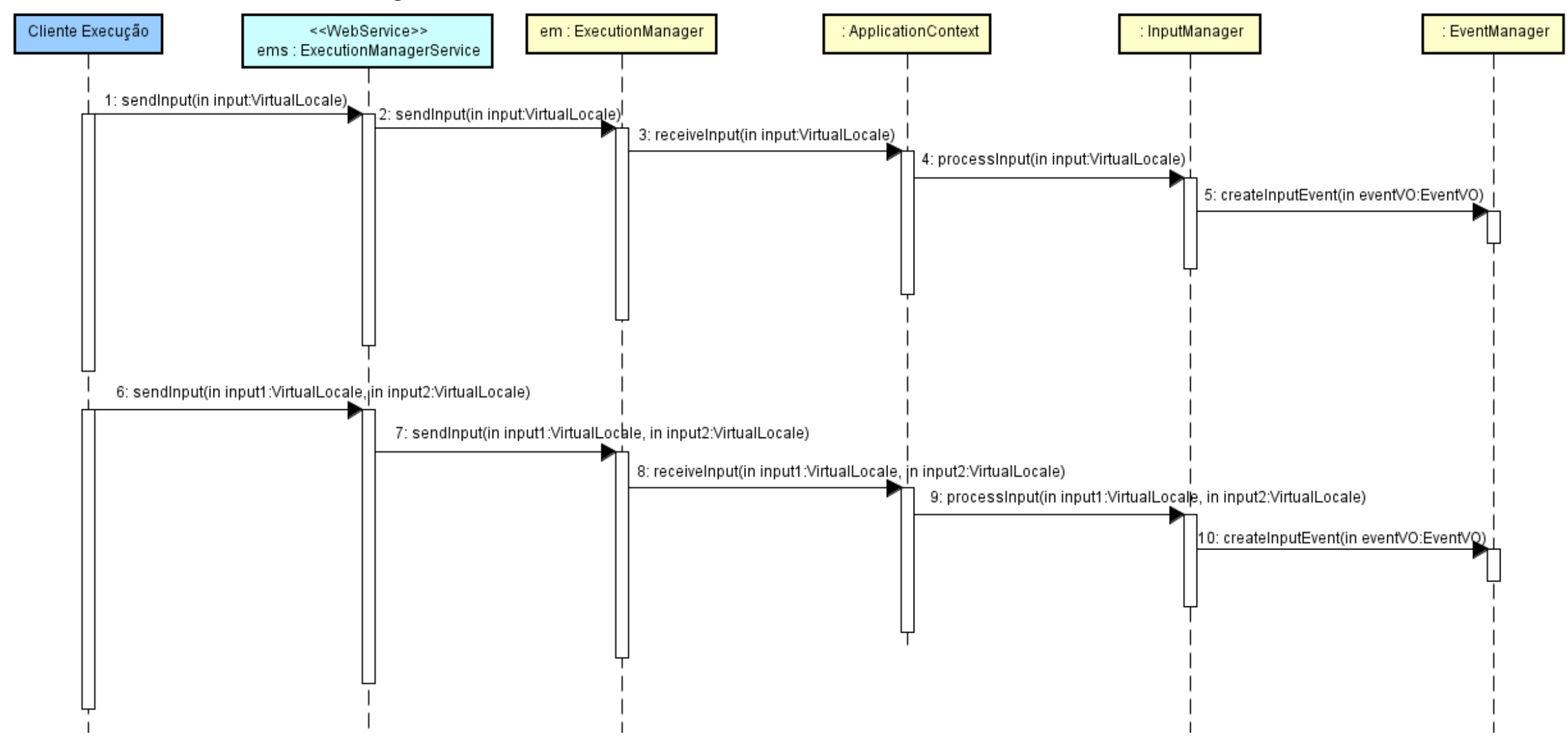

Fonte: Autor (2014) 


\subsection{Distribuição de Componentes e Serviços}

Os aspectos considerados para a definição da distribuição de componentes da plataforma VRServices foram dois: o primeiro foi a estrutura dos subsistemas projetados, o segundo, a natureza de distribuição da computação orientada a serviços. Os dois aspectos produziram um projeto que permite que cada subsistema possa ser alocado em uma máquina separada, onde a comunicação entre eles é realizada por meio de chamadas de serviços.

O projeto distribuído dos subsistemas permite que cada servidor possa ser implantado em uma máquina distinta, adequada as necessidades em particular de cada subsistema. O modelo de distribuição de componentes e serviços da plataforma VRServices é ilustrado pela Figura 59. Nela é possível observar cinco nós, em cada nó um subsistema.

Figura 59: Arquitetura de distribuição dos subsistemas

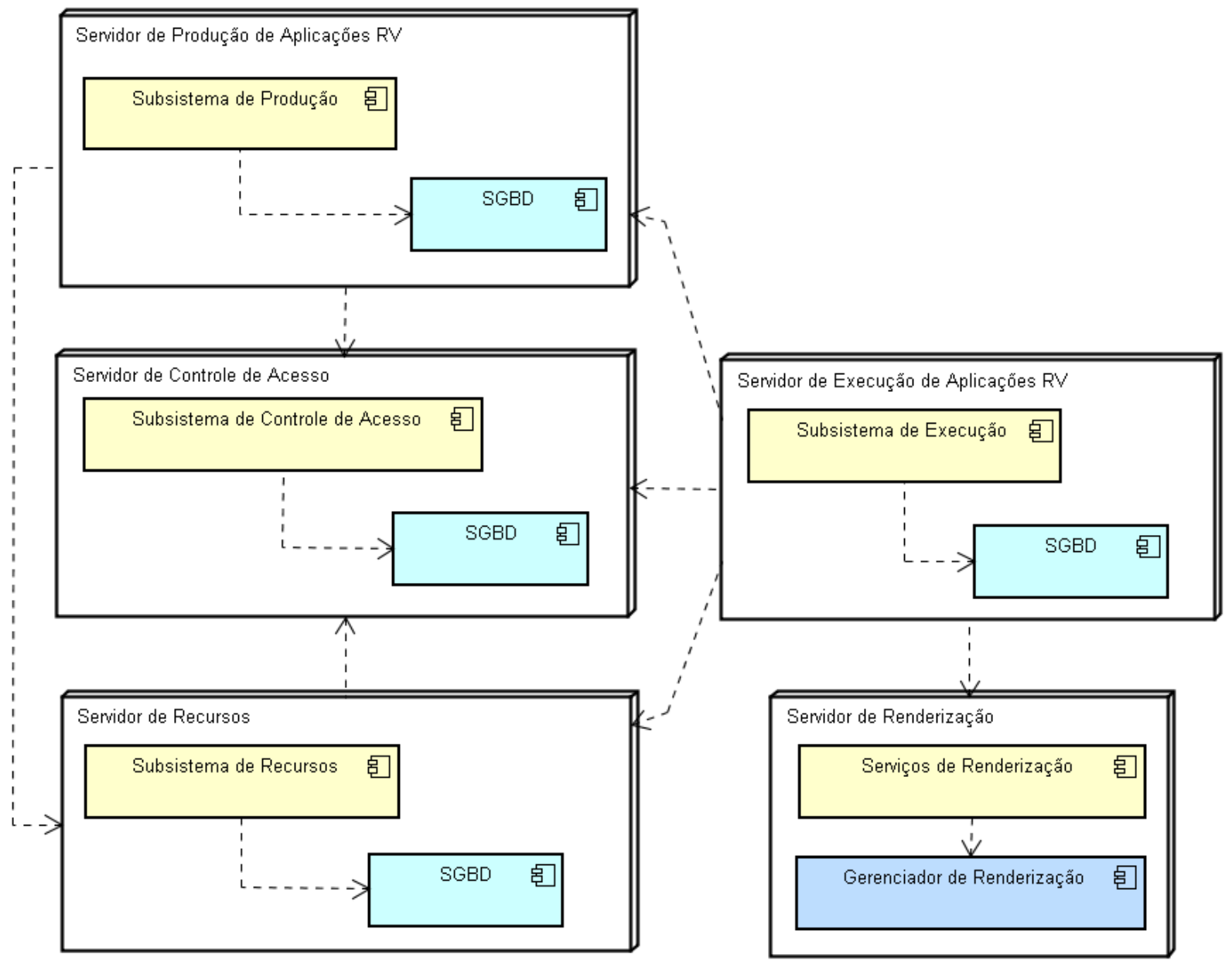

Fonte: Autor (2014)

Servidor de Controle de Acesso - nesse servidor estão os componentes 
de software do subsistema de controle de acesso e os serviços que publicam tais funcionalidades. Esses serviços são consumidos pelos servidores de produção, execução e recursos.

Servidor de Recursos - nesse servidor estão os componentes do subsistema de recursos e os serviços que publicam funcionalidades que permitem que os recursos possam ser catalogados, localizados e usados na produção e execução de aplicações RV. Esses serviços são consumidos pelos servidores de produção e execução. 0 servidor de recursos depende dos serviços do servidor de controle de acesso.

Servidor de Produção de Aplicações RV - nesse servidor estão os componentes de software do subsistema de produção e os serviços que disponibilizam as funcionalidades de produção de aplicações RV. Os serviços desse servidor são consumidos pelos clientes de produção e pelo servidor de execução. O servidor de produção depende dos servidores de controle de acesso e recursos.

Servidor de Execução de Aplicações RV - nesse servidor estão os componentes de software do subsistema de execução e os serviços que publicam as funcionalidades desse subsistema. Os serviços desse servidor são consumidos pelos clientes de execução. O servidor de execução depende de todos os outros servidores da plataforma.

Servidor de Renderização - nesse servidor estão os componentes de software de renderização e os serviços de renderização publicados por meio de Invocação Remota de Métodos (RMI). Os serviços de renderização desse servidor são consumidos exclusivamente pelo servidor de execução.

As justificativas da separação das tarefas de renderização do servidor de execução são:

- trata-se de tarefas críticas, controlar a execução das aplicações em ambiente on-line, que envolve entrada, processamento e saída, e a de renderização gráfica que exige capacidade de processamento gráfico;

- as tecnologias para implementação de serviços, em especial a de Web Services, não permite a criação de contexto gráfico. Para isso, foi projetado um componente de software que, encapsula uma API de renderização gráfica, separado do servidor de aplicação que executa o subsistema de execução.

A comunicação entre o subsistema de execução e o componente de renderização é realizada com a tecnologia de computação distribuída RMI. Não há a necessidade de separação física do componente de renderização com o subsistema 
de execução, embora seja uma prática recomendada, haja visto, que são duas tarefas que exigem muito recurso computacional.

\subsection{Considerações Finais do Capítulo}

Este capítulo apresentou o projeto arquitetural da plataforma proposta. 0 projeto arquitetural iniciou pela análise da decomposição funcional, usada como insumo para a definição dos subsistemas da plataforma, apresentada por meio da visão lógica dos elementos da plataforma.

Foi apresentado o projeto da arquitetura padrão para os subsistemas, descrito por meio da arquitetura lógica dos subsistemas. Também foram apresentadas as descrições dos subsistemas e o projeto de distribuição dos subsistemas em servidores da plataforma.

A principal característica da plataforma proposta e descrita neste capítulo é o acesso às funcionalidades por meio de serviços. Cada subsistema que compõe a plataforma possui em seu projeto uma camada de serviços, que expõem suas funcionalidades para aplicações remotas. O projeto arquitetural da plataforma baseado em serviços, em conjunto com o modelo de representação RM-VRServices permite que aplicações RV possam ser produzidas e executadas em ambiente on-line, com interoperabilidade de acesso, de linguagens de programação e de plataforma computacional.

Os resultados dos experimentos envolvendo o modelo RM-VRServices e a plataforma VRServices são apresentados no Capitulo 7. 


\section{RESULTADOS}

A definição do modelo RM-VRServices, descrita no Capítulo 5, estabelece os conceitos que representam elementos de mundos virtuais e aplicações RV. O modelo arquitetural da plataforma VRServices, descrita no Capítulo 6, foi concebido para viabilizar a edição, compartilhamento e execução das aplicações RV, produzidas a partir do modelo RM-VRServices, em um ambiente on-line orientado a serviços.

Com o objetivo de analisar a viabilidade do modelo de representação RM-VRServices e da plataforma VRServices, foram realizadas implementações de elementos de software do lado servidor da plataforma e protótipos de aplicações clientes. A partir desses protótipos implementados foram produzidas duas aplicações de RV por meio da representação do modelo RM-VRServices. A Figura 60 ilustra o planejamento e a execução das provas de conceito realizadas para verificação dos resultados.

Figura 60: Etapas de realização das provas de conceito

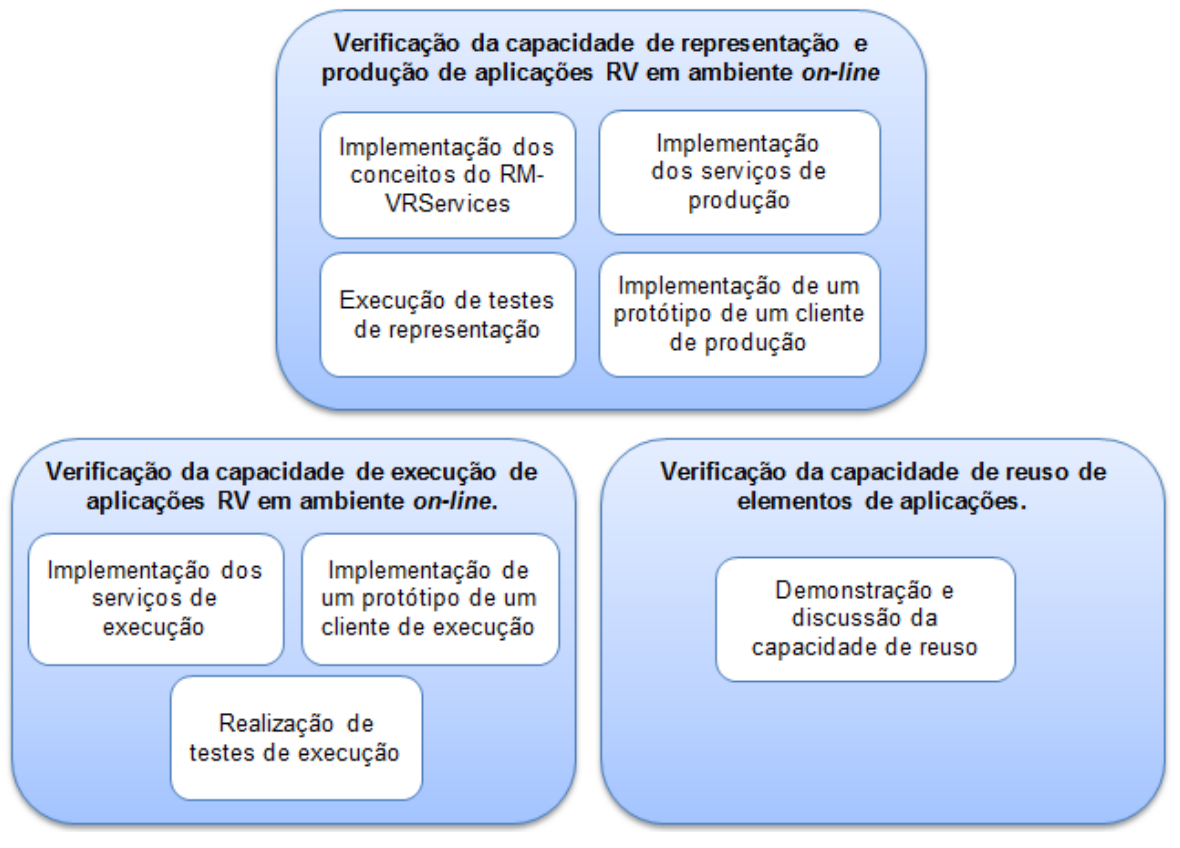

Fonte: Autor (2014)

$\mathrm{Na}$ etapa de verificação da capacidade de representação do modelo RM-VRServices foi realizada uma prova de conceito por meio da instanciação, 
persistência e recuperação dos conceitos do modelo para a representação de uma aplicação de realidade virtual escolhida como estudo de caso. $\mathrm{Na}$ etapa de verificação da capacidade de produção em ambiente on-line foram implementados os serviços que dão acesso às funcionalidades dos subsistemas de produção e recursos. A partir dos serviços foram produzidos protótipos de clientes para os testes de produção de aplicações em ambiente on-line.

$\mathrm{Na}$ etapa de verificação da capacidade de execução de aplicações de realidade virtual em ambiente on-line, foi implementado o serviço que dá acesso às funcionalidades do subsistema de execução e um cliente de execução, para realizar os testes de execução de aplicações armazenadas no repositório, em um ambiente remoto e on-line. Por último, a verificação da capacidade de reuso de elementos de aplicações foi realizada por meio de uma discussão sobre a estrutura hierárquica projetada para o modelo de representação de aplicações RV. As seções seguintes descrevem com maior nível de detalhe as provas de conceito realizadas e os resultados obtidos.

As implementações e testes foram realizados utilizando-se as seguintes tecnologias de implementação e execução: kit de desenvolvimento Java (JDK 7), Java Runtime (JRE 7), IDE Netbeans 7.2.1, API Java 3D 1.5.1, API de mapeamento objeto relacional JPA 2.0 com motor EclipseLink, API JAX-WS para definição, implementação e geração de Web Services, banco de dados PostgreSQL 9 e o servidor de aplicação Glassfish 3.1.2.

\subsection{Escopo Funcional das Provas de Conceito}

As provas de conceito realizadas são baseadas no software Virtual and Interactive Distance-learning on Anatomy (VIDA), desenvolvido pelo grupo de pesquisa do laboratório Interlab da Escola Politécnica da Universidade de São Paulo.

O software VIDA teve como objetivo a produção de um atlas anatômico virtual, voltado ao treinamento de estudantes de Medicina e áreas afins. No software foram usadas técnicas de RV e RA, estereoscopia e reconhecimento de gestos para possibilitar a manipulação direta dos elementos anatômicos virtuais (TORI et al., 2009). O VIDA permite três formas de interação para as manipulações dos elementos anatômicos: teclado, mouse e gestos com as mãos. A Figura 61, ilustra a tela principal do VIDA, exibindo modelos 3D de uma pelve feminina, composta por modelos 3D que representam: bacia, ovário esquerdo, ovário direito, útero, bulboesponjoso e

\footnotetext{
${ }^{1}$ http://www.pcs.usp.br/ interlab/ - acesso em 01/05/2014.
} 
isquiocavernoso.

Figura 61: Interface do software VIDA

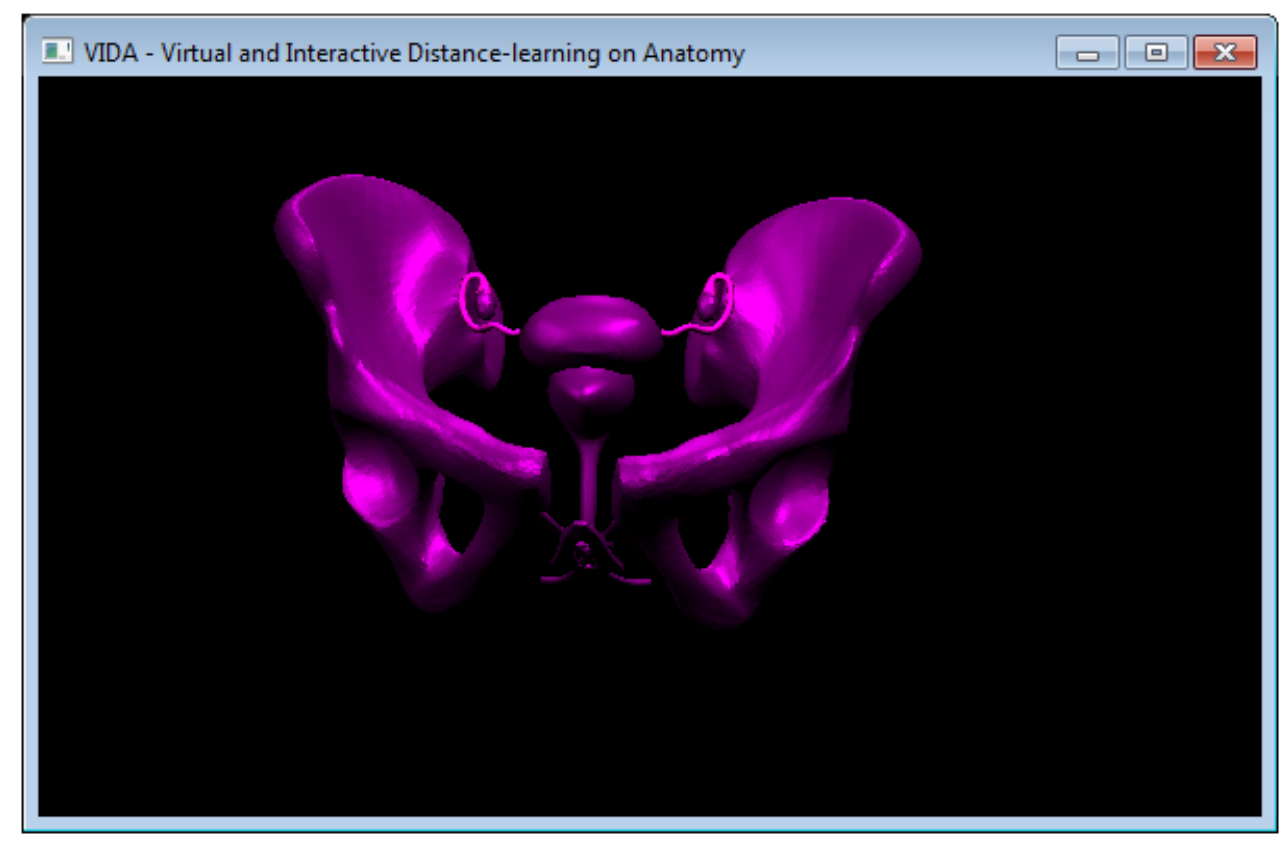

Fonte: adaptado de Tori et al. (2009)

Para realizar as provas de conceito desta pesquisa, foram escolhidas algumas funcionalidades do software VIDA, que devem ser representadas pelo modelo RM-VRServices e executadas na plataforma VRServices. As funcionalidades escolhidas são:

- apresentação de modelos 3D obtidos de arquivos;

- apresentação dos modelos baseados em agrupamentos (camadas);

- manipulação dos modelos 3D por meio de teclado;

- teclas 'a' e 'd' - movimentar a estrutura anatômica para a esquerda e direita do usuário respectivamente (translação no eixo x);

- teclas 'w' e 's' - movimentar a estrutura anatômica para cima e baixo respectivamente (translação no eixo y);

- teclas 'q' e 'e' - movimentar a estrutura anatômica para frente e trás respectivamente (translação no eixo z);

- teclas 'z' e 'x' - aumentar e diminuir o tamanho da estrutura anatômica respectivamente (escala nos três eixos);

- teclas 'j' e 'l' - girar a estrutura anatômica para a direita e esquerda do usuário respectivamente (rotação no eixo y);

- teclas 'i' e 'k' - girar a estrutura anatômica para trás e frente respectivamente (rotação no eixo x); 
- teclas 'u' e 'o' - girar a estrutura anatômica para a esquerda e direita respectivamente (rotação no eixo z);

- teclas '1', '2' e '3' - alternar entre os agrupamentos de modelos definidos.

- manipulação dos modelos 3D por meio de mouse;

- botão esquerdo combinado com movimentação do mouse

* movimento do mouse para frente e para trás (girar a estrutura anatômica para trás e para frente - rotação da estrutura no eixo $\mathrm{x})$;

* movimento do mouse para direita e para esquerda (girar a estrutura anatômica para direita e para esquerda do usuário rotação da estrutura no eixo y).

- botão direito combinado com movimentação do mouse

* movimento do mouse para frente e para trás (movimentar a estrutura anatômica para cima e para baixo - translação da estrutura no eixo y);

* movimento do mouse para direita e para esquerda (movimentar a estrutura anatômica para direita e para esquerda do usuário translação da estrutura anatômica no eixo x).

\subsection{Capacidade de Representação do RM-VRServices}

A primeira etapa de verificação tem como objetivo analisar a viabilidade de representação do modelo RM-VRServices proposto. Para isso, foram implementados os seguintes elementos:

Classes conceituais - Para cada conceito definido no modelo RM-VRServices foi implementada uma classe com o estilo arquitetural de objeto de valor (FOWLER, 2006);

Mapeamento objeto-relacional das classes conceituais - Cada classe do modelo RM-VRServices implementada foi complementada com as anotações de mapeamento objeto-relacional, conforme especificação da API JPA 2.0 (BAUER; KING, 2007). 
Figura 62: Representação de elementos de conteúdo do RM-VRServices

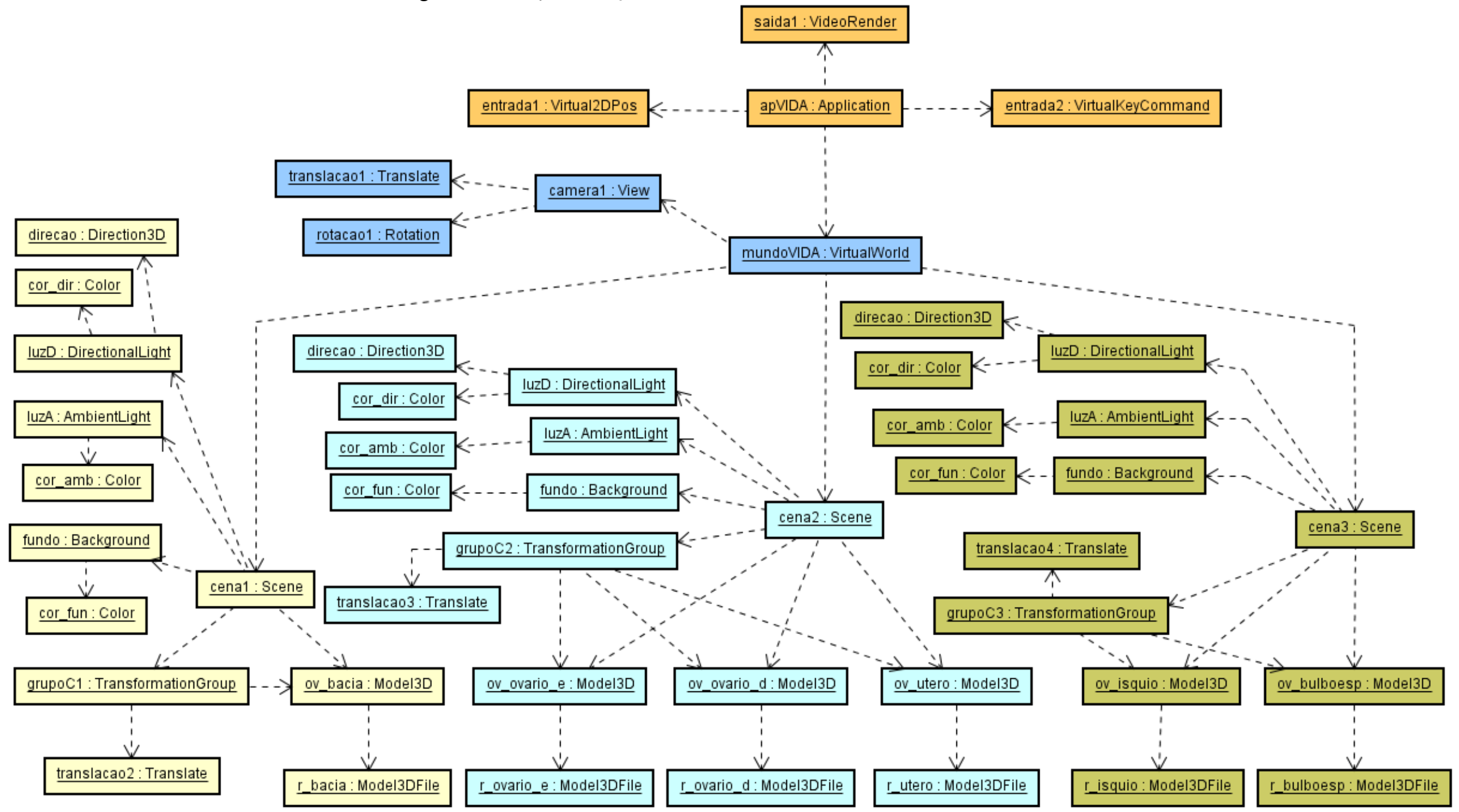

Fonte: Autor (2014) 
As classes conceituais e o mapeamento objeto-relacional definem os objetos, os atributos dos objetos e o relacionamento entre os objetos. O mapeamento objeto-relacional foi realizado nessa etapa para a verificação da viabilidade de persistência das instâncias dos objetos do modelo RM-VRServices, em um banco de dados relacional, usando a API JPA que automatiza o mapeamento objeto-relacional.

A verificação da viabilidade de representação foi realizada por meio do instanciamento dos objetos das classes do modelo RM-VRServices, com o objetivo de representar as funcionalidades escolhidas do software VIDA. A Figura 62 ilustra um diagrama de objetos que contém parte desse instanciamento. Nesse diagrama foram especificados os objetos que definem a visão estrutural, ou seja, a parte estática do modelo MR-VRServices. As instâncias das classes conceituais representam as seguintes características:

Recursos - Os objetos r-bacia, r-ovario-e, r-ovario-d, r-utero, r-isquio e r-bulboesp são instâncias da classe Model3DFile, subclasse de Resource e referenciam os arquivos dos modelos 3D: bacia, ovário esquerdo, ovário direito, útero, isquiocavernoso e bulboesponjoso, respectivamente, utilizados para representar as estruturas anatômicas;

Objetos virtuais - Os objetos ov-bacia, ov-ovario-e, ov-ovario-d, ov-utero, ov-isquio e ov-bulboesp são instâncias da classe Model3D, subclasse de VirtualObject. Cada instância da classe Model3D referencia uma instância da classe Model3DFile;

Cenas - Os objetos cena1, cena2 e cena3 são instâncias da classe Scene. Cada instância da classe Scene referencia uma lista de objetos virtuais. Neste caso, cena1 referencia o objeto ov-bacia, cena2 referencia os objetos ov-ovario-e, ov-ovario-d, ov-utero e cena3 referencia os objetos ov-isquio e ov-bulboesp. Os objetos cena1, cena2 e cena3 mantém instâncias das classes Background, AmbientLight e DirectionalLight, que representam informações sobre as características do fundo da cena, iluminação ambiente e iluminação direcionada, respectivamente.

Grupo de transformações - Os objetos grupoC1, grupoC2 e grupoC5 são instâncias da classe TransformationGroup, usados para aplicar operações geométricas para o posicionamento dos objetos virtuais na cena. Cada instância da classe TransformationGroup mantém uma instância da classe Translate e uma referência ao objeto virtual que posiciona. Neste caso está sendo considerado que cada objeto virtual deve ser posicionado individualmente. As instâncias grupoC3, grupoC4 e grupoC6 foram omitidas por restrições de espaço no 
diagrama.

Mundo Virtual - o objeto mundoVIDA é instância da classe VirtualWorld e representa o mundo virtual criado a partir das cenas definidas. Este objeto mantém referências aos objetos cena1, cena2 e cena3, que representam os agrupamentos dos objetos virtuais. O objeto mundoVIDA mantém uma referência ao objeto camera1, instância da classe View, que representa uma câmera virtual do mundo virtual associado. A instância camera1 referencia os objetos das classes Translate e Rotation, usados para posicionar a câmera virtual no mundo virtual.

Aplicação - o objeto apVIDA é instância da classe Application que representa a aplicação completa. A instância apVIDA referencia o objeto mundoVIDA. O objeto entrada1, instância da classe Virtual2DPos, subclasse de VirtualLocale, define a modalidade de entrada de dados para a aplicação, baseada em posicionamento 2D. O objeto entrada2, instância da classe VirtualKeyCommand, subclasse de VirtualCommand, define uma modalidade de entrada de dados para a aplicação baseada em teclas de comando.

Após a descrição dos elementos que definem o conteúdo da aplicação, a Figura 63 ilustra o diagrama de objetos que contém a definição de parte do comportamento da aplicação. Os comportamentos representados no diagrama de objetos estão associados ao objeto mundoVIDA, e são estabelecidos por meio de elementos de evento e elementos de comportamentos.

O comportamento desejado, na representação, é a troca de cena, provocada pelo fornecimento de entradas de dados, neste caso, a entrada do caractere '1' para selecionar a cena1, o caractere '2' para selecionar a cena2 e o caractere '3' para selecionar a cena3. Os objetos evento1, evento2 e evento3, ilustrados na Figura 63, são instâncias da classe CommandEvent, subclasse de InputEvent, são usados para estabelecer o evento que irá disparar o comportamento associado. Os objetos comp1, comp2 e comp3 são instâncias da classe SceneBehavior, que estabelece a seleção da cena associada. Assim, durante a execução, quando uma entrada do tipo CommandEvent for fornecida ao contexto de execução da aplicação, será verificado o valor contido na entrada e será disparado o comportamento associado ao evento que coincidir com a entrada de dados.

A Figura 64 ilustra uma parte do diagrama de objetos, destacando os objetos que definem os comportamentos associados ao objeto cena2. São representados dois comportamentos, um para executar uma rotação nos objetos da cena2 e o outro para executar uma translação nos objetos da cena2. Assim como foram apresentados 
Figura 63: Representação do comportamento de mudança de cena

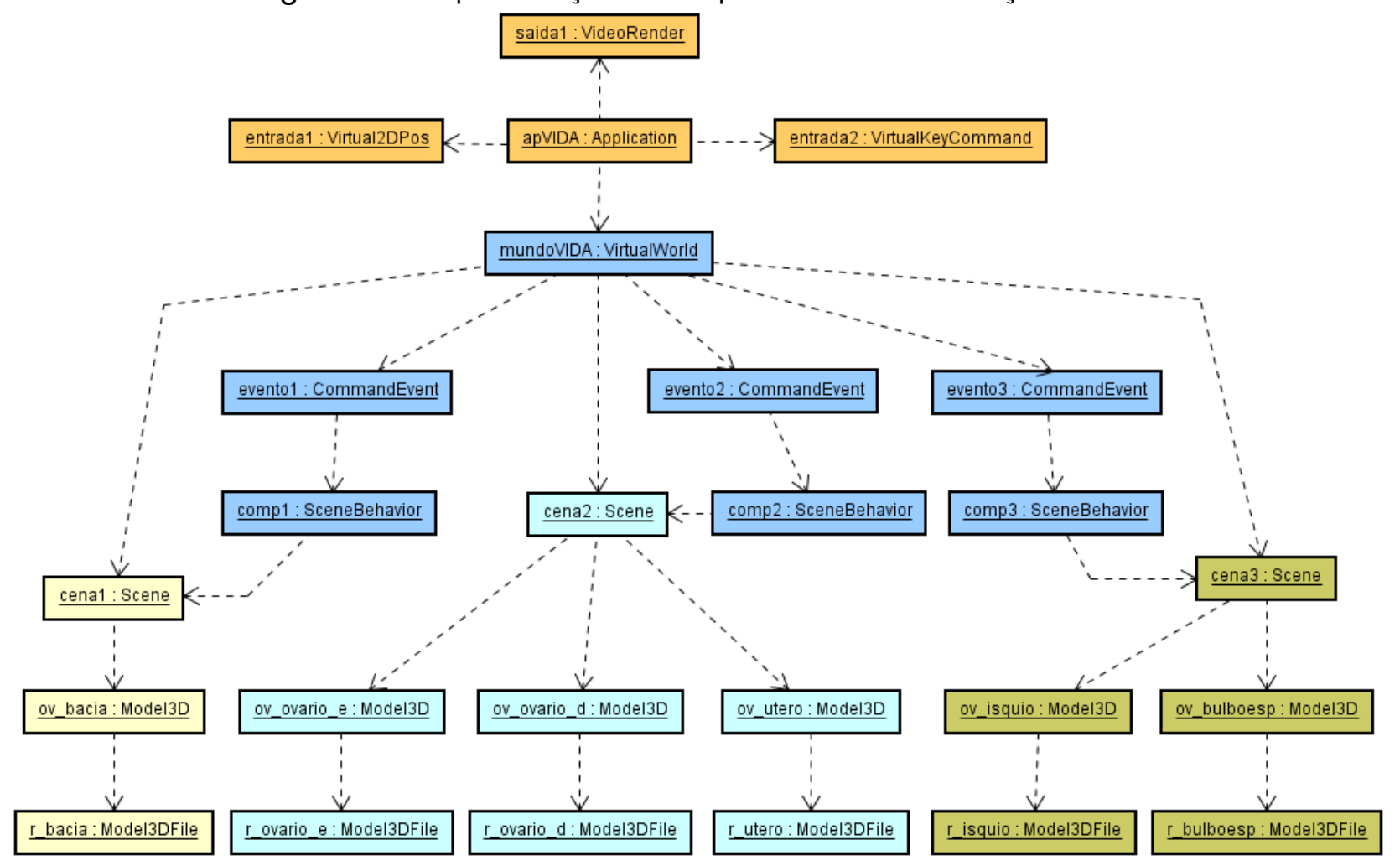

Fonte: Autor (2014)

os comportamentos de mudança de cena, os comportamentos de manipulação de objetos seguem a mesma estrutura. Os objetos evento1 e evento2, ambos instâncias da classe CommandEvent, definem quando que o evento é disparado, neste caso, quando uma determinada tecla for acionada. Os objetos comp1 e comp2, instâncias da classe TransformationBehavior, definem um comportamento de operação geométrica. A definição de quais operações geométricas serão realizadas é feita por meio de um objeto agrupador de transformações, instância da classe TransformationGroup, e os objetos das subclasses de Transformation, que no diagrama, o objeto rotacaoY é instância da classe Rotation, para realizar uma rotação em um dos eixos e o objeto translacaoX é instância da classe Translate, para realizar uma translação em um dos eixos.

Os demais comportamentos do escopo funcional estabelecido para a prova de conceito foram representados por meio dos elementos previstos no modelo RM-VRServices. Esses conceitos foram capazes de representar o escopo funcional pretendido. Após a representação da aplicação a próxima etapa foi verificar a viabilidade de persistência e recuperação das instâncias dos objetos criadas em tempo de execução nos testes de representação. 
Figura 64: Representação do comportamento de manipulação dos objetos virtuais

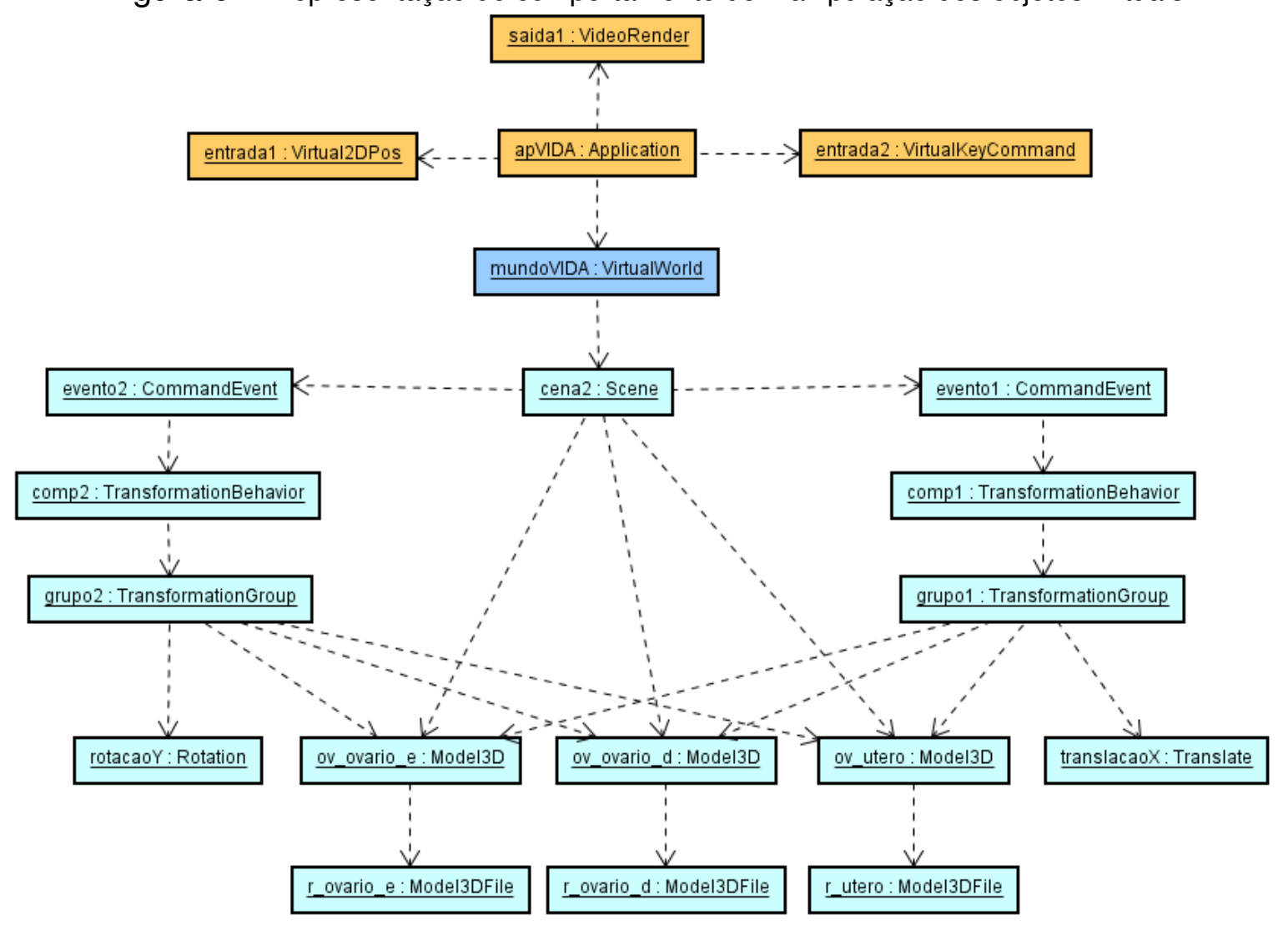

Fonte: Autor (2014)

Para realizar as tarefas de persistência dos objetos de representação, foram implementadas as camadas de persistência dos subsistemas de Recursos e Produção. A Figura 65 ilustra as classes que compõem a camada de persistência do subsistema de produção.

A classe FactoryEntityManager produz objetos de manipulação de entidades para a camada de persistência. Essa classe foi implementada por meio do padrão de projeto Singleton (GAMMA et al., 2007), para garantir que apenas uma instância da classe seja criada. A classe GenericDAO é superclasse de todas as classes de persistência da plataforma, implementa os métodos básicos para inclusão, alteração, exclusão e gerenciamento de transações.

A camada de persistência do subsistema de Recursos possui apenas a classe ResourceDAO e segue a mesma estrutura arquitetural das classes do subsistema de Produção.

Com as classes de persistência implementadas foi possível fazer os testes de persistência das instâncias do modelo RM-VRServices. O principal interesse é verificar a capacidade do mapeamento objeto-relacional estabelecido nas classes que representam os conceitos do modelo RM-VRServices. 
Figura 65: Camada de persistência do subsistema de produção

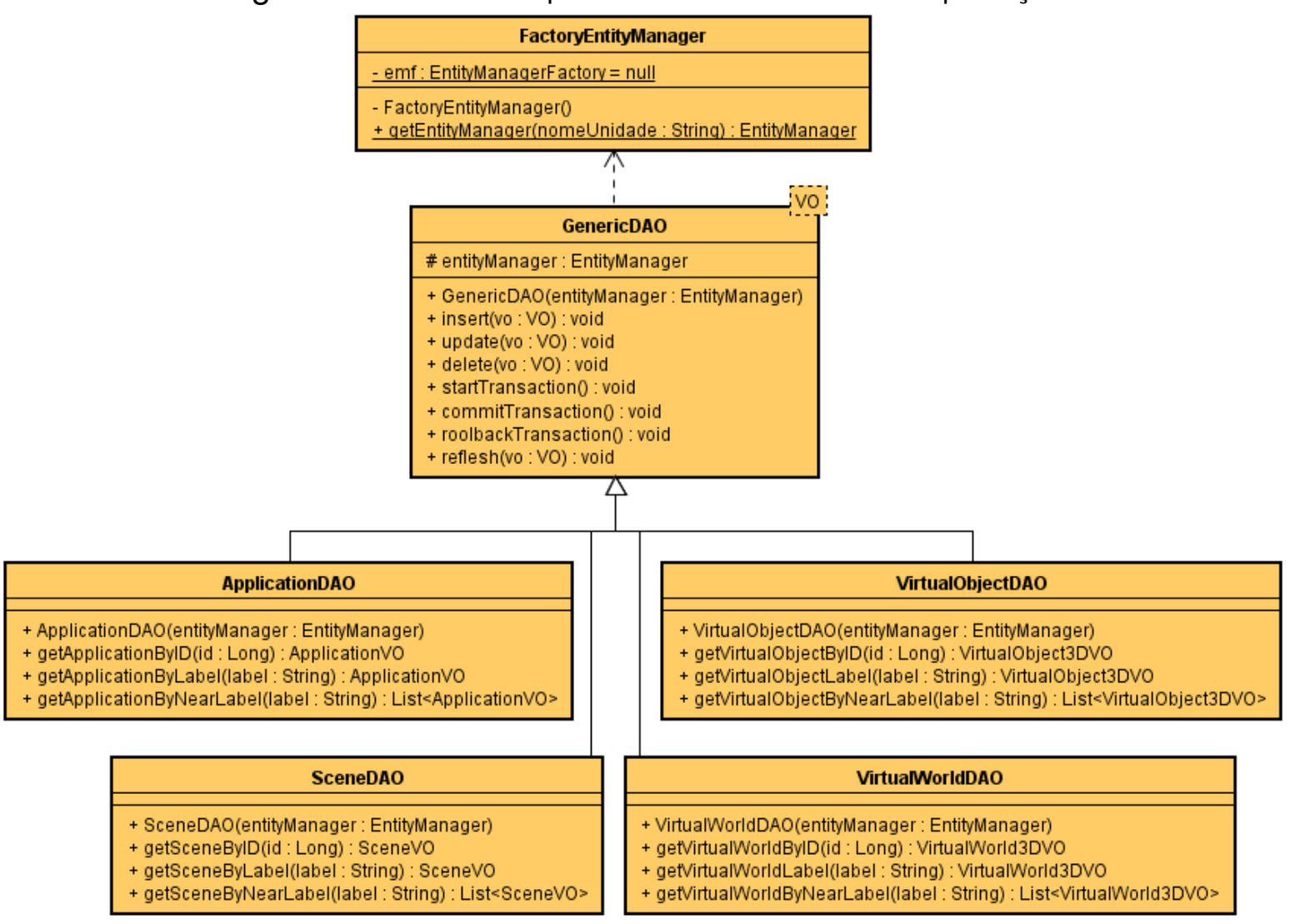

Fonte: Autor (2014)

A partir dos testes de persistência realizados, foram implementadas as classes de domínio dos subsistemas de Recursos e Produção. As classes de domínio possuem a responsabilidade de garantir a validade dos dados a serem persistidos. As validações vão desde a verificação de valores de atributos, até a verificação de relacionamentos entre as instâncias a serem persistidas. Cada classe de domínio possui uma instância da classe de persistência correspondente.

Vale ressaltar que as classes de persistência foram produzidas para manipularem subárvores do modelo RM-VRServices. Por exemplo, a classe SceneDAO, em suas operações de inclusão, alteração, exclusão e busca, manipulam uma instância de SceneVO e todos os objetos associados. Essas informações são definidas por meio de anotações de mapeamento objeto-relacional, da API JPA, realizadas nas classes do RM-VRServices. A definição de quais classes de persistência seriam implementadas e quais partes da árvore de representação elas iriam manipular, está associado ao nível de granularidade desejado para o modelo de representação. 


\subsection{Capacidade de Produção em Ambiente On-line}

A partir da definição do modelo MR-VRServices e da implementação das camadas de persistência e domínio dos subsistemas de produção e recursos, foi iniciada a etapa de implementação dos serviços que oferecem suporte à produção remota das aplicações na plataforma. Os serviços publicam as funcionalidades dos subsistemas, permitindo que sejam consumidas por clientes de produção.

A Figura 66, ilustra a classe ResourceManagerService, implementada com a tecnologia de Web Service. Essa classe publica as funcionalidades do subsistema de recursos que serão acessíveis remotamente.

Figura 66: Web Service do subsistema de recursos

\begin{tabular}{|l|}
\multicolumn{1}{c|}{ ResourceManagerService } \\
\hline - resourceManager : ResourceManager \\
- service : AccessControlServices_Service \\
\hline + insertResource(resourceVO : ResourceVO) : String \\
+ updateResource(resourceVO : ResourceVO) : String \\
+ deleteResource(resourcelD : long) : String \\
+ getResourceBylD(resourcelD : long) : ResourceVO \\
+ getResourceByLabel(label : String) : ResourceVO \\
+ getResourceByNearLabel(label : String) : List<ResourceVO> \\
- createContextWebService() : void \\
- getContextWebService() : ServletContext \\
- getSessionID() : String \\
- getServiceName() : String \\
+ login(login : String, senha : String) : boolean \\
+ logout(login : String, senha : String) : boolean
\end{tabular}

Fonte: Autor (2014)

Para verificar a funcionalidade do subsistema de recursos, acessado remotamente, foi produzido um protótipo de um cliente consumidor do serviço ResourceManagerService. Esse protótipo foi desenvolvido para ser executado em ambiente desktop, entretanto poderia ser desenvolvido para ambiente Web ou para dispositivos móveis. Foi usada a linguagem de programação Java para sua implementação, contudo poderiam ser utilizadas outras linguagens compatíveis com a tecnologia de Web Services. A Figura 67 ilustra a tela de inclusão de recursos.

Após a implementação do serviço de gerenciamento de recursos, foi implementado o serviço que expõe as funcionalidades do subsistema de produção. A Figura 68 ilustra o Web Service ProductionManagerService. Da mesma maneira que no subsistema de recursos, foi produzida uma aplicação cliente para verificar a viabilidade de uso do serviço de produção.

A Figura 69 ilustra a tela do protótipo de inclusão de objetos virtuais na plataforma. Nessa aplicação é possível criar objetos virtuais por meio da referência 
Figura 67: Interface do protótipo do cliente de gerenciamento de recursos - inclusão de recursos

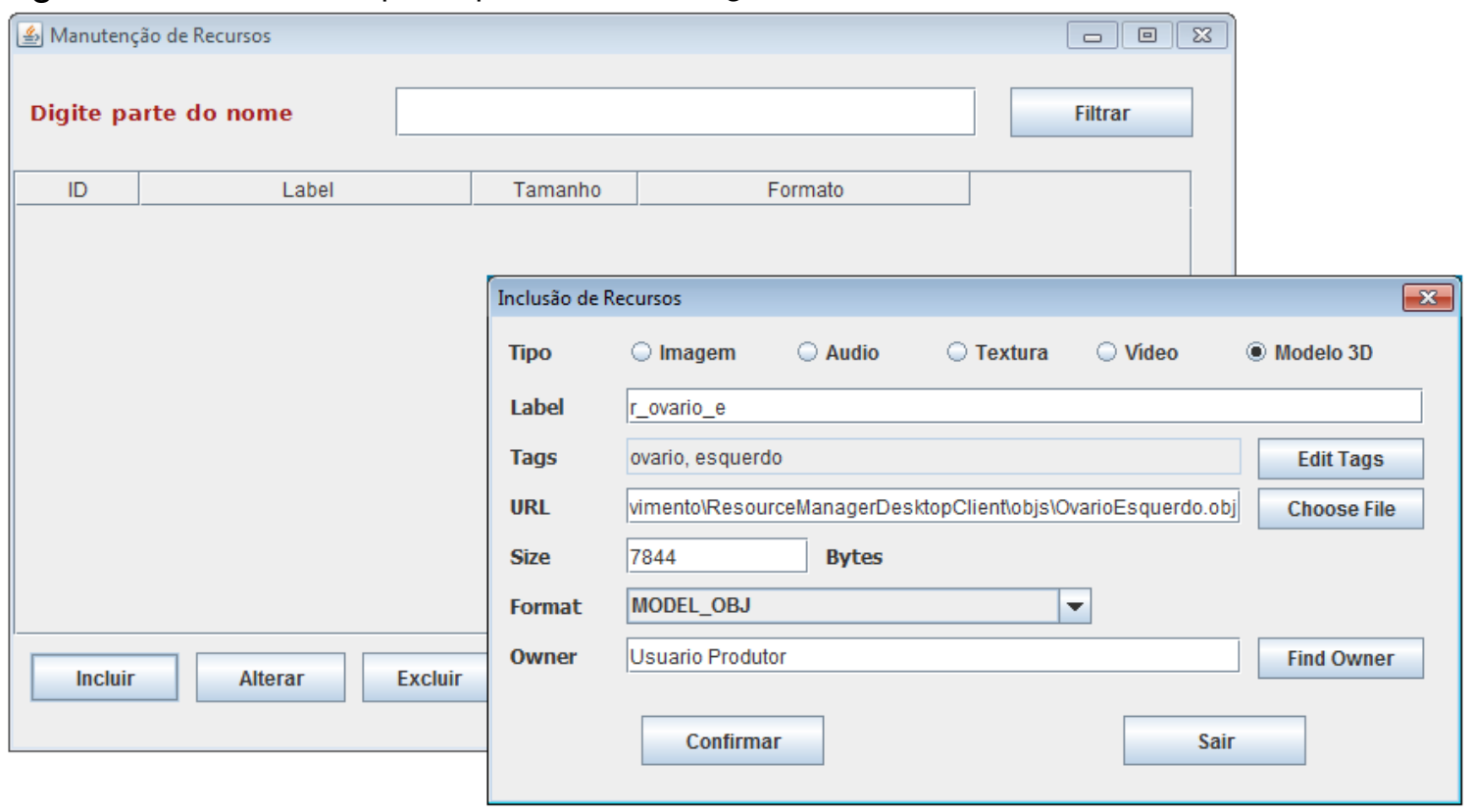

Fonte: Autor (2014)

Figura 68: Web Service do subsistema de produção

\begin{tabular}{|c|}
\hline $\begin{array}{l}\quad<<\text { WebService }>> \\
\text { ProductionManagerService }\end{array}$ \\
\hline $\begin{array}{l}\text { - productionManager : ProductionManager } \\
\text { - service : AccessControlServices_Service }\end{array}$ \\
\hline 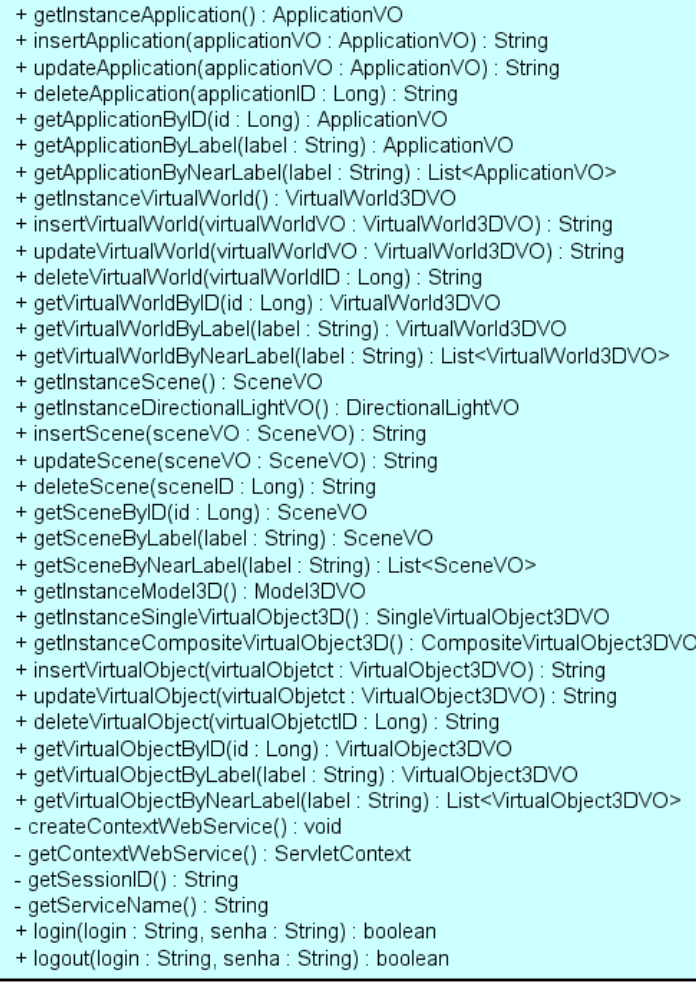 \\
\hline
\end{tabular}

Fonte: Autor (2014) 
a recursos, previamente inseridos no repositório, neste caso recurso que representa um modelo 3D. Os recursos presentes no repositório podem ser referenciados por inúmeras instâncias de objetos virtuais, caracterizando o primeiro nível de reuso do modelo RM-VRServices.

Figura 69: Interface do protótipo do cliente de produção - inclusão de objeto virtual

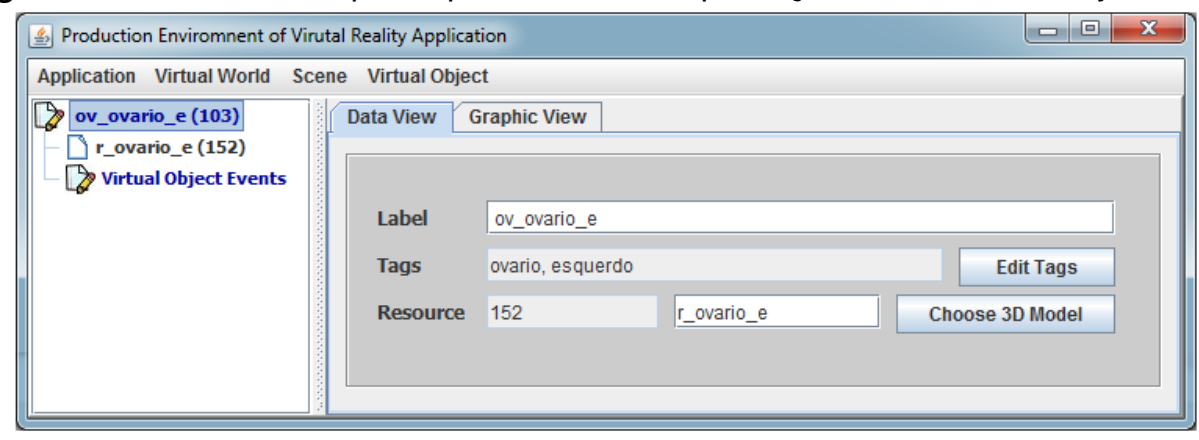

Fonte: Autor (2014)

Após a prototipação do cliente de produção de objetos virtuais, o próximo protótipo foi o de produção de cenas. Cada cena representa um conjunto de objetos virtuais e informações referentes a aparência e comportamento da cena. A Figura 70 ilustra uma das telas do protótipo de inclusão de cenas. Neste caso, apresenta a tela na qual são inseridos os dados de identificação da cena e a lista de objetos virtuais, previamente inseridos no repositório.

Figura 70: Interface do protótipo do cliente de produção - inclusão de cena

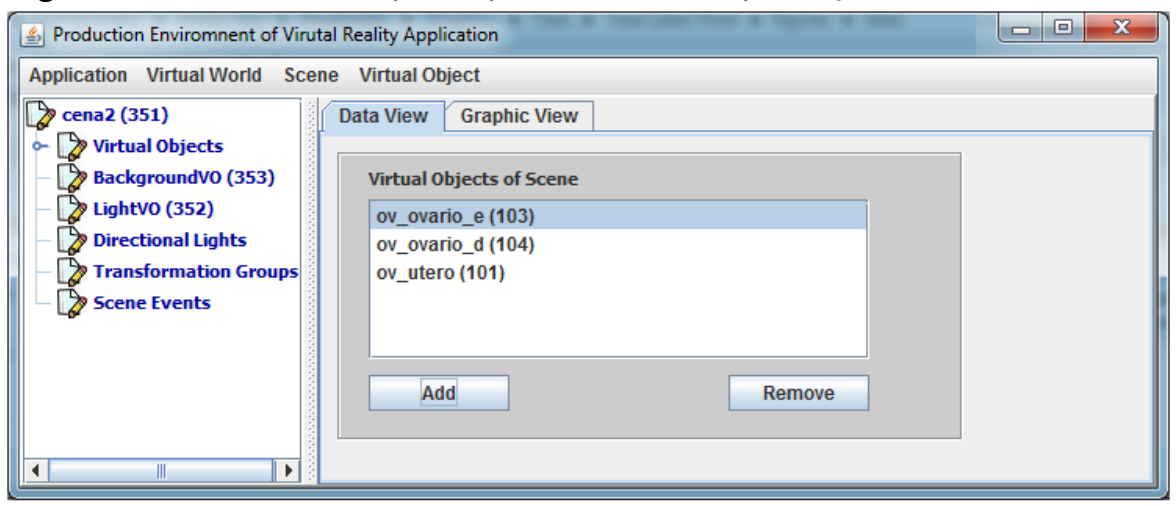

Fonte: Autor (2014)

A lista de objetos virtuais na cena ilustra o segundo nível de reuso do modelo RM-VRServices, pois um objeto virtual pode ser referenciado por inúmeras cenas. A Figura 71 e a Figura 72 ilustram a inclusão de um grupo de transformações para a execução de operações geométricas de posicionamento de objetos virtuais na cena.

O protótipo seguinte ilustra uma das telas de edição de mundos virtuais, que devem ser compostos por cenas, previamente inseridas no repositório. A Figura 78 
Figura 71: Interface do protótipo do cliente de produção - edição de transformações da cena

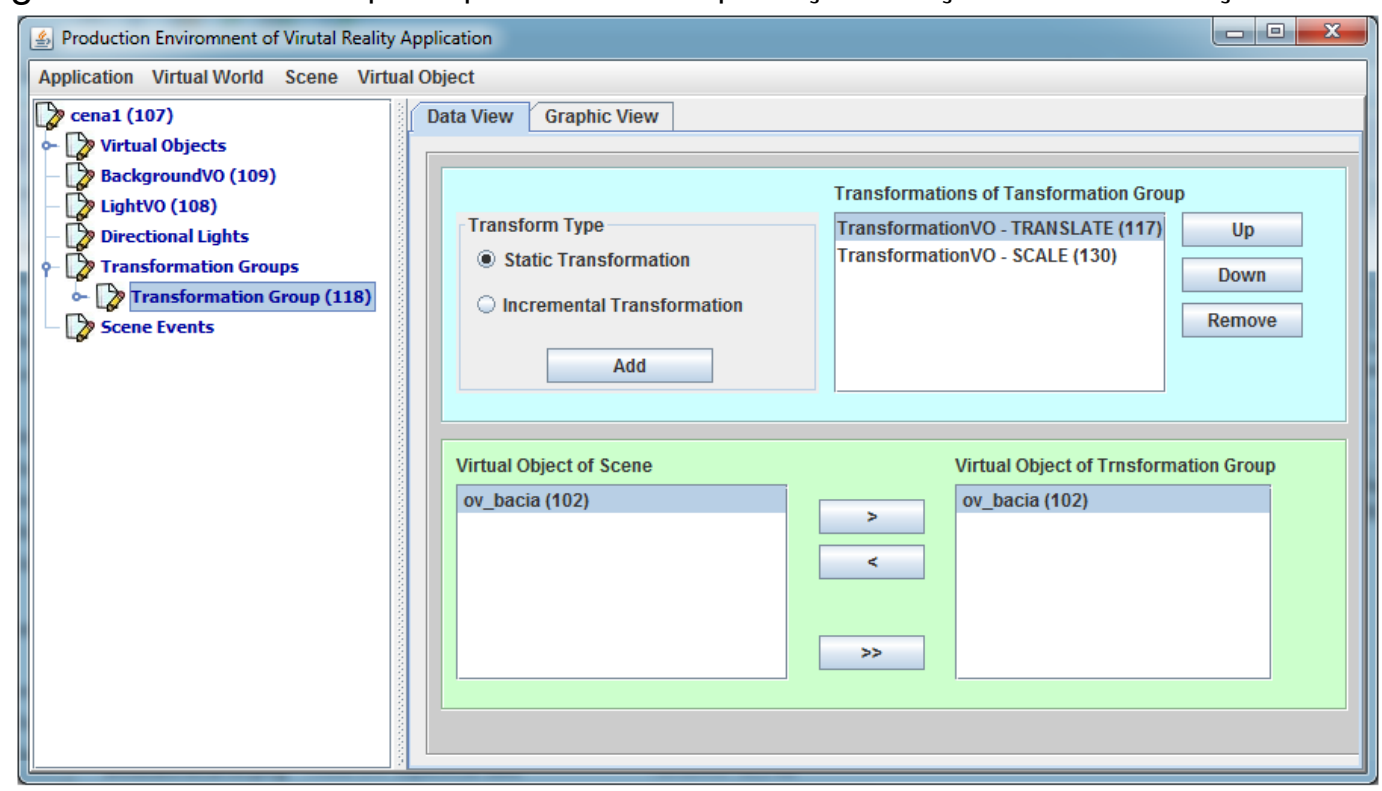

Fonte: Autor (2014)

Figura 72: Interface do protótipo do cliente de produção - configuração da transformação

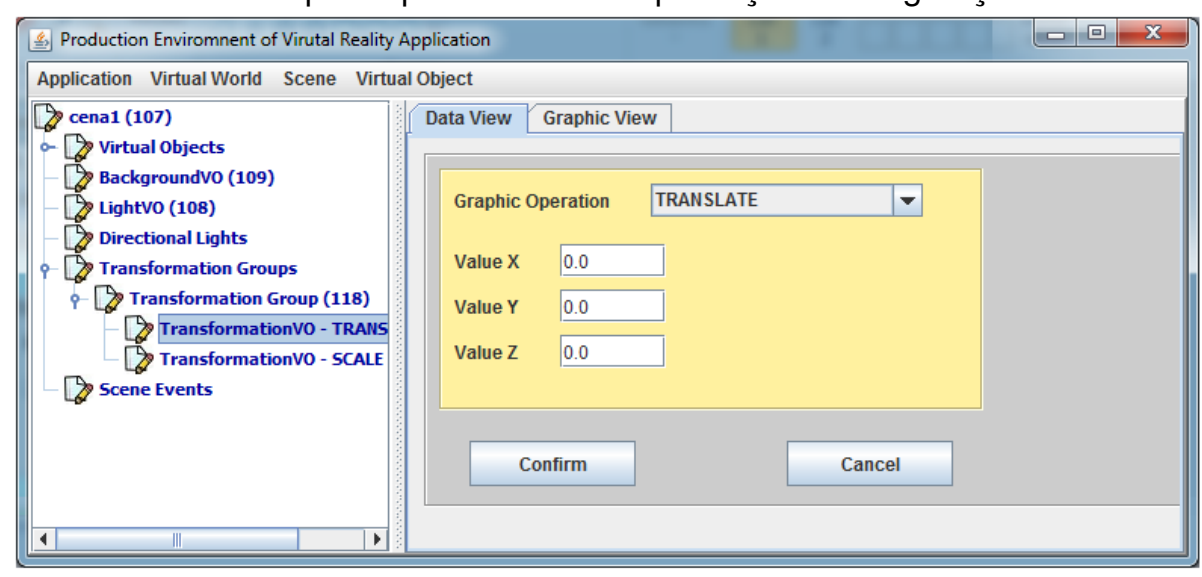

Fonte: Autor (2014)

ilustra a tela de edição de mundos virtuais. Nela são inseridas as informações de identificação do mundo virtual e a lista de cenas que constituem o mundo virtual. A lista de cenas ilustra o terceiro nível de reuso do modelo MR-VRServices, pois uma instância de cena pode ser usada para compor inúmeros mundos virtuais.

No nível mais alto da hierarquia de elementos do modelo RM-VRServices, está a representação de aplicação, que deve ser constituída por um mundo virtual. A Figura 74 ilustra uma das telas de edição de aplicações responsável pela inserção de informações de identificação da aplicação e a referência ao mundo virtual, previamente inserido no repositório.

A referência que a aplicação faz a um mundo virtual representa o quarto 
Figura 73: Interface do protótipo do cliente de produção - edição de mundos virtuais

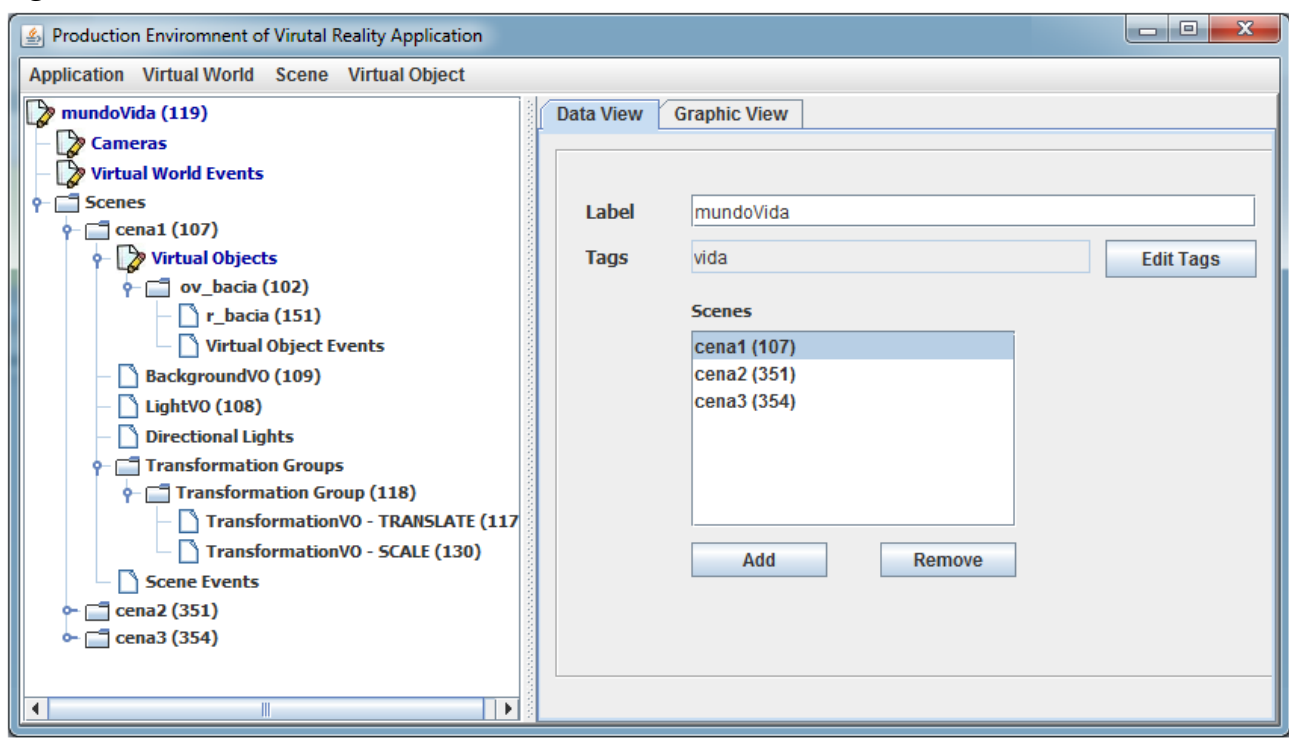

Fonte: Autor (2014)

Figura 74: Interface do protótipo do cliente de produção - edição de aplicações

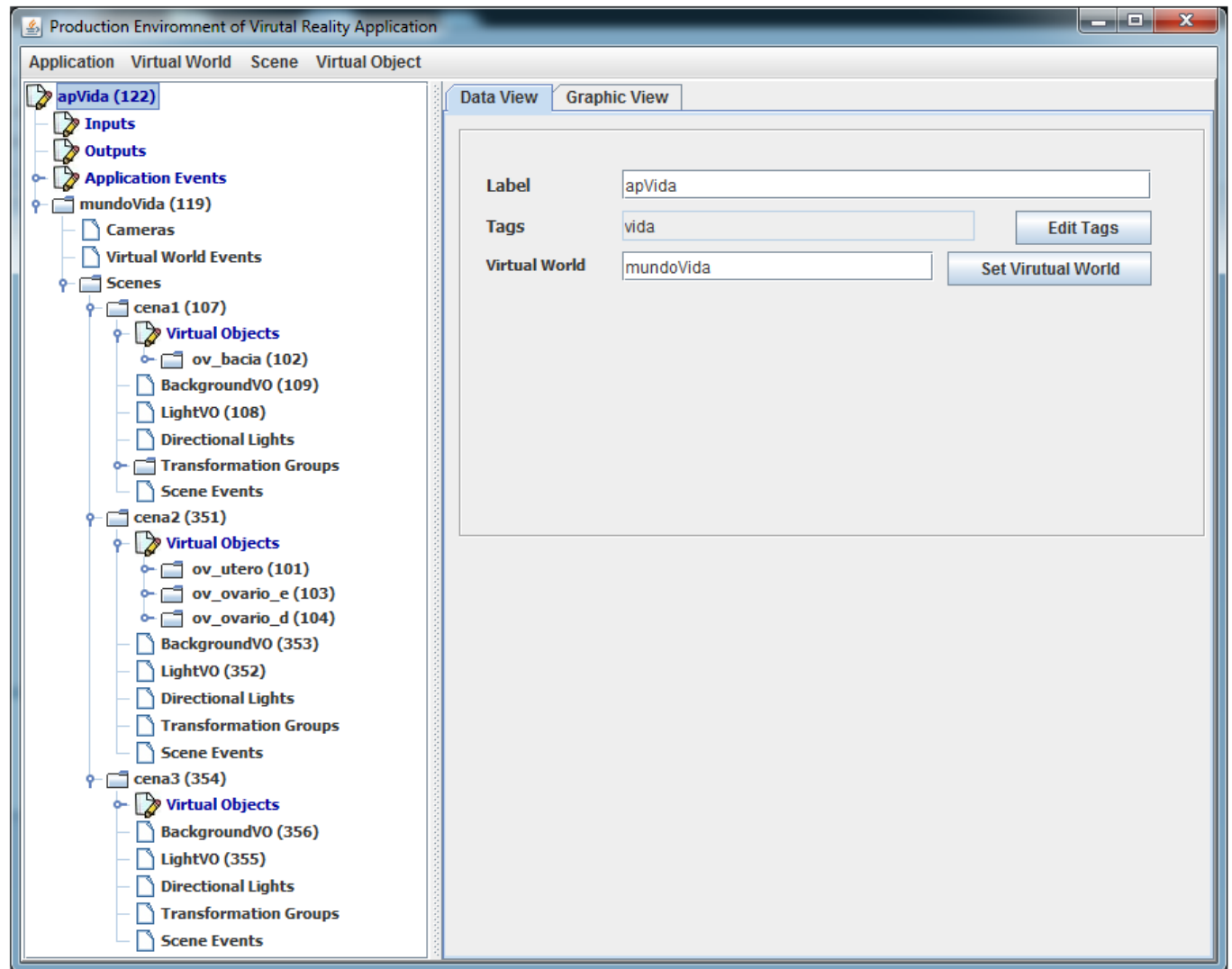

Fonte: Autor (2014)

nível possível de reuso do modelo RM-VRServices. Um mundo virtual presente no repositório pode ser referenciado por inúmeras aplicações.

A Figura 74 ilustra a hierarquia completa de elementos do modelo 
RM-VRServices. A aplicação RV produzida por meio do protótipo é a mesma ilustrada nos diagramas de objetos ilustrados nas Figuras 62, 63 e 64 .

A aplicação (apVida) referencia uma instância de mundo virtual (mundoVida), esse por sua vez, referencia três instâncias de cena (cena1, cena2 e cena3). A primeira instância de cena (cena1) referencia uma instância de objeto virtual (ov-bacia), que por sua vez referencia uma instância de recurso (r-bacia). A segunda instância de cena (cena2) referencia três instâncias de objetos virtuais (ov-ovario-e, ov-ovario-d e ov-utero), que referenciam respectivamente três instâncias de recursos (r-ovario-e, r-ovario-d e r-utero). A terceira instância de cena (cena3) referencia duas instâncias de objetos virtuais (ov-isquio e ov-bulvoesp), que referenciam respectivamente duas instâncias de recursos (r-isquio e r-bulboesp).

\subsection{Capacidade de Execução em Ambiente On-line}

A partir da implementação dos protótipos de edição de recursos e elementos de aplicações, foi implementado o serviço ExecutionManagerService, que publica as funcionalidades de execução de aplicações do contexto de execução da plataforma VRServices.

A Figura 75, ilustra a classe ExecutionManagerService, implementada com a tecnologia de Web Service.

Figura 75: Web Service do subsistema de execução

\begin{tabular}{|c|}
\hline $\begin{array}{c}\quad \ll<\text { WebService }>> \\
\text { ExecutionManagerService }\end{array}$ \\
\hline $\begin{array}{l}\text { - executionManager : ExecutionManager } \\
\text { - service : AccessControlServices_Service }\end{array}$ \\
\hline $\begin{array}{l}\text { + loadApplication(idApplication : Long) : String } \\
\text { + startExecution(idContextExec : String) : void } \\
\text { + stopExecution(idContextExec : String) : void } \\
\text { + sendlnput(input : VirtualLocale, idContextExec : String) : void } \\
\text { + sendlnput(input } 1: \text { VirtualLocale, input } 2: \text { VirtualLocale, idContexExec : String) : void } \\
\text { + sendlnput(input } 1: \text { VirtualLocale, input } 2: \text { VirtualCommand, idContextExec : String) : void } \\
\text { + sendlnput(input : VirtualCommand, idContextExec : String) : void } \\
\text { + sendlnput(input: VirtualSelect, idContextExec : String) : void } \\
\text { + sendlnput(input : VirtualDatalnput, idContextExec : String) : void } \\
\text { + receiveOutputVideo(idContextExec : String) : VideoRender } \\
\text { + receiveOutputAudio(idContextExec : String) : AudioRender } \\
\text { + receiveOutputHaptic(idContextExec : String) : HapticRender }\end{array}$ \\
\hline
\end{tabular}

Fonte: Autor (2014)

Para testar as operações do serviço de execução foi produzido um protótipo de uma aplicação consumidora desse serviço. A Figura 76 ilustra duas telas do protótipo de execução. A tela superior é usada para localizar a aplicação no repositório e iniciar a execução da aplicação. 
Figura 76: Interface do protótipo do cliente de execução

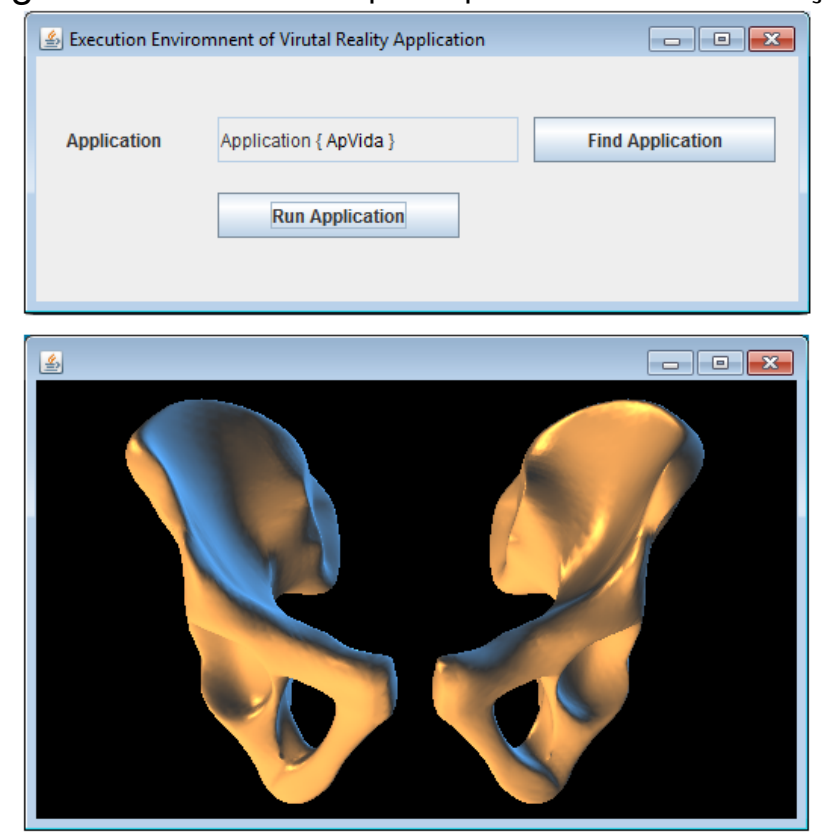

Fonte: Autor (2014)

Tanto o serviço ExecutionManagerService, quanto o protótipo de execução carecem de ampliação e adequação de suas funcionalidades. Devem ser ampliadas as operações relacionadas com as entradas de dados, para que possam dar suporte a todas as especializações das categorias de Virtuallnput, bem como a especialização das saídas de dados para suprir especificidades de formatos de codificação de vídeo, áudio e estruturas de dados de retornos de saídas hápticas. Outra questão que deve ser ampliada é o recebimento de dados de saída da execução por meio de fluxo de dados contínuos. Nessa modalidade as operações do serviço de execução serão usadas para estabelecer a conexão do fluxo, não sendo necessário, invocar a operação cada vez que se deseja receber o estado atual das saídas da execução de uma aplicação.

\subsection{Capacidade de Reuso de Elementos de Aplicações}

Cada classe de persistência e domínio projetada permite que o elemento por ela manipulado, possa ser criado, persistido e recuperado de maneira independente dos demais. Por exemplo, é possível manipular instâncias de Resource, independente das demais classes do RM-VRServices, da mesma forma que VirtualObject, Scene, VirtualWorld e Application. Essa organização do projeto arquitetural permite que esses elementos possam ser reusados em inúmeras associações.

A Figura 77 ilustra possíveis situações de reuso de elementos do 
modelo RM-VRServices. A figura apresenta coleções de instâncias de conceitos RM-VRServices e as referências que esboçam suas reutilizações. Podem ser destacadas as instâncias de Model3D referenciadas pelas instâncias de Scene, as instâncias de Scene referenciadas pelas instâncias de VirtualWorld e por fim uma instância de VirtualWorld referenciada por duas instâncias de Application.

Figura 77: Reuso de elementos do RM-VRServices

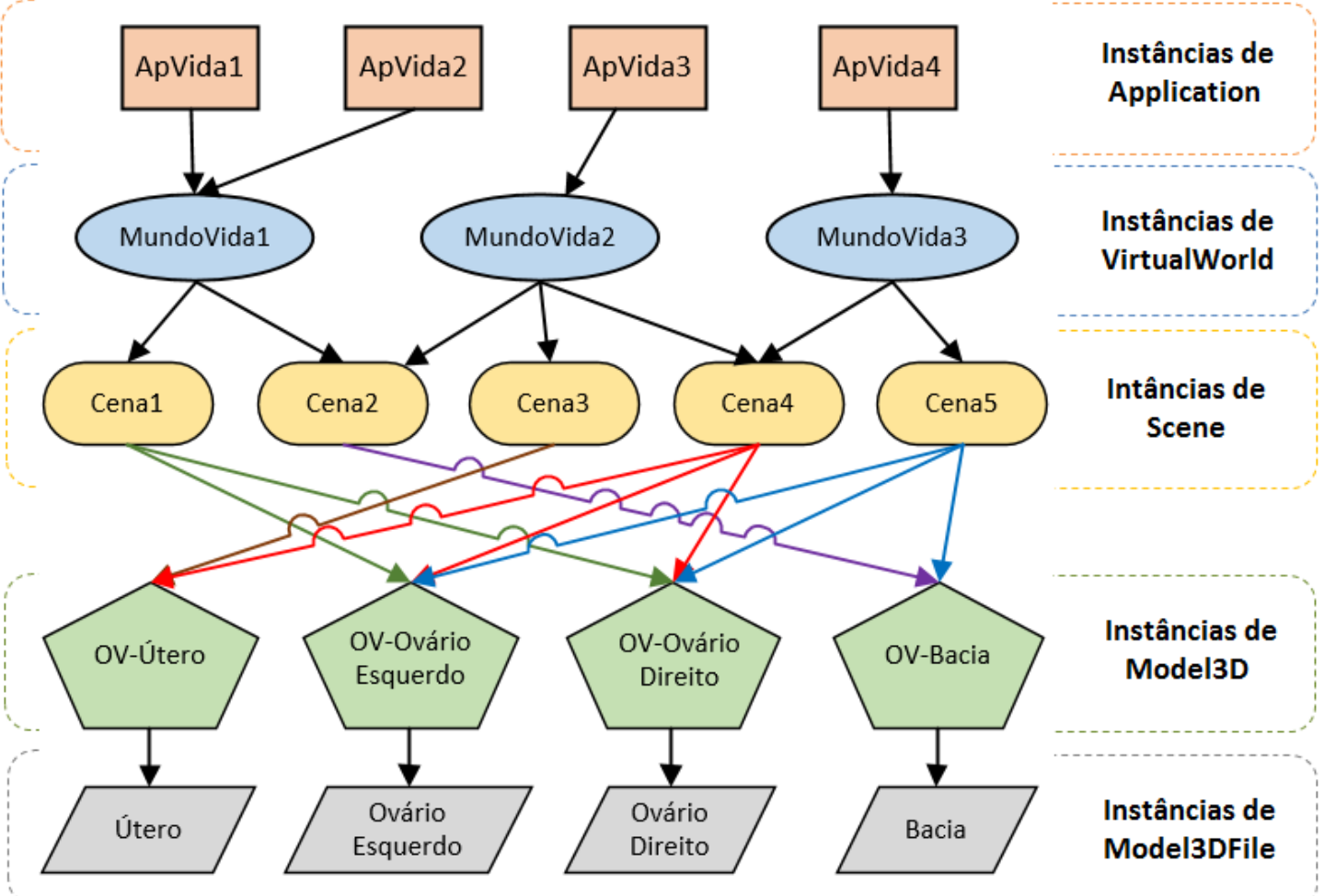

Fonte: Autor (2014)

O projeto arquitetural da plataforma VRServices define duas possibilidades de reuso de elementos do RM-VRServices, uma é o reuso pela referência a elementos existentes no repositório, a outra é o reuso pela duplicação de elementos existentes no repositório.

No modelo RM-VRServices, o reuso por referência é obtido com o relacionamento de agregação, por exemplo, um objeto da classe Scene mantém uma lista de referências a objetos da classe VirtualObjetct. Uma instância de VirtualObjetct pode ser referenciada por inúmeras instâncias de Scene. Da mesma forma, um objeto cena pode ser referenciado por inúmeros objetos de mundos virtuais. $\mathrm{O}$ reuso por referência implica em que, alterações realizadas em objetos referenciados, são propagadas automaticamente para todos os elementos que os referenciam.

O reuso pela duplicação é obtido com a cópia da instância do elemento a ser reusado. O reuso por duplicação implica que o novo elemento criado não tem vinculo 
com o elemento origem. Alterações no elemento de origem não serão propagadas para suas cópias. As cópias de instâncias podem ter suas propriedades alteradas.

Outra possibilidade prevista, mas ainda não definida no modelo RM-VRServices, é o reuso de elementos por herança de valores. Nessa modalidade, cria-se uma cópia da instância a ser reusada, mantem-se um vínculo com o elemento que lhe deu origem. No novo elemento, produzido pela cópia, tem-se a possibilidade de sobreposição de valores da instância herdada, caracterizando uma especialização das características. O reuso por herança de valor implica em que, as alterações ocorridas nas instâncias de origem, são propagadas para as instâncias que as herdaram, exceto para as propriedades que foram sobrepostas.

Para exemplificar o reuso de elementos na plataforma foi produzida uma segunda aplicação (apVida2). O objetivo é evidenciar a capacidade de reuso de elementos previamente inseridos na plataforma. A Figura 78 ilustra a inclusão de uma nova instância de mudo virtual (mundoVida2) que reusa uma das cenas (cena2) já usada na primeira aplicação produzida (apVida). Dessa forma a instância do mundo virtual reusa todas as definições da cena, tais como: objetos virtuais, configuração de fundo, iluminação, transformações geométricas de posicionamento dos objetos virtuais e os recursos associados, no caso os modelos 3D.

Figura 78: Interface do cliente de produção - novo mundo virtual

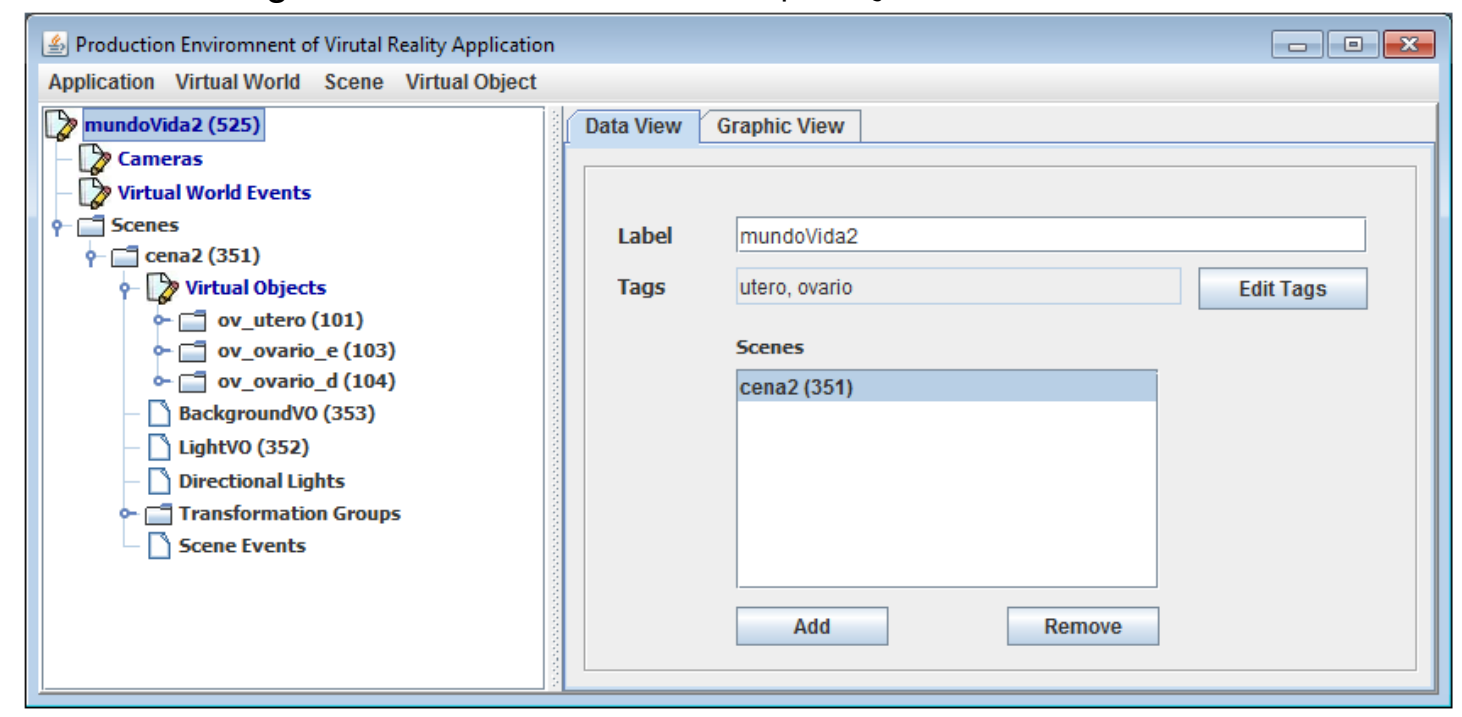

Fonte: Autor (2014)

A Figura 79 ilustra a hierarquia de elementos da aplicação apVida2, definida por meio do mundo virtual mundovida2. Na figura é possível observar, destacado por um retângulo, o reuso da instância cena2 e por consequência o reuso das instâncias dos objetos virtuais e recursos. 
Figura 79: Interface do cliente de produção - reuso da cena2 na Aplicação apVida2

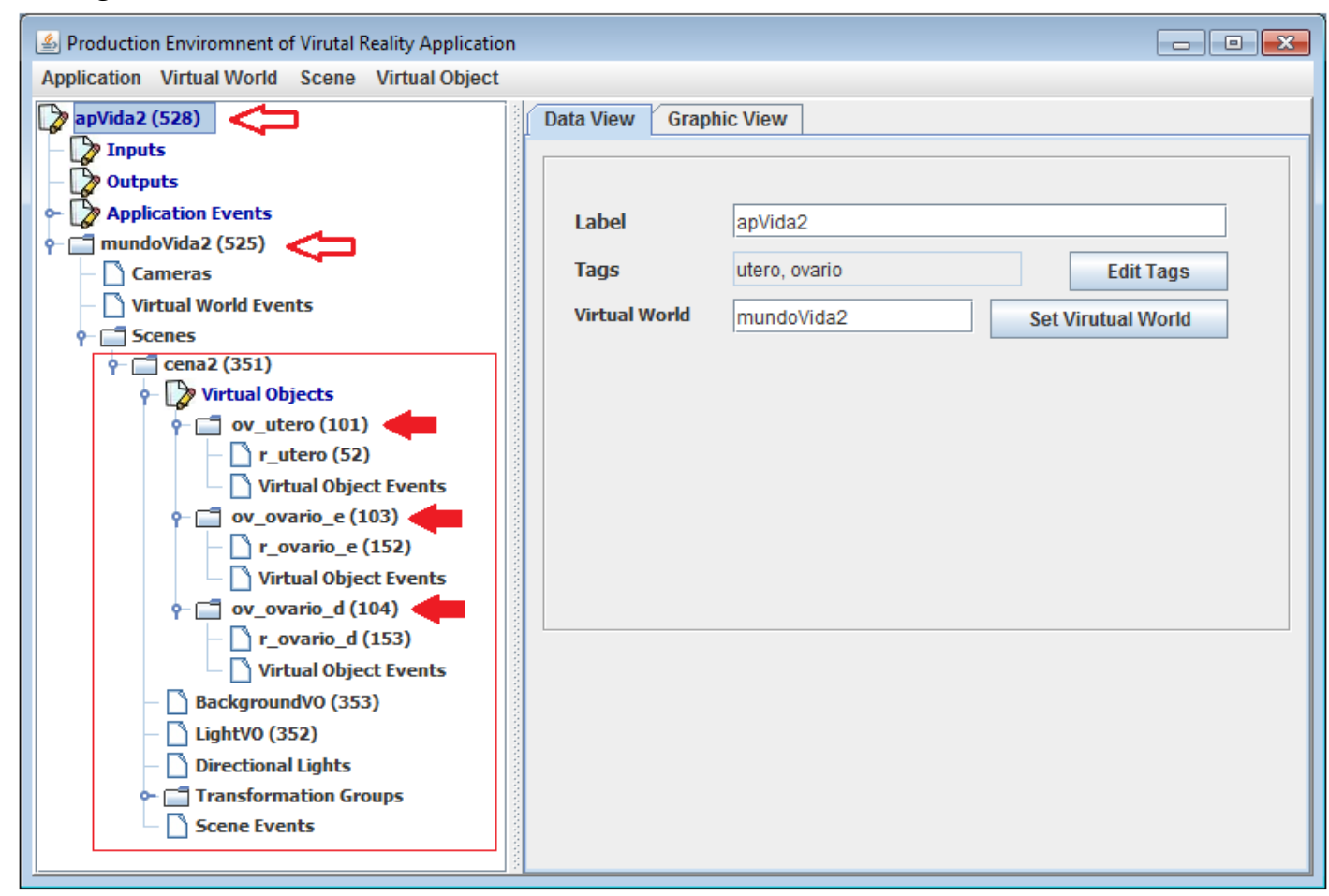

Fonte: Autor (2014)

A Figura 80 ilustra a execução da aplicação apVida2, constituída de uma única cena que reúne três objetos virtuais. A aplicação apVida2 além de personalizar quais objetos virtuais fazem parte do mundo virtual, também pode personalizar as formas de interação por meio da definição de comportamentos específicos para essa instância de aplicação.

Figura 80: Interface do cliente de execução - aplicação apVida2

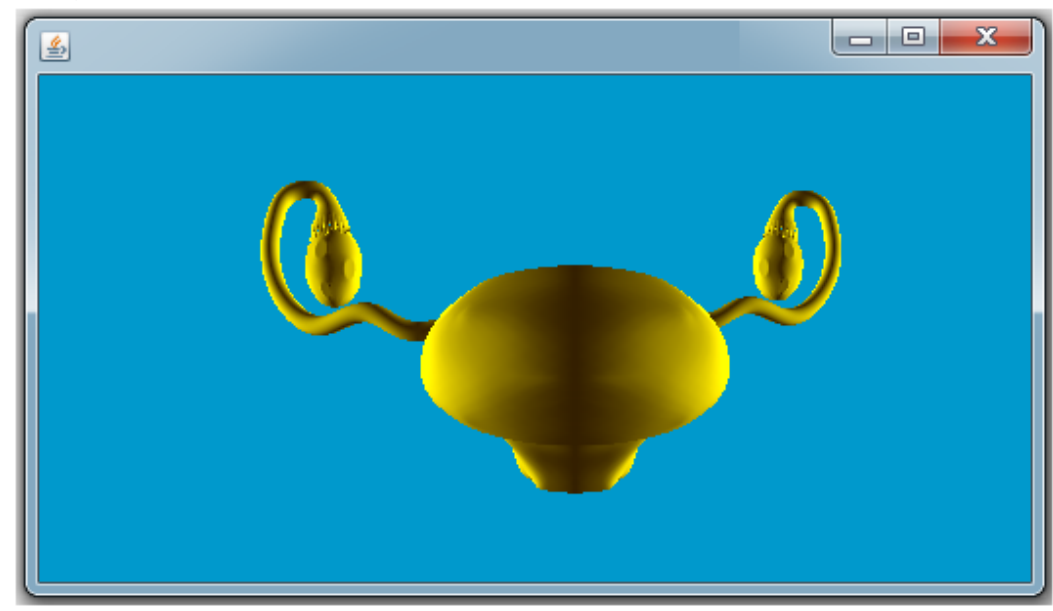

Fonte: Autor (2014)

Assim como foi demonstrado na produção da aplicação apVida2, que reusou a instância de cena2 para a definição de um novo mundo virtual, o modelo 
MR-VRServices, como já foi descrito, permite o reuso de quatro níveis de elementos:

1. reuso de recursos - os recursos inseridos na plataforma podem ser reusados em diferentes situações:

- imagem e texturas - pode ser reusado como plano de fundo de cenas, como texturas de objetos virtuais;

- áudio - pode ser reusado em diferentes cenas;

- modelo 3D - pode ser reusado na definição de diferentes instâncias de objetos virtuais. Cada objeto virtual pode personalizar o uso do modelo 3D aplicando configurações de aparências e comportamentos.

2. reuso de objetos virtuais - instâncias de objetos virtuais podem ser reusadas para compor diferentes instâncias de cenas;

3. reuso de cenas - instâncias de cenas podem ser reusadas para compor diferentes instâncias de mundos virtuais;

4. reuso de mundos virtuais - instâncias de mundos virtuais podem ser reusadas para compor diferentes instâncias de aplicações;

\subsection{Discussão dos Resultados}

Os resultados obtidos até o presente momento evidenciam pontos favoráveis do modelo RM-VRServices e da plataforma VRServices propostos. Em decorrência do modelo de representação e do armazenamento remoto das aplicações de RV, a produção de novas aplicações pode se dar pela composição de elementos existentes em quatro níveis de granularidade: recursos, objetos virtuais, cenas e mundos virtuais. Objetos virtuais, cenas e mundos virtuais armazenados no repositório podem ser reusados para compor diferentes aplicações. O ambiente remoto favorece também o compartilhamento de recursos, tais como: imagens, sons, vídeos, modelos 3D.

O ambiente remoto de produção e execução da plataforma é acessível por meio de serviços, disponibilizados com a tecnologia de Web Services. Essa característica possibilita que qualquer aplicação cliente possa embutir código para consumir os serviços da plataforma. Também possibilita que inúmeros ambientes de produção e execução possam ser produzidos, cada um com características e ferramentas voltadas para um domínio de aplicação desejado. Os ambientes gráficos de produção e execução das aplicações de RV podem ser manipulados por usuários que não possuem conhecimento técnico de desenvolvimento de software, 
especialmente na produção de aplicações de RV.

Com o armazenamento e a execução das aplicações mantida no lado do servidor, o cliente da plataforma não tem a necessidade de fornecer alto potencial de processamento e armazenamento. A virtualização dos dispositivos de entrada permite que os clientes atualizem seus respectivos estados por meio de chamadas de serviços, evitando a necessidade da existência de dispositivos específicos no lado cliente. Também permite que dispositivos não presentes no lado do cliente possam ser simulados ou substituídos por dispositivos similares, sendo necessário apenas que os dados sejam passados para o contexto de execução por meio de chamadas de serviços, conforme as categorias de entradas de dados estabelecidas no modelo RM-VRServices.

O modelo de construção e execução de aplicações RV em ambiente remoto promove uma série de benefícios, conforme discutido acima. Contudo, é reconhecida a existência de fatores críticos para seu uso, tais como: a necessidade de alta velocidade de conexão da rede e a capacidade do modelo de representação oferecido pelo ambiente de produção e execução.

A pesquisa teve como objetivo demonstrar a viabilidade de produção e execução de aplicações de RV em ambiente distribuído por meio da representação conceitual dos elementos que compõem as aplicações. É notória a necessidade de ampliar os estudos para garantir questões relacionadas a desempenho e robustez. Também é necessária a ampliação da capacidade de representação e especificação de comportamento para as aplicações produzidas na plataforma. 


\section{CONCLUSÃO}

Este Capítulo apresenta as considerações finais deste trabalho de pesquisa, considerando os objetivos propostos. São apresentadas as contribuições da pesquisa e as sugestões para trabalhos futuros que podem dar continuidade à pesquisa.

O desenvolvimento de aplicações de RV carece de pesquisas que fomentem a produção de aplicações com níveis de abstração mais alto do que o código fonte, API, extensão de arcabouços ou incorporação de componentes. Também é preciso facilitar a produção, compartilhamento e reuso de elementos de aplicações $\mathrm{RV}$ em diferentes níveis de representação, permitindo a recombinação de elementos existentes para a produção de novos elementos compostos.

Outro fator importante no desenvolvimento de aplicações RV, principalmente em ambientes on-line, é a busca pela interoperabilidade, quer seja na representação de conteúdo ou na capacidade de acesso às funcionalidades existentes. Outra possibilidade de interoperabilidade está relacionada com a capacidade de clientes remotos interagirem com um ambiente compartilhado por meio de diferentes dispositivos de interação, linguagem de programação ou plataforma operacional.

O modelo RM-VRServices e a plataforma VRServices propostos, proporcionam um ambiente on-line de produção e execução de instâncias de aplicações RV, acessível por meio de interfaces de serviços, resultam em vários aspectos favoráveis, tais como:

- permite a produção e armazenamento de aplicações de RV em ambiente on-line. Com o decorrer do uso, será formado um repositório de elementos de aplicações reutilizáveis, que podem ser reusados para o desenvolvimento de outras aplicações;

- a execução de aplicações de RV pode ser mantida on-line, assim os clientes consumidores dos serviços não precisam de recursos computacionais, tais como: alto potencial de processamento, aceleração gráfica, armazenamento, etc. Também facilita a produção de aplicações multiusuários e ambientes colaborativos;

- aumenta o potencial de reuso e compartilhamento de recursos (imagens, 
modelos 3D, sons, texturas), em função da existência de um repositório de recursos que podem ser compartilhados entre os usuários;

- a representação hierárquica orientada a objetos permite a exploração das características de serviços que promovem interoperabilidade de linguagem de programação e de plataforma computacional;

- permite o desenvolvimento de ambientes de produção e execução, baseados em interfaces gráficas com alto grau de abstração, possibilitando que usuários sem conhecimento técnicos de desenvolvimento de software possam produzir e executar aplicações de RV em ambiente on-line.

\subsection{Contribuições}

Este trabalho apresentou a proposição de um modelo de representação de elementos para a instanciação de aplicações de RV, apoiado por uma plataforma baseada em serviços que permite a produção, compartilhamento e execução de aplicações em um ambiente on-line, dentre as contribuições da tese, destacam-se:

- definição do RM-VRServices - não foi observado na literatura investigada uma representação com nível de abstração superior ao de código fonte, associada à capacidade de edição e compartilhamento de elementos de aplicações RV em ambiente on-line;

- definição de entrada virtual de dados - a especialização das modalidades de entradas virtuais de dados, com base nas quatro categorias de dispositivos virtuais propostos por Foley e Wallace (1974), possibilitou o tratamento da entrada de dados para aplicações RV de maneira desvinculada dos dispositivos físicos;

- definição do VRServices - como forma de apoiar o RM-VRServices e permitir o acesso às funcionalidades de produção, compartilhamento e execução de aplicações em ambiente on-line, foi definido um modelo arquitetural baseado em serviços;

- apoio ao ensino de conceitos de RV - o modelo RM-VRServices reúne conceitos, propriedades e relações que podem ser usados para o ensino da disciplina de realidade virtual;

- apoio ao ensino de projeto de software - a plataforma VRService envolve decisões arquiteturais e uso da tecnologia de serviços que podem ser usadas para o ensino de disciplinas que envolvem, projeto de software orientados a objetos e serviços. 
Dessa forma, contribui-se com o processo de desenvolvimento de aplicações de RV, propondo novas formas de representação, compartilhamento e reuso de elementos de aplicações RV.

Artigos publicados no decorrer da pesquisa:

1. Abordagens de Reuso em Aplicações de Realidade Virtual e Aumentada (FREIBERGER; NAKAMURA; NUNES, 2012), publicado no IX Workshop de Realidade Virtual e Aumentada - WRVA 2012, regional;

2. Architectural Model for VR and AR Applications in the Cloud (FREIBERGER; NAKAMURA; TORI, 2013a), publicado no XV Symposium on Virtual and Augmented Reality - SVR 2013, nacional;

3. Plataforma Orientada a Serviços para Aplicações de Realidade Virtual (FREIBERGER; NAKAMURA; TORI, 2013b), publicado na Conferência Ibero-Americana www/Internet - IADIS 2013, internacional;

4. Service-Oriented Platform for Reuse of Interactive Content of Virtual Reality Applications (FREIBERGER; NAKAMURA; TORI, 2014a), publicado no International Journal of e-Education, e-Business, e-Management and e-Learning.

5. Service-Oriented Platform for Virtual Reality Application Development (FREIBERGER; NAKAMURA; TORI, 2014b), publicado no 9TH International Conference on Evaluation of Novel Software Approaches to Software Engineering - ENASE 2014, internacional.

Artigos também foram escritos e apresentados na forma de resumo e pôster a respeito do andamento da pesquisa nas instituições de ensino vinculadas ao doutorado interinstitucional (DINTER) EPUSP/UFMT.

\subsection{Trabalhos Futuros}

No decorrer desta pesquisa foram identificadas algumas possíveis extensões deste trabalho, visando a sua complementação. Algumas propostas são:

- incorporar ao modelo e a plataforma a capacidade de gerenciamento de múltiplos usuários, tanto na definição das aplicações RV, quanto no contexto de execução;

- produzir clientes de produção com simbologia e interfaces adequadas para que usuários sem conhecimento técnico de desenvolvimento de software possam produzir aplicações RV por meio do modelo RM-VRServices e da plataforma VRServices; 
- produzir uma ontologia para identificação e recuperação de elementos nos repositórios da plataforma VRServices;

- com base no modelo RM-VRServices proposto, fomentar a definição de padrões de projeto para o projeto e implementação de aplicações de realidade virtual;

- produzir símbolos iconográficos para cada elemento da hierarquia de conceitos do RM-VRServices, para serem usados no aprendizado do modelo e em interfaces com usuário final em clientes de produção de aplicações;

- ampliar as representações de eventos e comportamentos do modelo RM-VRServices;

- ampliar as representações de objetos virtuais do modelo RM-VRServices, por meio de primitivas geométricas e composição de objetos virtuais.

\subsection{Considerações Finais}

A presente pesquisa apresenta como contribuição inédia a junção de um modelo de representação de aplicações de realidade virtual, associado à capacidade de produção e execução das aplicações produzidas a partir do modelo em um ambiente on-line, acessível por meio de serviços. As provas de conceito realizadas para verificar a capacidade de representação, a capacidade de produção de aplicações RV on-line, a capacidade de execução de aplicações RV on-line e a capacidade de reuso e recombinação de elementos do modelo RM-VRServices e da plataforma VRServices evidenciam que os objetivos estabelecidos para esta pesquisa foram atingidos.

A representação do modelo RM-VRServices por meio de instâncias de objetos permite que as aplicações RV possam ser definidas sem a escrita de código fonte. Essa característica possibilita que as aplicações RV sejam constituídas por objetos editados remotamente e armazenados em repositórios, viabilizando o reuso e compartilhamento. Também contribui para o desenvolvimento de aplicações clientes especializadas na edição de elemento reutilizáveis por usuários sem conhecimento técnico de desenvolvimento de software. A estrutura hierárquica projetada para a representação dos elementos que compõem o modelo resultou na capacidade de reuso das representações produzidas a partir do RM-VRServices em quatro níveis de granularidade.

O modelo arquitetural da plataforma proposta dá suporte a edição, armazenamento e compartilhamento remoto de elementos do modelo RM-VRServices, além de possibilitar a execução das aplicações em ambiente 
on-line. Isso foi possível por dois fatores, o primeiro é devido representação dos elementos ser realizada por meio de uma hierarquia de instâncias de objetos, e o segundo é em função do acesso às funcionalidades da plataforma ser por meio de serviços. Assim, o objetivo foi alcançado em função da junção dos fatores, pois não seria possível editar e compartilhar partes de código fonte de linguagens como C, $\mathrm{C}++$, Java, VRML ou X3D, remotamente, on-line, em ambiente concorrente e com possibilidade de recombinação de partes existentes para produzirem novas aplicações.

Outro resultado importante desta pesquisa são as várias possibilidades de interoperabilidade obtidas com a junção do modelo MR-VRServices e da plataforma VRServices. Pode-se enumerar: 1) interoperabilidade de acesso às funcionalidades de produção, que permite que clientes de produção implementados em qualquer linguagem de programação, sendo executado em qualquer plataforma computacional possam produzir novos elementos ou consultar e usar os elementos existentes nos repositórios; 2) interoperabilidade de acesso às funcionalidades de execução do contexto de execução da plataforma; 3) interoperabilidade de dispositivos de entrada de dados, em função da representação virtual baseada na funcionalidade da entrada e não dos dispositivos físicos; 4) interoperabilidade de saída de dados, também generalizada pela função da informação, e não baseada em dispositivos físicos de saída.

Apesar dos resultados das provas de conceito apontarem para a viabilidade do modelo de representação e para o modelo arquitetural propostos, é notório algumas limitações, considerando o estágio atual da pesquisa.

É necessário, por exemplo, implementar técnicas que melhorem o desempenho da plataforma, dentre elas: 1) incorporar uma biblioteca gráfica que permita o gerenciamento de vários clusters de processamento gráfico, como é o exemplo da biblioteca VR Juggler (BIERBAUM et al., 2001); 2) implementar canais de saída de dados baseados em fluxos de dados, como é o caso dos trabalhos (ZHANG; GRACANIN, 2007), (ZHANG; GRACANIN, 2008a) e (ZHANG; GRACANIN, 2008b); 3) incorporar um ESB na plataforma VRServices para permitir a replicação de servidores de serviços, permitindo a redundância de serviços e o balanceamento de carga entre os servidores.

Também é preciso incorporar novas capacidades à plataforma VRServices, como: 1) incorporar motores de interpretação de scripts para permitir a definição de comportamentos por meio de scripts, além dos comportamentos pré-definidos no modelo RM-VRServices; e, 2) incorporar novos carregadores de modelos 3D 
armazenados em arquivos, ampliando a capacidade de uso de diferentes formatos de representação de modelos 3D. 


\section{REFERÊNCIAS}

ALLARD, J. et al. FlowVR: A middleware for large scale virtual reality applications. In: DANELUTTO, M.; VANNESCHI, M.; LAFORENZA, D. (Ed.). Euro-Par 2004 Parallel Processing. Berlin, Heidelberg: Springer Berlin Heidelberg, 2004. v. 3149, p. 497-505. ISBN 978-3-540-22924-7.

BASS, L.; CLEMENTS, P.; KAZMAN, R. Software Architecture in Practice. 2. ed. Boston, MA: Addison-Wesley Professional, 2003. ISBN 0-321-15495-9.

BAUER, C.; KING, G. Java Persistence com Hibernate. Rio de Janeiro-RJ: Ciência Moderna, 2007. ISBN 978-85-7393-614-8.

BAUER, M. et al. Design of a component-based augmented reality framework. In: IEEE and ACM International Symposium on Augmented Reality, 2001. Proceedings. IEEE, 2001. p. 45-54. ISBN 0-7695-1375-1. Disponível em: <http://dx.doi.org/10.1109/ISAR. 2001.970514>.

BEIN, D.; BEIN, W.; MADIRAJU, P. The impact of cloud computing on web 2.0. Economy Informatics Journal, v. 9, n. 1/2009, 2009. Disponível em: <http://www.egr. unlv.edu/ bein/pubs/eij-final_Bein_Masiraju.pdf>.

BIERBAUM, A. et al. VR juggler: a virtual platform for virtual reality application development. In: Proceedings - IEEE Virtual Reality. Yokohama, Japan: IEEE, 2001. p. 89-96. Disponível em: <http://dx.doi.org/10.1109/VR.2001.913774>.

BIOCCA, F.; LEVY, M. R. (Ed.). Communication in the Age of Virtual Reality. Hillsdale, New Jersey: Routledge, 1995. ISBN 0805815503.

BRUGGE, B.; MACWILLIAMS, A.; REICHER, T. Study on Software Architectures for Augmented Reality Systems. Institut fur Informatik, 2002. 81 p.

CHEVAILLIER, P. et al. Semantic modeling of virtual environments using MASCARET. In: 2012 5th Workshop on Software Engineering and Architectures for Realtime Interactive Systems (SEARIS). Orange County, CA: IEEE, 2012. p. 1-8.

CORRÊA, C. G.; NUNES, F. L. S. Integração com dispositivos convencionais e não convencionais utilizando integração entre linguagens de programação. In: NUNES, F. L. S. et al. (Ed.). Abordagens Práticas de Realidade Virtual e Aumentada. Porto Alegre-RS: Sociedade Brasileira de Computação - SBC, 2009, (XI Symposium on Virtual and Augmented Reality, SVR2009). p. 146.

ERL, T. Soa Princípios de Design de Serviços. São Paulo-SP: Prentice Hall Brasil, 2009. ISBN 978-85-7605-189-3.

FACEBOOK. Rede Social, Facebook. 2014. Disponível em: <https://developers. facebook.com/>. Acesso em: 2014-03-03. 
FAYAD, M. E.; SCHMIDT, D. C.; JOHNSON, R. E. Building Application Frameworks. United States of America: Wiley Computer Publishing, 1999. ISBN 0-471-24875-4.

FILHO, R. F. d. A. Hydra: Arquitetura e Framework para Desenvolvimento de ambientes Virtuais. Tese (Mestrado) - Universidade Federal de Pernambuco, Recife-PE, 2011.

FILHO, R. F. d. A.; TEICHRIEB, V.; KELNER, J. Hydra: Virtual environments development platform. In: 2011 XIII Symposium on Virtual Reality (SVR). Uberlandia: IEEE, 2011. p. 102-111. Disponível em: <http://dx.doi.org/10.1109/SVR.2011.22>.

FOLEY, J.; WALLACE, V. The art of natural graphic man-machine conversation. Proceedings of the IEEE, v. 62, n. 4, p. 462-471, 1974. ISSN 0018-9219. Disponível em: <http://dx.doi.org/10.1109/PROC.1974.9450>.

FOLMER, E. Component based game development - a solution to escalating costs and expanding deadlines? In: SCHMIDT, H. W. et al. (Ed.). Component-Based Software Engineering. Berlin, Heidelberg: Springer Berlin Heidelberg, 2007. v. 4608, p. 66-73. ISBN 978-3-540-73550-2.

FOWLER, M. Padrões de Arquitetura de Aplicações Corporativas. Porto Alegre-RS: Bookman, 2006. ISBN 85-363-0638-6.

FREIBERGER, E. C.; NAKAMURA, R.; NUNES, F. L. S. Abordagens de reuso em aplicações de realidade virtual e aumentada. In: IX Workshop de Realidade Virtual e Aumentada - WRVA 2012. Paranavaí-PR: SBC, 2012. ISBN 1984-0799.

FREIBERGER, E. C.; NAKAMURA, R.; TORI, R. Architectural model for VR and AR applications in the cloud. In: 2013 XV Symposium on Virtual and Augmented Reality (SVR). Cuiabá-MT: SBC, 2013. p. 280-283. Disponível em: <http://dx.doi.org/10.1109/ SVR.2013.35>.

Plataforma orientada a serviços para aplicações de realidade virtual. In: Conferência IADIS Ibero-Americana www/Internet 2013. São Leopoldo-RS: IADIS Press, 2013. V. 1, p. 107-114. ISBN 978-972-8939-95-3.

. Service-oriented platform for reuse of interactive content of virtual reality applications. International Journal of e-Education, e-Business, e-Management and e-Learning, v. 4, n. 3, p. 224-231, 2014. ISSN 20103654. Disponível em: <http: //dx.doi.org/10.7763/IJEEEE.2014.V4.335>.

Service-oriented platform for virtual reality application development. In: 9th International Conference on Evaluation of Novel Software Approaches to Software Engineering - ENASE 2014. Lisboa, Portugal: SCITEPRESS - Science and and Technology Publications, 2014. p. 196-203. ISBN 978-989-758-030-7. Disponível em: <http://dx.doi.org/10.5220/0004895301960203>.

GAMMA, E. et al. Padrões de Projeto - Soluções reutilizáveis de software orientado a objetos. Porto Alegre-RS: Bookman, 2007. ISBN 978-85-7307-610-3.

Google. Aplicativos para produtividade, Google Apps for Business. 2014. Disponível em: <http://www.google.com/intx/pt-BR/enterprise/apps/business/>. Acesso em: 2014-03-03. 
HE, T.; KAUFMAN, A. Virtual input devices for 3d systems. In: Proceedings - IEEE Conference on Visualization. San Jose, CA: IEEE, 1993. p. 142-148. Disponível em: <http://dx.doi.org/10.1109/VISUAL.1993.398862>.

JINHONG, W. et al. A virtual high-speed railway scene modeling method based on basic-element model combination. In: 2013 Seventh International Conference on Image and Graphics (ICIG). Qingdao: [s.n.], 2013. p. 711-715. Disponível em: <http://dx.doi.org/10.1109/ICIG.2013.144>.

JORDAN, K.; PACKER, R. (Ed.). Multimedia-From Wagner to Virtual Reality, Expanded Edition. Expanded edition. New York, NY: W. W. Norton \& Company, 2002. ISBN 0393323757.

KALIN, M. Java Web Services - Implementando. Rio de Janeiro-RJ: Alta Books, 2010. ISBN 9780596521127.

KITCHENHAM, B. Procedures for Performing Systematic Reviews. Department of Computer Science - Keele University. Austrália, 2004.

KUMAR, B. V.; NARAYAN, P.; NG, T. Implementando SOA usando Java EE. Rio de Janeiro-RJ: Alta Books, 2012. (Java). ISBN 978-85-7608-597-3.

KURKOVSKY, S. et al. Convergence of web 2.0 and SOA: Taking advantage of web services to implement a multimodal social networking system. In: Computational Science and Engineering Workshops, 2008. CSEWORKSHOPS '08. 11th IEEE International Conference on. [s.n.], 2008. p. 227 -232. Disponível em: <http://dx.doi. org/10.1109/CSEW.2008.15>.

LA, H. J.; KIM, S. D. A conceptual framework for provisioning context-aware mobile cloud services. In: 2010 IEEE 3rd International Conference on Cloud Computing (CLOUD). IEEE, 2010. p. 466-473. ISBN 978-1-4244-8207-8. Disponível em: <http: //dx.doi.org/10.1109/CLOUD.2010.78>.

LAB, L. Site oficial do Second Life. 2014. Disponível em: <http://secondlife.com/>.

LARMAN, C. Utilizando UML e Padrões. 3. ed. Porto Alegre-RS: Bookman, 2007. ISBN 978-85-60031-52-8.

LI, M.; WANG, S.; HE, T. A transformer substation simulation engine based on virtual reality. In: International Conference on Computer, Mechatronics, Control and Electronic Engineering (CMCE). Changchun: IEEE, 2010. v. 2, p. 41-44. ISBN 978-1-4244-7957-3. Disponível em: <http://dx.doi.org/10.1109/CMCE.2010. $5609559>$.

LINKEDIN. Rede Profissional, Linkedln. 2014. Disponível em: <https://www.linkedin. com/>. Acesso em: 2014-03-03.

LLORA, X. et al. Meandre: Semantic-driven data-intensive flows in the clouds. In: IEEE Fourth International Conference on eScience, 2008. eScience '08. IEEE, 2008. p. 238-245. ISBN 978-1-4244-3380-3. Disponível em: <http://dx.doi.org/10.1109/ eScience.2008.172>. 
LUZ, R. P. d.; KIRNER, T. G. Processo de desenvolvimento de sistemas de realidade virtual. In: TORI, R.; KIRNER, C.; SISCOUTTO, R. (Ed.). Fundamentos e Tecnologia de Realidade Virtual e Aumentada. Belém-PA: Sociedade Brasileira de Computação SBC, 2006. ISBN 85-7669-068-3.

MIAN, P. G.; NATALI, A. C. C.; TRAVASSOS, G. H. Systematic Review in Software Engineering. Engenharia de Sistemas e Departamento de Ciência da Computação COOPE. Rio de Janeiro, 2005. $31 \mathrm{p}$.

$\mathrm{MILI}, \mathrm{H}$. et al. Reuse based software engineering: techniques, organization and measurement. New York: Wiley, 2002. ISBN 0-471-39819-5.

MUKUNDAN, R. Scene graphs. In: Advanced Methods in Computer Graphics. London: Springer, 2012. p. 31-52. ISBN 978-1-4471-2339-2, 978-1-4471-2340-8.

MYERS, B. A. A new model for handling input. ACM Trans. Inf. Syst., v. 8, n. 3, p. 289-320, jul. 1990. ISSN 1046-8188. Disponível em: <http://dx.doi.org/10.1145/ 98188.98204>.

OLIVEIRA, A. C. M. T. G.; NUNES, F. d. L. d. S. Building a open source framework for virtual medical training. Journal of digital imaging : the official journal of the Society for Computer Applications in Radiology, v. 23, n. 6, 2010. ISSN 1618-727X.

OLIVEIRA, A. C. M. T. G. et al. Virtual reality framework for medical training: implementation of a deformation class using java. In: Proceedings of the 2006 ACM international conference on Virtual reality continuum and its applications. New York, NY, USA: ACM, 2006. (VRCIA '06), p. 347-351. ISBN 1-59593-324-7. Disponível em: $<$ http://dx.doi.org/10.1145/1128923.1128985>.

OLIVEIRA, M.; CROWCROFT, J.; SLATER, M. An innovative design approach to build virtual environment systems. In: Proceedings of the workshop on Virtual environments 2003. Zurich, Switzerland: ACM, 2003. (EGVE '03), p. 143-151. ISBN 1-58113-686-2. ACM ID: 769970. Disponível em: <http://dx.doi.org/10.1145/769953.769970>.

PAGE-JONES, M. Fundamentos do desenho orientado a objeto com UML. São Paulo-SP: Makron Books, 2001. ISBN 1243-9.

PAN, K. et al. Multi-user gaming on the grid using a service oriented HLA RTI. In: 13th IEEE/ACM International Symposium on Distributed Simulation and Real Time Applications, 2009. DS-RT '09. IEEE, 2009. p. 48-56. ISBN 978-0-7695-3868-6. Disponível em: <http://dx.doi.org/10.1109/DS-RT.2009.39>.

PAPAZOGLOU, M. et al. Service-oriented computing: State of the art and research challenges. Computer, v. 40, n. 11, p. 38-45, 2007. ISSN 0018-9162. Disponível em: $<$ http://dx.doi.org/10.1109/MC.2007.400>.

PAPAZOGLOU, M. P.; HEUVEL, W. J. V. D. Service oriented architectures: Approaches, technologies and research issues. VLDB Journal, v. 16, n. 3, p. 389-415, 2007.

PAPAZOGLOU, M. P. et al. Service-oriented computing: A research roadmap. International Journal of Cooperative Information Systems, v. 17, n. 2, p. 223-255, 2008. 
PAVLIK, R.; VANCE, J. VR JuggLua: A framework for VR applications combining lua, OpenSceneGraph, and VR juggler. In: 2012 5th Workshop on Software Engineering and Architectures for Realtime Interactive Systems (SEARIS). Orange County, CA: [s.n.], 2012. p. 29-35. Disponível em: <http://dx.doi.org/10.1109/SEARIS. 2012.6231166>.

PRIETO-DIAZ, R. Status report: software reusability. IEEE Software, v. 10, n. 3, p. 61-66, 1993. ISSN 0740-7459. Disponível em: <http://dx.doi.org/10.1109/52. 210605>.

SAMETINGER, J. Software Engineering with Reusable Components. 1997. ed. Berlin: Springer-Verlag, 2001. ISBN 3540626956.

SHAO, G.; MCGRAW, R. Service-oriented simulations for enhancing situation awareness. In: Proceedings of the 2009 Spring Simulation Multiconference. San Diego, California: Society for Computer Simulation International, 2009. (SpringSim '09), p. 48:1-48:7. ACM ID: 1639859.

SHERMAN, W. R.; CRAIG, A. B. Understanding virtual reality interface, application, and design. San Francisco, CA: Morgan Kaufmann, 2003. ISBN 9780080520094 008052009X.

SILVA, R. J. M. d.; RAPOSO, A. B.; GATTASS, M. Grafo de Cena e Realidade Virtual. Rio de Janeiro-RJ: PUC-RIO, 2004. ISBN 0103-9741.

SOMMERVILLE, I. Engenharia de Software. 8. ed. São Paulo-SP: Pearson Education do Brasil, 2007. ISBN 978-85-88639-28-7.

TAYLOR, C.; PASQUALE, J. Towards a proximal resource-based architecture to support augmented reality applications. In: Virtual Reality Workshop (CMCVR), 2010 Cloud-Mobile Convergence for. Waltham, MA: IEEE, 2010. p. 5-9. ISBN 978-1-4244-5859-2. Disponível em: <http://dx.doi.org/10.1109/CMCVR.2010. $5560606>$.

TOBLER, R. Separating semantics from rendering: a scene graph based architecture for graphics applications. The Visual Computer, v. 27, n. 6-8, p. 687-695, 2011. ISSN 0178-2789. Disponível em: <http://dx.doi.org/10.1007/s00371-011-0572-0>.

TORI, R.; KIRNER, C. Fundamentos de realidade virtual. In: TORI, R.; KIRNER, C.; SISCOUTTO, R. (Ed.). Fundamentos e Tecnologia de Realidade Virtual e Aumentada. VIII Symposium on Virtual Reality Belém - PA: Editora SBC - Sociedade Brasileira de Computação, Porto Alegre, 2006. p. 02-21. ISBN 85-7669-0683.

TORI, R. et al. Design de interação para um atlas virtual de anatomia usando realidade aumentada e gestos. In: Interation 2009. São Paulo-SP: [s.n.], 2009.

TROYER, O. D. et al. Conceptual modeling for virtual reality. In: Tutorials, Posters, Panels and Industrial Contributions at the 26th International Conference on Conceptual Modeling - Volume 83. Darlinghurst, Australia, Australia: Australian Computer Society, Inc., 2007. (ER '07), p. 3-18. ISBN 978-1-920682-64-4.

TWITTER. Rede social, Microblogging, Twitter. 2014. Disponível em: <https://twitter. com/>. Acesso em: 2014-03-03. 
VERBRAECK, A.; HOUTEN, S. T. van. From simulation to gaming: an object-oriented supply chain training library. In: Simulation Conference, 2005 Proceedings of the Winter. IEEE, 2005. ISBN 0-7803-9519-0. Disponível em: <http://dx.doi.org/10.1109/ WSC.2005.1574525>.

W3C. Web Services Description Language-Core Language. W3C, 2007. Disponível em: <http://www.w3.org/TR/2007/REC-wsdl20-20070626/>. Acesso em: 2014-02-03.

WANG, A. J. A.; QIAN, K. Component-Oriented Programming. 1. ed. Georgia-USA: Wiley-Interscience, 2005. ISBN 0471644463.

WAZLAWICK, R. S. Análise e Projeto de Sistemas de Informação Orientados a Objetos. 1. ed. Rio de Janeiro: Elsevier, 2004. ISBN 85-352-1564-6.

WIKIPEDIA. Wiki, Wikipedia. 2014. Disponível em: <http://www.wikipedia.org/>. Acesso em: 2014-03-03.

YOUTUBE. Compartilhamento de Vídeos, YouTube. 2014. Disponível em: <http://www. youtube.com/>. Acesso em: 2014-03-03.

ZHANG, X.; GRACANIN, D. From coarse-grained components to DVE applications: A service- and component-based framework. In: Proceedings of the Twelfth International Conference on 3D Web Technology. New York, NY, USA: ACM, 2007. (Web3D '07), p. 113-121. ISBN 978-1-59593-652-3. Disponível em: <http://dx.doi.org/10.1145/ 1229390.1229411>.

Service-oriented-architecture based framework for multi-user virtual environments. In: Proceedings of the 40th Conference on Winter Simulation. Miami, Florida: Winter Simulation Conference, 2008. (WSC '08), p. 1139-1147. ISBN 978-1-4244-2708-6.

. Streaming web services for $3 d$ portal applications. In: Proceedings of the 13th international symposium on 3D web technology. New York, NY, USA: ACM, 2008. (Web3D '08), p. 23-26. ISBN 978-1-60558-213-9. Disponível em: <http://dx.doi.org/ $10.1145 / 1394209.1394216>$. 


\section{APÊNDICE A - REVISÃO SISTEMÁTICA}

A revisão sistemática realizada nesse trabalho teve o objetivo de identificar plataformas que dão suporte ao desenvolvimento de aplicações de RV e RA com reuso de elementos de software. Para a condução da revisão foi produzido um protocolo elaborado com base nos modelos propostos em (KITCHENHAM, 2004) e (MIAN; NATALI; TRAVASSOS, 2005).

\section{A.1 Protocolo de Revisão}

Para responder as questões de pesquisa foram usadas strings de busca aplicadas nos motores de busca das bases IEEE (IEEE Xplore Digital Library ${ }^{1}$ ), ACM (ACM Digital Library ${ }^{2}$ ) e SprigerLink ${ }^{3}$. As pesquisas foram realizadas no segundo semestre de 2011, tendo como critérios de filtragem o período de 2001 a 2011, sendo considerados os campos título e resumo para busca das palavras-chave.

O protocolo de revisão sistemática foi desenvolvido para responder as seguintes questões de pesquisa:

- Quais são as arquiteturas existentes para o desenvolvimento de aplicações de RV e RA em ambiente computacional de nuvem?

- Quais são as arquiteturas existentes para o desenvolvimento de jogos pervasivos em ambiente computacional de nuvem?

- Quais técnicas e representações são usadas para construir/definir aplicações a partir dessas arquiteturas?

As Strings executadas nas bases IEEE, ACM e SprigerLink foram:

- component AND reuse AND ("virtual reality"OR "augmented reality"OR game OR VR OR AR)

\footnotetext{
${ }^{1} \mathrm{http}: / /$ ieeexplore.ieee.org

${ }^{2} \mathrm{http}: / / \mathrm{dl} . \mathrm{acm} . \mathrm{org} /$

${ }^{3} \mathrm{http}: / /$ link.springer.com/
} 
- service AND reuse AND ("virtual reality"OR "augmented reality"OR game OR VR OR AR)

- component AND reuse AND ("cloud computing"OR "mobile computing"OR "service computing")

- service AND reuse AND ("cloud computing"OR "mobile computing"OR "service computing")

- reference AND architecture AND ("cloud computing"OR "mobile computing"OR "service computing")

- reference AND architecture AND ("virtual reality"OR "augmented reality"OR game OR VR OR AR)

- reuse $A N D$ architecture $A N D$ ("virtual reality"OR "augmented reality"OR "game"OR "VR"OR "AR")

- reuse AND architecture AND ("cloud computing"OR "mobile computing"OR "service computing")

Foram estabelecidos critérios de inclusão e exclusão para os trabalhos obtidos com as pesquisas nas bases de dados. Os critérios de inclusão são:

Cl1 - Descrições de plataformas de software que dão suporte ao desenvolvimento de aplicações de RV e RA em ambiente computacional de nuvem e Web 2.0;

Cl2 - Descrições de linguagens e representações que possibilitem a construção de aplicações de RV e RA sobre arquiteturas, frameworks ou plataformas de software;

Cl3 - Descrições de aplicações de RV e RA desenvolvidas por meio de reuso de componentes de software;

Cl4 - Descrições de arquiteturas/frameworks que dão suporte ao desenvolvimento de aplicações RV e RA.

Os critérios de exclusão são:

CE1 - Trabalhos que simplesmente descrevam aplicações de RV e RA sem uma abordagem de reuso ou generalização de elementos de software;

CE2 - Artigos que abordam o assunto de RV e RA em Nuvem, com foco em questões ligadas a infraestrutura da nuvem, questões de desempenho, questões de segurança e balanceamento de carga;

CE3 - Artigos cujos arquivos não estejam disponíveis on-line;

CE4 - Artigos cujo foco não corresponda à questão de pesquisa. 


\section{A.1.1 Processo de Seleção dos Trabalhos}

Os trabalhos obtidos com a revisão devem subsidiar a definição de uma arquitetura de componentes e serviços capazes de generalizar as principais funções de um grupo de aplicações que envolvam RV e RA em ambiente de computação em nuvem. Para isso, os trabalhos obtidos com as buscas foram tratados em três etapas: seleção preliminar, seleção final e sumarização dos resultados. A seguir são detalhadas cada uma dessas etapas.

Os trabalhos recuperados das bases foram inicialmente armazenados em um software de organização de referências bibliográficas (Zotero ${ }^{4}$ ), em seguida foi realizada a leitura dos resumos dos trabalhos recuperados. Constatando-se a relevância dos trabalhos, observada pela análise do resumo, eles foram selecionados para leitura na íntegra. Em seguida, foram registrados em um formulário de condução da revisão e selecionados com base nos critérios previamente definidos.

O processo de seleção final consistiu da leitura completa dos trabalhos selecionados na etapa de seleção preliminar. Foi produzida uma síntese geral e algumas considerações sobre os resultados observados nos trabalhos selecionados, destacando os trabalhos que são aderentes as questões de generalização e reutilização de componentes de software usados na construção de aplicações de RV e RA. Para conceitos clássicos provenientes de livros, teses de doutorado e dissertações de mestrado da área, serão realizados fichamentos de conteúdo acompanhado de um fichamento de citações.

\section{A.1.2 Sumarização dos resultados}

Por meio dos critérios definidos para seleção dos estudos, os artigos encontrados durante a revisão, sejam eles incluídos ou excluídos, foram agrupados e ordenados em uma tabela pelos seguintes critérios:

1. Generalização de componentes de software de RV e RA;

2. Proposta arquitetural para software de RV e RA;

3. Linguagens / representações para definição de aplicações a partir de uma plataforma de componentes de RV e RA;

4. Uso de paradigma de serviços na construção de aplicações de RV e RA;

5. Uso de ambiente computacional de nuvem para construção de aplicações de RV e RA.

\footnotetext{
${ }^{4}$ https://www.zotero.org/
} 
A condução do protocolo de revisão sistemática produziu um conjunto de 134 artigos. Desses, 27 foram selecionados pelos critérios de inclusão estabelecidos. Com a leitura detalhada dos 27 artigos, verificou-se a existência de um subconjunto de 11 artigos, cujas propostas, compreendem o uso de abordagens de reuso de software para produção de aplicações de RV e RA.

A Tabela 7 apresenta a distribuição dos artigos analisados em relação as abordagens de desenvolvimento de software utilizadas como estratégias para o reuso de software, no desenvolvimento de aplicações de RV e RA. É possível observar que vários trabalhos usam mais de uma abordagem para proporcionar o reuso de software. As colunas da tabela usam as seguintes siglas: Framework (Arcabouço de software), DBC (Desenvolvimento Baseado em Componentes), COS (Computação Orientada a Serviços) e Nuvem (Computação em Nuvem).

Tabela 7: Artigos por abordagem de Desenvolvimento

\begin{tabular}{|c|c|c|c|c|}
\hline \multirow[t]{2}{*}{ Artigos } & \multicolumn{4}{|c|}{ Abordagem de Desenvolvimento } \\
\hline & Framework & DBC & $\cos$ & Nuvem \\
\hline Bauer et al. (2001) & $x$ & $x$ & $x$ & \\
\hline Oliveira, Crowcroft e Slater (2003) & $\mathrm{x}$ & $\mathrm{X}$ & & \\
\hline Brugge, MacWilliams e Reicher (2002) & & $x$ & & \\
\hline Allard et al. (2004) & & $x$ & & \\
\hline Verbraeck e Houten (2005) & & $x$ & & \\
\hline Llora et al. (2008) & & $\mathrm{X}$ & & \\
\hline Pan et al. (2009) & $\mathrm{x}$ & $\mathrm{x}$ & $\mathrm{x}$ & \\
\hline Shao e McGraw (2009) & $x$ & & $\mathrm{x}$ & $\mathrm{x}$ \\
\hline Oliveira e Nunes (2010) & $x$ & & & \\
\hline La e Kim (2010) & $x$ & & $\mathrm{X}$ & $x$ \\
\hline Li, Wang e He (2010) & & $\mathrm{X}$ & & \\
\hline
\end{tabular}

Fonte: Autor (2014)

A Figura 81 apresenta o gráfico que sintetiza a distribuição de abordagens de desenvolvimento de software observadas nos trabalhos analisados. O estudo mostrou que a abordagem de desenvolvimento baseada em componentes é largamente utilizada no desenvolvimento de plataformas de produção de aplicações de RV e RA, aparecendo em 8 trabalhos. Outra abordagem presente em 6 dos trabalhos, é a de arcabouços especializado por domínios de problema. A computação orientada a serviços foi identificada em 4 dos trabalhos e computação em nuvem em 2 trabalhos.

A revisão sistemática produziu um resultado que aponta, por um lado, a ampla utilização do desenvolvimento baseado em componentes, por outro, pode-se observar um número baixo do uso da abordagem de computação orientada a serviços nos domínios investigados. Uma hipótese é que COS não garanta o atendimento de todos 
Figura 81: Artigos por Abordagem de Desenvolvimento

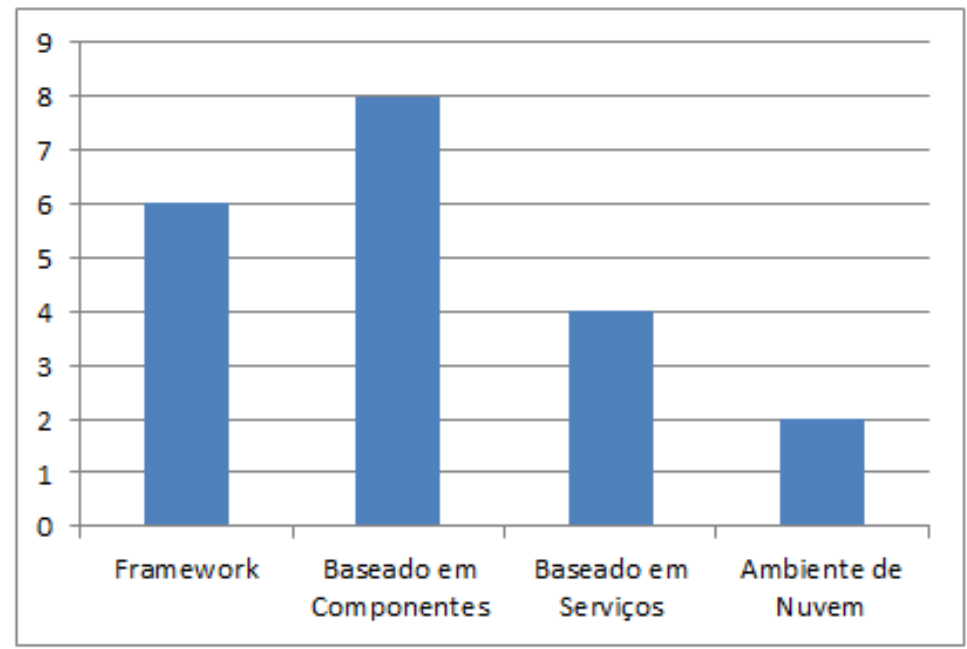

Fonte: Autor (2014)

os requisitos desses domínios de aplicação, outra é que, como COS é uma abordagem relativamente nova, ainda não foi amplamente explorada em tais domínios. Também ficou evidente, o número reduzido de trabalhos que propõem arquiteturas de referência para os domínios de RV e RA. 


\section{APÊNDICE B - LISTAGEM DE CLASSES POR SUBSISTEMA}

Neste apêndice é apresentada uma listagem das classes implementadas como prova de conceito para o modelo RM-VRServices e para a plataforma VRSevices. As classes são divididas por subsistema e em cada subsistema são divididas em pacotes. A listagem foi produzida por meio da ferramenta Javadoc da plataforma de desenvolvimento Java, que gera a documentação a partir do código fonte e comentários específicos inseridos nas classes.

\section{B.1 Subsistema de Recursos}

\section{B.1.1 Lado Servidor}

\section{Package platform.resource.service}

\begin{tabular}{|ll|}
\hline Class & Description \\
\hline ResourceManagerService & $\begin{array}{l}\text { Publica as funcionalidades relacionadas a manutencao de instancias de Resource por meio de } \\
\text { servicos (WebServices). }\end{array}$ \\
\hline
\end{tabular}

Package platform.resource.domain

\begin{tabular}{|ll|}
\hline Class & Description \\
\hline Resource & Classe de dominio que representa a manipulacao de instancias de Resourcevo. \\
\hline ResourceManager & Centraliza as acoes relacionadas ao gerenciamento de recursos (imagem, vídeos, sons, texturas, etc). \\
\hline & \\
\hline Exception & Description \\
\hline ResourceException & Classe especializada para representar excecoes de dominio do subsistema de Resource. \\
\hline
\end{tabular}

Package platform.resource.persistence

\begin{tabular}{|ll|}
\hline Class & Description \\
\hline FactoryEntityManager & $\begin{array}{l}\text { Implementada como um Singleton, gerencia as instâncias de EntityManager usadas para a execução } \\
\text { das operações de persistênica. }\end{array}$ \\
\hline RenericDAO<VO> & $\begin{array}{l}\text { Base para todas os DAOs de persitência da plataforma. } \\
\text { Realiza operacoes de persitencia e recuperacao de instancias de ResourceVO. }\end{array}$ \\
\hline Exception & Description \\
\hline DAOException & $\begin{array}{l}\text { Especialização da classe Exception para personalizar a captura de exceções da camada de } \\
\text { persistência. }\end{array}$ \\
\hline
\end{tabular}


Package platform.resource.vo

\begin{tabular}{|ll|}
\hline Interface & Description \\
\hline LocalizableElement & Define um tipo de elemento que pode ser localizado na base de dados. \\
\hline Class & Description \\
\hline AudiofileVO & Especializacao de recurso para representar videos disponiveis em uma URL. \\
\hline BaseVO & Serve de superclasse para todos os VO que serao produzidos. \\
ImageFileVO & Especializacao de recurso para representar imagens disponíveis em uma URL. \\
\hline Model3DFileVO & Especializacao de recurso para representar modelos 3D em arquivos disponiveis em uma URL. \\
ResourceVo & Representacao abstrata de recursos que podem ser usados na execucao de uma aplicacao. \\
\hline TextureFileVO & Especialização de recurso para representar texturas disponiveis em uma URL. \\
VideoFileVO & Especialização de recurso para representar vídeos disponiveis em uma URL. \\
\hline
\end{tabular}

\section{B.1.2 Lado Cliente}

\section{Package view}

\begin{tabular}{|c|c|}
\hline Class & Description \\
\hline EditorTagList & \\
\hline FormularioAlterarRecurso & \\
\hline FormularioExcluirRecurso & \\
\hline FormulariolncluirRecurso & \\
\hline FormularioLogin & \\
\hline FormularioManutencaoRecurso & \\
\hline SelectOwner & \\
\hline TableModelResource & \\
\hline TableModelUser & \\
\hline
\end{tabular}

\section{B.2 Subsistema de Controle de Acesso}

\section{B.2.1 Lado Servidor}

\section{Package platform.access.service}

\begin{tabular}{|ll|}
\hline Class & Description \\
\hline AccessControlServices & Publica as funcionalidades de controle de acesso na forma de servicos (WebServices). \\
AccessManagerServices & Publica as funcionalidades de gerenciamento de acesso na forma de servicos (WebServices). \\
\hline
\end{tabular}

\section{Package platform.access.domain}

\begin{tabular}{|ll|}
\hline Class & Description \\
\hline AccessControl & Coordena as acoes de controle de autenticacao e credencias de usuarios na plataforma. \\
\hline AccessManager & Coordena as acoes de configuracao e gerenciamento de acesso de usuarios da plataforma. \\
Functionality & Classe de dominio que representa as operacoes relacionadas ao conceito Funcionalityvo. \\
User & Classe de dominio que representa as operacoes relacionadas ao conceito UserVO. \\
UserProfile & Classe de dominio que representa as operacoes relacionadas ao conceito UserProfileVO. \\
\hline UserRegister & Classe de dominio que mantem um mapa de logins (ID de sessão) relacionados com um usuario. \\
\hline Exception & Description \\
\hline AccessManagerException & Especializacao do tratamento de exceções para a camada de dominio \\
\hline
\end{tabular}




\section{Package platform.access.persistence}

\begin{tabular}{|ll|}
\hline Class & Description \\
\hline FactoryEntityManager & Gerencia instancias de manipuladores de entidades (EntityManager). \\
FunctionalityDAO & Reune as acoes de persistencia e recuperacao de dados relacionados ao conceito Functionality \\
GenericDAO<VO $>$ & Base para todas os DAOs de persitencia da plataforma. \\
UserDAO & Reune as acoes de persistencia e recuperacao de dados relacionados ao conceito UserVO. \\
UserProfileDAO & Reune as acoes de persistencia e recuperacao de dados relacionados ao conceito UserProfileVO. \\
\hline Exception & Description \\
\hline DAOException & Especializacao do tratamento de excecoes da camada de persistencia. \\
\hline
\end{tabular}

\section{Package platform.access.vo}

\begin{tabular}{|c|c|}
\hline Interface & Description \\
\hline BaseVo & Serve de superclasse para todos os VO que serao produzidos. \\
\hline Credentialvo & Elemento que é usado para associar uma funcionalidade da plataforma com um perfil de usuario. \\
\hline Login SessionVo & Representa uma sessao aberta para um servico em especifico. \\
\hline UserLoginVo & Reune as informacoes de login de um usuario na plataforma. \\
\hline UserProfileVo & $\begin{array}{l}\text { Usado para agrupar informacoes de credenciais que definem um perfil que pode ser reusado em } \\
\text { usuarios. }\end{array}$ \\
\hline FunctionalityEnum & Reune as funcionalidades da plataforma relacionadas com o controle de acesso. \\
\hline
\end{tabular}

\section{B.2.2 Lado Cliente}

\section{Package view}

\begin{tabular}{|c|c|}
\hline Class & Description \\
\hline \multicolumn{2}{|l|}{ FormularioLogin } \\
\hline FormularioPrincipal & \\
\hline
\end{tabular}

\section{Package view.functionality}

\begin{tabular}{|l|}
\hline Class \\
\hline FormularioAlterarFuncionalidade \\
\hline FormularioExcluirFuncionalidade \\
\hline FormulariolncluirFuncionalidade \\
\hline FormularioManutencaoFuncionalidade \\
\hline TableModelFuncionalidade \\
\hline
\end{tabular}




\section{Package view.profile}

\begin{tabular}{|l|}
\hline Class \\
\hline FormularioAlterarPerfil \\
\hline FormularioExcluirCredencial \\
FormularioExcluirPerfil \\
\hline FormulariolncluirCredencial \\
\hline FormulariolncluirPerfil \\
\hline FormularioManutencaoCredencial \\
\hline FormularioManutencaoPerfil \\
\hline TableModelCredencial \\
\hline TableModelPerfil \\
\hline
\end{tabular}

\section{Package view.user}

Class Description

FormularioAlterarUsuario

FormularioExcluirUsuario

FormulariolncluirUsuario

FormularioManutencaoUsuario

TableModelUsuario

\section{B.3 Subsistema de Produção}

\section{B.3.1 Lado Servidor}

\section{Package platform.production.service}

\begin{tabular}{|c|c|}
\hline Class & Description \\
\hline ApplicationManagerService & Implementação de um serviço (Web Services) que publica as ações de produção de Aplicações. \\
\hline ProductionManagerService & $\begin{array}{l}\text { Implementação de um serviço (Web Services) que publica de forma centralizada as ações de produção } \\
\text { de Objetos Virtuais, Cenas, Mundos Virtuais e Aplicações. }\end{array}$ \\
\hline SceneManagerService & Implementação de um serviço (Web Services) que publica as ações de produção de Cenas. \\
\hline VirtualObjectManagerService & Implementação de um serviço (Web Services) que publica as ações de produção de Objetos Virtuais. \\
\hline VirtualWorldManager Service & Implementação de um serviço (Web Services) que publica as ações de produção de Mundos Virtuais. \\
\hline
\end{tabular}

\section{Package platform.production.domain}

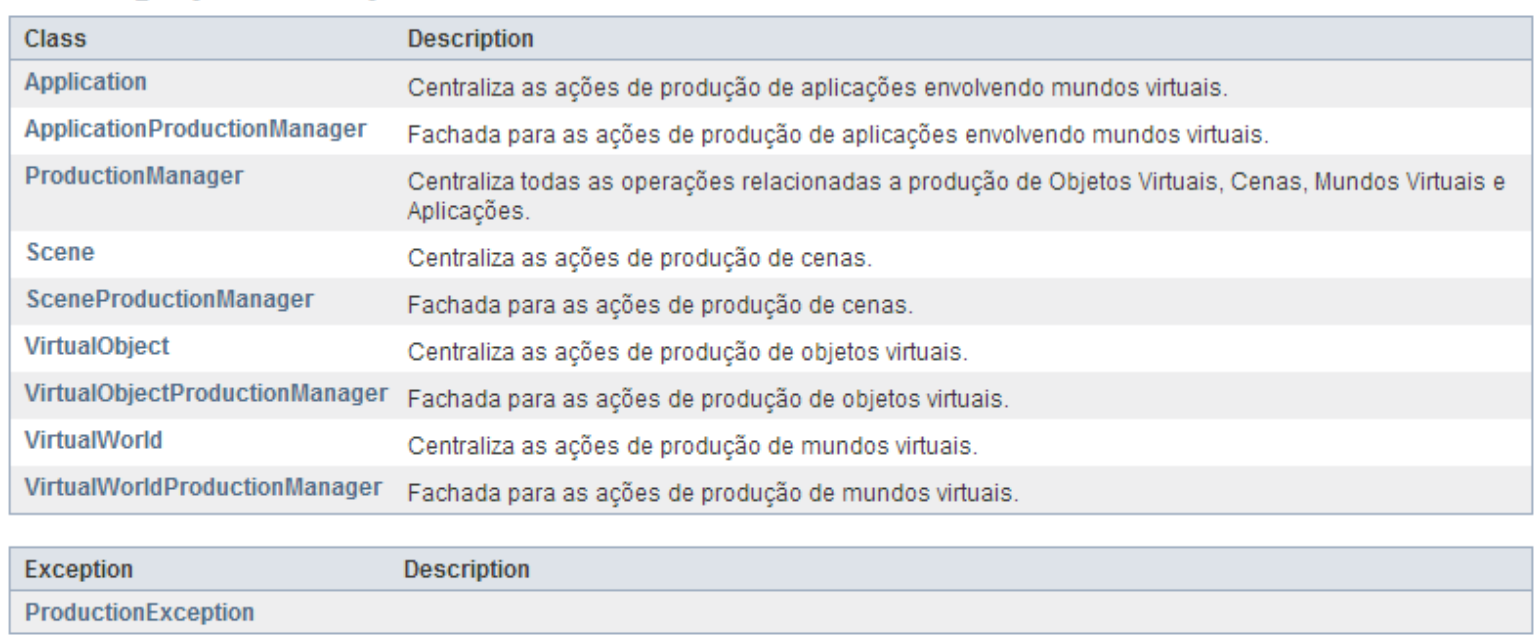




\section{Package platform.production.persistence}

\begin{tabular}{|ll|}
\hline Class & Description \\
\hline ApplicationDAO & Contém as operações de persistência e recuperação de Aplicações da plataforama. \\
\hline FactoryEntityManager & $\begin{array}{l}\text { Implementada como um Singleton, gerencia as instâncias de EntityManager usadas para a execução } \\
\text { das operações de persistênica. }\end{array}$ \\
\hline GenericDAO<VO> & Base para todas os DAOs de persitência da plataforma. \\
VirtualObjectDAO & Contém as operações de persistência e recuperação de Cenas. \\
VirtualWorldDAO & Contém as operações de persistência e recuperação de objetos virtuais. \\
\hline Exception & Contém as operações de persistência e recuperação de Mundos virtuais. \\
\hline DAOException & Description \\
\hline
\end{tabular}

\section{Package platform.production.vo.appearance}

\begin{tabular}{|ll|}
\hline Class & Description \\
\hline AppearanceVo & Representa a aparência (características visuais) de um objeto3D. \\
BackgroundVo & Representa informações de fundo de uma cena. \\
LightAmbientvo & Representa uma cor, definida pelas três cores primárias (vermelho, verde e azul). \\
LightDirectionalvo & Representa propriedades de luz ambiente da cena \\
\hline LightPointvo & Representa um ponto de luz direcional da cena \\
Lightvo & Representa um ponto de luz da cena \\
\hline Materialvo & Representa a super classe usada para definir as característica de luz da cena. \\
Texturevo & Representa as características do material que forma a aparência de um objeto virtuais. \\
\hline
\end{tabular}

\section{Package platform.production.vo.base}

\begin{tabular}{|ll|}
\hline Interface & Description \\
\hline LocalizableElement & Define um tipo de elemento que pode ser localizado na base de dados. \\
\hline Class & Description \\
\hline BaseVo & Serve de superclasse para todos os VO que serao produzidos. \\
\hline
\end{tabular}

\section{Package platform.production.vo.behavior}

\begin{tabular}{|ll|}
\hline Class & Description \\
\hline BehaviorSceneVO & Representa um comportamento que ao ser invocado dispara uma mudança de cena. \\
\hline BehaviorTransformationVo & Representa um comportamento que ao ser invocado dispara um grupo de transformações associado. \\
\hline BehaviorVo & Super classe para a definição de subtipos de comportamentos. \\
\hline
\end{tabular}

\section{Package platform.production.vo.delimiter}

\begin{tabular}{|ll|}
\hline Class & Description \\
\hline DelimiterSpherevo & Estabelece um volume, na forma de esfera, que serve de limite para aplicação de ações. \\
\hline
\end{tabular}




\section{Package platform.production.vo.enumered}

\begin{tabular}{|ll|}
\hline Enum & Description \\
\hline AudioFormatEnum & Enumeração para os tipos possiveis de áudio \\
\hline BehaviorSceneTypeEnum & Enumeração para os eixos cartesianos \\
BehaviorTransformationTypeEnum & Enumeração para os tipos possiveis de operações com cenas \\
CharEnum & Enumeração para os tipos possiveis de operações com as matrizes de transformações \\
ControlKeyEnum & Enumeração para as teclas de controle possiveis para a plataforma. \\
EventPriorityEnum & Prioridades para processamento de eventos da aplicação. \\
GestureFormatEnum & Enumeração para os tipos possiveis de formatos de representação de gestos. \\
IlluminationTypeEnumvo & Enumeração que representa os tipos de iluminação que um material pode ter. \\
InputDataEncodingEnum & Enumeração para os padrões de caracteres possiveis para a plataforma. \\
KeyEnum & Enumeração para os caracteres (teclas) possiveis para a plataforma. \\
\hline TransformationTypeEnum & Enumeração para os tipos possiveis de operações geométricas da plataforma. \\
VideoFormatEnum & Enumeração para os tipos possiveis de representação de videos da plataforma. \\
VoiceFormatEnum & Enumeração para os tipos possiveis de representação de videos da plataforma. \\
\hline
\end{tabular}

\section{Package platform.production.vo.event}

\begin{tabular}{|c|c|}
\hline Class & Description \\
\hline EventApplicationAfterLoadVO & Representa evento que ocorre depois da carga de uma aplicacao. \\
\hline EventApplicationBeforeCloseVO & Representa evento que ocorre antes que a aplicacao seja fechada. \\
\hline EventApplicationBeforeLoadVO & Representa evento que ocorre antes da carga de uma aplicacao. \\
\hline EventApplicationBeforeRunVo & Representa evento que ocorre antes que a aplicacao seja executada. \\
\hline EventApplicationvo & Representa eventos associados ao contexto de aplicacao. \\
\hline EventChangeObjectVo & Representa eventos ocorridos a partir de objetos virtuais (mudanca de propriedades). \\
\hline EventCollisionObjectVo & Representa eventos ocorridos a partir de objetos virtuais (colisão). \\
\hline EventCommandinputVo & Representa eventos ocorridos a partir da entrada de comandos. \\
\hline EventCommandKeyVo & $\begin{array}{l}\text { Representa eventos ocorridos a partir da entrada de comandos por meio de teclas de } \\
\text { função. }\end{array}$ \\
\hline EventContinuousTimeVo & Representa eventos ocorridos a partir da contagem de tempo. \\
\hline EventDatalnputvo & Representa eventos ocorridos a partir da entrada de dados. \\
\hline EventIndicateObjectVo & Representa eventos ocorridos quando um objetos virtuais é apontado. \\
\hline Eventinputvo & Representa eventos ocorridos a partir da entrada (superclasse). \\
\hline EventLocale2DPosvo & Representa eventos ocorridos a partir da entrada de posicionamento $2 \mathrm{D}$. \\
\hline EventLocalelnputvo & Representa eventos ocorridos a partir da entrada de posicionamento (superclasse). \\
\hline EventObjectVo & Representa eventos ocorridos apartir de objetos virtuais (superclasse). \\
\hline EventSceneAfterRendervo & Representa evento que ocorre depois da renderização de uma cena. \\
\hline EventSceneBeforeRenderVo & Representa evento que ocorre antes da renderização de uma cena. \\
\hline EventSceneVo & Representa eventos ocorridos a partir de cenas (superclasse). \\
\hline EventSelectlnputVo & Representa eventos ocorridos a partir da entrada de seleção (superclasse). \\
\hline EventSelectObjectVo & Representa eventos ocorridos a partir da entrada de seleção de objetos. \\
\hline EventTimeVO & Representa eventos ocorridos a partir da contagem de tempo. \\
\hline EventVirtualWorldAfterChangeSceneVO & Representa evento que ocorre depois da mudança de propriedades de um mundo virtual. \\
\hline EventVirtualWorldBeforeChangeSceneVO & Representa evento que ocorre antes da mudança de propriedades de um mundo virtual. \\
\hline EventVirtualWorldVo & $\begin{array}{l}\text { Representa evento que ocorre com a mudança de propriedades de um mundo virtual } \\
\text { (superclasse). }\end{array}$ \\
\hline EventVO & $\begin{array}{l}\text { Superclasse que representa todos os tipos de eventos que podem ser estabelecidos em } \\
\text { uma aplicação RV. }\end{array}$ \\
\hline
\end{tabular}


Package platform.production.vo.input

\begin{tabular}{|c|c|}
\hline Class & Description \\
\hline InputCommandGestureVO & Representa uma entrada de um comando por gestos. \\
\hline InputCommandKeyVO & Representa uma instância de um comando expresso por um caracter. \\
\hline InputCommandNumericVO & Representa uma instância de um comando expresso por um inteiro. \\
\hline InputCommandTextVO & Representa uma instância de um comando expresso por uma cadeia de caracter (texto). \\
\hline InputCommandVO & Representa o conceito de entrada de dados relacionada a um comando (superclasse). \\
\hline InputCommandVoiceVO & Representa uma instância de um comando expresso por meio de voz. \\
\hline InputDataByteArrayVo & Representa o conceito de entrada de dados por meio de um array de bytes. \\
\hline InputDataCaractervo & Representa o conceito de entrada de dados para representação de caracteres. \\
\hline InputDataDateTimevo & Representa o conceito de entrada de dados para representação de data e hora. \\
\hline InputDataDiscreteVO & Representa o conceito de entrada de dados para entrada de valores literais de dados. \\
\hline InputDataFloatVo & Representa o conceito de entrada de dados de números reais. \\
\hline InputDataFlowAudioVO & Representa o conceito de entrada de dados de audio em fluxo contínuo. \\
\hline InputDataFlowBinaryvo & Representa o conceito de entrada de dados de sequência de bytes em fluxo contínuo. \\
\hline InputDataFlowHapticVO & Representa o conceito de entrada de dados de hapticos em fluxo contínuo. \\
\hline InputDataFlowVideoVo & Representa o conceito de entrada de dados de video em fluxo contínuo. \\
\hline InputDataFlowvo & Representa o conceito de entrada de dados para representação de fluxos de dados contínuos. \\
\hline InputDatalntegervo & Representa o conceito de entrada de dados para representação de inteiro. \\
\hline InputDataTextVo & Representa o conceito de entrada de dados para representação de texto. \\
\hline InputDatavo & Representa o conceito de entrada de dados (superclasse). \\
\hline InputLocale2DPosvo & Representa o conceito de entrada de dados para representação de posição 2D. \\
\hline InputLocale3DPosvo & Representa o conceito de entrada de dados para representação de posição 3D. \\
\hline InputLocaleGPSVO & $\begin{array}{l}\text { Representa o conceito de entrada de dados para representação de posição do sistema de } \\
\text { posicionamento global. }\end{array}$ \\
\hline InputLocaleVO & Representa o conceito de entrada de dados para representação de localização. \\
\hline InputSelect2DPointVO & $\begin{array}{l}\text { Representa o conceito de entrada de dados para representação de uma seleção com base em } \\
\text { informações } 2 D \text {. }\end{array}$ \\
\hline InputSelect3DPointVO & $\begin{array}{l}\text { Representa o conceito de entrada de dados para representação de uma seleção com base em } \\
\text { informações } 3 D \text {. }\end{array}$ \\
\hline InputSelectAreaVO & $\begin{array}{l}\text { Representa o conceito de entrada de dados para representação de uma seleção com base em uma } \\
\text { área. }\end{array}$ \\
\hline InputSelectObjectVO & Representa o conceito de entrada de dados para representação de uma seleção de objetos. \\
\hline InputSelectSphereVo & $\begin{array}{l}\text { Representa o conceito de entrada de dados para representação de uma seleção com base em } \\
\text { informações de um volume estabelecido por uma esfera. }\end{array}$ \\
\hline InputSelectVO & Representa o conceito de entrada de dados para representação de seleção. \\
\hline InputVideoVo & Representa o conceito de entrada de dados na forma de vídeo. \\
\hline InputVirtualVO & Representa uma entrada de dados virtual. \\
\hline
\end{tabular}

\section{Package platform.production.vo.location}

\begin{tabular}{ll}
\hline Class & Description \\
\hline Directioin3DVO & Representa uma direção em um ambiente 3D por meio de coordenadas cartesianas ( $x, y$ e $z$ ). \\
\hline GeoCoodinateVO & Representa uma posição definida por meio de coordenadas geográficas (graus, minutos e segundos). \\
Position2DVO & Representa uma posição 2D por meio de coordenadas cartesianas ( $x, y$ ). \\
Position3DVO & Representa uma posição 3D por meio de coordenadas cartesianas ( $x, y$ e $z$ ). \\
PositionGPSVO & $\begin{array}{l}\text { Representa uma posição em um ambiente 3D por meio de coordenadas de GPS (latitude, longitude e } \\
\text { altura). }\end{array}$ \\
\hline
\end{tabular}




\section{Package platform.production.vo.output}

\begin{tabular}{|ll|}
\hline Class & Description \\
\hline OutputAudioRenderVO & Representa um display de saida de áudio. \\
OutputHapticForceVO & Representa um display de haptico que representa o retorno de força. \\
OutputHapticPressureVo & Representa um display de haptico que representa o retorno de pressão. \\
OutputHapticRenderVo & Representa um display de haptico (superclasse). \\
OutputHapticTemperatureVo & Representa um display de haptico que representa o retorno de temperatura. \\
OutputVideoRenderVo & Representa um display de saida de video. \\
OutputVirtualvo & Representa um dispositivo abstrato de saída de dados (monitor, autofalante, haptico, atuador, etc). \\
\hline
\end{tabular}

\section{Package platform.production.vo.shape}

\begin{tabular}{|ll|}
\hline Class & Description \\
\hline Boxvo & Representa um paralelepipedo definido pelos tamanhos das arestas x, y e z. \\
ConeVo & Representa um cone definido pelo raio e altura. \\
CylinderVo & Representa um cilindro definido pelo raio e altura. \\
Shape2DVO & Representa um objeto 2D independente se está no mundo virtual ou real. \\
Shape3DVO & Representa um objeto 3D independente se está no mundo virtual ou real. \\
ShapeVo & Representa um objeto 3D independente se está no mundo virtual ou real. \\
SphereVo & Representa uma esfera definida pelo raio. \\
\hline
\end{tabular}

\section{Package platform.production.vo.transformation}

\begin{tabular}{|ll|}
\hline Class & Description \\
\hline TransformationGroupVO & $\begin{array}{l}\text { Representa um grupo de transformações que define a posição de um grupo de objetos de um grafo de } \\
\text { cena }\end{array}$ \\
\hline TransformationIncrementalVO & Representa uma transformação geométrica que e associada a um grupo de transformações. \\
TransformationVo & Representa uma transformação geométrica que e associada a um grupo de transformações. \\
\hline
\end{tabular}

\section{Package platform.production.vo.virtualobject}

\begin{tabular}{|ll|}
\hline Class & Description \\
\hline VirtualObjectCompositeVO & Representa uma composicao de objetos virtuais em um mundo 3D. \\
\hline VirtualObjectModel3DVO & Representa um modelo 3D a partir de um arquivo. \\
VirtualObjectSingleVO & Representa um objeto virtual simples em um mundo 3D. \\
VirtualObjectVo & Representa um objeto virtual em um mundo 3D. \\
\hline
\end{tabular}

\section{Package platform.production.vo.virtualworld}

\begin{tabular}{|ll|}
\hline Class & Description \\
\hline ApplicationVo & Representa o conceito de uma aplicação RV. \\
CameraViewVo & Representa uma câmera em um grafo de cena \\
SceneVo & Representa um grafo de cena, que pode ser inserido em um mundo 3D. \\
VirtualWorld3DVo & Representa um mundo 3D formado por grafos de cena, as quais conterão objetos virtuais e reais. \\
\hline
\end{tabular}




\section{B.3.2 Lado Cliente}

\section{Package view}

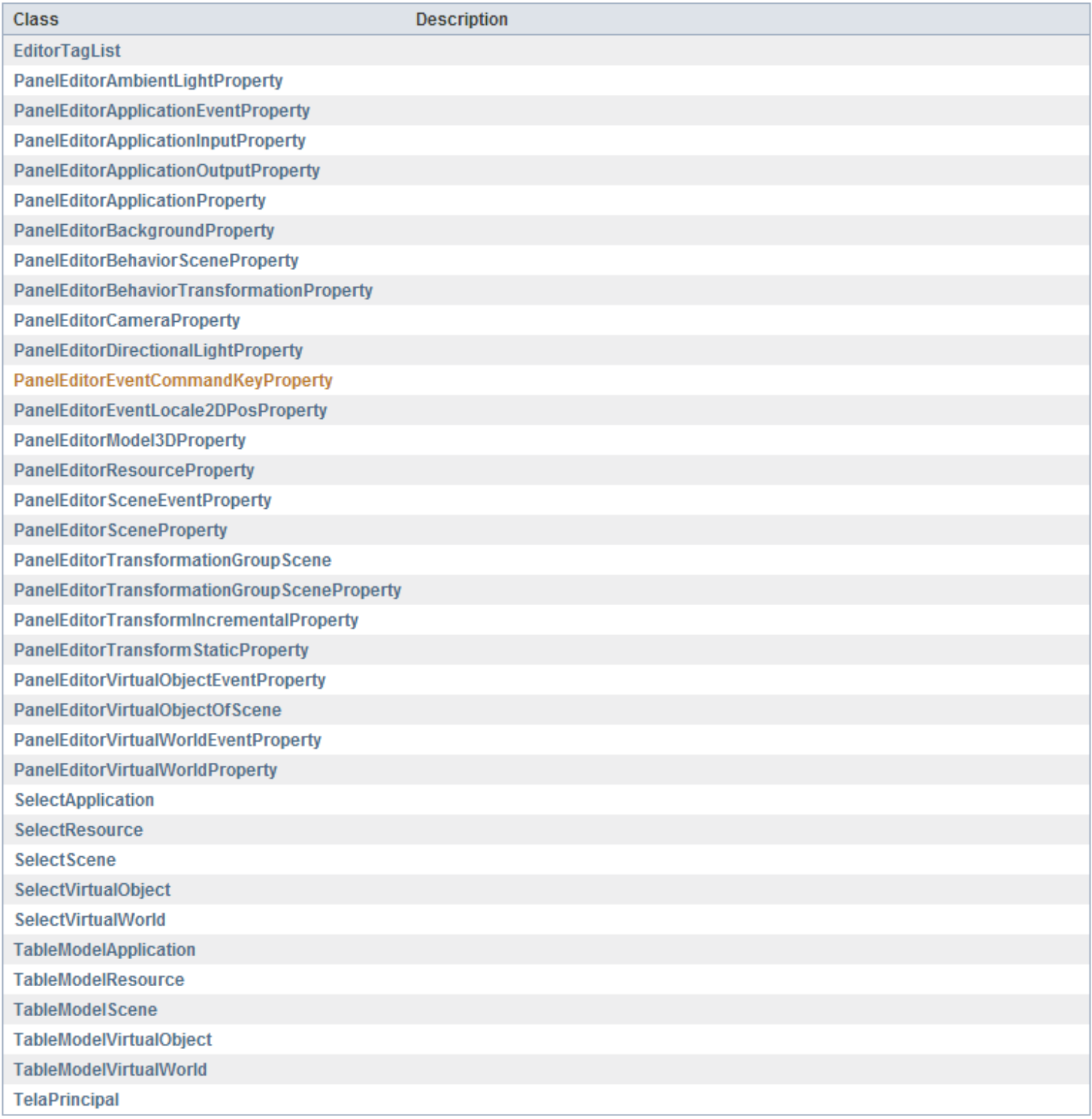

\section{Package view.jtree}

\begin{tabular}{ll}
\hline Class & Description \\
\hline CustomCellRenderer & \\
CustomCellRendererOld & \\
GeneratorWrapperJTreeElement & Classe que montam elementos que sao usados para formar os nos de uma Arvore grafica JTree \\
GeneratorWrapperJTreeElementOld & Classe que montam elementos que sao usados para formar os nÃs de uma Ãirvore grafica JTree \\
WrapperJTreeElement &
\end{tabular}

\begin{tabular}{l|l|}
\hline Enum & Description \\
\hline WrapperJTreeElementEnum & \\
WrapperJTreeElementEnumOId & \\
\hline
\end{tabular}


Package wrapper

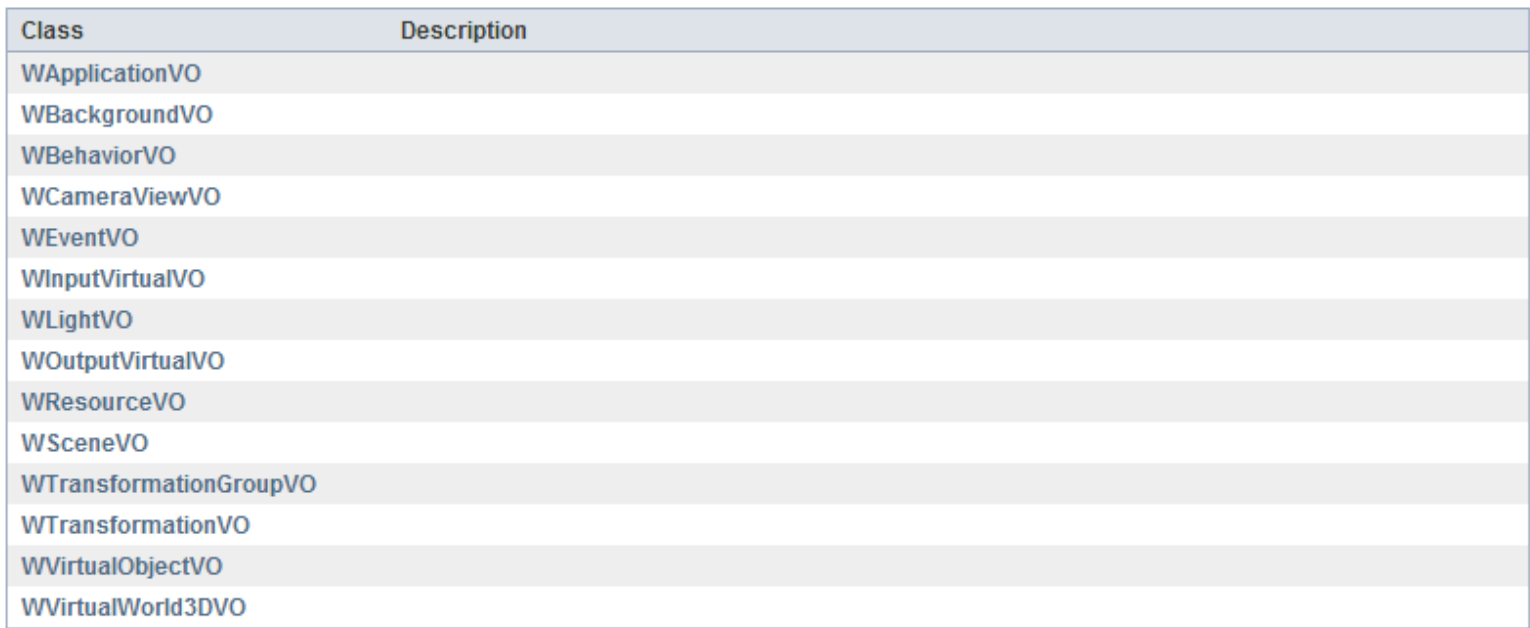

\section{B.4 Subsistema de Execução}

\section{B.4.1 Lado Servidor}

\section{Package platform.execution.service}

Class Description

ExecutionManagerService

\section{Package platform.execution.domain}

\begin{tabular}{|c|c|}
\hline Class & Description \\
\hline \multicolumn{2}{|c|}{ ApplicationContext } \\
\hline \multicolumn{2}{|c|}{ AudioStreamManager } \\
\hline \multicolumn{2}{|c|}{ ExecutionManager } \\
\hline \multicolumn{2}{|c|}{ HapticStreamManager } \\
\hline \multicolumn{2}{|l|}{ Render } \\
\hline \multicolumn{2}{|l|}{ RenderManager } \\
\hline \multicolumn{2}{|l|}{ UserContext } \\
\hline \multicolumn{2}{|c|}{ VideoStreamManager } \\
\hline \multicolumn{2}{|l|}{ VideoEncoding } \\
\hline
\end{tabular}

Exception Description

ExecutionException 


\section{Package platform.execution.persistence}

\begin{tabular}{|ll|}
\hline Class & Description \\
\hline ExecutionDataDAO & Contém as operações de persistência e recuperação de Grafos de Cena. \\
\hline $\begin{array}{l}\text { FactoryEntityManager } \\
\text { GenericDAO<VO }>\end{array}$ & Base para todas os DAOs de persitã̃ncia da plataforma. \\
\hline Exception & Description \\
\hline DAOException & \\
\hline
\end{tabular}

\section{Package platform.execution.vo}

\begin{tabular}{|ll|}
\hline Class & Description \\
\hline Basevo & $\begin{array}{l}\text { Serve de superclasse para todos os Vo que serao produzidos. } \\
\text { ExecutionDataVo }\end{array}$ \\
\begin{tabular}{|l|} 
Representa a ocorrência de uma informação de execução que será armazenada durante a execução de \\
uma aplicãa.
\end{tabular} \\
\hline Enum & Description \\
\hline ExecutionDataTypeEnum & \\
\hline
\end{tabular}

\section{B.4.2 Lado Cliente}

\section{Package platform.execution.behavior}

\begin{tabular}{|ll|}
\hline Class & Description \\
\hline BehaviorCommandKeyChangeScene & $\begin{array}{l}\text { Implementa um comportamento de mudanca de cena baseado em um evento de entrada de um } \\
\text { comando por meio de uma tecla. }\end{array}$ \\
\hline BehaviorCommandKeyTransform & $\begin{array}{l}\text { Implementa um comportamento de transformação baseado em um evento de entrada de um } \\
\text { comando por meio de uma tecla. }\end{array}$ \\
BehaviorLocale2DMoveTransform & $\begin{array}{l}\text { Implementa um comportamento de transformação baseado em um evento de entrada de uma } \\
\text { posição 2D. }\end{array}$ \\
BehaviorLocale2DPosChangeScene & $\begin{array}{l}\text { Implementa um comportamento de mudanca de cena baseado em um evento de entrada de uma } \\
\text { posicao 2D. }\end{array}$ \\
CodeConverter & $\begin{array}{l}\text { Reúne operações que convertem códigos de teclas e caracteres do padrão da plataforma para } 0 \\
\text { padrão da API de renderização. }\end{array}$ \\
\hline
\end{tabular}

\section{Package platform.execution.render}

\begin{tabular}{|ll|}
\hline Interface & Description \\
\hline IRender & Interface que define um tipo genérico de Renderizador. \\
\hline Class & Description \\
\hline JavalmageBuffer & Armazena um objeto Bufferedlmagem e disponibiliza a imagem como um array de bytes. \\
\hline JavaRender & Representa um cenário completo 3D, que pode conter várias cenas. \\
\hline RenderCanvas3D & $\begin{array}{l}\text { Extensão da classe Canvas3D, acrescentando uma instancia de JavalmageBuffer e sobreposição do } \\
\text { método postSwap(). }\end{array}$ \\
\hline TranslatorEventVo & Interpreta e traduz um evento do modelo RM-VRService para um evento da API de renderização. \\
\hline TranslatorSceneVO & Cria todos os BranchGroup a partir da lista de SceneVO. \\
\hline TranslatorTransformation & $\begin{array}{l}\text { Interpreta e traduz as representações de transformações do modelo RM-VRService para a } \\
\text { representação da API de renderização. }\end{array}$ \\
\hline TranslatorVirtualObject3DVO & $\begin{array}{l}\text { Transforma todos os VirtualObject3DVO em um mapa de Node (Java 3D), identificados pelo ID dos } \\
\text { VirtualObject3DVO. }\end{array}$ \\
\hline Exception & Description \\
\hline RenderException & Especialização para tratar exceções de renderização. \\
\hline
\end{tabular}




\section{Package view}

Class

SelectApplication

Description

TableModelApplication

TelaPrincipal 